D7

Referent:

PD Dr. Gertrud Lohaus

Korreferent:

Prof. Dr. Hans-Walter Heldt

Tag der mündlichen Prüfung:

06.11 .2003 


\title{
Aminosäuretransport in Raps unter besonderer Berücksichtigung des Entwicklungsstadiums der Pflanze und der Stickstoffdüngung
}

\author{
Dissertation \\ zur Erlangung des Doktorgrades \\ der Mathematisch-Naturwissenschaftlichen Fakultäten \\ der Georg-August-Universität zu Göttingen
}

vorgelegt von

Jens Tilsner

aus Hamburg

Göttingen 2003 


\section{Inhaltsverzeichnis}

1.1 Stickstoff als pflanzliches Nährelement 1

1.2 Assimilation von anorganischem Stickstoff 2

1.3 Ferntransport von Assimilaten und Ionen in der Pflanze 3

1.4 Anatomie des Phloems 5

1.5 Phloem-Beladungsmechanismen 5

1.6 Phloem-Entladung 7

1.7 Verlagerung von Stickstoff in der Pflanze: Source-Sink-Verhältnisse 8

1.8 Identifizierung pflanzlicher Aminosäuretransporter 9

1.9 Familien von Aminosäuretransportern in Arabidopsis 11

1.10 Die Problematik der Stickstoffnutzung bei Raps 15

1.11 Zielsetzung 16

$\begin{array}{lll}2 & \text { Material und Methoden } & 17\end{array}$

2.1 Allgemeines 17

$\begin{array}{lll}2.2 & \text { Material } & 17\end{array}$

$\begin{array}{lll}\text { 2.2.1 Pflanzenmaterial und Anzucht } & 17\end{array}$

$\begin{array}{lll}2.2 .2 & \text { Bakterienstämme } & 18\end{array}$

$\begin{array}{lll}2.2 .3 & \text { Häufig verwendete Nährmedien } & 19\end{array}$

$\begin{array}{lll}2.2 .4 & 20\end{array}$

2.3 Feldversuch zur Untersuchung der genetischen Variabilität der $\begin{array}{ll}\text { Stickstoffnutzung bei Winterraps } & 20\end{array}$

2.3.1 Bestimmung der Nitratreduktaseaktivität (NRA) 21

2.4 Extraktion von Metaboliten aus Pflanzengeweben 23

2.4.1 Chloroform-Methanol-Extraktion von Blattgeweben 23

2.4.2 Nichtwässrige Fraktionierung 23

2.4.2.1 $\alpha$-Mannosidase-Test 26

2.4.2.2 Saure Phosphatase-Test 26

2.4.2.3 Glycerinaldehydphosphat-Dehydrogenase-Test 27 
$\begin{array}{lll}\text { 2.4.2.4 Phosphoenolpyruvat-Carboxylase-Test } & 27\end{array}$

$\begin{array}{lll}2.4 .3 & \text { Extraktion von Apoplastensaft } & 28\end{array}$

2.5 Metabolit-Messungen 29

2.5.1 Chromatographische Bestimmung von Aminosäuren 29

2.5.2 Chromatographische Bestimmung von Zuckern 31

2.5.3 Chromatographische Bestimmung von Ionen 32

2.6 Methoden zur Isolierung von Proteinen 33

2.6.1 Isolierung von Plasmamembran-Proteinen aus Pflanzen 33

2.6.1.1 Anreicherung von Plasmamembran-Proteinen in einem

Zwei-Phasen System 33

$\begin{array}{lll}\text { 2.6.1.2 P-ATPase-Test } & 36\end{array}$

2.7 Quantitative Proteinbestimmung 37

2.7.1 Proteinbestimmung nach Bradford 37

2.7.2 Proteinbestimmung nach Lowry 38

2.7.3 Proteinbestimmung mit dem „, $\mathrm{D}_{\mathrm{C}}$ Protein Assay“ 38

$\begin{array}{lll}2.7 .4 & \text { Chlorophyllbestimmung } & 39\end{array}$

2.8 Gelelektrophoretische Auftrennung von Proteinen 39

2.8.1 SDS-Polyacrylamid-Gelelektrophorese 39

2.8.2 Coomassie-Färbung 42

2.8.3 Silverstain-Färbung $\quad 42$

2.8.4 KCl-Färbung und Elution von Proteinen aus präparativen SDS-Gelen 43

2.9 Präparation und Reinigung von Nukleinsäuren 44

$\begin{array}{lll}2.9 .1 & \text { Isolation von RNA }\end{array}$

2.9.1.1 Mini-Präparation pflanzlicher Gesamt-RNA 44

2.9.1.2 Extraktion großer Mengen pflanzlicher Gesamt-RNA 44

2.9.2 Isolation genomischer pflanzlicher DNA 45

2.9.3 Isolation bakterieller Plasmid-DNA 47

2.9.3.1 Plasmid-Mini-Präparation aus E. coli 47

2.9.3.2 Plasmid-Maxi-Präparation aus E. coli 48

2.9.3.3 Plasmid-Mini-Präparation aus Agrobacterium tumefaciens $\quad 48$

2.9.4 Ethanolfällung von DNA oder RNA 49

2.9.5 Phenol/Chloroform-Reinigung von DNA oder RNA 49

2.9.6 Bestimmung von Nukleinsäurekonzentrationen $\quad 50$ 
2.10 Gelelektrophoretische Auftrennung von Nukleinsäuren 50

2.10.1 Agarose-Gelelektrophorese von Nukleinsäuren 50

2.10.2 Elution von DNA-Fragmenten aus Agarosegelen 51

2.11 Hybridisierungsmethoden $\quad 52$

2.11.1 Radioaktive Markierung von DNA-Fragmenten (,Random Priming“) 52

2.11.2 Northern Blot 53

2.12 cDNA-Synthese 56

2.13 Auf der Polymerase-Kettenreaktion basierende Methoden 56

2.13.1 Kriterien bei der Ableitung von synthetischen Oligonukleotiden (Primern) 57

2.13.2 Polymerase-Kettenreaktion 59

$\begin{array}{lll}2.13 .3 & \text { Kolonie-PCR } & 61\end{array}$

2.13.4 Amplifikation von cDNA-Enden (RACE) 62

2.13.4.1 Identifizierung des Transkriptions-Endpunktes durch 3' RACE 63

2.13.4.2 Identifizierung des Transkriptions-Startpunktes durch 5' 65

$\begin{array}{ll}\text { RACE } & 67\end{array}$

2.13.5 Amplifikation von Promotoren durch „Genome Walking“ 67

2.13.5.1 Herstellung einer „Genome Walker Library“ 70

2.13.5.2 „Genome Walking“PCR 72

$\begin{array}{lll}\text { 2.13.6 DNA-Sequenzierung } & 74\end{array}$

$\begin{array}{lll}2.14 & \text { Klonierungsmethoden } & 74\end{array}$

2.14.1 Restriktionsverdau von DNA-Fragmenten 74

2.14.2 Auffüllen von überstehenden Enden doppelsträngiger DNA-Moleküle 75

2.14.3 Alkalische Phosphatase-Behandlung 75

2.14.4 Ligation von DNA 76

2.14.5 Herstellung chemokompetenter E. coli Zellen

2.14.5.1 Herstellung kompetenter Zellen nach der Rubidiumchlorid- $\quad 76$

Methode 77

2.14.5.2 Herstellung kompetenter Zellen nach Inoue et al. (1990) 78

2.14.6 Chemische Transformation von E. coli 79

2.14.7 Herstellung elektrokompetenter Agrobacterium tumefaciens Zellen $\quad 80$

2.14.8 Elektroporation von Agrobacterium tumefaciens 80

$\begin{array}{lll}2.14 .9 & \text { Bakteriendauerkultur } & 80\end{array}$

2.14.10 Transformation von Arabidopsis thaliana 
2.15 Funktionelle Expression von Membranproteinen in Xenopus Oocyten 82

2.16 Nachweis der Promotoraktivität durch einen histochemischen GUS-Test 83

2.17 Immunologische Methoden $\quad 84$

2.17.1 Herstellung von polyklonalen Antikörpern 85

$\begin{array}{lll}\text { 2.17.2 Western-Blot } & 87\end{array}$

2.17.3 Immunohistochemischer Nachweis von Proteinen in Gewebeschnitten 89

2.17.3.1 Einbettung von Pflanzengewebe in Methacrylat 89

2.17.3.2 Herstellung von Dünnschnitten 90

2.17.3.3 Behandlung der Schnitte mit Antikörpern und

$\begin{array}{ll}\text { Fluoreszenzfarbstoffen } & 90\end{array}$

2.18 Computergestützte Analyseverfahren 91

2.18.1 Sequenzanalyse von DNA und Proteinen 91

2.18.2 Untersuchungen zur Proteinstruktur 92

2.19 Statistische Auswertung der Experimente $\quad 92$

$3 \quad$ Ergebnisse

3.1 Feldversuche zur Variabilität der Stickstoffnutzung und -verteilung in B. napus 93

3.2 Aminosäurekonzentrationen in subzellulären Kompartimenten von Mesophyllzellen $\quad 99$

3.3 Aminosäurekonzentrationen im Apoplasten und Vergleich der Aminosäure-Zusammensetzung in den untersuchten Kompartimenten 103

3.4 Identifizierung von Brassica napus Aminosäuretransportern 107

$\begin{array}{lll}3.4 .1 & B n A A P 1 & 108\end{array}$

$\begin{array}{lll}3.4 .2 & 109\end{array}$

$\begin{array}{lll}3.4 .3 \quad B n A A P 2 & 111\end{array}$

3.5 Elektrophysiologische Untersuchungen zur Substratspezifität von BnAAP1 und BnAAP6 durch funktionelle Expression in Xenopus Oozyten 113

3.6 Untersuchungen zur Expression von BnAAPl und BnAAP6 in der Pflanze 117

3.6.1 Untersuchung einer BnAAP6-Promotor-Reportergenfusion $\quad 117$

3.6.2 Herstellung von BnAAP6-spezifischen polyklonalen 119

Antikörpern 
3.6.3 Expression von BnAAPl und BnAAP6 in verschiedenen

Blattaltersstufen

3.6.3.1 BnAAP1

3.6.3.2 BnAAP6

4.1 Variabilität der Stickstoffeffizienz bei Winterraps 127

4.2 Subzelluläre Konzentrationen und Phloembeladung von Aminosäuren in $\quad 130$

$\begin{array}{ll}\text { Raps } & 134\end{array}$

4.3 Charakterisierung von Aminosäuretransportern aus Raps 137

4.4 Expression von BnAAP1 und BnAAP6 in der Pflanze 140

4.5 Expression von BnAAPl und BnAAP6 während der Blattentwicklung

4.6 Möglichkeiten zur gentechnischen Verbesserung der Stickstoffeffizienz 141 von Raps

146

$5 \quad$ Zusammenfassung

149

$6 \quad$ Abkürzungsverzeichnis

152

$7 \quad$ Literaturverzeichnis

172

$8 \quad$ Anhang

8.1 Verteilung der Markerenyzme bei der nichtwässrigen Fraktionierung 174

8.2 cDNA- und Aminosäuresequenz von BnAAPl 176

8.3 cDNA- und Aminosäuresequenz von BnAAP6 178

8.4 Nukleotidsequenz des BnAAP6-Promotors 180

8.5 Partielle cDNA- und Aminosäuresequenz von BnAAP2 181

8.6 Vektorkarten 


\section{Einleitung}

\subsection{Stickstoff als pflanzliches Nährelement}

Über die Fixierung von Kohlendioxid $\left(\mathrm{CO}_{2}\right)$ in der Photosynthese sind Pflanzen in der Lage, ihren Bedarf an Kohlenstoff (C) aus der Luft zu decken. Die Aufnahme aller weiteren zum Aufbau organischer Substanz und zur Aufrechterhaltung ihrer biologischen Funktionen benötigten Nährelemente erfolgt dagegen fast ausschließlich über die Wurzel aus der Bodenlösung. Nach dem quantitativen Bedarf der Pflanze an diesen Elementen werden sie in Makronährelemente (in der Reihenfolge der benötigten Mengen: N, K, Ca, Mg, P, S) und Mikronährelemente (Cl, B, Fe, Mn, Zn, Cu, Ni, Mo) eingeteilt. Die Elemente Na, Si, und Co sind in geringen Mengen wachstumsfördernd, aber nicht (oder nur für einige Spezies) essentiell („beneficial elements“) (Marschner 1995). Stickstoff (N) ist das quantitativ bedeutenste Makronährelement und stellt in den meisten natürlichen Ökosystemen den wachstumslimitierenden Faktor dar (Ellenberg 1977, Foyer \& Ferrario 1994). Dagegen sorgt in intensiv bewirtschafteten Agrarsystemen der Mensch durch hohe Gaben mineralischer Stickstoffdünger für eine weitgehende Stickstoffsättigung des pflanzlichen Stoffwechsels, um maximale Erträge zu erwirtschaften. Diese anthropogenen N-Einträge gelangen letztlich in globale Stoffkreisläufe und führen zu erheblichen Schädigungen vieler Ökosysteme, z.B. durch Nährstoffungleichgewichte (Schulze 1989), Rückgang der Biodiversität (Ellenberg 1986), Stickstoffausträge ins Grundwasser (Durka et al. 1994) und verstärkte Freisetzung des Treibhausgases $\mathrm{N}_{2} \mathrm{O}$ aus Böden (Granli \& Bøckman 1994).

Im Boden tritt Stickstoff hauptsächlich anorganisch als Nitrat $\left(\mathrm{NO}_{3}{ }^{-}\right)$und Ammonium $\left(\mathrm{NH}_{4}{ }^{+}\right)$ auf, aber auch in organischen Verbindungen, z.B. Aminosäuren. Nitrat ist leicht löslich, wogegen Ammonium meist in gebundener Form vorliegt. Pflanzen können alle diese Stickstoff-Formen nutzen, wobei in der Regel Nitrat die hauptsächliche N-Quelle darstellt. Ammoniumaufnahme dominiert in Böden, in denen durch einen niedrigen $\mathrm{pH}-\mathrm{Wert}$ oder Staunässe die Nitrifikation gehemmt ist, z.B. in Nadelwäldern, Reisfeldern und der arktischen Tundra. Die Aufnahme organischer Stickstoffverbindungen spielt wahrscheinlich nur bei Pflanzen borealer und arktischer Regionen eine quantitative Rolle in der Sticktoffversorgung (Chapin et al. 1993, Näsholm et al. 1998). Transportproteine für die Aufnahme all dieser Stickstoffverbindungen aus dem Boden wurden inzwischen charakterisiert (Williams \& Miller 2001, Desimone et al. 2002, Glass et al. 2002, Liu et al. 2003). Neben der Aufnahme aus dem Boden sind weitere Möglichkeiten der Stickstoffbeschaffung für eine Pflanze u.a. die 
Symbiose mit $\mathrm{N}_{2}$ reduzierenden Bakterien (Mylona et al. 1995), Carnivorie (Ellison \& Gotelli 2002) oder Parasitismus (Taylor \& Bruns 1997).

\subsection{Assimilation von anorganischem Stickstoff}

Im pflanzlichen Organismus wird Stickstoff als Bestandteil von Aminosäuren und Proteinen, Nukleotiden und Nukleinsäuren, sowie zahlreichen Sekundärstoffwechsel-Produkten benötigt. Der überwiegend in anorganischer Form aus dem Boden aufgenommene Stickstoff muß dazu unter Energieaufwand assimiliert, d.h. reduziert und in organische Verbindungen eingebaut werden. Nitrat wird in zwei Stufen zunächst zu Ammonium reduziert. Im ersten Schritt wird Nitrat durch eine Zwei-Elektronen-Übertragung zu Nitrit reduziert. Dies geschieht im Zytoplasma durch den Enzymkomplex Nitratreduktase (NR) (Solomonson \& Barber 1990). Nitrit wird danach durch die Nitritreduktase (NiR) in einer Sechs-Elektronen-Übertragung in Ammonium überführt (Siegel \& Wilkerson 1989). Die benötigte Reduktionsenergie stammt in den Chloroplasten grüner Blätter aus der Lichtreaktion der Photosynthese und wird über Ferredoxin übertragen. In den Leukoplasten der Wurzel stellt der oxidative Pentosephosphatweg die benötigten Reduktionsäquivalente zur Verfügung.

Aus dem Boden aufgenommenes sowie bei der Nitratreduktion oder der Photorespiration gebildetes Ammonium (Leegood et al. 1995) wird durch die Enzyme Glutamin-Synthetase (GS) und Glutamat-Synthase (= Glutamin-Oxoglutarat-Aminotransferase, GOGAT) in Aminosäuren eingebaut: Die GS synthetisiert Glutamin unter ATP-Verbrauch aus freiem Ammonium und Glutamat. Glutamat wird in der GOGAT-katalysierten Reaktion durch Übertragung einer Aminogruppe von Glutamin auf $\alpha$-Ketoglutarat (= Oxoglutarat) regeneriert. Insgesamt entsteht so aus je einem Molekül $\alpha$-Ketoglutarat und $\mathrm{NH}_{4}{ }^{+}$ein Molekül Glutamat. Dieses steht als Aminogruppen-Donor weiteren Synthesewegen zur Verfügung. Isoformen sowohl der GS als auch der GOGAT finden sich im Zytosol und in den Plastiden (Lam et al. 1996).

Obwohl die Assimilation von Ammonium wesentlich weniger metabolische Energie verbraucht, als die von Nitrat, ist eine N-Versorgung ausschließlich oder überwiegend mit $\mathrm{NH}_{4}{ }^{+}$für die meisten Pflanzen problematisch. Ammonium ist bereits in geringen Konzentrationen zytotoxisch, möglicherweise weil es im Gleichgewicht mit freiem Ammoniak $\left(\mathrm{NH}_{3}\right)$ steht, der als Entkoppler von Protonengradienten an Membranen wirkt (Kleiner 1981). Es wird deshalb bereits in der Wurzel assimiliert (Givan 1979) und seine Konzentration im Zytosol liegt in der Regel unter $15 \mu \mathrm{M}$. Höhere Konzentrationen können in der Vakuole auftreten, wo der saure pH-Wert die Bildung von $\mathrm{NH}_{3}$ verhindert (Roberts \& 
Pang 1992). Ausschließliche Ammonium-Ernährung führt zu einer massiven Umstellung des Kohlenhydratstoffwechsels zugunsten der Versorgung der Wurzel mit C-Skeletten, sowie Ungleichgewichten in der Versorgung mit anderen Nährstoffionen. Daraus resultieren schwere physiologische und morphologische Störungen in der Osmo- und pH-Regulation, die als “Ammonium-Syndrom” bezeichnet werden (Chaillou et al. 1986, Mehrer \& Mohr 1989). Im Gegensatz zu Ammonium kann dagegen Nitrat sowohl in der Wurzel als auch im Sproß assimiliert und problemlos in der Vakuole gespeichert werden (Miller \& Smith 1992).

Das bei der Nitratreduktion auftretende Nitrit wirkt mutagen (Desaminierung von Adenin zu Hypoxanthin und von Cytosin zu Uracil) und darf wie Ammonium nicht in der Zelle akkumulieren (Becker et al. 1992). Die NR stellt deshalb den langsamsten, geschwindigkeitsbestimmenden Schritt der gesamten N-Assimilation dar. Da außerdem Nitrat als anorganische Stickstoffquelle meistens überwiegt, kann die Nitratreduktase-Aktivität (NRA) als Maß für die N-Assimilationsaktivität der Pflanze insgesamt betrachtet werden (Lee \& Steward 1978). Aufgrund des hohen Energiebedarfs der Nitratreduktion (bis zu $25 \%$ der Energieausbeute der Lichtreaktion, Champigny 1995) und der engen Kopplung von C- und NMetabolismus über den Bedarf an Kohlenstoffgerüsten, ATP und Reduktionsäquivalenten wird die NRA sehr genau reguliert. Dies geschieht auf Ebene der Transkription, des Proteinabbaus und der reversiblen Enzyminaktivierung durch Phosphorylierung (Solomonson \& Barber 1990, Kaiser \& Spill 1991). Die NR wird durch Nitrat, Licht und Kohlenhydrate induziert und durch Glutamin inhibiert, die mRNA- und Proteinkonzentration sowie die Enzymaktivität zeigen diurnale Rhythmen (Solomonson \& Barber 1990, Becker et al. 1992, Lillo 1994).

\subsection{Ferntransport von Assimilaten und Ionen in der Pflanze}

Für den Ferntransport von Nährstoffen und organischen Verbindungen besitzt die Pflanze zwei Gewebetypen, das Xylem und das Phloem, die zusammen die Leitbündel bilden. Das Xylem besteht aus toten, lignifizierten Zellen, die ein ununterbrochenes Kapillarsystem darstellen, und parenchymatischen Zellen, die für die Be- und Entladung entlang der Gefäße und die transiente Speicherung von Nährstoffen zuständig sind. Bei den Angiospermen sind die Xylemgefäße in weitlumige Tracheen und englumige Tracheiden differenziert. Die in ihnen transportierte Nährstofflösung enthält vor allem Aminosäuren und andere organische Säuren (zusammen bis zu $25 \mathrm{mM}$ ), sowie anorganische Ionen, bei denen $\mathrm{K}^{+}$(ca. $25 \mathrm{mM}$ ), $\mathrm{NO}_{3}^{-}$(bis $20 \mathrm{mM}$ ) und $\mathrm{Ca}^{2+}$ (ca. $10 \mathrm{mM}$ ) dominieren (Triplett et al. 1980). Die Ammoniumkonzentration im Xylemstrom ist sogar bei reiner $\mathrm{NH}_{4}{ }^{+}$-Ernährung stets niedrig, 
bei Mais steigt sie z.B. nie signifikant über $1 \mathrm{mM}$ (van Beusichem et al. 1988, Engels \& Marschner 1993). Obwohl Aminosäuren die häufigsten Substanzen im Xylem sind (Pate et al. 1977, Pate 1980), ist ihre Gesamtkonzentration dennoch ca. zehnfach kleiner als im Phloem (Lam et al. 1995). Angetrieben wird der Xylemstrom durch die Kapillarkräfte in den Gefäßen und die Transpiration der oberirdischen Pflanzenteile, also letztlich durch die Wasserpotentialdifferenz zwischen Atmosphäre und Boden. Im Xylem ist daher nur ein aufwärts gerichteter Transport von der Wurzel in den Sproß möglich.

Im Gegensatz zum Xylem besteht das Phloem aus lebenden Zellen, in denen eine komplexe, hochkonzentrierte Lösung transportiert wird, die neben verschiedenen Kohlenhydraten (Disaccharide, Zuckeralkohole und Oligosaccharide) auch Aminosäuren und anorganische Ionen enthält (Ziegler 1975, Zimmermann \& Ziegler 1975, Lohaus et al. 1995, Hayashi et al. 2000). Anders als im Xylemsaft kommen aber weder Nitrat noch Ammonium vor (Lohaus et al. 1995, Lohaus et al. 1998). Mit einem Anteil von bis zu $90 \%$ an der Trockensubstanz des Phloemsaftes (Hocking 1980) dominiert bei weitem das Disaccharid Saccharose. Es kann im Phloemsaft Konzentrationen bis zu 1,5 M erreichen (Lohaus et al. 1994, 1995) und dient in den meisten Pflanzen als Haupttransportform für Photoassimilate. Die Gesamtkonzentration von Aminosäuren im Phloem liegt dagegen bei ca. 100-300 mM (Riens et al. 1991, Lohaus et al. 1994, 1995, 1998, Lohaus \& Möllers 2000). Dabei sind die Konzentrationsverhältnisse der Aminosäuren untereinander im Phloem und dem umgebenden Gewebe sehr ähnlich (Riens et al. 1991, Winter et al. 1992), woraus man auf eine unspezifische Aufnahme von Aminosäuren ins Phloem schließen kann. Die häufigsten Aminosäuren sowohl im Mesophyll als auch im Phloem sind Glutamin, Glutamat und Aspartat, die deshalb oft als Transport-Aminosäuren bezeichnet werden. Die Transportgeschwindigkeit ist im Phloem für alle Substanzen etwa gleich (Housley et al. 1979) und beträgt bis zu 40-100 $\mathrm{cm} \mathrm{h}^{-1}$ (Fischer 1990).

Im Phloem werden außer Assimilaten auch Phytohormone (Ziegler 1975) und Makromoleküle wie Oligopeptide, Proteine und RNA transportiert (Oparka \& Santa Cruz 2000). Peptide im Phloem können der Stickstoffverlagerung dienen, häufig handelt es sich aber um Wachstumsfaktoren (Stacey et al. 2002). Kleinen, im Phloem transportierten RNASpezies wird eine Rolle bei der systemischen Aktivierung der Pathogenabwehr durch RNAInterferenz (RNAi) zugeschrieben (Systemic Aquired Resistance, Ryals et al. 1996). Das Phloem dient somit nicht nur dem Stoff-, sondern auch dem Signaltransport (Ruiz-Medrano et al. 2001). Sogar die Weiterleitung von Aktionspotentialen im Phloem wird diskutiert (Rhodes et al. 1996). Auch Pflanzenviren breiten sich häufig über den Phloemstrom in der Pflanze aus (Nelson \& van Bel 1998, Oparka \& Santa Cruz 2000). 


\subsection{Anatomie des Phloems}

Im Phloem bilden die kernlosen Siebzellen das eigentliche Transportsystem. Sie sind an ihren Enden jeweils über Zellwände mit zahlreichen Plasmodesmata (Siebplatten) verbunden, so daß sie zusammen eine lange, kontinuierliche Siebröhre bilden. Jede Siebzelle steht mit ein oder mehreren Geleitzellen über spezialisierte verzweigte Plasmodesmata (,Pore/Plasmodesma Units“) in enger symplastischer Verbindung. Die Geleitzelle versorgt die Siebzelle u.a. mit Proteinen, da reife Siebzellen keine Ribosomen mehr besitzen (Sjölund 1997). Sieb- und Geleitzellen entstehen jeweils durch inäquale Teilung aus derselben PhloemMutterzelle und bilden eine funktionale Einheit, die als Siebelement-Geleitzell-Komplex bezeichnet wird. Die Ausdifferenzierung der Siebzelle erfolgt durch eine genau regulierte partielle Autolyse, die der Apoptose ähnelt und an deren Ende die Siebzelle nur noch modifizierte Mitochondrien und Endoplasmatisches Reticulum als subzelluläre Strukturen enthält. Diese liegen zusammen mit Aggregaten von siebröhrenspezifischen Proteinen eng an der Plasmamembran an und bilden die sogenannte Parietalschicht (Oparka \& Turgeon 1999, Ehlers et al. 2000). Im übrigen Zytoplasma bewegt sich der Phloemstrom.

Nach der Druckstromtheorie von Münch (1930) wird der Massenfluß in den Siebröhren durch ein osmotisches Potentialgefälle zwischen Be- und Entladungsorten angetrieben. Die ungewöhnliche Morphologie der Siebzellen ist dafür eine notwendige Vorraussetzung: Sie können gleichzeitig einen Volumenstrom durch ihr Inneres passieren lassen und einen kontrollierten Zellturgor aufrechterhalten (van Bel 2003). Da die Richtung der Phloembewegung nach der Druckstromtheorie von den Be- und Entladungsorten abhängt, kann der Phloemstrom im Gegensatz zum Xylem in der Pflanze auch abwärts verlaufen und außerdem seine Flußrichtung im Verlaufe der Pflanzenentwicklung je nach Ressourcenverhältnissen ändern (Wright et al. 2003). Organe, die einen Netto-Überschuß von C- bzw. N-Assimilaten erzeugen werden als (C- oder N-) Source-Organe bezeichnet. In ihnen erfolgt die Beladung des Phloems. Organe, die einen Netto-Bedarf an Assimilaten aufweisen und Nährstoffe aus dem Phloem entladen, heißen Sink-Organe.

\subsection{Phloem-Beladungsmechanismen}

Eine Vorraussetzung für den Druckstrom im Phloem ist die Anreicherung der Transportsubstanzen in den Siebröhren gegenüber dem umgebenden Gewebe, die den Aufbau eines osmotischen Potentials ermöglicht. Saccharose ist im Phloemsaft gegenüber dem Zytosol der umgebenden Mesophyllzellen ca. zehnfach höher konzentriert, Aminosäuren bis 
zu dreifach höher (Riens et al. 1991, Lohaus \& Möllers 2000). Die Siebröhren sind vom umgebenden Gewebe weitgehend symplastisch isoliert, und die Phloembeladung erfolgt hauptsächlich an den Geleitzellen. Dabei werden Pflanzen mit geschlossener und offener Phloemanatomie unterschieden.

In Pflanzen mit offener Phloemanatomie steht die Geleitzelle durch zahlreiche Plasmodesmata in engem Kontakt mit dem umgebenden Gewebe und wird als Intermediärzelle bezeichnet (Gunning \& Pate 1969). Bei diesen Pflanzen können transportierte Substanzen theoretisch durch die Plasmodesmata direkt in den SiebelementGeleitzell-Komplex gelangen, ohne den Apoplasten passieren zu müssen (symplastische Phloembeladung). Symplastische Belader transportieren neben Saccharose meist auch Oligosaccharide aus der Raffinose-Familie (Ziegler 1975), die erst in den Intermediärzellen synthetisiert werden (Holthaus \& Schmitz 1991). Turgeon $(1991,1996)$ formulierte deshalb das „polymer-trap“ Modell, wonach die Raffinose-Oligosaccharide zu groß sind, um durch die Plasmodesmata wieder aus dem Phloem heraus $\mathrm{zu}$ diffundieren. Inwiefern die Ausschlußgröße der Plasmodesmata diese Annahme bestätigt, ist noch umstritten. In letzter Zeit wurden jedoch auch bei potentiell symplastischen Beladern $\mathrm{H}^{+}$-Saccharose-Symporter im Phloem lokalisiert (Knop et al. 2001), die vermutlich an der Phloembeladung mit Saccharose beteiligt sind. Der Mechanismus der symplastischen Phloembeladung muß noch endgültig geklärt werden.

Bei einer geschlossenen Phloemanatomie hat auch die Geleitzelle nur wenige symplastische Verbindungen zum Mesophyll. Dies erfordert, daß die im Phloem transportierten Metaboliten zunächst aus dem Zytosol der Mesophyllzellen in den Zellwandraum (Apoplast) austreten und von dort wieder in die Geleitzelle aufgenommen werden (apoplastische Phloembeladung). Die Geleitzellen von apoplastischen Beladern können durch zahlreiche Einstülpungen der Zellwand und der anliegenden Plasmamembran ins Zytoplasma eine stark vergößerte Oberfläche haben, die den Stoffaustausch erleichtert. Sie werden dann als Transferzellen bezeichnet (Gunning \& Pate 1969). Bei der apoplastischen Phloembeladung müssen die Assimilate mindestens zwei Plasmamembranen passieren. Zumindest für die Aufnahme in die Geleitzelle sind dabei aktive Transportprozesse notwendig (Riesmeier et al. 1994, Koch et al. 2003). Die Bestimmung der Konzentrationen von Metaboliten im Apoplast ist schwierig (Lohaus et al. 2001). Sie sind aber insgesamt sehr niedrig und liegen für Saccharose und verschiedene Aminosäuren in der Größenordnung von <0,1 bis $5 \mathrm{mM}$ (Lohaus et al. 1995). Der tatsächliche Konzentrationsgradient, gegen den die Phloembeladung erfolgt, ist also bis zu hundertfach höher als der Konzentrationsunterschied zwischen dem Zytosol der 
Mesophyllzellen und dem Phloemsaft. Zahlreiche Transportproteine, die für diesen aktiven Transport verantwortlich sind, sind inzwischen charakterisiert worden, u.a. für Saccharose (Riesmeier et al. 1992, Gahrtz et al. 1994, Sauer \& Stolz 1994), Aminosäuren (Abschnitt 1.3), Mannit (Noiraud et al. 2001) und Sorbit (Gao et al. 2003).

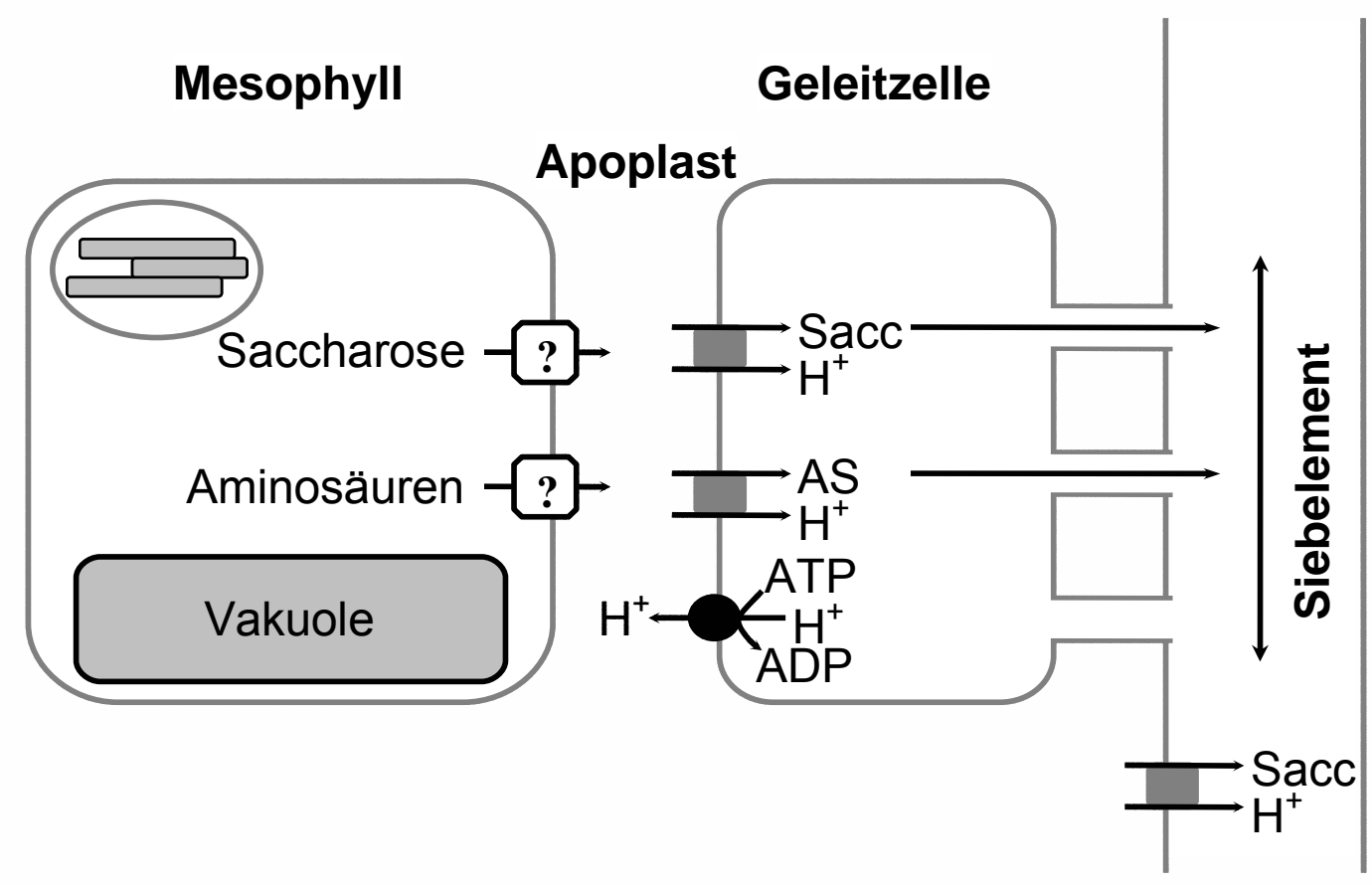

Abb. 1.1: Apoplastische Phloembeladung. Im Phloem transportierte Metaboliten verlassen auf noch unbekannte Weise die Mesophyllzelle des Source-Blattes und werden von Protonensymportern in der Plasmamembran der Geleitzelle aus dem Apoplasten aufgenommen. Der Transport wird über den von $\mathrm{H}^{+}$-ATPasen aufgebauten Protonengradienten angetrieben. Weitere Transporter entlang der Siebröhre dienen möglicherweise der Wiederaufnahme aus dem Phloem ausgetretener Metabolite.

\subsection{Phloem-Entladung}

Die Entladung des Phloems kann prinzipiell ebenfalls auf apoplastischem oder symplastischem Weg erfolgen. Verschiedene Pflanzenarten unterscheiden sich dabei u.a. in Abhängigkeit der von ihnen bevorzugt gespeicherten Kohlenhydrate (Stärke, Saccharose oder Hexosen). In den meisten Geweben scheint aber die symplastische Entladung vorzuherrschen (Lalonde et al. 2003). Dies läßt sich sehr elegant durch die Expression des im Phloem mobilen Grün Fluoreszierenden Proteins (GFP) unter der Kontrolle eines geleitzellenspezifischen Promotors visualisieren: Die Ausbreitung des grünen Fluoreszenzsignals über die Siebröhren und in die Zielorgane beweist die symplastische 
Kontinuität dieses Transportweges (Imlau et al. 1999). Viola et al. (2001) fanden, daß während der Entwicklung von Kartoffelknollen ein Umschalten von anfänglicher apoplastischer zu symplastischer Entladung stattfindet. Bei einer apoplastischen Entladung des Phloems müssen die Transportmetabolite wiederum mindestens zwei Plasmamembranen passieren. Der Austritt aus den Siebröhren erfolgt mit dem Konzentrationsgefälle und muß deshalb nicht über einen aktiven Transport erfolgen. Für Saccharose wird das Konzentrationsgefälle noch dadurch verstärkt, daß Invertasen die apoplastische Konzentration permanent auf einem niedrigen Niveau halten (Sturm \& Tang 1999, Roitsch et al. 2000). Die freigesetzten Monosaccharide können durch Hexosetransporter in die Zielzellen aufgenommen werden (Büttner \& Sauer 2000). Ein vergleichbarer Mechanismus existiert für Aminosäuren nicht.

\subsection{Verlagerung von Stickstoff in der Pflanze: Source-Sink-Verhältnisse}

Der Stickstofftransport in der Pflanze ist ein sehr komplexes Phänomen (Frommer et al. 1994b). Verschiedene Organe können im Verlauf der Pflanzenentwicklung zeitweise als NSource- und zeitweise als N-Sink-Gewebe fungieren und die transportierten Metabolite variieren in Abhängigkeit von diesen Source-Sink-Verhältnissen.

Wenn Ammonium, das in der Wurzel assimiliert wird, einen großen Teil der Stickstoffversorgung ausmacht, stellt die Wurzel ein N-Source-Organ dar. Zugleich ist sie aber auch ein C-Sink und der Phloemstrom ist zur Versorgung der Wurzel mit Saccharose abwärts gerichtet. Der Export von Aminosäuren in die oberirdischen Pflanzenteile muß unter diesen Umständen im Xylem erfolgen. Bei hauptsächlicher Nitraternährung überwiegt die Nitratreduktion im Sproß (Pate 1980, Andrews 1986, Schulze \& Gebauer 1997) und Nitrat wird mit dem Xylemstrom aufwärts transportiert. Die Wurzel stellt dann ein C- und N-SinkOrgan dar und wird über das Phloem sowohl mit Saccharose als auch mit Aminosäuren versorgt.

Blätter sind N-Sink-Organe, solange sie noch nicht zur Photosynthese befähigt sind. Reife Blätter fungieren dagegen als N-Source, ebenso wie seneszierende Blätter und andere seneszierende Gewebe, die Proteine abbauen. Während reife Blätter hauptsächlich Aminosäuren exportieren, machen bei seneszierenden Blättern auch proteolytische Peptide einen gewissen Anteil des Stickstoff-Exports aus (Stacey et al. 2002, Miranda et al. 2003).

Reifende Samen, die die stärksten N-Sinks in der Pflanze darstellen, erhalten den größten Teil ihres Stickstoffreservoirs aus der Remobilisation von bereits zuvor aufgenommenem Stickstoff und nicht aus der Neuaufnahme über die Wurzel (Thorne 1985, Frommer et al. 
1994b). Aminosäuren werden sowohl im Xylem als auch im Phloem in die Infloreszenz transportiert, erreichen aber nur über das Phloem den Samen. Es muß deshalb ein quantitativer Transfer vom Xylem ins Phloem erfolgen (Peoples \& Gifford 1990). Bei der Keimung werden die im Samen angelegten Speicherproteine wieder abgebaut und die Keimblätter versorgen den Rest des Keimlings über das Phloem mit Stickstoff, Kohlenhydraten und anderen Nährstoffen.

Viele dieser Transportprozesse erfordern die Translokation von Aminosäuren über eine Plasmamembran, so z.B. die Aufnahme in den Zentralzylinder der Wurzel an der Endodermis, die (apoplastische) Phloembeladung und die Beladung des symplastisch von der Mutterpflanze isolierten Samens mit Stickstoff. Die dafür verantwortlichen Transportproteine sind erst seit zehn Jahren bekannt.

\subsection{Identifizierung pflanzlicher Aminosäuretransporter}

Pflanzliche Aminosäuretransporter wurden bereits in den 1970er Jahren physiologisch untersucht. Aus der Aufnahme radioaktiv markierter Aminosäuren in Blattscheiben, abgeriebene Blattoberflächen, Protoplasten, Zellkulturen (Reinhold \& Kaplan 1984) und Plasmamembran-Vesikel (Li \& Bush 1991, 1992) schloß man, daß der Transport wie bei Saccharose aktiv ist und durch den Protonengradienten der Plasmamembran angetrieben wird. Es wurden komplexe mehrphasige Kinetiken beobachtet, die das Vorkommen mehrerer unabhängiger Transportsysteme belegten. So schlossen z.B. Li \& Bush (1990, 1991) aus Untersuchungen an Plasmamembran-Vesikeln auf mindestens vier unterschiedliche Systeme, je eines spezifisch für saure und basische Aminosäuren, sowie ein hoch- und ein niedrigaffines System für neutrale Aminosäuren. Für die Substraterkennung bei den neutrale Aminosäuren transportierenden Systemen erwies sich die $\alpha$-Aminogruppe als essentiell (Li \& Bush 1992).

Aufgrund der Schwierigkeiten, die mit der biochemischen Isolation relativ seltener integraler Membranproteine verbunden sind, gelang es lange Zeit nicht, die Aminosäuretransporter einzeln zu charakterisieren. Dies wurde erst auf molekularbiologischem Weg durch die Verwendung von Hefemutanten mit defizienter Aminosäure-Aufnahme möglich (Frommer \& Ninnemann 1995). Durch Expression von cDNA-Banken aus Arabidopsis in solchen Hefestämmen und Selektion auf Medien mit niedrigen Konzentrationen der betreffenden Aminosäure konnten pflanzliche cDNAs identifiziert werden, die die Hefe-Transportmutanten komplementierten. Auf diese Weise identifizierten Frommer et al. (1993) und Hsu et al. (1993) unabhängig voneinander die zu mehr als 99 \% identischen cDNAs von AAP1 („Amino 
Acid Permease 1“) und NAT2 („Neutral Amino Acid Transport System II“). Frommer et al. verwendeten dazu ein Prolin- und Hsu et al. ein Histidin-Selektionssystem.

Durch die Hefekomplementation konnten seitdem zahlreiche weitere Aminosäuretransporter aus insgesamt 6 Genfamilien in Arabidopsis identifiziert werden (Frommer et al. 1994b, Fischer et al. 1998, Rentsch et al. 1998, Ortiz-Lopez et al. 2000, Wipf et al. 2002). Die Methode erlaubt allerdings nur die Identifizierung von Transportern, die für ihre Funktion nur eine Untereinheit benötigen und in Hefe korrekt in die Plasmamembran inseriert werden (Frommer et al. 1994b). Weitere potentielle Aminosäuretransporter konnten anhand ihrer Homologie mit tierischen oder Hefe-Transportern in der vollständigen Sequenz des Arabidopsis-Genoms (The Arabidopsis Genome Initiative 2000) identifiziert werden, ihre tatsächliche Substratspezifität ist aber in vielen Fällen noch nicht untersucht. Insgesamt enthält das Arabidopsis-Genom 53 (putative) Aminosäuretransporter in 9 Proteinfamilien (Tab. 1.1, Wipf et al. 2002). Weitere für Aminosäuren spezifische Transporter könnten sich auch unter den bisher nicht charakterisierten Mitgliedern anderer Proteinfamilien befinden, wie z.B. den ABC-Transportern (Theodoulou 2000).

Tab. 1.1: Familien von (potentiellen) Aminosäuretransportern in Arabidopsis. Im Anschluß an die Familie ist die Anzahl offener Leseraster im Arabidopsis-Genom in Klammern angegeben. TM: Anzahl putativer Transmebranhelices; MFS: „Major Facilitator Superfamily”; APC: „Amino Acid-Polyamine-Choline Transporter Superfamily“; ATF: „Amino Acid Transporter Family 1“. Nach Wipf et al. 2002 und Lam et al. 1998 (GLRs), Grallath et al. 2003 (ProTs) und Lee \& Tegeder 2003 (LHT2).

\begin{tabular}{|c|c|c|c|}
\hline Superfamilie & Familie & TM & Substrate \\
\hline \multirow{2}{*}{ MFS } & VGT-like (5) & $8-12$ & $?$ \\
\hline & GLRs (7) & 4 & putative Glutamat-gesteuerte Calciumkanäle \\
\hline \multirow{2}{*}{ APC } & LATs (5) & 12 & $?$ \\
\hline & CATs (9) & 14 & basische und neutrale Aminosäuren \\
\hline \multirow{5}{*}{ ATF1 } & AAPs (8) & $(9-) 11$ & $\begin{array}{l}\text { neutrale und saure Aminosäuren (Aspartat: } \\
\text { nur AAP6 und 8; außerdem basische } \\
\text { Aminosäuren: nur AAP3 und 5) }\end{array}$ \\
\hline & LHTs (8) & $9-10$ & $\begin{array}{l}\text { Lysin und Histidin (LHT1), neutrale und saure } \\
\text { Aminosäuren (LHT2) }\end{array}$ \\
\hline & ANTs (3) & 11 & aromatische und neutrale Aminosäuren \\
\hline & ProTs (5) & 10 & Betain, D- und L-Prolin, $\gamma$-Aminobuttersäure \\
\hline & AUXs (3) & 10 & Auxin \\
\hline
\end{tabular}




\subsection{Familien von Aminosäuretransportern in Arabidopsis}

Die bisher bekannten (potentiellen) Aminosäuretransporter verteilen sich auf drei Superfamilien:

(1) Zur „Major Facilitator Superfamily“ (MFS) gehören (1a) 5 Gene, die Homologie zu tierischen VGTs (,Vesicular Glutamate Transporters“) aufweisen und (1b) eine weitere Genfamilie, die GLRs, mit Sequenzähnlichkeit zu tierischen ionotrophen Glutamatrezeptoren (Lam et al. 1998). Keines dieser Proteine ist bisher untersucht worden (Wipf et al. 2002).

(2) In der „Amino Acid-Polyamine-Choline Transporter Superfamily“ (APC), zu der auch alle Hefe-Aminosäuretransporter gehören, finden sich zwei pflanzliche Genfamilien: (2a) Die uncharakterisierten Gene AtLAT1 bis 5 weisen Homologien zu den Hefetransportern und zu tierischen LATs (System L-HATs [„Heteromeric Amino Acid Transporters“]) auf. Es handelt sich um Proteine mit 12 putativen Transmembrandomänen. Für den Hefetransporter GAP1 wurde diese Struktur experimentell belegt (Gilstring \& Ljungdahl 2000). Die tierischen HATTransporter benötigen für ihre Funktion eine zweite, schwere Untereinheit, die nur eine Transmembranhelix aufweist und für die Aktivität des eigentlichen Transporters notwendig ist. Weder in Hefe noch in Pflanzen wurden Homologe dieser schweren Untereinheiten gefunden (Wipf et al. 2002).

(2b) Die zweite Arabidopsis-Genfamilie innerhalb der APC Superfamilie enthält den Transporter AtCAT1 = AtAAT1 (Frommer et al. 1995) und vier verwandte Gene, die den CATs (Cationic Amino Acid Transporters) aus Tieren ähneln. CAT1/AAT1 ist ein 58 kDa Protein mit 14 putativen Transmembrandomänen und transportiert nicht-stereospezifisch ein breites Spektrum von Aminosäuren, wobei die höchste Affinität zu basischen Aminosäuren besteht. Der Transporter wird in allen Organen von Arabidopsis exprimiert, in Blättern und Wurzeln konnte die Expression auf die Leitbündel eingegrenzt werden. Wahrscheinlich ist CAT1/AAT1 am Ferntransport, Xylem-Phloem-Transfer und der Versorgung sich entwickelnder Embrynen mit basischen Aminosäuren beteiligt.

(3) Alle übrigen in Arabidopsis identifizierten Aminosäuretransporter gehören in die Superfamilie ATF1 („Amino Acid Transporter Family 1“) und sind Protonen-Symporter. (3a) ProTs sind Transporter für Betain, L- und D-Prolin sowie $\gamma$-Aminobuttersäure (Rentsch et al. 1996, Grallath et al. 2003). Es handelt sich um $48 \mathrm{kDa}$ Proteine mit 10 putativen Transmembranhelices. ProT1 spielt eine Rolle bei der Induktion der Blütenentwicklung durch Prolin (Kavi Kishor et al. 1995, Rentsch et al. 1996). ProT2 ist im Cortex und der Epidermis der Wurzel exprimiert und wird bei Salz- und Trockenstreß stark induziert, so daß eine Funktion bei der Verteilung von Prolin als Osmoregulator (“compatible solute") angenommen 
wird (Delauney \& Verma 1993, Rentsch et al. 1996). ProT3 ist in der Epidermis von Blattunterseiten exprimiert (Grallath et al. 2003). Zwei weitere verwandte Transporter sind noch nicht näher untersucht (Wipf et al. 2002).

(3b) LHT1 („Lysine and Histidine Transporter 1“, Chen \& Bush 1997) gehört zu einer weiteren Familie von 8 Genen (Wipf et al. 2002). Das 50,5 kDa Protein mit 9-10 putativen Transmembrandomänen katalysiert die Aufnahme von Lysin und Histidin in Hefezellen, hat aber nur eine geringe Affinität für Arginin. LHT1 ist ubiquitär in Arabidopsis exprimiert, besonders stark in Sink-Geweben. Der kürzlich charakterisierte Transporter LHT2 (Lee \& Tegeder 2003) transportiert dagegen mit hoher Affinität neutrale und saure Aminosäuren und ist im Tapetum der Staubbeutel exprimiert.

(3c) Der erst 2001 identifizierte Transporter ANT1 (,Aromatic and Neutral Amino Acid Transporter 1", Chen et al. 2001) bildet mit 2-4 weiteren, noch nicht untersuchten Genen eine dritte Familie innerhalb der ATF1-Transporter. Das $50 \mathrm{kDa}$ Protein mit 11 putativen Transmembranhelices ist in allen Organen von Arabidopsis exprimiert und transportiert neben neutralen und aromatischen Aminosäuren auch Arginin und Auxin.

(3d) Die als erste pflanzliche Aminosäuretransporter identifizierten AAPs sind bei weitem die am besten untersuchte Gruppe und gehören ebenfalls zur ATF1-Superfamilie. Das Arabidopsis-Genom enthält acht $A A P$-Gene, von denen 7 bisher funktionell charakterisiert und auf mRNA-Ebene in der Pflanze lokalisiert wurden (Frommer et al. 1993, Hsu et al. 1993, Kwart et al. 1993, Fischer et al. 1995, Rentsch et al. 1996, Hirner et al. 1998, Fischer et al. 2002, Okumoto et al. 2002, Wipf et al. 2002). Mitglieder dieser Proteinfamilie wurden auch in Nicotiana sylvestris (Lalanne et al. 1997), Ricinus communis (Bick et al. 1998), Vicia faba (Montamat et al. 1999, Miranda et al. 2001), Nepenthes alata (Schulze et al. 1999), Pisum sativum (Tegeder et al. 2000), und Solanum tuberosum (Koch et al. 2003) identifiziert. Es handelt sich um Proteine mit ca. 490 Aminosäuren mit einem Molekulargewicht von 53 kDa und 9-11 putativen Transmembrandomänen. Für AAP1 konnte eine Tertiärstruktur mit 11 die Plasmamembran durchspannenden Helices, zytosolischem N- und extrazellulärem CTerminus experimentell gezeigt werden (Chang \& Bush 1997). Wahrscheinlich weisen auch die anderen AAPs diese Struktur auf. Die in Hefezellen und Xenopus-Oocyten funktionell charakterisierten Transporter AAP1-6 und AAP8 katalysieren eine pH-abhängige und durch Entkoppler oder $\mathrm{H}^{+}$-ATPase-Hemmstoffe inhibierbare Akkumulation von Aminosäuren in den betreffenden Zellen gegenüber dem Medium. Das pH-Optimum der AAPs liegt bei 5,0, was etwa der apoplastischen Protonenkonzentration entspricht (Pfanz \& Dietz 1987). Mit $A A P 1$ - und AAP5-exprimierenden Xenopus-Oocyten wurden detaillierte elektro- 
physiologische Messungen vorgenommen (Boorer et al. 1996, Boorer \& Fischer 1997), die zeigten, daß alle Aminosäuren unabhängig von ihrer Ladung zusammen mit einem Proton transportiert werden. Die Substrate der Transporter sind dabei die einfach positiven Kationen von Arginin und Lysin und die neutralen Zwitterionen aller anderen Aminosäuren.

Alle AAPs weisen eine breite Substratspezifität auf und transportieren die meisten proteinogenen Aminosäuren. Dabei bestehen allerdings einige signifikante Unterschiede zwischen den einzelnen Transportern: Nur AAP3 und AAP5 transportieren effizient basische Aminosäuren, und nur AAP6 und AAP8 besitzen eine unter physiologischen Bedingungen relevante Affinität zu Aspartat (Fischer et al. 2002, Okumoto et al. 2002). Mit Ausnahme der ProTs sind somit alle bisher bekannten pflanzlichen Aminosäuretransporter in der Lage, jeweils ein ganzes Spektrum verschiedener Aminosäuren zu transportieren, wobei die AAPs das breiteste Substratspektrum besitzen. Da die Phloembeladung von Aminosäuren unspezifisch erfolgt, sind die AAPs dafür die wahrscheinlichsten Kandidaten. Allerdings muß dabei die Konzentration der Substrate in vivo berücksichtigt werden. So besitzen AAP3 und AAP5 zwar eine höhere Affinität für basische Aminosäuren als für Glutamin, Glutamat und Aspartat, transportieren aber unter physiologischen Bedingungen möglicherweise doch eher diese in bis zu hundertfach höherer Konzentration auftretenden Hauptaminosäuren. Das würde erklären, warum Pflanzen zusätzlich Transporter mit relativ hoher Spezifität für basische Aminosäuren (CAT1, LHT1) und Tryptophan (ANT1) besitzen (Fischer et al. 2002). Bei so vielen Transportern mit überlappender Substratspezifität stellt sich auch die Frage nach möglicher Redundanz. Northern Blot-Analysen, RNA in situ Hybridisierungen und PromotorGUS-Studien haben für alle AAPs ein unterschiedliches Expressionsmuster in der Pflanze gezeigt. Zusammen decken sie die wesentlichen Aminosäure-Transportvorgänge in der Pflanze ab (Rentsch et al. 1996). AAP1 ist wahrscheinlich an der Beladung des Samens und der Remobilisierung der Stickstoffreserven im Keimling beteiligt (Kwart et al. 1993, Okumoto et al. 2002). AAP2, AAP3 und AAP4 werden im Phloem von Source-Blättern exprimiert und dienen dort dem Aminosäure-Export. AAP2 und AAP4 spielen außerdem eine Rolle in der Wiederaufnahme von aus dem Phloem ausgetretenen Aminosäuren entlang des Transportweges im Stengel und möglicherweise beim Transfer zwischen Phloem und Xylem. AAP3-Expression in der Wurzel deutet auf eine zusätzliche Funktion dieses Transporters bei der Aufnahme von Aminosäuren aus dem Boden hin. AAP5 wird ebenfalls im Phloem von Source-Blättern, Stengeln und Blüten exprimiert. Möglicherweise ist seine Funktion der Export und Xylem-Phloem-Transfer von Glutamin (Kwart et al. 1993, Fischer et al. 1995). AAP6 ist spezifisch für Sink-Blätter und Wurzeln (Rentsch et al. 1996, Okumoto et al. 2002). 
Eine Expression von AAP7 in der Pflanze konnte bisher nicht nachgewiesen werden. In Hefe exprimiert, katalysierte das Protein keinen Aminosäuretransport (Okumoto et al. 2002). AAP8 ist wie AAP1 für die Beladung des Samens zuständig, wobei seine höhere Affinität zu Aspartat von Bedeutung ist, das von AAP1 nur ungenügend transportiert wird (Okumoto et al. 2002). Für ein genaues Verständnis der Funktion einzelner Transporter ist ihre zellspezifische Lokalisation innerhalb des Phloems entscheidend (van Bel 2003). Eine Immunolokalisation gelang aber bisher für keinen einzigen pflanzlichen Aminosäuretransporter.

Für einige Gene der $A A P$-Familie existieren auch Daten zur Transkriptions-Regulation. So werden AAP4 und AAP6 bei Trocken- und Salzstreß herunterreguliert (Rentsch et al. 1996), die Expression von AAP1 und 2 wird abhängig von der Samenentwicklung gesteuert (Hirner et al. 1998), VfAAPl aus Vicia faba ist Cystein-reprimierbar (Miranda et al. 2001) und beim Übergang vom Sink zum Source in Blättern wird in Arabidopsis die Expression von AtAAP6 herunter- und in Kartoffel die von StAAP1 hochreguliert (Fischer et al. 2002, Koch et al. 2003). Daten zur Regulation auf Proteinebene fehlen bisher vollkommen (Delrot et al. 2000), ebenso wie zur Regulation der Transporter in Abhängigkeit von der Stickstoffversorgung. Auch die Expression der AAPs während der Blattseneszenz und Remobilisation von Aminosäuren aus der Proteolyse ist noch kaum untersucht. Sakr et al. $(1993,1997)$ fanden bei seneszierenden Beta vulgaris Blättern eine Induktion des Aminosäure-Transports in Blattscheiben und Plasmamembran-Vesikeln, konnten dieses Ergebnis aber nicht mit molekularbiologischen Daten ergänzen.

(3e) Die letzte Familie innerhalb der ATF1-Superfamilie beinhaltet $A U X 1$ und zwei verwandte Gene. AUX1 ist kein eigentlicher Aminosäuretransporter, sondern katalysiert die Aufnahme des mit der Aminosäure Tryptophan chemisch verwandten Phytohormons Auxin in Zielzellen (Bennett et al. 1996).

Abgesehen von den eigentlichen Aminosäuretransportern ist auch für den Oligopeptid- und Nitrattransporter NTR1 (CHL1) aus Arabidopsis sowie für den homologen Transporter BnNTR1;2 aus Raps der Transport von Histidin beschrieben worden (Frommer et al. 1994a, Rentsch et al. 1995, Zhou et al. 1998). BnNRT1;2 ist das einzige bisher in Raps identifizierte Protein mit einer Aminosäure-Transportaktivität. In den Datenbanken fand sich nur der „Expressed Sequence Tag“ (EST) eines zu AtAAP6 homologen Raps-Gens (Acc. No. H07512, Sohn et al. 1995). Im Verlauf der vorliegenden Arbeit wurden aber von Noiraud et al. (2002) partielle cDNA-Sequenzen von drei zu den Arabidopsis-Transportern AAP1, AAP2 und AAP4 homologen Genen aus B. napus hinterlegt (Acc. No. AY188953, AY188954, AY188955). 


\subsection{Die Problematik der Stickstoffnutzung bei Raps}

Raps (Brassica napus L.) gehört wie die molekularbiologische Modellpflanze Arabidopsis thaliana zur Familie der Kreuzblütler (Brassicaceae). Die Brasicaceen sind nach morphologischen Gesichtspunkten und der Zusammensetzung ihres Phloemsaftes apoplastische Phloembelader (Haritatos et al. 2000b, Lohaus \& Möllers 2000). Im Gegensatz zu seinem nahen Verwandten ist Raps aber mit 40-50 \% Öl und 20-30 \% Protein im Samen (Finlayson 1976, Uppström 1995) eine wirtschaftlich bedeutsame Nutzpflanze, die v.a. in Mitteleuropa und Asien angebaut wird. Die Samen dienen der Ölproduktion und die Preßrückstände als eiweißreiches Viehfutter. Der restliche Sproß verbleibt in der Regel als Gründünger auf dem Feld. Den Nutzungsanforderungen entsprechend ist Raps seit langem mit den Methoden der klassischen Züchtung in Hinblick auf den Öl- und Proteinertrag der Samen optimiert worden und heute werden fast ausschließlich sogenannte 00-Sorten angebaut, die frei von nahrungsunverträglicher Erucasäure und Glucosinolaten sind.

Ein bislang ungelöstes Problem beim Rapsanbau ist jedoch sein hoher Bedarf an Stickstoffdünger und die geringe Stickstoff-Nutzungseffizienz. Rapskulturen benötigen etwa 180-220 kg N ha ${ }^{-1} \mathrm{a}^{-1}$, deutlich mehr als Getreidekulturen. Dabei wird der applizierte Stickstoff sogar mit höherer Effizienz aufgenommen als von anderen Nutzpflanzen (Lainé et al. 1993, Dejoux et al. 2000), aber nur etwa 30-70 \% gelangen am Ende der Vegetationsperiode in die Samen (Aniol 1994, Sieling \& Christen 1999). Der übrige Stickstoff verbleibt in den vegetativen Pflanzenteilen und damit letztlich in der Streu. RapsStreu wird schnell mineralisiert, so daß es zu erheblichen N-Verlusten ins Grundwasser kommt (Dejoux et al. 1999, Sieling \& Christen 1999, Trinsoutrot et al. 1999, 2000), die aus wirtschaftlicher und ökologischer Sicht unerwünscht sind.

Wie viele Pflanzen legt auch Raps zunächst in den Blättern transiente Stickstoffspeicher in From von vegetativen Speicherproteinen an (Fernandez et al. 1991, Sjöhdahl et al. 1993) und die reifenden Samen erhalten den größten Teil ihres Stickstoffreservoirs aus der Remobilisierung dieser Reserven (Thorne 1985, Feller \& Keist 1986, Aniol 1994, Frommer et al. 1994b). Dabei ist von besonderer Bedeutung, daß Raps anders als die meisten anderen Kulturpflanzen einen großen Teil seiner Blätter bereits während der Blüte abwirft und zum Zeitpunkt der Samenreife nahezu blattlos ist. Noch in den Blättern gebundener Stickstoff geht dabei für die Retranslokation in den Samen verloren (Aniol 1994, Schjoerring 1995). Diese Verluste können bis zu 15 \% des gesamten pflanzlichen Stickstoffs ausmachen (Rossato et al. 2001). Die Remobilisierung von Stickstoff aus den Blättern stellt deshalb möglicherweise 
einen Schlüsselprozeß dar, über dessen gentechnische Modifikation eine Verbesserung der Stickstoffeffizienz von Raps erreicht werden könnte.

\subsection{Zielsetzung}

Die vorliegende Arbeit ist Teil des DFG-Projekts „Verbesserung der Stickstoffeffizienz bei Raps", in dem in einer interdisziplinären Zusammenarbeit von Pflanzenzüchtern und Molekularbiologen die Ursachen der niedrigen Stickstoff-Nutzungseffizienz bei Raps untersucht und die genotypische Variabilität dieses Merkmals quantifiziert werden sollte, um Ansätze für eine züchterische oder gentechnische Verbesserung zu liefern. Dazu wurden einerseits in groß angelegten Feldversuchen zahlreiche Rapssorten miteinander verglichen (Kessel 2000, Zhou 2000) und eine Teilaufgabe dieser Arbeit war es, einige der Versuchspflanzen physiologisch zu charakterisieren. Andererseits sollte die Remobilisierung von Stickstoff aus den Blättern genauer untersucht werden. Zwar war aus vorherigen Arbeiten innerhalb des Projekts bekannt, daß Raps Aminosäuren in hohen Konzentrationen im Phloemsaft transportiert (Lohaus \& Möllers 2000), aber nicht, ob diese Aminosäuren aus seneszierenden Blättern stammen. Im Rahmen der vorliegenden Arbeit sollten deshalb biochemische und molekularbiologische Methoden angewandt werden, um die Vorgänge bei der Phloembeladung von Aminosäuren in Raps detailliert zu charakterisieren. Die Verhältnisse in alten Blättern sollten dabei einen Schwerpunkt bilden.

Im Einzelnen waren die Ziele der Arbeit:

- Bestimmung der Nitratreduktaseaktivitäten und Metabolitkonzentrationen in Blättern der Rapspflanzen aus den Feldversuchen

- Bestimmung der Aminosäurekonzentrationen in subzellulären Kompartimenten von Mesophyllzellen und im Apoplasten von Rapsblättern bei unterschiedlicher Stickstoffversorgung und in Abhängigkeit vom Blattalter

- Klonierung von Aminosäuretransportern mit breiter Substratspezifität (AAPs) aus Raps

- Funktionelle Charakterisierung dieser Transporter durch Expression in Xenopus-Oocyten

- Untersuchung der gewebe- und zellspezifischen Expression der Transporter

- Untersuchung möglicher Veränderungen der Expression der Transporter während der Blattentwicklung 


\section{Material und Methoden}

\subsection{Allgemeines}

Sofern nicht anders angegeben

- wurde ausschließlich zweifach destilliertes Wasser verwendet;

- entsprachen alle Chemikalien einem analytischen Reinheitsgrad und wurden von den Herstellern Carl Roth (Karlsruhe), Fluka (Buchs, Schweiz), Merck (Darmstadt), Sigma-Aldrich (Steinheim) oder Serva Electrophoresis (Darmstadt) bezogen;

- fanden alle Zentrifugationen bei Raumtemperatur (RT) und 13.000 Upm (= $16.000 \mathrm{x}$ g) in einer Heraeus Biofuge Pico Zentrifguge (Bodo Schmidt, Göttingen) statt (im Folgenden als Tischzentrifuge bezeichnet);

- wurden alle Arbeiten mit sterilen Bakterien- oder Pflanzenkulturen an einer Sterilbank (Bio-II-A; Prettl Reinraumtechnik, Pfullingen) durchgeführt;

- wurden für alle Arbeiten mit isolierten Nukleinsäuren oder Sterilkulturen nur autoklavierte Pipettenspitzen, Lösungen (einschließlich $\mathrm{H}_{2} \mathrm{O}$ ) und Gefäße verwendet.

\subsection{Material}

\subsubsection{Pflanzenmaterial und Anzucht}

Verwendete Rapssorten (Brassica napus L.):

In Zusammenarbeit mit dem Institut für Pflanzenzucht und Pflanzenbau der Universität Göttingen wurden die Öl-, Protein- und Aminosäuregehalte sowie Nitratreduktaseaktivitäten verschiedener doppelt haploider (DH-) Winterraps-Linien aus einer Kreuzung der Sorten Apex und Mohican bestimmt (2.3). Für molekularbiologische Untersuchungen wurden nur die Winterraps-Sorte Lirajet, sowie eingefrorenes Blattmaterial einer Kreuzung Bristol $\mathrm{x}$ Mansholts verwendet.

Die Anzucht aller im Labor verwendeten Winterraps-Sorten erfolgte von der Samenauslegung bis zur 8-10 wöchigen Vernalisation der Keimlinge im Institut für Pflanzenzucht und Pflanzenbau der Universität Göttingen. Vernalisierte Rapskeime wurden anschließend entweder in Komposterde weitergezogen, wenn der Status der Stickstoff-Versorgung nicht versuchsrelevant war, oder in Hydrokultur mit definiertem Nitratgehalt (0,5 oder $4 \mathrm{mM})$ überführt. 
Hydrokultur-Nährlösung (Spurenelemente nach Randall \& Bouma 1973):

$\begin{array}{llll}0,1 \mathrm{mM} & \mathrm{KCl} & 10 \mu \mathrm{M} & \mathrm{H}_{3} \mathrm{BO}_{3} \\ 0,7 \mathrm{mM} & \mathrm{K}_{2} \mathrm{SO}_{4} & 0,5 \mu \mathrm{M} & \mathrm{MnSO}_{4} \\ 0,5 \mathrm{mM} & \mathrm{MgSO}_{4} & 0,1 \mu \mathrm{M} & \mathrm{ZnSO}_{4} \\ 0,1 \mathrm{mM} & \mathrm{K}_{2} \mathrm{HPO}_{4} / \mathrm{KH}_{2} \mathrm{PO}_{4} \mathrm{pH} 7,2 & 0,2 \mu \mathrm{M} & \mathrm{CuSO}_{4} \\ 160 \mu \mathrm{M} & \mathrm{FeCl}_{3} & 0,017 \mu \mathrm{M} & \mathrm{Na}_{2} \mathrm{MoO}_{4} \\ 91 \mu \mathrm{M} & \mathrm{Na}_{2} \mathrm{EDTA} & & \\ \text { M Nitrat-Lösung: } & 0,25 \mathrm{mM} \mathrm{Ca}\left(\mathrm{NO}_{3}\right)_{2}+2 \mathrm{mM} \mathrm{CaCl}_{2} & \\ \text { Nitrat-Lösung: } & 2 \mathrm{mM} \mathrm{Ca}\left(\mathrm{NO}_{3}\right)_{2} & \end{array}$

Als transformierbare Modellpflanze zur Untersuchung der gewebespezifischen Promotoraktivität diente Arabidopsis thaliana L. (Ökotyp Columbia). Arabidopsis wurde ebenfalls auf Komposterde angezogen.

Die Wachstumsbedingungen für B. napus und A. thaliana sowohl im Gewächshaus als auch in Klimakammern waren 300-330 $\mu \mathrm{mol}$ Photonen $\mathrm{m}^{-2} \mathrm{~s}^{-1}, 15 \mathrm{~h}$ Belichtung (Langtag) und eine Temperatur von $23{ }^{\circ} \mathrm{C} \mathrm{Tag} / 18^{\circ} \mathrm{C}$ Nacht.

\subsubsection{Bakterienstämme}

Zur Klonierung von DNA-Fragmenten und zur Vermehrung von DNA-Konstrukten wurde der Escherichia coli Stamm DH5a (Hanahan 1983) verwendet:

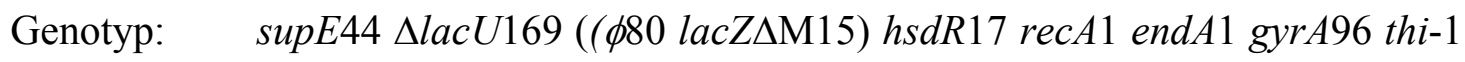
relA 1

Alternativ kam auch E. coli XL1-Blue (Bullock et al. 1987) zur Anwendung.

Genotyp: $\quad$ supE44 hsdR17 recAl endA1 gyrA46 thi relAl lac ${ }^{-}$

$\mathrm{F}^{\prime}\left[\right.$ proAB $^{+}$lacl $^{\mathrm{q}}{\left.\text { lacZ } \Delta \mathrm{M} 15 \operatorname{Tn} 10\left(\text { tet }^{\mathrm{r}}\right)\right]}^{\mathrm{N}}$

Zur Überexpression eines MBP-BnAAP6-N-Terminus Fusionsproteins (2.17.1) diente der $E$. coli Stamm BL21 (DE3) (Studier \& Moffat 1986).

Genotyp: $\quad$ hsdS gal ( $\lambda$ cIts857 ind1 Sam7 nin5 lacUV5-T7 gene 1) 
Das BnAAP6-Protein wurde in von E. coli BL21 abgeleitete Rosetta-gami (DE3) pLysS Zellen (Novagen, Madison, USA) exprimiert, die eine Lyse durch wiederholtes Schockgefrieren und Auftauen bei $37^{\circ} \mathrm{C}$ erlauben.

Genotyp: $\quad$ ahpC* $C^{*}$ ara-leu7697 $\triangle$ lacX74 $\triangle$ phoAPvuII phoR araD139 galE galK rpsL $\mathrm{F}^{\prime}\left[\right.$ lac $^{+}\left(\right.$lacI $\left.{ }^{I}\right)$ pro] gor522 ::Tn10 $\left(\mathrm{Tc}^{\mathrm{R}}\right) \operatorname{trx} B:: \mathrm{kan}(\mathrm{DE} 3)$ pLysSRARE $\left(\mathrm{Cm}^{\mathrm{R}}\right)$

Zur Transformation von Arabidopsis thaliana L. wurden zwei verschiedene Agrobacterium tumefaciens-Stämme verwendet: GV3101 pMP90, (Charest et al. 1989) diente zur Transformation von Konstrukten, die auf dem Plasmid pBI101.3 basierten, EHA105 (Hood et al. 1993) für Plasmide auf pCAMBIA3300-Basis.

\subsubsection{Häufig verwendete Nährmedien}

LB (Lurija-Bertani)-Medium für E. coli Kulturen:

$10 \mathrm{~g} / 1$ Select Pepton 140 (Invitrogen, Karlsruhe)

$5 \mathrm{~g} / 1$ Hefe Extrakt (Invitrogen, Karlsruhe

$10 \mathrm{~g} / 1 \mathrm{NaCl}$

pH 7,5 mit $\mathrm{NaOH}$ einstellen

[für Agar-Platten: 15 g/l Agar (Duchefa, Haarlem, Niederlande)]

autoklavieren

YEB-Medium für A. tumefaciens Kulturen:

$2 \mathrm{~g} / \mathrm{l}$ Hefe Extrakt (Invitrogen, Karlsruhe)

5 g/l Lab-Lemco-Powder (Oxoid, Basingstoke, England)

$5 \mathrm{~g} / 1$ Pepton (Casein-Hydrolysat)

$5 \mathrm{~g} / 1$ Saccharose

pH 7,0 mit $\mathrm{NaOH}$ einstellen

[für Agar-Platten: 15 g/l Agar (Duchefa, Haarlem, Niederlande)]

autoklavieren

danach $2 \mathrm{ml} 1 \mathrm{M} \mathrm{MgSO}_{4}$ (sterilfiltriert) zugeben 
MS (Murashige \& Skoog)-Medium für Pflanzenkulturen:

4,4 g/l MS-Salze (Duchefa, Haarlem, Niederlande)

$20 \mathrm{~g} / 1$ Saccharose

pH 5,8 mit KOH einstellen

[für Agar-Platten: 15 g/l Agar (Duchefa, Haarlem, Niederlande)]

autoklavieren

Antibiotika-Zusätze:

Stamm-Lsg.

Endkonzentration

Ampicillin:

$100 \mathrm{mg} / \mathrm{ml}$

$100 \mu \mathrm{g} / \mathrm{ml}(1: 1.000)$

Kanamycin

$50 \mathrm{mg} / \mathrm{ml}$

$50 \mu \mathrm{g} / \mathrm{ml}(1: 1.000)$

Rifampicin

$10 \mathrm{mg} / \mathrm{ml}$ (in Methanol)

$50 \mu \mathrm{g} / \mathrm{ml}(1: 200)$

\subsubsection{Plasmide}

$\begin{array}{lll}\text { pGEM-T Easy } & \mathrm{Amp}^{\mathrm{R}} & \text { Promega, Mannheim } \\ \text { pBI101.3 } & \mathrm{Km}^{\mathrm{R}} & \text { Jefferson } \text { et al. }(1987) \\ \text { pBF1 } & \mathrm{Amp}^{\mathrm{R}} & \mathrm{W} \text {. Frommer, Tübingen; freundlicherweise zur } \\ & & \text { Verfügung gestellt von C. Struck, Konstanz } \\ \text { pET-15b } & \mathrm{Amp}^{\mathrm{R}} & \text { Novagen, Madison, USA } \\ \text { pCAMBIA3300 } & \mathrm{Km}^{\mathrm{R}}, \text {,BASTA” }^{\text {CBM }} & \text { CAMBIA, Canberra, Australien } \\ \text { pMAL-c2X } & \mathrm{Amp}^{\mathrm{R}} & \text { New England Biolabs, Frankfurt }\end{array}$

\subsection{Feldversuch zur Untersuchung der genetischen Variabilität der Stickstoffnutzung bei Winterraps}

In dieser Arbeit wurden Metabolitkonzentrationen und Enzymaktivitäten in Rapspflanzen bestimmt, die Teil eines großangelegten Feldversuchs zur Untersuchung der genetischen Variabilität der Stickstoffeffizienz bei Raps waren. Der Feldversuch wurde von der Arbeitsgruppe Prof. Becker (Institut für Pflanzenbau und Pflanzenzüchtung, Universität Göttingen) und kooperierenden Arbeitsgruppen im DFG-Projekt „Verbesserung der Stickstoffeffizienz bei Raps“ durchgeführt. Es wurden über mehrere Jahre jeweils unterschiedliche DH-Linien aus einer Kreuzung der Sorten Apex und Mohican unter zwei NDüngungsstufen ( 0 und $240 \mathrm{~kg} \mathrm{~N} \mathrm{ha}^{-1} \mathrm{a}^{-1}$ ) angepflanzt. Von jeder Linie und N-Düngungsstufe wurden 2 unabhängige Wiederholungen angelegt. Zusätzlich wurden auch die Elternsorten und einige weitere aus pflanzenzüchterischem Interesse ausgewählte Sorten angepflanzt. Die 
Zahl der getesteten DH-Linien betrug 1999/2000 und 2000/2001 45, und 2001/2002 acht. Der genaue Aufbau des Feldversuchs und weitere daraus resultierende Ergebnisse sind u.a. in Kessel 2000 und Zhou 2000 beschrieben. Die Ernte von Blattproben erfolgte zur Zeit der Samenreifung am frühen Nachmittag an regenfreien Tagen. Pro Wiederholung wurden jeweils 10 Blätter unterschiedlicher Größe, Höhe am Stengel und von verschiedenen Pflanzen gesammelt, aufeinander gelegt und einmal mit einem $2 \mathrm{~cm}$-Blattausstanzer durchstochen. Die Blattscheiben wurden sofort in flüssigem Stickstoff eingefroren und bis zur Weiterverarbeitung darin aufbewahrt. Für die Analyse wurde das Pflanzenmaterial fein gemörsert und anschließend bei $-80{ }^{\circ} \mathrm{C}$ gelagert. Mit diesen Proben wurde eine Bestimmung der Nitratreduktaseaktivität sowie eine Chloroform-Methanol-Extraktion (2.4.1) mit anschließender chromatographischer Metabolitanalyse (2.5) durchgeführt.

\subsubsection{Bestimmung der Nitratreduktaseaktivität (NRA)}

Das Meßprinzip dieses Enzymtests war die photometrische bestimmung von Nitrit, das durch die Nitratreduktase aus Nitrat gebildet wurde (modifiziert nach Kaiser et al. 1992). Dabei wurde Sulfanilsäure durch salpetrige Säure diazotiert und das Diazoniumsalz mit $\alpha$ Naphthylamin zu einem Azofarbstoff umgesetzt, dessen Extinktion bei $535 \mathrm{~nm}$ photometrisch bestimmt wurde.

$200 \mathrm{mg}$ gefrorenes Pflanzenmaterial wurden mit $1 \mathrm{ml}$ Extraktionspuffer versetzt und gründlich gevortext. In Eppendorfgefäßen wurden jeweils $940 \mu 1$ Reaktionsmix und $60 \mu 1$ Additive vorgelegt. Der Reaktionsstart erfolgte durch $200 \mu \mathrm{l}$ Extrakt. Von jedem Reaktionsansatz wurden nach 5, 10 und 15 min Inkubation bei $30{ }^{\circ} \mathrm{C}$ jeweils $300 \mu$ Aliquots entnommen und die Reaktion durch Mischen mit $100 \mu 1$ Stopmix gestoppt. Alle gestoppten Proben wurden für mindestens 15 min bei $4{ }^{\circ} \mathrm{C}$ inkubiert und dann mit $600 \mu 1$ Farbmix gemischt. Bis zu diesem Zeitpunkt fanden alle Inkubationen wegen der Lichtempfindlichkeit von Phenazinmethosulfat im Dunkeln statt. Nach der Farbmix-Zugabe erfolgte eine halb- bis mehrstündige Inkubation bei RT. Zum Schluß wurden die Proben 2 min abzentrifugiert und die Extinktion bei $535 \mathrm{~nm}$ gemessen (Uvikon 932; Kontron, Mailand, Italien). Die Konzentration des gebildeten Nitrit wurde anhand einer Eichgeraden von 0-15 nmol bestimmt und die NRA aus der zeitlichen Rate der Konzentrationszunahme berechnet. 


$\begin{array}{lll}\text { Extraktionspuffer: } & 100 \mathrm{mM} & \text { HEPES } \\ 10 \%(\mathrm{v} / \mathrm{v}) & \text { Glycerin } \\ 1 \mathrm{mM} & \text { EDTA } \\ & 5 \mathrm{mM} & \text { Magnesiumacetat } \\ & 0,2 \%(\mathrm{v} / \mathrm{v}) & \text { Triton X-100 } \\ & 0,5 \%(\mathrm{w} / \mathrm{v}) & \mathrm{BSA}^{2} \\ & 5 \mu \mathrm{M} & \mathrm{Na}_{2} \mathrm{MoO}_{4} \\ & 1 \%(\mathrm{w} / \mathrm{v}) & \mathrm{PVPP} \\ & * 5 \mathrm{mM} & \text { DTT } \\ & * 8 \mu \mathrm{M} & \text { FAD } \\ & * 0,2 \mathrm{mM} & \text { PMSF } \\ & * 10 \mu \mathrm{M} & \text { Leupeptin } \\ & \mathrm{pH} 7,5 \mathrm{mit} \text { KOH einstellen }\end{array}$

* frisch zugegeben

$\begin{array}{lll}\text { Reaktionsmix: } & 100 \mathrm{mM} & \text { HEPES } \\ & 6 \mathrm{mM} & \mathrm{KNO}_{3} \\ & 6 \mathrm{mM} & \text { EDTA } \\ & * 5 \mathrm{mM} & \text { DTT } \\ & * 200 \mu \mathrm{M} & \mathrm{FAD} \\ & * 10 \mathrm{mM} & \mathrm{NADH} \\ & * 100 \mu \mathrm{M} & \mathrm{Na}_{2} \mathrm{MoO}_{4} \\ & * 333 \mu \mathrm{M} & \text { Leupeptin } \\ & \text { pH } 7,5 \mathrm{mit} \mathrm{KOH} \text { einstellen }\end{array}$

* frisch zugegeben

Stopmix: 0,6 M Zinkacetat:0,2 mM Phenazinmethosulfat (1:3), frisch angesetzt

Farbmix: 0,02\%(w/v) N-Naphthylendiamin-Dihydrochlorid:1 \% (w/v) Sulfanilamid in $2 \mathrm{M}$ $\mathrm{HCl}(1: 1)$, frisch angesetzt 


\subsection{Extraktion von Metaboliten aus Pflanzengeweben}

\subsubsection{Chloroform-Methanol-Extraktion von Blattgeweben}

Die Chloroform-Methanol-Extraktion diente zur Extraktion wasserlöslicher Metabolite aus Blättern. Bezugsgröße für die Metabolitgehalte war die eingesetzte Menge an Frischgewicht. Für die Chloroform-Methanol-Extraktion wurden ausschließlich dreifach destilliertes HPLCReinstwasser und damit gespülte Gefäße verwendet.

Die Proben wurden unter flüssigem Stickstoff gemörsert und 100-200 mg des Pulvers in ein Reagenzglas abgewogen. Nach Zugabe von 0,6 $\mathrm{ml} 20 \mathrm{mM}$ HEPES/KOH pH 7,0 und $5 \mathrm{ml}$ Chloroform:Methanol (1,5:3,5, v/v) wurde 2 min kräftig geschüttelt und $30 \mathrm{~min}$ auf Eis inkubiert. Die Extraktion erfolgte durch Ausschütteln mit $3 \mathrm{ml} \mathrm{H}_{2} \mathrm{O}$ und anschließende Zentrifugation für 5 min bei 5.000 Upm in einer Tischzentrifuge (Hettich EBA 35; Carl Roth, Karlsruhe). Die wässrige Oberphase wurde in einen Rundkolben überführt. Nach erneuter Extraktion der Unterphase mit $2 \mathrm{ml} \mathrm{H}_{2} \mathrm{O}$ wurden die vereinigten Oberphasen am Rotationsverdampfer bei $34{ }^{\circ} \mathrm{C}$ bis zur Trockne eingeengt. Der Rückstand wurde in $1 \mathrm{ml}$ HPLC-Reinstwasser aufgenommen, durch 0,45 $\mu \mathrm{m}$ Nitrozellulosefilter (Sartorius, Göttingen) filtriert und sofort in flüssigem Stickstoff eingefroren. Bis zur Analyse wurden die Proben bei $-80{ }^{\circ} \mathrm{C}$ aufbewahrt.

\subsubsection{Nichtwässrige Fraktionierung}

Die Nichtwässrige Fraktionierung (Gerhardt \& Heldt 1984) erlaubt es, die Konzentrationen von Metaboliten in den subzellulären Kompartimenten Zytosol, Vakuole und Chloroplast zu bestimmen. Dazu wird durch Ultraschall aufgebrochenes Pflanzenmaterial in einem Dichtegradienten fraktioniert und anschliessend in allen Fraktionen sowohl die relevante Metabolitkonzentration als auch die Aktivität von Markerenzymen für die verschiedenen Kompartimente bestimmt. Mit Hilfe eines computergestützten numerischen Analyseverfahrens (Programm Bestfit, Riens et al. 1991) wird anhand der Verteilung der Markerenzyme die wahrscheinlichste Zuordnung der Metabolitkonzentrationen zu den Kompartimenten errechnet. Die Verwendung ausschließlich nichtwässriger Medien verhindert, daß während der Extraktion und Fraktionierung eine enzymatische Umsetzung der Metabolite stattfindet. Es wurden ausschließlich mit HPLC-Reinstwasser gespülte, detergenzfreie Gefäße verwendet. 
Geerntetes Blattmaterial wurde unter flüssigem Stickstoff gemörsert, lyophyllisiert und bis zur Verwendung in dicht schließenden Plastikboxen bei $-80{ }^{\circ} \mathrm{C}$ in einem Exsikkator aufbewahrt. Alle Arbeiten wurden bei $4{ }^{\circ} \mathrm{C}$ oder auf Eis durchgeführt.

Zur Herstellung des Dichtegradienten wurden drei unterschiedliche Gemische definierter Dichte aus Heptan $\left(\rho_{20{ }^{\circ} \mathrm{C}}=0,684 \mathrm{~g} \mathrm{~cm}^{-3}\right)$ und Tetrachlorethylen $\left(\mathrm{C}_{2} \mathrm{Cl}_{4}, \rho_{20}{ }^{\circ} \mathrm{C}=1,623 \mathrm{~g} \mathrm{~cm}^{-3}\right)$ hergestellt. Wegen der Lichtempfindlichkeit von Tetrachlorethylen wurden die Lösungen in dunklen Flaschen bei $4{ }^{\circ} \mathrm{C}$ aufbewahrt. Die tatsächliche Dichte der Gemische bei $4{ }^{\circ} \mathrm{C}$ wurde jeweils vor ihrer Verwendung mit einem Pykrometer überprüft und und gegebenenfalls durch Zugabe von Heptan oder $\mathrm{C}_{2} \mathrm{Cl}_{4}$ nochmals eingestellt. Zur Herstellung des jeweils benötigten Gradienten wurden in einem Nitrozellulose-Ultrazentrifugenröhrchen 0,5 ml Lösung mittlerer Dichte mit einem 2 ml-Kissen der Lösung höchster Dichte unterschichtet. Darauf wurde mit einem Gradientenmischer der eigentliche Gradient aus ca. $10 \mathrm{ml}$ leichtester Dichtelösung und $7 \mathrm{ml} \mathrm{mittlerer} \mathrm{Dichtelösung} \mathrm{aufgeschichtet.} \mathrm{Der} \mathrm{optimale} \mathrm{Dichtebereich} \mathrm{für} \mathrm{eine} \mathrm{saubere}$ Fraktionierung der Zellkompartimente mußte jeweils empirisch ermittelt werden, und lag im Allgemeinen zwischen 1,2 und 1,6 $\mathrm{g} \mathrm{cm}^{-3}$.

Zur Entnahme von lyophyllisiertem Probenmaterial wurden die Probeboxen möglichst nur kurz geöffnet und das entnommene Material (ca. 2-3 g) sofort in ein Reagenzglas mit $20 \mathrm{ml}$ Gradientenlösung der geringsten Dichte überführt, um die Aufnahme von Luftfeuchtigkeit gering zu halten. Die Probe wurde gevortext und anschließend durch Ultraschall aufgeschlossen (höchste Stufe, 2 min lang je 5 sec Puls und 5 sec Pause, 30 sec Pause, 1 kurzer Puls, weitere $30 \mathrm{sec}$ Pause, 1 min lang je $5 \mathrm{sec}$ Puls und $5 \mathrm{sec}$ Pause, Sonifier B15; Branson, Genf, Schweiz). Während der Ultrabeschallung stand das Reagenzlas in einem mit Trockeneis gekühlten Heptan-Bad. Um eine Wasseraufnahme aus der Luft zu verhindern blieb die Probe bis zur Auftragung auf den Gradienten mit einem Gummistopfen verschlossen. Auch während der Ultraschall-Behandlung wurde ein Gummistopfen mit entsprechender Öffnung für den Ultraschallstab verwendet. Die Ultraschall-behandelte Probe wurde gevortext und auf vier 12 ml-Zentrifugenröhrchen verteilt. Diese wurden mit Heptan aufgefüllt, geschüttelt und $2 \mathrm{~min}$ bei $3.000 \mathrm{Upm}$ (Heraeus Megafuge 1.0; Bodo Schmidt, Göttingen) zentrifugiert. Nach dem Verwerfen des Heptan-Überstands wurden die Probenpellets in insgesamt $3 \mathrm{ml}$ Gradientenlösung geringster Dichte aufgenommen. Dazu wurde zuerst mit $2 \mathrm{ml}$ von einem Röhrchen ins nächste gespült und anschließend mit $1 \mathrm{ml}$ nachgespült. Die Probe wurde zügig durch ein $40 \mu \mathrm{m}$ Netz (Merck, Darmstadt) filtriert und ein $200 \mu 1$ Aliquot entnommen (Fraktion „,G“ = gesamt). Das verbleibende Probenvolumen wurde notiert und vorsichtig auf den Gradienten aufgeschichtet. Anschließend erfolgte die 
Fraktionierung für 120 min bei 25.000 x g. (Centrikon T-1065, Rotor HB4; Kontron, Mailand, Italien).

Nach dem Zentrifugenlauf wurden die Fraktionen nacheinander vorsichtig mit einer $2 \mathrm{ml}-$ Meßpipette abgenommen und ihr Volumen notiert. Die oberste Fraktion (,0”) war gelblich bis farblos, darunter folgte die klar abgegrenzte dunkelgrüne, trübe Chloroplastenfraktion („,”). Der der darunter liegende hellgrüne Teil des Gradienten wurde in 4 gleichmäßigen Fraktionen abgenommen (,2-4”), die unterste und letzte Fraktion (,6”) war farblos. Ein eventuell vorhandenes Pellet wurde durch Vortexen in Fraktion 6 gelöst und mit aufgenommen.

$0,8 \mathrm{ml}$ jeder Fraktion wurde für die Enzymtests in ein 1,5 ml Eppendorfgefäß überführt, die restlichen ca. 1,2 $\mathrm{ml}$ für die Metabolitanalysen in ein $2 \mathrm{ml}$ Eppendorfgefäß. Beide Aliquots (und auch das anfänglich entnommene Aliquot „G”) wurden mit Heptan aufgefüllt und die Proben $15 \mathrm{~min}$ bei $11.500 \mathrm{Upm}$ in einer Tischzentrifuge pellettiert. Nach dem Verwerfen des Heptan-Überstandes wurden die Proben in einem Exsikkator unter Vakuum getrocknet (mehrmals ja 10 min Anlegen des Vakuums mittels einer Wasserstrahlpumpe). Schließlich wurde der verschlossene Exsikkator mit den Proben bis zur Weiterverwendung am nächsten Tag bei $4{ }^{\circ} \mathrm{C}$ gelagert.

Nach der Trocknung am nächsten Morgen wurden die Teilproben für die Metabolitanalysen (2.5) bis zur Verwendung bei $-80{ }^{\circ} \mathrm{C}$ eingefroren. Aus den Aliquots für die Enzymtests wurden die Proteine mit Phosphatpuffer extrahiert. Dazu wurden $500 \mu$ l Phosphatpuffer auf die Pellets gegeben, $30 \mathrm{sec}$ gevortext, $1 \mathrm{~min}$ auf Eis inkubiert, erneut $30 \mathrm{sec}$ gevortext und nochmal 5 min auf Eis inkubiert. Nach Zugabe weiterer $500 \mu 1$ Phosphatpuffer und Vortexen wurden $300 \mu \mathrm{l}$ entnommen und bei $-80{ }^{\circ} \mathrm{C}$ gelagert. Diese Proben dienten später zur Bestimmung des Protein- und Chlorophyllgehaltes. Die Proteinbestimmung erfolgte nach Lowry (2.7.2), die Bestimmung der Chlorophyllkonzentration ist unter 2.7.4 beschrieben. Die restlichen $700 \mu \mathrm{l}$ wurden abzentrifugiert (Tischzentrifuge, $5 \mathrm{~min} 13.000 \mathrm{Upm}$ ) und der Überstand mit den löslichen Proteinen für die folgenden Enzymtests abgenommen und auf Eis aufbewahrt.

Phosphatpuffer: $\quad \mathrm{K}_{2} \mathrm{HPO}_{4} / \mathrm{KH}_{2} \mathrm{PO}_{4} \mathrm{pH} 7,5 \quad 50 \mathrm{mM}$

EDTA $0,5 \mathrm{mM}$

*DTT $\quad 5 \mu \mathrm{M}$ (bei altem Blattmaterial $20 \mu \mathrm{M}$ )

* frisch zugegeben

Im Folgenden werden die Enzymtests für die Markerenzyme einzeln beschrieben. 


\subsubsection{1 $\alpha$-Mannosidase-Test (vakuolisches Markerenzym)}

Die Bestimmung der $\alpha$-Mannosidaseaktivität erfolgte über die Umsetzung des synthetischen Substrats PNP-Mannosid (para-Nitrophenyl- $\alpha$-D-Manno-Pyranosid), das in D-Mannose und $p$-Nitrophenol gespalten wird. $p$-Nitrophenol ist photometrisch bei $405 \mathrm{~nm}$ detektierbar.

Für jede Probe wurde eine Doppelbestimmung und ein Blindwert durchgeführt. Zu je $500 \mu 1$ $100 \mathrm{mM}$ Citrat/KOH pH 4,5 wurden für die Doppelbestimmung je $50 \mu 1$ Probe gegeben. Der Reaktionsstart in den Proben und im Blindwert erfolgte durch $500 \mu 10$ mM PNP-Mannosid. Alle Reaktionsgefäße einschließlich dem Blindwert wurden für $40-155$ min bei $37{ }^{\circ} \mathrm{C}$ inkubiert, wobei die Inkubationszeit für alle Ansätze identisch war. Durch Zugabe von $500 \mu 1$ 0,8 M Borsäure/KOH pH 9,8 wurde die Reaktion gestoppt. Anschließend erfolgte auch beim Blindwert die Zugabe von $50 \mu 1$ Probe. Die Reaktionsansätze wurden abzentrifugiert und im Überstand die Extinktion bei $405 \mathrm{~nm}$ gegen den Blindwert gemessen (Uvikon 932; Kontron, Mailand, Italien). Der Extinktionskoeffizient von $p$-Nitrophenol ist $\varepsilon=18,5 \mathrm{mM}^{-1} \mathrm{~cm}^{-1}$.

\subsubsection{Saure Phosphatase-Test (vakuolisches Markerenzym)}

Die saure Phosphatase stellte eine empfindlicheres vakuoläres Markerenzym als die $\alpha$ Mannosidase dar, dessen Aktivität alternativ gemessen werden konnte. Das Meßprinzip beruht auf der Spaltung von PNP-P (para-Nitrophenylphosphat) in $p$-Nitrophenol und Phosphat. Auch hier wurde das $p$-Nitrophenol bei $405 \mathrm{~nm}$ photometrisch bestimmt.

Die Durchführung verlief ähnlich dem $\alpha$-Mannosidase-Test: In 3 Reaktionsgefäße für Doppelproben und einen Blindwert wurden je $500 \mu 1100 \mathrm{mM} \mathrm{Citrat/KOH} \mathrm{pH} \mathrm{5,5} \mathrm{vorgelegt,}$ in die Doppelproben zusätzlich je $20 \mu$ Probe. Die Reaktion wurde durch $50 \mu 1$ 0,3 M PNP-P (frisch angesetzt) gestartet und nach 30-50 min Inkubation bei $37{ }^{\circ} \mathrm{C}$ durch $500 \mu 10,8 \mathrm{M}$ $\mathrm{H}_{3} \mathrm{BO}_{3} / \mathrm{KOH} \mathrm{pH} 9,8$ wieder gestoppt. Alle Proben wurden exakt gleich lange inkubiert. Nach dem Reaktionsstop wurde auch in den Blindwert $20 \mu 1$ Probe pipettiert. Die Ansätze wurden 5 min abzentrifugiert und die gebildete $p$-Nitrophenolmenge wie oben beschrieben durch die Extinktion bei $405 \mathrm{~nm}$ bestimmt. 


\subsubsection{Glycerinaldehydphosphat-Dehydrogenase-Test (plastidäres Markerenzym)}

Das Meßprinzip dieses Enzymtests war die Reduktion von 1,3-Bisphosphoglycerat durch die Glycerinaldehyphosphat-Dehydrogenase (GAP-DH) zu D-Glycerinaldehyd-3-Phosphat unter Oxidation von NADPH zu NADP ${ }^{+}$. Die Extinktionsabnahme bei $334 \mathrm{~nm}$ durch den NADPHVerbrauch wurde gemessen. 1,3-Bisphosphoglycerat wurde erst im Reaktionsansatz durch 3Phosphoglycerat-Kinase (3-PGK) aus 3-Phosphoglycerat (3-PGA) gebildet. Von jeder Probe wurde eine Doppelbestimmung durchgeführt.

Der folgende Reaktionsansatz wurde direkt in einer Küvette vorgelegt: $580 \mu 1$ GAP-DHPuffer, $20 \mu 1$ 0,2 M DTT (frisch angesetzt), $20 \mu 1$ 0,2 M ATP (frisch angesetzt), $20 \mu 110 \mathrm{mM}$ NADPH (frisch angesetzt), $20 \mu 1$ 3-PGK (3,7 U/ $\mu$ l) und $20 \mu 1$ Probe. In Blindwert-Küvetten wurden $600 \mu \mathrm{l}$ GAP-DH-Puffer und Reagenzien ohne Probe vorgelegt. Der Reaktionsstart erfolgte im Photometer durch Zugabe von $20 \mu 1200$ mM 3-PGA. Die Extintionsabnahme bei $334 \mathrm{~nm}$ in der Probe wurde gegen den Blindwert für ca. 15 min gemessen und aus der Steigung die Enzymaktivität berechnet. Der Extinktionskoeffeizient für NADPH bei $334 \mathrm{~nm}$ ist $\varepsilon=6,18 \mathrm{mM}^{-1} \mathrm{~cm}^{-1}$.

GAP-DH-Puffer:

$\begin{array}{ll}100 \mathrm{mM} & \text { HEPES } \\ 20 \mathrm{mM} & \mathrm{KCl} \\ 2 \mathrm{mM} & \text { EDTA } \\ 30 \mathrm{mM} & \mathrm{MgCl}_{2} \\ \text { pH } 8,0 \text { mit } \mathrm{KOH} \text { einstellen }\end{array}$

\subsubsection{Phosphoenolpyruvat-Carboxylase-Test (cytosolisches Markerenzym)}

Die Bestimmung der Phosphoenolpyruvat-Carboxylase ( $\left.\mathrm{PEP}_{\mathrm{CX}}\right)$-Aktivität erfolgte über einen indirekten photometrischen Test: Phosphoenolpyruvat (PEP) wird durch die PEP $_{\mathrm{CX}} \mathrm{zu}$ Oxalacetat (OA) unter Phosphat-Abspaltung carboxyliert. Das gebildete OA wurde durch Malat-Dehydrogenase (MDH) unter Verbrauch von NADH zu L-Malat reduziert. Der NADHVerbrauch wurde durch die Messung der Differenz zwischen den Extinktionen bei $334 \mathrm{~nm}$ und $405 \mathrm{~nm}$ bestimmt.

Es wurden jeweils Doppelbestimmungen für jede Probe durchgeführt. Dazu wurden direkt in Glasküvetten $600 \mu \mathrm{l}$ Gly-Gly-Puffer, $10 \mu 120 \mathrm{mM} \mathrm{NADH}$ (frisch angesetzt), $10 \mu 15 \mathrm{mg} / \mathrm{ml}$ MDH in Gly-Gly-Puffer und $70 \mu$ Probe vorgelegt, gevortext und 10 min bei RT inkubiert. 
Danach erfolgte im Doppelwellenlängen-Photometer (ZFP 22; Sigma, Steinheim) der Reaktionsstart durch Zugabe von $10 \mu 150$ mM PEP in Gly-Gly-Puffer (frisch angesetzt). Die Abnahme der Extinktion bei $334 \mathrm{~nm}$ gegenüber der bei $405 \mathrm{~nm}$ wurde für ca. 3-5 min verfolgt und aus der Steigung der NADH-Verbrauch berechnet $\left(\varepsilon=6,18 \mathrm{mM}^{-1} \mathrm{~cm}^{-1}\right)$.

Gly-Gly-Puffer:

$\begin{array}{lc}50 \mathrm{mM} & \text { Glycylglycin } \\ 10 \mathrm{mM} & \mathrm{MgCl}_{2} \\ 4 \mathrm{mM} & \mathrm{KHCO}_{3} \\ \text { pH 7,9 mit } \mathrm{KOH} \text { einstellen }\end{array}$

\subsubsection{Extraktion von Apoplastensaft (Lohaus et al. 2001)}

Eine Beprobung des Apoplasten ist durch Infiltration des Pflanzenmaterials mit $\mathrm{H}_{2} \mathrm{O}$-Bidest und anschließendes Auszentrifugieren der Flüssigkeit möglich. Dazu wurden frisch vom Sproß abgetrennte Blätter ohne sie zu verletzen aufgerollt und in einer $50 \mathrm{ml}$ Spritze durch abwechselndes manuelles Erzeugen von Unter- und Überdruck infiltriert. Um Stoffwechselund Transportvorgänge zu minimieren war das Infiltrationswasser auf $4{ }^{\circ} \mathrm{C}$ vorgekühlt und die Extraktionszeit betrug höchstens 5 min. Die vollständige Füllung des Gasraumes der Blätter war durch eine deutliche Verdunkelung des Grüntones äußerlich erkennbar. Die Blattoberflächen wurden vorsichtig abgetrocknet und die infiltrierte Flüssigkeit durch Zentrifugation extrahiert. Dazu wurden die Blätter aufgerollt, in Reagenzröhrchen mit durchbohrtem Boden, unter dem ein 1,5 ml Eppendorfgefäß befestigt war, gegeben und bei 4 ${ }^{\circ} \mathrm{C}$ und 1.000-2.000 Upm 3-4 min zentrifugiert (Centrifuge $5810 \mathrm{R}$; Eppendorf Gerätebau, Hamburg). Dabei wurde darauf geachtet, stets eine unbeschädigte Blattkante nach unten zu orientieren, so daß die Apoplastenflüssigkeit nur durch die Stomata und nicht aus XylemGefäßen an den Schnittstellen oder anderen Verletzungen austreten und somit mit Zellinhalt kontaminiert werden konnte. Ein optisches Anzeichen für eine solche Kontamination war eine Grünfärbung des Extraktes. Auch die Zentrifugationszeit und -geschwindigkeit mußten ausreichend niedrig gewählt werden, um ein Aufbrechen von Zellen im Gewebe zu vermeiden. Zellulär kontaminierte (grüngefärbte) Proben wurden nicht weiterverwendet. Die Analyse des Apoplastensaftes erfolgte durch Aminosäure-HPLC (2.5.1). Bis zur Analyse wurden die Proben bei $-80{ }^{\circ} \mathrm{C}$ aufbewahrt. Zur Berechnung der Metabolitkonzentrationen im Apoplasten von Raps aus den Konzentrationen in der Auswaschlösung wurde folgender Verdünnungsfaktor zugrunde gelegt (Lohaus et al. 2001): 


$$
\text { Verdbnnungsfaktor }=\frac{\left(V_{\text {Apoplast }}+V_{\text {Gasraum }}\right)}{V_{\text {Gasraum }}}=7
$$

\subsection{Metabolit-Messungen}

Aminosäuren, Zucker, sowie organische und anorganische Ionen in den verschiedenen pflanzlichen Extrakten (aus Chloroform-Methanol-Extraktion, Apoplasten-Infiltration und nichtwässriger Fraktionierung; 2.4.1, 2.4.2 und 2.4.3) wurden durch HochdruckFlüssigkeitschromatographie (HPLC) qualitativ und quantitativ bestimmt.

\subsubsection{Chromatographische Bestimmung von Aminosäuren}

Um eine Auftrennung an einer „Reversed Phase“ Säule und anschließende Fluoreszenzdetektion $\mathrm{zu}$ ermöglichen, mußten die Aminosäuren zunächst mit orthoPhthaldialdehyd (OPA) und $\beta$-Mercaptoethanol $\mathrm{zu}$ fluorophoren apolaren Indolderivaten umgesetzt werden (Riens et al. 1991). Die Fluoreszenzdetektion erhöht die Sensitivität des Nachweises um das zwanzigfache gegenüber der herkömmlichen Ninhydrin-Derivatisierung. Prolin ist mit dieser Methode nicht nachweisbar, da seine Iminstruktur die Reaktion mit OPA verhindert.

Derivatisierungsreagenzien:

$\begin{array}{lll}\text { OPA-Stock: } & 16 \mathrm{mM} & o \text {-Phthaldialdehyd } \\ & 88 \%(\mathrm{v} / \mathrm{v}) & \text { Methanol } \\ 0,1 \mathrm{M} & \text { Kaliumborat } \mathrm{pH} 10,4 \\ 1,1 \%(\mathrm{v} / \mathrm{v}) & \beta \text {-Mercaptoethanol }\end{array}$

Arbeitslösung: $\quad$ OPA-Stock 1:3 mit $1 \mathrm{M}$ Kaliumborat $\mathrm{pH}$ 10,4 verdünnt

OPA-Stock und Kaliumborat wurden bis zu 5 Tage lichtgeschützt aufbewahrt. Der Arbeitslösung wurden $5 \mu 1 \beta$-Mercaptoethanol zugesetzt, wenn die Stocklösung älter als einen Tag war. Einige der gebildeten Aminosäurederivate waren sehr instabil (Cooper et al. 1984). Um dennoch reproduzierbare Ergebnisse zu erhalten, wurde die Auftragung der Proben auf die Säule mit einem automatisch gesteuerten Probengeber (Autosampler 2157; LKB Pharmacia, Freiburg) vereinheitlicht und die Säulentemperatur $\left(35^{\circ} \mathrm{C}\right)$ konstant gehalten 
(Säulenofen 2155; LKB Pharmacia, Freiburg). $20 \mu 1$ Arbeitslösung und $20 \mu 1$ Probe wurden gemischt und 1 min derivatisiert. Davon wurden $20 \mu 1$ auf eine „Reversed Phase“ Säule (LiChro Cart 125-4, Supersphere 100RP 18 endcapped; Merck, Darmstadt) aufgetragen. Das Säulenmaterial bestand aus Octadecylsilicat. Um Verunreinigungen der Säule zu verhindern, wurde eine Vorsäule (Superpac ODS2; LKB Pharmacia, Freiburg) verwendet. Die gesamte Aminosäurekonzentration betrug im Derivatisierungsansatz maximal 0,5 mM.

Ein Gradient aus Acetonitril und Phosphatpuffer eluierte die Aminosäurederivate vom apolaren Säulenmaterial. Der Gradient wurde durch einen Gradientenmischer (Low Pressure Mixer; LKB Pharmacia, Freiburg) und eine Pumpe (HPLC-Pumpe 2248; LKB Pharmacia, Freiburg) erzeugt. Alle verwendeten Chemikalien und Lösungsmittel entsprachen dem höchsten Reinheitsgrad.

Elutionslösungen:

HPLC-Stockpuffer:

$$
\begin{aligned}
& 0,12 \%(\mathrm{v} / \mathrm{v}) \quad \mathrm{H}_{3} \mathrm{PO}_{4} \\
& 0,05 \%(\mathrm{w} / \mathrm{v}) \text { EDTA } \\
& \text { pH mit } 50 \% \mathrm{NaOH} \text { auf 7,06-7,08 einstellen }
\end{aligned}
$$

Verlauf des Gradienten:

\begin{tabular}{lllll}
\hline Minute & $\% \mathrm{~A}$ & $\% \mathrm{~B}$ & $\% \mathrm{C}$ & Flußrate $(\mathrm{ml} / \mathrm{min})$ \\
\hline 0 & 100 & 0 & 0 & 0,9 \\
12 & 81 & 19 & 0 & 0,9 \\
20 & 81 & 19 & 0 & 0,9 \\
38 & 52 & 48 & 0 & 0,9 \\
41 & 52 & 48 & 0 & 0,9 \\
48 & 32 & 68 & 0 & 0,9 \\
51 & 0 & 0 & 100 & 1,2 \\
66 & 0 & 0 & 100 & 1,2 \\
68 & 100 & 0 & 0 & 0,9 \\
78 & 100 & 0 & 0 & 0,9 \\
\hline
\end{tabular}



A: $\quad 5 \% \quad$ Acetonitril in HPLC-Stockpuffer
B: $\quad 50 \%$ Acetonitril in HPLC-Stockpuffer
C: $\quad 70 \%$ Acetonitril in HPLC-Reinstwasser

Zur Anregung der Derivatisierungsprodukte wurde ein $330 \mathrm{~nm}$ Interferenzfilter verwendet. Die Emission des Eluats wurde bei $408 \mathrm{~nm}$ direkt am Säulenausgang mit einer Empfindlichkeit von 500-1.000 nA im kontinuierlichen Fluß gemessen (Fluoreszenzdetektor 2144; LKB Pharmacia, Freiburg). Jede Meßreihe erforderte eine eigene Kalibrierung, denn die Fluoreszenzintensität der Aminosäurederivate war abhängig vom Alter der Derivatisierungsreagenzien, der Fluoreszenzlampe, der Säule und sehr empfindlich gegenüber geringen pH-Wert-Änderungen. Die Kalibrierung erfolgte mit HPLC-Reinstwasser als Blindwert und drei verschiedenen Aminosäurekonzentrationen (4, 10 und $20 \mu \mathrm{M})$. Die Linearität der Eichgeraden wurde in einem Bereich von 1-50 $\mu \mathrm{M}$ getestet. Dem AminosäureStandard-Gemisch (Amino Acid Standard Solution A-2161; Sigma-Aldrich, Steinheim) wurden die entsprechenden Konzentrationen an Glutamin, Asparagin, Tryptophan und $\gamma$ Aminobuttersäure (GABA) zugesetzt, sowie $\alpha$-Aminobuttersäure (ABA, $16 \mu \mathrm{M})$ als interner Standard. Der interne Standard wurde verwendet, um mögliche Geräteungenauigkeiten der Pumpe und des automatischen Probengebers nachzuweisen. Blattextrakte und Apoplastensaftproben wurden vor der Analyse durch 0,2 $\mu \mathrm{m}$ Nitrozellulose-Filter (Schleicher \& Schüll, Dassel) gefiltert und mit HPLC-Reinstwasser entsprechend verdünnt. Alle Standardgemische und Proben wurden mit $5 \%$ (v/v) 1 M Kaliumborat pH 10,4 gepuffert.

Die Pumpe, der Autosampler und die Meßsequenz wurden von einem Computerprogramm (HPLC-Manager; LKB Pharmacia, Freiburg) gesteuert und die Daten des Fluoreszenzdetektors kontinuierlich gespeichert. Die Auswertung der Daten erfolgte mit einem Integrationsprogramm (PeakNet 5.0; Dionex, Idstein).

\subsubsection{Chromatographische Bestimmung von Zuckern}

Die chromatographische Bestimmung von Zuckern erfolgte über ein HPLC-System mit PulsAmperometrischer Detektion. Vor der Messung wurde die Proben durch 0,2 $\mu \mathrm{m}$ Nitrozellulose-Filter (Schleicher \& Schüll, Dassel) filtriert. Die Zucker wurden über eine Anionenaustauscher-Säule (CarboPac PA10; Dionex, Idstein) mit zugehöriger Vorsäule (CarboPac PA10 Guard; Dionex, Idstein) aufgetrennt und isokratisch mit $80 \mathrm{mM} \mathrm{NaOH}$ eluiert. Die Flußrate $(1 \mathrm{ml} / \mathrm{min}$ ) und die Elutionsdauer (30 min pro Lauf) wurden über eine Pumpe (LC-9A; Shimadzu, Duisburg) gesteuert. Das Wasser für den Elutionspuffer wurde 
zuvor 20 min mit Helium entgast, um die Bildung schwerlöslichen Natriumhydrogencarbonats $\mathrm{zu}$ verhindern. Zum Probenauftrag stand ein automatischer Probengeber (Autosampler 2157; LKB Pharmacia, Freiburg) zur Verfügung. Die elektrochemische Detektion erfolgte über eine Dünnschicht-Amperometrische Zelle (\#5040; ESA, Bedford, USA) mit einer Goldelektrode. Ein Amperometer (Coulochem II; ESA, Bedford, USA) steuerte die Spannungspulse und war für die Messung der Stromstärken erforderlich.

\begin{tabular}{llll}
\hline Puls-Modus & Spannung & Dauer & Messverzögerung \\
\hline Messung & $50 \mathrm{mV}$ & $500 \mathrm{~ms}$ & $400 \mathrm{~ms}$ \\
Reinigung & $700 \mathrm{mV}$ & $540 \mathrm{~ms}$ & \\
Regenerierung & $-800 \mathrm{mV}$ & $540 \mathrm{~ms}$ & \\
\hline
\end{tabular}

Für die Stabilität der Basislinie war es notwendig, nur hochreine Substanzen und HPLCreines Wasser zu verwenden. Die Kalibrierung erfolgte mit Zuckerkonzentrationen von 50, 100, 200 und $500 \mu \mathrm{M}$. Die Eichgeraden waren in diesem Bereich linear. Die Daten wurden kontinuierlich gespeichert und mit Hilfe des Integrationsprogramms PeakNet 5.0 (Dionex, Idstein) ausgewertet.

\subsubsection{Chromatographische Bestimmung von Ionen}

Anionen und Kationen wurden über eine Ionen-HPLC (DX500; Dionex, Idstein) getrennt und über einen Leitfähigkeitsdetektor (CD20; Dionex, Idstein) quantifiziert. Zur Messung von Anionen diente eine Anionenaustauscher-Säule (IonPac AS4 und AS4a kombiniert; Dionex, Idstein), die für 20 min mit $1,8 \mathrm{mM} \mathrm{Na}_{2} \mathrm{CO}_{3}, 1,7 \mathrm{mM} \mathrm{NaHCO}_{3}$ eluiert wurde. Die KationenHPLC erfolgte über eine IonPac CS12A Kationenaustauscher-Säule (Dionex, Idstein), die für 16 min mit $15 \mathrm{mM} \mathrm{H}_{2} \mathrm{SO}_{4}$ eluiert wurde. Die Kalibrierung wurde für Ionenkonzentrationen zwischen $100 \mu \mathrm{M}$ und $1 \mathrm{mM}$ durchgeführt. Zur Datenauswertung diente das Integrationsprogramm PeakNet 5.0 (Dionex, Idstein). 


\subsection{Methoden zur Isolierung von Proteinen}

Kleinere Mengen unfraktionierten Gesamtproteins aus verschiedenen Organismen und Zelltypen wurden für die Untersuchung in SDS-Polyacrylamidgelen (2.8.1) und Immunoblots (2.17.2) benötigt. Je nach Objekt wurden zur Isolation geeignete, einfache Aufschlußmethoden gewählt:

- Raps-Aminosäuretransporter exprimierende Xenopus Oocyten (2.15) wurden in LaemmliProbenpuffer (2.8.1) mit einem Pistill zermörsert (ca. 25 Ooycten in $500 \mu 1$ ) und die Zelltrümmer $5 \mathrm{~min}$ in einer Tischzentrifuge pellettiert.

- E. coli BL21 (DE3)-Zellen, die ein Maltose-Bindeprotein-BnAAP6-N-Terminus Fusionsprotein überexprimierten (2.17.1), wurden aus der Nährlösung abzentrifugiert, in Laemmli-Probenpuffer aufgenommen und $5 \mathrm{~min}$ bei $95{ }^{\circ} \mathrm{C}$ aufgeschlossen. Zelltrümmer wurden auch hier 5 min abzentrifugiert.

- Zur Expression von BnAAP6 verwendete E. coli Rosetta-gami (DE3) pLysS Zellen exprimieren intrazellulär Lysozym. Die Lyse der Zellen wurde durch zweimaliges Schockfrieren in flüssig- $\mathrm{N}_{2}$ (Freisetzung von Lysozym durch Schädigung der Plasmamembran) und anschließendes Auftauen bei $37{ }^{\circ} \mathrm{C}$ erreicht. Zusätzlich wurde DNase I $(0,1 \mathrm{mg} / \mathrm{ml})$ zugesetzt, um genomische DNA zu hydrolysieren, die beim folgenden Pellettieren der Zellreste (5 min, Tischzentrifuge), v.a. bei höheren Zelldichten eine schleimige Konsistenz des weiterverwendeten Überstandes hervorrufen kann.

- Kleine Mengen von unfraktioniertem Gesamtprotein aus Rapsblättern wurden duch Mörsern von etwa $2 \mathrm{~g}$ Blattmaterial mit etwas Seesand in $5 \mathrm{ml} 0,1 \mathrm{M} \mathrm{K}_{2} \mathrm{HPO}_{4} / \mathrm{KH}_{2} \mathrm{PO}_{4} \mathrm{pH}$ 7,4 erhalten. Das aufgeschlossene Material wurde in einer Tischzentrifuge $5 \mathrm{~min}$ abzentrifugiert und der Überstand weiterverwendet.

Alle Proteinproben wurden bei $-20^{\circ} \mathrm{C}$ gelagert.

\subsubsection{Isolierung von Plasmamembran-Proteinen aus Pflanzen}

\subsubsection{Anreicherung von Plasmamembran-Proteinen in einem Zwei-Phasen System}

Plasmamembran-Vesikel können in einem PEG-Dextran Zwei-Phasen System angereichert werden, in dem sich Vesikel mit innen liegender cytosolischer Membranseite (,outside-out“) in der leichteren PEG-Phase verteilen, und solche mit invertierter Membranorientierung (,inside-out“) in der schwereren Dextran-Phase (Robinson \& Hinz 2001). Dazu wurde zuerst ein großes Volumen Zwei-Phasen-Mischung hergestellt: 75,6 g Dextran 500-Lösung + 37,8 g 
PEG 3350-Lösung + 60 g PSK-Puffer $+66,6$ g $\mathrm{H}_{2} \mathrm{O}$ wurden in einem Scheidetrichter gründlich gemischt und über Nacht bei $4{ }^{\circ} \mathrm{C}$ zur Phasentrennung stehen gelassen. Die untere (Dextran-) Phase wurde weiterverwendet.

$\mathrm{Da}$ zur Vermeidung einer Kontamination der Homogenisierungspuffer frei von stabilisierendem BSA sein muß - es wird bei der Membranprotein-Isolation nur ungenügend abgereichert - wurden alle auf die Ernte des Pflanzenmaterials folgenden Schritte ausschließlich bei $4{ }^{\circ} \mathrm{C} /$ auf Eis durchgeführt und möglichst viele zur Verfügung stehende Proteinase-Inhibitoren verwendet. Etwa $10 \mathrm{~g}$ frisches junges Blattmaterial wurden mit einer Rasierklinge in kleine Stücke zerschnitten und in $200 \mathrm{ml}$ halbgefrorenem Homogenisationspuffer mit einem Pürierstab („waring blendor") drei mal $15 \mathrm{sec}$ lang homogenisiert. Das Homogenat wurde durch zwei lagen Mull und eine Lage Miracloth (Merck Biosciences, Schwalbach) filtriert und anschließend $20 \mathrm{~min}$ bei $13.000 \mathrm{~g}$ zentrifugiert, um Zellwandbestandteile abzutrennen (10.400 Upm, Sorvall RC-5B, Rotor SS34; Du Pont, Bad Homburg). Zum Pellettieren der Mikrosomenfraktion wurde der Überstand abgenommen und auf Ultrazentrifugenröhrchen verteilt. Die Sedimentation der Mikrosomen erfolgte für $1 \mathrm{~h}$ bei $100.000 \mathrm{x}$ g und $4{ }^{\circ} \mathrm{C}$ in der Ultrazentrifuge (28.000 Upm, Optima LE-80K, Rotor SW28; Beckman Coulter, Krefeld). Das Mikrosomenpellet wurde mittels eines Potters in $5 \mathrm{ml}$ PSKPuffer resuspendiert und ein $100 \mu \mathrm{l}$ Aliquot für spätere Proteinbestimmungen und ATPaseTests (2.6.1.2) entnommen.

Ein kleines Volumen Zwei-Phasen-Mischung wurde in einem SS34-Röhrchen vorgelegt: 7,5 g Dextran 500-Lösung + 3,78 g PEG 3350-Lösung + 4,75 g PSK-Puffer + 2,91 g $\mathrm{H}_{2} \mathrm{O}$. Darauf wurde die Mikrosomenfraktion aufgetragen, das Röhrchen mit Parafilm verschlossen und gründlich geschüttelt. Es folgte eine Phasentrennung durch 5 min Zentrifugation bei $1.500 \mathrm{x}$ g und $4{ }^{\circ} \mathrm{C}$ (3.650 Upm, Sorvall RC-5B, Rotor HB6; Du Pont, Bad Homburg), weiterverwendet wurde die Oberphase. Diese wurde vorsichtig abgenommen und in in einem neuen Röhrchen mit frischer Unterphase aus dem anfänglich hergestellten großen Volumen auf 24 g Gesamtgewicht verdünnt, wiederum gründlich geschüttelt und zur Phasentrennung wie oben beschrieben zentrifugiert. Es folgte ein weiteres Ausschütteln der Oberphase mit frischer Unterphase und erneute Phasentrennung. Zuletzt wurde die so erhaltene dritte Oberphase mit Waschpuffer auf $75 \mathrm{ml}$ Gesamtvolumen verdünnt und die angereicherten Plasmamembran-Vesikel durch Ultrazentrifugation für $1 \mathrm{~h}$ bei $100.000 \mathrm{~g}$ und $4{ }^{\circ} \mathrm{C}$ sedimentiert (28.000 Upm, Optima LE-80K, Rotor SW28; Beckman Coulter, Krefeld). Das Pellet wurde in $1 \mathrm{ml}$ Waschpuffer resuspendiert (Potter) und bei $-20{ }^{\circ} \mathrm{C}$ aufbewahrt. 



\subsubsection{P-ATPase-Test}

Die Proteingehalte der Mikrosomen- und Plasmamembran-Fraktonen wurden mit dem „, $\mathrm{D}_{\mathrm{C}}$ Protein Assay“ (2.7.3; BioRad, München) und durch SDS-PAGE (2.8.1) bestimmt. Anschließend konnte die Anreicherung von Plasmamembran-Proteinen anhand der Aktivität der Vanadium-inhibierbaren P-ATPase überprüft werden. Hierzu diente eine Kombination der bei Robinson \& Hinz (2001) beschriebenen P-ATPase-Nachweisreaktion mit der in derselben Quelle für einen Inosin-5-Diphosphatase-Test angegebenen photometrischen Phosphatbestimmung.

Mikrosomen wurden etwa 1:10, Plasmamembran-Vesikel etwa 1:2 verdünnt $(2-5 \mu \mathrm{g}$ Protein $/ 10 \mu \mathrm{l})$ und als Doppelproben gemessen. Als Eichgerade dienten Verdünnungen von $1,25 \mathrm{mM} \mathrm{KH} \mathrm{PO}_{4}$ mit 0-250 nmol $\mathrm{PO}_{4}{ }^{3-} / 10 \mu 1$. Alle Verdünnungen und die Eichgerade wurden in Waschpuffer (2.6.1.1) angesetzt, alle Messungen wurden getrennt mit ATPase-Mix mit und ohne Vanadat durchgeführt.

- Start der Reaktion durch Zugabe von $10 \mu 1$ Probe zu $90 \mu$ l ATPase-Mix +/- Vanadat

- $10 \min 37^{\circ} \mathrm{C}$

- Reaktionsstop durch $500 \mu 1$ kalte $10 \%$ w/v Trichloressigsäure

- Proteinfällung bei $4{ }^{\circ} \mathrm{C}$ für mindestens $2 \mathrm{~h}$

- $10 \mathrm{~min}$ bei $9.000 \mathrm{Upm}$

- $200 \mu 1$ Überstand $+1,8$ ml Farbreagenz

- $1 \mathrm{~h} 37^{\circ} \mathrm{C}$

Die Phosphatkonzentration wurde bei $\mathrm{E}_{820}$ gegen Waschpuffer ohne $\mathrm{PO}_{4}{ }^{3-}$ gemessen und die P-ATPase-Aktivität aus der Differenz der gehemmten (mit Vanadat) und der GesamtATPase-Aktivität (ohne Vanadat) berechnet. Der Anreicherungsfaktor wurde als Verhältnis der P-ATPase-Aktivität entweder zur Gesamt-ATPase-Aktivität berechnet.

Farbmix:

$\begin{array}{ll}1 \text { Anteil } & 3 \mathrm{M} \mathrm{H}_{2} \mathrm{SO}_{4} \\ 1 \text { Anteil } & 2,5 \%(\mathrm{w} / \mathrm{v})\left(\mathrm{NH}_{4}\right)_{6} \mathrm{Mo}_{7} \mathrm{O}_{24} \cdot 4 \mathrm{H}_{2} \mathrm{O} \\ 1 \text { Anteil } & 10 \%(\mathrm{w} / \mathrm{v}) \text { Ascorbat } \\ 6 \text { Anteile } & \mathrm{H}_{2} \mathrm{O}\end{array}$

Frisch angesetzt, Reagenzien in dieser Reihenfolge gemischt. 
ATPase-Mix:

\begin{tabular}{|c|c|}
\hline $35 \mathrm{mM}$ & Tris/MES pH 6,5 \\
\hline $5 \mathrm{mM}$ & $\mathrm{MgSO}_{4}$ \\
\hline $55 \mathrm{mM}$ & $\mathrm{KCl}$ \\
\hline $1 \mathrm{mM}$ & $\mathrm{NaMoO}_{4}$ \\
\hline $1 \mathrm{mM}$ & $\mathrm{NaN}_{3}$ \\
\hline $0,05 \%(\mathrm{v} / \mathrm{v})$ & Triton X-100 \\
\hline $3 \mathrm{mM}$ & *ATP \\
\hline $70 \mu \mathrm{M}$ & $* \mathrm{Na}_{3} \mathrm{VO}_{4}$ \\
\hline
\end{tabular}

* frisch dazugegeben

\subsection{Quantitative Proteinbestimmung}

\subsubsection{Proteinbestimmung nach Bradford}

Eine einfache Methode zur Bestimmung des Gehalts an löslichem Protein nutzt nach Bradford (1976) die Färbung von Proteinen durch Coomassie Brilliant Blue zur Mengenabschätzung. $50 \mu 1$ Probe (Proteingehalt zwischen 5 und $10 \mu \mathrm{g}$ ) wurden mit $1 \mathrm{ml}$ Farbmix versetzt und 5 min bei RT inkubiert. Anschließend wurde die Extinktion bei $595 \mathrm{~nm}$ gegen gleich behandelten Probenpuffer gemessen (Uvikon 932; Kontron, Mailand, Italien). Die Proteinmenge wurde anhand einer Eichreihe von 0 bis $15 \mu \mathrm{g}$ aus entfettetem BSA bestimmt. Die Eichreihe wurde jeweils nur einmal für frisch angesetzten Farbmix hergestellt, da das Farbreagenz über längere Zeit stabil war. Die Bradford-Methode wird durch SDS gestört, nicht jedoch durch $\beta$-Mercaptoethanol.

Farbmix:

$$
\begin{array}{lllll}
\text { Lösung 1: } & 600 & \mathrm{ml} & \mathrm{H}_{2} \mathrm{O} & \\
& & 100 & \mathrm{ml} & 85 \% \mathrm{H}_{3} \mathrm{PO}_{4}
\end{array}
$$

Lösung 2: $\quad 70 \mathrm{mg}$ Coomassie Brilliant Blue G-250 in $50 \mathrm{ml}$ 99,6 \% Ethanol Lösungen 1 und 2 mischen, ad $1.000 \mathrm{ml} \mathrm{mit} \mathrm{H}_{2} \mathrm{O}$ auffüllen Der Farbmix wurde lichtgeschützt aufbewahrt. 


\subsubsection{Proteinbestimmung nach Lowry}

Für die Proteinquantifizierung nach Lowry et al. (1951) muß im Gegensatz zur BradfordMethode für jede Messung eine neue Eichreihe hergestellt werden. $\beta$-Mercaptoethanol stört die Messung, aber nicht SDS. Der Proteingehalt in Proben aus Chloroform-MethanolExtraktion (2.4.1) und nichtwässriger Fraktionierung (2.4.2) wurde mit dieser Methode bestimmt. Für jede Proteinbestimmung wurde jeweils frischer Farbmix aus den Stammlösungen angesetzt und eine Eichreihe aus 0-36 $\mu \mathrm{g}$ entfettetem BSA hergestellt.

Farbmix-Stammlösungen:

$\begin{array}{lll}\text { Lösung A: } & 2 \%(\mathrm{w} / \mathrm{v}) & \text { Natriumcarbonat in } 0,1 \mathrm{M} \mathrm{NaOH} \\ \text { Lösung B: } & 1 \%(\mathrm{w} / \mathrm{v}) & \mathrm{CuSO}_{4} \\ \text { Lösung C: } & 2 \%(\mathrm{w} / \mathrm{v}) & \text { Natrium-Kalium-Tartrat }\end{array}$

Mischungsverhältnis A:B:C = 99:0,5:0,5

$700 \mu 1$ Farbmix und $150 \mu 1$ Probe wurden gemischt und 15 min bei RT inkubiert. Danach erfolgte die Zugabe von $100 \mu \mathrm{l}$ Folin-Chiocalteus-Phenolreagenz $\left(1: 3\right.$ mit $\mathrm{H}_{2} \mathrm{O}$ frisch verdünnt; Merck, Darmstadt), sofortiges Vortexen der Probe und eine weitere Inkubation für $15 \mathrm{~min}$ bei RT. Die Extinktion wurde bei $578 \mathrm{~nm}$ gegen gleichbehandelten Probenpuffer gemessen (Uvikon 932; Kontron, Mailand, Italien) und die Proteinkonzentration anhand der Eichreihe bestimmt.

\subsubsection{Proteinbestimmung mit dem „ $\mathrm{D}_{\mathrm{C}}$ Protein Assay“}

Der $\quad \mathrm{D}_{\mathrm{C}}$ Protein Assay der Firma BioRad (München) basiert auf der Proteinbestimmungsmethode nach Lowry, ermöglicht aber eine beschleunigte Durchführung und ergibt einen länger stabilen farbigen Komplex. Wie bei der Lowry-Methode stört $\beta$ Mercaptoethanol die Messung, aber nicht SDS, Tween, oder Triton X-100. Mit dem $\mathrm{D}_{\mathrm{C}}$ Protein Assay wurde die Proteinmenge in Plasmamembranfraktionen (2.6.1) und Lysaten von E. coli Zellen und Xenopus Oocyten (2.6) bestimmt.

Vor Beginn der Messung wurde jeweils Arbeitslösung $\mathrm{A}^{\prime}$ aus $20 \mu \mathrm{l}$ Lösung $\mathrm{S}$ und $1 \mathrm{ml}$ Lösung A frisch angesetzt (Lösung $\mathrm{S}$ konnte bei detergenzfreien Proben weggelassen werden). $25 \mu 1$ Probe wurden mit $125 \mu$ l Arbeitslösung A' gevortext. Anschließend erfolgte die Zugabe von $1 \mathrm{ml}$ Lösung B, sofortiges Vortexen und eine Inkubation für $15 \mathrm{~min}$ bei RT. Lösung A entspricht der alkalischen Kupfer-Tartrat-Lösung, Lösung B dem Folin-Reagenz 
der Lowry-Methode. Die Extinktion der Proben wurde bei $750 \mathrm{~nm}$ gegen gleichbehandelten Probenpuffer gemessen und die Proteinkonzentration anhand einer Eichreihe von 0,2 bis 1,5 $\mu \mathrm{g} / \mu \mathrm{l}$ entfettetem BSA in Probenpuffer ermittelt.

\subsubsection{Chlorophyllbestimmung}

Der Chlorophyllgehalt der Proben aus Chloroform-Methanol-Extraktion (2.4.1) und nichtwässriger Fraktionierung (2.4.2) wurde nach Arnon (1949) gemessen. Bei der Chloroform-Methanol-Extraktion wurden die Unterphasen verwendet, bei der nichtwässrigen Fraktionierung das lyophyllisierte Pflanzenpulver, das durch Ultraschall (12 x je 5 sec Puls und $25 \mathrm{sec}$ Pause, Sonifier B15; Branson, Genf, Schweiz) in $50 \mathrm{mM} \mathrm{K}{ }_{2} \mathrm{HPO}_{4} / \mathrm{KH}_{2} \mathrm{PO}_{4} \mathrm{pH}$ 7,5, 0,5 mM EDTA, 0,5 mM DTT homogenisiert und durch ein $40 \mu \mathrm{m}$ Netz (Merck, Darmstadt) filtriert wurde. Die Probe wurde mit 99,6 \% Ethanol auf $1 \mathrm{ml}$ aufgefüllt, geschüttelt und 5 min abzentrifugiert (Tischzentrifuge). Die Extinktion des jeweiligen Überstandes wurde bei $652 \mathrm{~nm}$ gemessen (Uvikon 932; Kontron, Mailand, Italien). Der Extinktionskoeffizient von Chlorophyll in Ethanol bei $652 \mathrm{~nm}$ ist $\varepsilon=36 \mathrm{M}^{-1} \mathrm{~cm}^{-1}$.

\subsection{Gelelektrophoretische Auftrennung von Proteinen}

\subsubsection{SDS-Polyacrylamid-Gelelektrophorese}

Bei der denaturierenden SDS-Polyacrylamid-Gelelektrophorese (SDS-PAGE) (Laemmli 1970) werden Proteine durch die Einlagerung von Natrium-Dodecylsulfat (SDS) linearisiert und mit einer einheitlichen, negativen Oberflächenladung versehen. Dies erlaubt in der Gelelektrophorese eine Auftrennung, die nur durch das Molekulargewicht und nicht die Tertiärsturktur oder Eigenladung der Proteine bestimmt ist. Die Proteinproben wurden zunächst mit Laemmli-Probenpuffer versetzt, entweder durch Verdünnung mindestens im Verhältnis 1:2 mit 1 x Probenpuffer, oder durch Zugabe von 5 x Probenpuffer und Auffüllen ad 1 x Puffer mit $\mathrm{H}_{2} \mathrm{O}$. Durch Aufkochen für $3-5$ min bei $95{ }^{\circ} \mathrm{C}$ wurden die Proteine solubilisiert und denaturiert. Membranproteinproben wurden wegen ihrer größeren Empfindlichkeit nur bei $65{ }^{\circ} \mathrm{C}$ denaturiert (Sauer \& Stolz 2000). Anschließend wurde zur Abtrennung unlöslicher Bestandteile 5 min bei $13.000 \mathrm{Upm}$ zentrifugiert. 
Laemmli-Probenpuffer: $\quad 15 \mathrm{mM} \quad$ Tris/ $\mathrm{HCl} \mathrm{pH} 6,8$

$$
\begin{aligned}
& 5 \%(\mathrm{w} / \mathrm{v}) \quad \text { SDS } \\
& 2 \%(\mathrm{v} / \mathrm{v}) \quad \beta \text {-Mercaptoethanol } \\
& 20 \%(\mathrm{v} / \mathrm{v}) \quad \text { Glycerin } \\
& 0,01 \%(\mathrm{v} / \mathrm{v}) \text { Bromphenolblau }
\end{aligned}
$$

Die Polyacrylamidgele enthielten 12,5 \% (w/v) Acrylamid im Trenngel und wurden in Mini Protean 3-Kammern (BioRad, München) gegossen. Die Gele waren 0,75 mm dick, die Länge des Sammelgels betrug ca. 0,8 cm und die Länge des Trenngels $5 \mathrm{~cm}$. Für präparative Gele standen größere, selbstkonstruierte Gelkammern zur Verfügung, in den $1 \mathrm{~mm}$ dicke Gele mit ca. 0,8 cm langem Sammel- und $7 \mathrm{~cm}$ langem Trenngel gegossen wurden. Für diese Gele mußte jeweils das Vierfache des unten angegebenen Ansatzes eingesetzt werden.

Sammelgel:

$$
\begin{array}{ll}
0,13 \mathrm{M} & \text { Tris/HCl pH 6,8 } \\
0,1 \%(\mathrm{w} / \mathrm{v}) & \text { SDS } \\
4,6 \%(\mathrm{w} / \mathrm{v}) & \text { Acrylamid } \\
0,12 \%(\mathrm{w} / \mathrm{v}) & \text { N,N-Methylenbisacrylamid } \\
0,06 \%(\mathrm{w} / \mathrm{v}) & \text { Ammoniumperoxodisulfat }
\end{array}
$$

Trenngel:

$$
\begin{array}{ll}
0,38 \mathrm{M} & \text { Tris/HCl } \mathrm{pH} 8,8 \\
0,1 \%(\mathrm{w} / \mathrm{v}) & \text { SDS } \\
12,5 \%(\mathrm{w} / \mathrm{v}) & \text { Acrylamid } \\
0,33 \%(\mathrm{w} / \mathrm{v}) & \text { N,N-Methylenbisacrylamid } \\
0,05 \%(\mathrm{w} / \mathrm{v}) & \text { Ammoniumperoxodisulfat }
\end{array}
$$

Für ein Gel wurden folgende Komponenten gemischt:

\begin{tabular}{lll}
\hline & Trenngel & Sammelgel \\
\hline Lower Gel Stock & $1,12 \mathrm{ml}$ & - \\
Upper Gel Stock & - & $0,5 \mathrm{ml}$ \\
Acrylamid Stock & $1,88 \mathrm{ml}$ & $0,32 \mathrm{ml}$ \\
$\mathrm{H}_{2} \mathrm{O}$ & $1,5 \mathrm{ml}$ & $1,18 \mathrm{ml}$ \\
APS & $1,75 \mu 1$ & $2 \mu 1$ \\
TEMED (Start der Polymerisation) & $6,9 \mu 1$ & $4 \mu 1$ \\
\hline
\end{tabular}

$\begin{array}{lll}\text { Lower Gel Stock: } & 1,5 \mathrm{M} & \text { Tris/HCl pH 8,8 } \\ & 0,4 \%(\mathrm{w} / \mathrm{v}) & \mathrm{SDS} \\ & & \\ \text { Upper Gel Stock: } & 0,5 \mathrm{M} & \text { Tris/HCl pH 6,8 } \\ & 0,4 \%(\mathrm{w} / \mathrm{v}) & \mathrm{SDS}\end{array}$


Acrylamid Stock: $\quad 30 \%(\mathrm{w} / \mathrm{v}) \quad$ Acrylamid

$0,8 \%(\mathrm{w} / \mathrm{v}) \quad \mathrm{N}, \mathrm{N}-$ Methylenbisacrylamid

$\begin{array}{lll}\text { APS: } & 10 \%(\mathrm{w} / \mathrm{v}) & \text { Ammoniumperoxodisulfat } \\ \text { TEMED: } & 100 \% & \mathrm{~N}, \mathrm{~N}^{\circ} \mathrm{N}^{\star}, \mathrm{N}^{6} \text {-Tetramethylendiamin }\end{array}$

Es wurde zunächst das Trenngel gegossen und mit wassergesättigtem Isobutanol überschichtet, um Luftblasenbildung zu verhindern und eine gerade Geloberfläche zu erzeugen. Nach der Auspolymerisation (ca. $30 \mathrm{~min}$ ) wurde das Isobutanol entfernt und das Sammelgel auf das Trenngel gegossen. Die Polymerisationsdauer betrug ebenfalls etwa 30 min. Im Anschluß daran wurde das Gel in die Elektrophorese-Apparatur eingespannt und diese mit Laufpuffer befüllt. Pro Geltasche konnten bis $\mathrm{zu} 20 \mu \mathrm{l}$ Probe mit einer Mikroliterspritze (Microliter \#702; Hamilton, Bonaduz, Schweiz) auf das Gel geladen werden. Die Elektrophorese erfolgte zunächst für $25 \mathrm{~min}$ bei $15 \mathrm{~mA}$ pro Gel, dann für weitere ca. $30 \mathrm{~min}$ bei $25 \mathrm{~mA}$ pro Gel bis der Bromphenolblau-Marker das Ende des Trenngels erreichte. Spannung und Leistung des Spannungsgerätes (Consort E 865; Scie-Plas, Southam, England) wurden dabei auf die maximalen Werte eingestellt. Zur Größenbestimmung wurde ein „Protein Molecular Weight Marker“ (MBI, Vilnius, Litauen) mit Markerproteinen von 18,4-116 kDa verwendet.

Laufpuffer: $\quad 50 \mathrm{mM} \quad$ Tris/ $\mathrm{HCl}(\mathrm{pH}$ nicht eingestellt)

$$
\begin{array}{ll}
380 \mathrm{mM} & \text { Glycin } \\
0,1 \%(\mathrm{w} / \mathrm{v}) & \text { SDS }
\end{array}
$$

Proteine im Größenstandard:

$\begin{array}{lll}\beta \text {-Galactosidase } & 116 & \mathrm{kDa} \\ \text { BSA } & 66,2 & \mathrm{kDa} \\ \text { Ovalbumin } & 45 & \mathrm{kDa} \\ \text { Lactat-Dehydrogenase } & 35 & \mathrm{kDa} \\ \text { RE Bsp98I } & 25 & \mathrm{kDa} \\ \beta \text {-Lactoglobulin } & 18,4 & \mathrm{kDa} \\ \text { Lysozym } & 14,4 & \mathrm{kDa}\end{array}$


Die im Gel aufgetrennten Proteine wurden durch eines von mehreren im Folgenden dargestellten Färbeverfahren sichtbar gemacht oder zur immunologischen Detektion auf eine Nitrozellulosemembran geblottet (2.17.2).

\subsubsection{Coomassie-Färbung}

Für eine Coomassie-Färbung von Proteinen in SDS-Polyacrylamid-Gelen muß die aufgetragene Proteinmenge ca. 2-20 $\mu \mathrm{g}$ betragen. Das Gel wurde für mindestens $30 \mathrm{~min}$ in Färbelösung fixiert und angefärbt. Anschließend wurde mehrmals für 15 min in Entfärber entfärbt, bis der Gelhintergrund nahezu farblos war. Das entfärbte Gel konnte dann für lange Zeit in $\mathrm{H}_{2} \mathrm{O}$ gelagert werden.

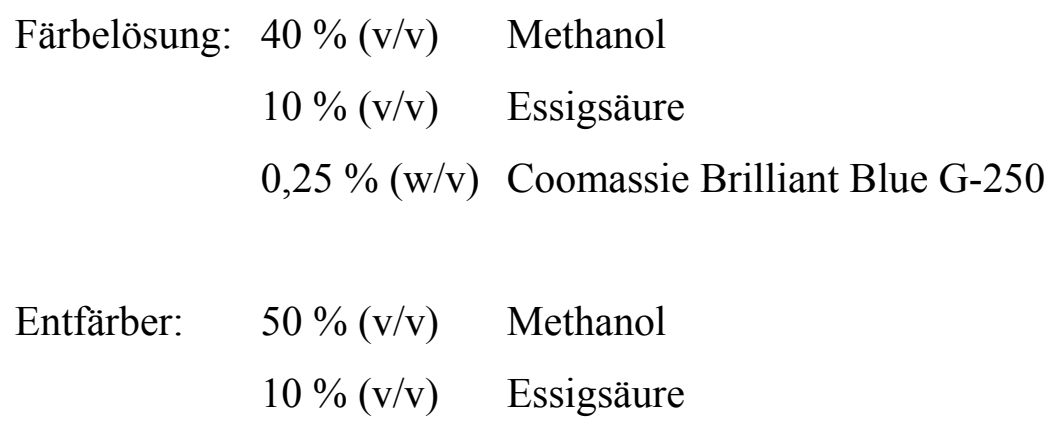

\subsubsection{Silverstain-Färbung}

Die Silverstain-Färbung (Blum et al. 1987) von Proteinen in SDS-Polyacrylamid-Gelen ist etwa 10-100fach empfindlicher als die Coomassie-Färbung, so daß noch Proteinmengen bis zu 10 ng detektierbar sind.

Silbernitrat reagiert mit Proteinseitengruppen nichtstöchiometrisch unter sauren Bedingungen und wird anschließend durch Formaldehyd unter alkalischen Bedingungen zu metallischem Silber reduziert. Die bei der Silverstain-Färbung reaktiven Gruppen der Proteine sind freie Amino- und Sulfhydrylgruppen. Daraus folgt, daß die Intensität der Färbung von der Aminosäuresequenz des Proteins abhängt und bei basischen Proteinen am größten ist. Die Färbung wurde auf einem Horizontalschüttler (Unimax 1010; Heidolph, Schwabach) wie folgt durchgeführt: 
1. Fixierung: $\quad 90$ min bis über Nacht

Fixierer: $\quad 50 \%(\mathrm{v} / \mathrm{v}) \quad$ Ethanol

$12 \%(\mathrm{v} / \mathrm{v}) \quad$ Essigsäure

$0,05 \%(\mathrm{v} / \mathrm{v}) \quad 37 \%$ Formaldehyd

2. Waschen: $\quad 3 \times 20 \mathrm{~min}$

$50 \%(\mathrm{v} / \mathrm{v}) \quad$ Ethanol

3. Imprägnierung: $1 \mathrm{~min}$

$$
0,01 \%(\mathrm{w} / \mathrm{v}) \quad \mathrm{Na}_{2} \mathrm{~S}_{2} \mathrm{O}_{3}
$$

4. Waschen: $3 \times 20 \mathrm{sec}$

\section{$\mathrm{H}_{2} \mathrm{O}$}

5. Färbung: $\quad 20 \mathrm{~min}$

Färbelösung: $0,1 \%(\mathrm{w} / \mathrm{v}) \quad \mathrm{AgNO}_{3}$

$0,075 \%(v / v) 37 \%$ Formaldehyd

6. Waschen: $2 \times 20 \mathrm{sec}$

$$
\mathrm{H}_{2} \mathrm{O}
$$

7. Entwicklung: $\quad 1-2 \mathrm{~min} *$

Entwickler: $\quad 3 \%(\mathrm{w} / \mathrm{v}) \quad \mathrm{Na}_{2} \mathrm{CO}_{3}$

$0,05 \%(\mathrm{v} / \mathrm{v}) \quad 37 \%$ Formaldehyd

$0,2 \%$ (w/v) $\quad \mathrm{Na}_{2} \mathrm{~S}_{2} \mathrm{O}_{3}$

8. Abstoppen: $\quad 10 \mathrm{~min}$

$10 \mathrm{mM} \quad \mathrm{Na}_{2}$ EDTA

9. Lagerung: $\quad \mathrm{H}_{2} \mathrm{O}$

* Die tatsächliche Färbedauer war vom Erscheinen der Proteinbanden im Gel abhängig, wobei beachtet werden mußte, daß das Gel beim Abstoppen noch weiter nachfärbte.

\subsubsection{KCl-Färbung und Elution von Proteinen aus präparativen SDS-Gelen}

Die KCl-Färbung (Prussak et al. 1989) von Proteinen in SDS-Polyacrylamid-Gelen ist noch weniger sensitiv als die Coomassie-Färbung, im Gegensatz zu dieser und der SilverstainFärbung läßt sich aber das Färbemittel hinterher mühelos wieder entfernen. Deshalb wurde diese Methode angewandt, um in E. coli überexprimiertes und in großen Mengen in präparativen SDS-Polyacrylamidgelen aufgetrenntes Maltose-Bindeprotein-BnAAP6-NTerminus Fusionsprotein (2.17.1) zum Ausschneiden der Proteinbande sichtbar zu machen. Das Gel wurde dazu 5 min bei $4{ }^{\circ} \mathrm{C}$ in $250 \mathrm{mM} \mathrm{KCl}$ gelegt und anschließend für $15 \mathrm{~min}$ in 
eiskaltes Wasser. Die Proteine wurden dabei als milchigweiße Banden sichtbar. Zum Ausschneiden der gewünschten Bande wurde ein schwarzer Hintergrund verwendet.

Die ausgeschnittenen Gelstücke wurden mit einer Rasierklinge auf einer Glasplatte zerkleinert und anschließend durch ein auf eine aufgeschnittene $20 \mathrm{ml}$-Spritze aufgeschmolzenes Sieb gepresst. Der Gelbrei wurde über Nacht bei $4{ }^{\circ} \mathrm{C}$ in $\mathrm{H}_{2} \mathrm{O}$ geschüttelt und die Gelreste anschließend entfernt, indem die Lösung durch vier Lagen Baumwolltaschentuch zentrifugiert wurde. Zuletzt wurde die Proteinlösung in einer Vakuumzentrifuge (Speedvac Concentrator; Bachhofer, Reutlingen) auf $1 \mathrm{ml}$ eingeengt. Sie konnte direkt zur Immunisierung von Kaninchen verwendet werden (2.17.1).

\subsection{Präparation und Reinigung von Nukleinsäuren}

\subsubsection{Isolation von RNA}

\subsubsection{Mini-Präparation pflanzlicher Gesamt-RNA}

Bei wenig polysaccharidhaltigem Pflanzenmaterial (Arabidopsis) oder geringem RNA-Bedarf (RT-PCR, 2.12, 2.13) kamen zur RNA-Isolation verschiedene kommerziell erhältliche Kits zur Anwendung, wobei je nach Ausgangsmaterial der am besten geeignete empirisch ermittelt werden mußte. Verwendet wurden der „Invisorb Spin Plant-RNA Mini Kit“ (Invitek, Berlin) sowie „peqGOLD RNAPure“ und „peqGOLD OptiPure“ Lösungen (PeqLab, Erlangen). Der Invisorb Kit diente auch zur nachträglichen weiteren Aufreiningung von RNA-Proben.

\subsubsection{Extraktion großer Mengen pflanzlicher Gesamt-RNA}

Für die Isolation großer Mengen RNA aus polysaccharidreichem Rapsgewebe für Northern Blots (2.11.2) wurde eine kombinierte Phenol- und Guanidinium-RNA-Extraktion mit einer „peqGOLD OptiPure“ Reinigung (PeqLab, Erlangen) kombiniert. Dazu wurden ca. 300 mg Pflanzenmaterial mit einer Spatelspitze Polyclar AT unter flüssigem Stickstoff fein gemörsert. Nach dem Verdampfen des Stickstoffs wurde das noch gefrorene Pflanzenpulver in $6 \mathrm{ml}$ Extraktionslösung überführt und unter Vortexen aufgetaut. Nach einer fünfminütigen Inkubation bei RT wurden Zelltrümmer, genomische DNA und Polyclar AT 10 min bei $10.000 \mathrm{x}$ g und $4{ }^{\circ} \mathrm{C}$ abzentrifugiert (Sorvall RC-5B, Rotor SS-34; Du Pont, Bad Homburg). Der Überstand wurde mit 1,2 ml Chroroform versetzt, kräftig geschüttelt und 2-3 min bei RT inkubiert. Zur Phasentrennung wurde $15 \mathrm{~min}$ bei $10.000 \mathrm{~g}$ und $4{ }^{\circ} \mathrm{C}$ zentrifugiert. Die wässrige Oberphase wurde abgenommen und zur RNA-Fällung mit $3 \mathrm{ml}$ Isopropanol und 3 
ml 0,8 M Natriumcitrat/1,2 M NaCl versetzt. Nach dem Durschmischen durch Invertieren erfolgte eine 10 min Inkubation bei RT und das Pellettieren der RNA für 10 min bei $10.000 \mathrm{~g}$ und $4{ }^{\circ} \mathrm{C}$. Das Pellet wurde mit $5 \mathrm{ml} 75 \%$ Ethanol gewaschen und nochmal 5 min bei 10.000 g und $4{ }^{\circ} \mathrm{C}$ abzentrifugiert. Nach dem Abnehmen des Ethanol-Überstandes, wurde das Pellet in $600 \mu \mathrm{l}$ OptiPure (200 $\mu \mathrm{l}$ je $100 \mathrm{mg}$ Ausgangsmaterial) durch kräftiges Vortexen aufgeschwemmt. Dabei gehen Polysaccharide und Polyphenole in Lösung, während das RNA-Pellet unlöslich bleibt. Die OptiPure-Lösung wurde mit dem RNA-Pellet in ein Eppendorfgefäß überführt und $10 \mathrm{~min}$ bei $3.000 \mathrm{~g}$ abzentrifugiert. Der Überstand wurde verworfen, das Pellet in $200 \mu 1$ 0,5 \% (w/v) SDS pH 7,0 resuspendiert. Nach Zugabe von 200 $\mu 1$ Chloroform wurde erneut geschüttlt und $5 \mathrm{~min}$ bei $3.000 \mathrm{~g}$ zentrifugiert. Die wässrige Oberphase wurde abgenommen und die RNA mit 1 Volumen Isopropanol und 0,2 Vol. 2 M Natriumacetat pH 5 (Endkonzentration 0,2 M) gefällt (15 min 16.000 g). Das Pellet wurde luftgetrocknet und in 100-200 $\mu \mathrm{H}_{2} \mathrm{O}$ resuspendiert. Die RNA-Konzentration wurde durch Agarose-Gelelektrophorese (2.10.1) und Messung der Extinktion bei $260 \mathrm{~nm}$ bestimmt (2.9.6)

$\begin{array}{lll}\text { Extraktionslösung: } & 38 \%(\mathrm{v} / \mathrm{v}) & \text { Roti-Phenol (Carl Roth, Karlsruhe) } \\ & 20 \%(\mathrm{v} / \mathrm{v}) & 4 \mathrm{M} \text { Guanidiniumthiocyanat } \\ & 10 \%(\mathrm{v} / \mathrm{v}) & 4 \mathrm{M} \text { Ammoniumthiocyanat } \\ 3,34 \%(\mathrm{v} / \mathrm{v}) & 3 \mathrm{M} \text { Natriumacetat } \mathrm{pH} 5,0 \\ 5 \%(\mathrm{v} / \mathrm{v}) & \text { Glycerin }\end{array}$

\subsubsection{Isolation genomischer pflanzlicher DNA}

Zur Isolation großer Mengen intakter genomischer DNA für die Herstellung einer „GenomeWalking“ Bibliothek (2.13.5.1) wurde eine modifizierte HexadecyltrimethylAmmoniumbromid- (CTAB-) Methode nach Rogers \& Bendich (1988) angewandt. Ca. $10 \mathrm{~g}$ gewaschene, frische junge Blätter ohne Mittelrippen wurden unter Zugabe einer Spatelspitze Polyclar AT (Serva Electrophoresis, Darmstadt) in flüssig- $\mathrm{N}_{2}$ sorgfältig gemörsert. Das Pulver wurde mitsamt dem $\mathrm{N}_{2}$ in ein 250 ml-Gefäß überführt und nach dem Verdampfen des Stickstoffs in $10 \mathrm{ml} 65^{\circ} \mathrm{C}$ warmem 2 x CTAB-Puffer aufgenommen. Wenn die Suspension zu dickflüssig war, wurde entsprechend mehr Puffer zugegeben. Nach Zusatz von $100 \mu \mathrm{g} / \mathrm{ml}$ Proteinase $\mathrm{K}$ erfolgte eine einstündige Inkubation bei $65{ }^{\circ} \mathrm{C}$ im Wasserbad unter gelegentlichem Schütteln.

Die Lösung wude zu gleichen Teilen auf vier Zentrifugenröhrchen aufgeteilt und das Gefäß mit $10 \mathrm{ml}$ Chloroform ausgespült, die anschließend ebenfalls gleichmäßig auf die 
Zentrifugenröhrchen aufgeteilt wurden. Durch kurzes Vortexen der Röhrchen erfolgte eine Chloroformextraktion, anschliessend wurde zur Phasentrennung $20 \mathrm{~min}$ bei $12.000 \mathrm{Upm}$ und $4{ }^{\circ} \mathrm{C}$ zentrifugiert. Die wässrigen Oberphasen wurden in frische Zentrifugenröhrchen überführt und mit jeweils 0,1 Vol. 10 \% CTAB-Lösung versetzt. Anschließend erfolgte eine erneute Extraktion mit 1 Vol. Chloroform und Phasentrennung für 20 min bei $12.000 \mathrm{Upm}$ und $4{ }^{\circ} \mathrm{C}$. Die wässrigen Oberphasen wurden abgenommen und $\mathrm{zu}$ je $1 \mathrm{ml}$ auf $2 \mathrm{ml}$ Eppendorfgefäße verteilt. Der CTAB-DNA Komplex wurde durch Zugabe von je $1 \mathrm{ml}$ CTAB-Präzipitationspuffer und 10 min Zentrifugation bei $13.000 \mathrm{Upm}$ und RT pellettiert. Die Sedimente wurden in je $200 \mu$ l Hochsalz-TE-Puffer $10 \mathrm{~min}$ bei $65{ }^{\circ} \mathrm{C}$ resuspendiert. Zur Fällung der DNA wurden je 2 Vol. (400 $\mu$ l) kalter 99,6 \% Ethanol zugefügt und $1 \mathrm{~h}$ bei -20 ${ }^{\circ} \mathrm{C}$ inkubiert. Es folgte eine 25 min Zentrifugation bei $13.000 \mathrm{Upm}$ und das Waschen des DNA-Pellets mit $150 \mu 175 \%$ Ethanol. Die Pellets wurden bei RT getrocknet und über Nacht bei $4{ }^{\circ} \mathrm{C}$ in je $100 \mu 1 \mathrm{H}_{2} \mathrm{O}$ resuspendiert. Zuletzt wurden alle Aliquots vereinigt und die DNA nochmal durch eine Phenol/Chloroform-Extraktion und anschließende Ethanol-Fällung (2.9.4, 2.9.5) gereinigt.

2 x CTAB-Puffer: $\quad 100 \mathrm{mM} \quad$ Tris/ $\mathrm{HCl} \mathrm{pH} 8,0$

$\begin{array}{ll}2 \%(\mathrm{w} / \mathrm{v}) & \text { CTAB } \\ 20 \mathrm{mM} & \text { EDTA } \\ 1,4 \mathrm{M} & \mathrm{NaCl} \\ 1 \%(\mathrm{w} / \mathrm{v}) & \mathrm{PVP}\end{array}$

10 \% CTAB-Lösung: $10 \%(w / v) \quad$ CTAB

$0,7 \mathrm{M} \quad \mathrm{NaCl}$

CTAB-Präzipitationspuffer:

$\begin{array}{ll}10 \mathrm{mM} & \text { Tris/HCl } \mathrm{pH} 8,0 \\ 1 \%(\mathrm{w} / \mathrm{v}) & \text { CTAB } \\ 1 \mathrm{mM} & \text { EDTA }\end{array}$

$\begin{array}{cl}\text { Hochsalz-TE-Puffer: } 10 \mathrm{mM} & \text { Tris/HCl pH 8,0 } \\ 1 \mathrm{mM} & \text { EDTA } \\ 1 \mathrm{M} & \mathrm{NaCl}\end{array}$

Alle Lösungen wurden autoklaviert. 


\subsubsection{Isolation bakterieller Plasmid-DNA}

\subsubsection{Plasmid-Mini-Präparation aus E. coli}

Zur Kontrolle potentiell positiver Kolonien auf Transformationsplatten (2.14.6) wurden von diesen mit einem sterilen Zahnstocher jeweils $3 \mathrm{ml}$ LB-Flüssigmedium mit einem entsprechenden Antibiotikum (2.2.3) angeimpft und über Nacht bei $37{ }^{\circ} \mathrm{C}$ im Reagenzglasschüttler inkubiert. Die gewachsenen Bakterienkulturen wurden auf zwei 1,5 ml Eppendorfgefäße aufgeteilt und die Zellen $1 \mathrm{~min}$ bei $13.000 \mathrm{Upm}$ pellettiert. Der MediumsÜberstand wurde dekantiert und eine Probe zunächst bei $-20{ }^{\circ} \mathrm{C}$ gelagert. Aus dem zweiten Bakterienpellet wurde Plasmid-DNA mittels des ,Triton-Boiling“-Protokolls isoliert:

Das Bakterienpellet wurde in $150 \mu$ l kaltem STEL-Puffer resuspendiert und die Zellen $30 \mathrm{sec}$ bei $100{ }^{\circ} \mathrm{C}$ lysiert. Durch anschließende Zentrifugation für $20 \mathrm{~min}$ bei $13.000 \mathrm{Upm}$ bildeten die Zellüberreste (inklusive genomischer DNA) ein zähes Pellet, das mit einem sterilen Zahnstocher entfernt wurde. Durch Zugabe von $180 \mu$ I Isopropanol und 5 minütige Zentrifugation bei $13.000 \mathrm{Upm}$ wurde die im Überstand befindliche Plasmid-DNA gefällt. Das DNA-Pellet wurde mit $500 \mu 175 \%$ Ethanol gewaschen und nochmals 5 min bei 13.000 Upm abzentrifugiert. Nach dem Abnehmen des Überstandes wurde die DNA 5 min bei $37^{\circ} \mathrm{C}$ getrocknet und danach in $50 \mu \mathrm{l} 0,2 \mathrm{mg} / \mathrm{ml}$ RNaseA resuspendiert und $15 \mathrm{~min}$ bei $37{ }^{\circ} \mathrm{C}$ inkubiert. $6 \mu \mathrm{l}$ der Plasmid-Präparation wurden für einen Restriktionsanalyse eingesetzt (2.14.1). Alternativ wurde zusammen mit der Übernachtkultur mit demselben sterilen Zahnstocher auch eine PCR-Probe angeimpft und die Kolonie über Kolonie-PCR (2.13.3) überprüft.

$\begin{array}{lll}\text { STEL-Puffer: } & 50 \mathrm{mM} & \text { Tris/HCl pH } 8.0 \\ & 8 \% \mathrm{w} / \mathrm{v} & \text { Saccharose } \\ & 5 \% \mathrm{v} / \mathrm{v} & \text { Triton X-100 } \\ & 50 \mathrm{mM} & \text { EDTA } \\ 0,5 \mathrm{mg} / \mathrm{ml} & \text { Lysozym }\end{array}$

Sofern ein durch Restriktionsanalyse oder Kolonie-PCR als positiv identifizierter Klon zusätzlich ansequenziert werden sollte, war die Reinheit der „Triton-Boiling“ PlasmidPräparation nicht ausreichend. Aus dem zuvor eingefrorenen zweiten Bakterienpellet wurde dann Plasmid-DNA mit dem Quiprep Spin Miniprep Kit (Quiagen, Hilden) nach Herstellerangaben isoliert, wobei die DNA statt mit dem beigefügten Salzpuffer mit $\mathrm{H}_{2} \mathrm{O}$ 
eluiert wurde. Der Kit basiert auf der Birnboim-Methode (Birnboim \& Doly 1979), bei der die Zellen alkalisch lysiert werden, so daß genomische DNA denaturiert, während die superspiralisierte Plasmid-DNA intakt bleibt. Bei der folgenden Neutralisation verklumpt die genomische DNA mit den übrigen Zelltrümmern, Plasmide bleiben im Überstand.

\subsubsection{Plasmid-Maxi-Präparation aus E. coli}

Um größere Mengen sauberer Plasmid-DNA für präparative Restriktion, in vitro-Translation (2.15) o.ä. zu erhalten, wurden von einer Bakterienkolonie $50 \mathrm{ml}$ LB-Flüssigmedium mit entsprechendem Antibiotikum (2.2.3) angeimpft und über Nacht bei $37{ }^{\circ} \mathrm{C}$ im Schüttler inkubiert. Die gewachsene Kultur wurde auf 4 sterile $12,5 \mathrm{ml}$ Schraubdeckelröhrchen aufgeteilt und die Zellen 10 min bei 4.500 Upm pellettiert. Zur Plasmid-Präparation diente der „E.Z.N.A. Plasmid Miniprep Kit II“ (PeqLab, Erlangen). Die DNA wurde mit $120 \mu 1 \mathrm{H}_{2} \mathrm{O}$ in zwei Zentrifugationsschritten $(80 \mu \mathrm{l}+40 \mu \mathrm{l})$ eluiert.

\subsubsection{Plasmid-Mini-Präparation aus Agrobacterium tumefaciens}

Um die Transformation von Agrobakterien (2.14.8) zu überprüfen, mußten aus diesen die Plasmide reisoliert und anschliessend nochmals in E. coli transformiert (2.14.6) und dort vermehrt werden, da die DNA-Ausbeute aus Agrobacterium Plasmid-Präparationen i.d.R. zu gering für eine Sequenzierung ist. Zur Plasmid-Isolation aus A. tumefaciens wurde ein modifiziertes Protokoll nach Le Gouill et al. (1994) verwendet.

Eine 3 ml-Übernachtkultur der gewünschten Agrobakterien-Kolonie wurde in YEB-Medium mit entsprechenden Antibiotika (2.2.3) angezogen, auf zwei 1,5 ml Eppendorfgefäße verteilt und die Zellen $1 \mathrm{~min}$ bei $13.000 \mathrm{Upm}$ sedimentiert. Der Überstand wurde verworfen und das Pellet in $100 \mu$ Lösung I resuspendiert. Durch Zugabe von $200 \mu 1$ Lösung II wurden die Zellen lysiert. Anschließend erfolgte die Zugabe von $200 \mu$ l Chloroform und eine 5 minütige Inkubation bei RT. Zuletzt wurden $150 \mu$ Lösung III hinzugefügt, gevortext und 10 min bei 13.000 Upm zur Phasentrennung zentrifugiert. Die obere wässrige Phase mit der PlasmidDNA wurde abgenommen, mit 1 Vol. Phenol/Chloroform (2.9.5) versetzt, erneut gevortext und zur Phasentrenung 10 min zentrifugiert. Die obere Phase wurde abgenommen und die DNA mit 2 Vol. kaltem 99,6 \% Ethanol gefällt. Nach einer 5 min Zentrifugation bei 13.000 Upm wurde das DNA-Pellet mit $150 \mu 1 \quad 75 \%$ Ethanol gewaschen, erneut 5 min abzentrifugiert, ca. $15 \mathrm{~min}$ bei RT getrocknet und dann in $50 \mu 1 \mathrm{H}_{2} \mathrm{O}$ resuspendiert. Die Plasmid-DNA wurde durch Restriktionsanalyse (2.14.1) oder PCR (2.13.2) überprüft und 
gegenbenenfalls zur Retransformation von E. coli eingesetzt, wenn eine Sequenzierung erwünscht war.

Lösung I: $\quad 25 \mathrm{mM} \quad$ Tris/ $\mathrm{HCl} \mathrm{pH} 8,0$

$50 \mathrm{mM} \quad$ Glukose

$10 \mathrm{mM} \quad$ EDTA

Lösung II: $\quad 0,2 \mathrm{M} \quad \mathrm{NaOH}$

$1 \%(\mathrm{w} / \mathrm{v}) \quad$ SDS

Lösung III: $\quad 3 \mathrm{M} \quad$ Kaliumacetat $\mathrm{pH} 4,8$

Alle Lösungen wurden autoklaviert.

\subsubsection{Ethanolfällung von DNA oder RNA}

Zur Aufkonzentrierung von Nukleinsäurelösungen wurde eine Fällung der DNA oder RNA durchgeführt. Hierzu wurden 0,1 Vol. 3 M Natriumacetat pH 6,0 und 2,5 Vol. 99,6 \% Ethanol zugegeben und die Nukleinsäuren bei $-20{ }^{\circ} \mathrm{C}$ für mindestens eine Stunde gefällt. Nach 10 min Zentrifugation bei $13.000 \mathrm{Upm}$ wurde das Pellet mit $75 \%$ Ethanol gewaschen, erneut abzentrifugiert (5 min $13.000 \mathrm{Upm}$ ), etwa $15 \mathrm{~min}$ bei $37^{\circ} \mathrm{C}$ getrocknet und in einem geringeren Volumen $\mathrm{H}_{2} \mathrm{O}$ oder Puffer resuspendiert.

\subsubsection{Phenol/Chloroform-Reinigung von DNA oder RNA}

Um DNA- oder RNA-Lösungen von Protein- oder Polysaccharid-Rückständen zu reinigen wurde die Lösung mit 1 Vol. Phenol:Chloroform (1:1) versetzt, gevortext und zur Phasentrennung für $5 \mathrm{~min}$ in einer Tischzentrifuge zentrifugiert. Denaturierte Proteine sammeln sich dabei an der Phasengrenze. Dieser Arbeitsschritt wurde je nach Bedarf 1-3 mal wiederholt. Die wässrige Oberphase wurde abgenommen und mit 1 Vol. Chloroform gründlich gemischt. Zur Phasentrennung wurde wiederum für $5 \mathrm{~min}$ zentrifugiert. Die wässrige Oberphase wurde in ein neues Reaktionsgefäß überführt und die Nukleinsäuren mit Ethanol gefällt (2.9.4.).

Herstellung von Phenol:Chloroform (1:1): $100 \mathrm{~g}$ Phenol wurden in $100 \mathrm{ml} 100 \mathrm{mM}$ Tris/HCl pH 8 gelöst. Anschließend wurde die (wassergesättigte) Phenolphase von der wässrigen Phase 
in einem Scheidetrichter getrennt und so lange mit $100 \mathrm{mM}$ Tris/ $\mathrm{HCl} \mathrm{pH} 8$ ausgeschüttelt, bis sie pH 8 erreicht hatte. Danach wurde 1 Vol. Chloroform zugegeben, gründlich geschüttelt und zur Phasentrennung $10 \mathrm{~min}$ bei $4.000 \mathrm{Upm}$ zentrifugiert (Centrifuge $5810 \mathrm{R}$; Eppendorf Gerätebau, Hamburg). Verwendet wurde die untere, phenolische Phase.

\subsubsection{Bestimmung von Nukleinsäurekonzentrationen}

Zur Bestimmung von Nukleinsäurekonzentrationen standen zwei Methoden zur Verfügung. Bei beiden kann eine Kontamination mit Polysacchariden zu einer Überschätzung der DNAbzw. RNA-Menge führen. Zum einen wurde $1 \mu$ Aliquot der Lösung in einer AgaroseGelelektrophorese (2.10.1) aufgetrennt und die gewünschte Bande in ihrer Intensität mit einer Bande des verwendeten $\lambda / P s t \mathrm{I}-$ Markers verglichen. Aus der Größe der betreffenden Markerbande, der Gesamtgröße des $\lambda$-Genoms (50 kb) und der aufgetragenen Gesamtmenge an $\lambda$-DNA $(1 \mu \mathrm{g})$ konnte die DNA-Menge abgeschätzt werden. Diese Methode ist ungenauer und wurde für schnelle Abschätzungen der DNA- bzw. RNA-Menge verwendet. Eine genauere Quantifizierung erlaubt die UV-photometrische Bestimmung:

Doppelproben von $1 \mu 1$ Nukleinsäurelösung wurden in je $600 \mu 1$ Wasser verdünnt und die Extinktion bei 230, 260 und $280 \mathrm{~nm}$ gemessen (Uvikon 932; Kontron, Mailand, Italien). Die Quotienten der Extinktionswerte $(230 \mathrm{~nm} / 260 \mathrm{~nm}$ und $260 \mathrm{~nm} / 280 \mathrm{~nm})$ stellen ein Maß für die Verunreinigung der Lösung mit Polysacchariden bzw. Proteinen dar. Idealerweise sollten sie zwischen 1,8 und 2,0 liegen. Die Nukleinsäurekonzentrationen wurden nach folgenden Formeln berechnet, die für doppelsträngige DNA und einzelsträngige RNA gelten (Sambrook et al. 1989):

$$
\begin{aligned}
& \text { RNA }[\mu \mathrm{g} / \mathrm{ml}]=\mathrm{E}_{260} \times 42 \times \mathrm{V}_{\text {Küvette }} \times \mathrm{V}_{\text {Aliquot }}{ }^{-1} \\
& \text { DNA }[\mu \mathrm{g} / \mathrm{ml}]=\mathrm{E}_{260} \times 50 \times \mathrm{V}_{\text {Küvette }} \times \mathrm{V}_{\text {Aliquot }}{ }^{-1}
\end{aligned}
$$

\subsection{Gelelektrophoretische Auftrennung von Nukleinsäuren}

\subsubsection{Agarose-Gelelektrophorese von Nukleinsäuren}

Die Auftrennung von DNA oder RNA durch TEA-Agarose-Gelelektrophorese diente zur Quantifizierung (2.9.6) und Reinheitsüberprüfung, Fragment-Größenbestimmung, Kontrolle von Restriktionsverdau (2.14.1), Detektion von PCR-Produkten (2.13.2) und zur gezielten Isolierung einzelner Fragmente. Im letzteren Fall mußte die entsprechende Bande aus dem 
Gel ausgeschnitten und die DNA aus der Agarosematrix eluiert werden (2.10.2). Die Gele bestanden aus $1 \%(\mathrm{w} / \mathrm{v})$ Agarose (Invitrogen, Karlsruhe) in 1 x TEA-Puffer, die durch Aufkochen geschmolzen und bis zum Gießen der Gele bei $60{ }^{\circ} \mathrm{C}$ aufbewahrt wurde. Für die Gelelektrophorese von RNA wurden die Gelkammer und Gießvorrichtung $1 \mathrm{~h}$ in $1 \%$ SDS eingelegt, um RNasen zu inaktivieren. Vor dem Probenauftrag wurde den Proben jeweils 0,2 Vol. „loading dye“ zugesetzt. Als Größenstandard diente mit PstI verdaute $\lambda$-DNA. Die Elektrophorese erfolgte bei $70 \mathrm{~V}$ in 1 x TEA-Puffer. Anschließend wurden die Gele etwa 5 min in $10 \mu \mathrm{g} / \mathrm{ml}$ Ethidiumbromidlösung gefärbt und ebenso lange in $\mathrm{H}_{2} \mathrm{O}$ entfärbt. Die DNABanden konnten dann an einem UV-Transilluminator sichtbar gemacht und photographiert werden (IDA; Raytest, Straubenhardt).

50 x TEA-Puffer: $\quad 2 \mathrm{M} \quad$ Tris/Acetat $\mathrm{pH} 8,3$

$100 \mathrm{mM} \quad$ EDTA

„loading dye“: $\quad 50 \%(\mathrm{v} / \mathrm{v}) \quad$ Glycerin

$10 \mathrm{mM} \quad \mathrm{NaPO}_{4} \mathrm{pH} \mathrm{7,0}$

$0,4 \%(\mathrm{w} / \mathrm{v})$ Orange $\mathrm{G}$

\subsubsection{Elution von DNA-Fragmenten aus Agarosegelen}

Häufig ist es notwendig, ein bestimmtes DNA-Fragment von anderen, z.B. PCR-Produkten (2.13.2) oder Fragmenten eines Restriktionsverdaus (2.14.1), zu trennen, um es in einer Ligation (2.14.4) oder als Sonde in einer Hybridisierung (2.11) einzusetzen. Dazu wurden die DNA-Fragmente in einem präparativen Agarosegel aufgetrennt, das besonders dick gegossen war, so daß die Geltaschen das Auftragen von bis zu $50 \mu$ l Probenvolumen erlaubten. Die gewünschte Bande wurde aus dem Ethidiumbromid-gefärbten Gel unter UV-Licht ausgeschnitten und die DNA aus dem Gel eluiert. Dazu wurde der „QIAquick Gel Extraction Kit“ (Qiagen, Hilden) verwendet. Dieser Kit beruht auf dem Schmelzen der Agarose bei relativ niedriger Temperatur $\left(50{ }^{\circ} \mathrm{C}\right)$ in einem Puffer, der ein chaotropes Salz enthält. Anschließend wird die DNA bei hoher Salzkonzentration selektiv an eine Kieselgel-Säule gebunden. Schließlich wurde die DNA mit $25 \mu \mathrm{H}_{2} \mathrm{O}$ eluiert und durch AgaroseGelelektrophorese von $1 \mu 1$ Eluat quantifiziert (2.9.6). 


\subsection{Hybridisierungsmethoden}

Der spezifische Nachweis von Nukleinsäuresequenzen erfolgt durch die Hybridisierung eines radioaktiv markierten DNA-Fragmentes (Sonde) an die betreffende Sequenz. Je nach Hybridisierungsbedingunen kann dieser Nachweis mit höherer oder niedriger Spezifität (Stringenz) erfolgen. Wenn die gesuchte Sequenz dabei in einem Nukleinsäuregemisch vorliegt, z.B. eine bestimmte mRNA in einer Gesamt-RNA Probe, so kann das Gemisch zunächst in einer Agarose-Gelelektrophorse aufgetrennt und in dieser Form durch Übertragung auf eine Nylonmembran immobilisiert werden. Dies wird als Blotten und ein RNA Gel-Blot als Northern Blot bezeichnet. Der Northern Blot ermöglicht u.a. die Bestimmung der Häufigkeit einer bestimmten mRNA Spezies in unterschiedlichen Geweben.

\subsubsection{Radioaktive Markierung von DNA-Fragmenten („Random Priming“)}

Die radioaktive Markierung von DNA-Fragmenten als Hybridisierungs-Sonden erfolgte mit dem „Hexalabel DNA Labeling Kit“ (MBI, Vilnius, Litauen). Hierbei werden an das hitzedenaturierte Fragment Hexanukleotide mit zufälliger Sequenz gebunden, die anschließend dem großen proteolytischen Fragment der DNA Polymerase I aus E. coli (Klenow-Fragment) als Primer für eine Auffüllreaktion dienen (siehe auch 2.14.2). Dem Enzym wird zunächst ein dNTP-Gemisch als Substrat zur Verfügung gestellt, daß dCTP nur in radioaktiv markierter Form enthält. Durch Verwendung einer mutierten Version des Klenow Fragments ohne $3^{\prime} \rightarrow 5^{\prime}$ Exonukleaseaktivität (exo $\left.{ }^{-}\right)$wird verhindert, daß bereits eingebaute Radionukleotide durch das Korrekturlesen der Polymerase wieder entfernt werden. Die als Sonden verwendeten DNA-Fragmente wurden zuvor aus Plasmiden ausgeschnitten (2.14.1), über eine Gelelution gereinigt (2.10.2) und durch Agarose-Gelelektrophorese quantifiziert (2.9.6).

100-200 ng DNA-Fragment wurden mit $10 \mu 1$ Hexanukleotiden gemischt und auf $43 \mu 1$ mit $\mathrm{H}_{2} \mathrm{O}$ aufgefüllt. Dieser Ansatz wurde für 5 min bei $100{ }^{\circ} \mathrm{C}$ denaturiert und dann auf Eis gestellt. Nun wurden $3 \mu \mathrm{l}$ Mix C (0,33 mM dNTPs ohne dCTP), $30 \mu \mathrm{Ci}(3 \mu \mathrm{l}) \alpha^{32} \mathrm{P}$-dCTP und $1 \mu 1(5 \mathrm{U})$ Klenow-Fragment exo ${ }^{-}$zugegeben. Dieser Ansatz wurde für 10 min bei $37{ }^{\circ} \mathrm{C}$ inkubiert. Dann wurden $4 \mu \mathrm{l}$ vollständiger dNTP-Mix $(10 \mathrm{mM})$ zugegeben um vorzeitige Kettenabbrüche durch dCTP-Mangel zu vermeiden und nochmals 5 min bei $37^{\circ} \mathrm{C}$ inkubiert. Die Reaktion wurde durch Zugabe von $1 \mu 1$ 0,5 M EDTA pH 8,0 gestoppt.

Die Trennung der markierten Sonde von den nicht eingebauten Nukleotiden erfolgte durch einen „ProbeQuant G-50” Kit (Amersham Biosciences, Freiburg). Die freien Desoynukleotide 
werden dabei an eine G-50 Sephadex Säule gebunden, wogegen die doppelsträngige DNASonde sich im Eluat findet. Das Säulenmaterial lag fertig äquilibriert vor und brauchte nur durch Vortexen aufgeschüttelt und anschließend durch 1 min Zentrifugation bei 3.000 Upm sedimentiert und getrocknet zu werden, dann konnte die Probe aufgetragen und in einem einzelnen Zentrifugationsschritt (2 min $3.000 \mathrm{Upm}$ ) gereinigt werden. Von der gereinigten Sonde wurde ein $1 \mu$ Aliquot im Szintillationszähler (Packard Tri-Carb 1900 TR; PerkinElmer Life Sciences, Jügesheim) gemessen. Die Gesamtaktivität der Sonde sollte größer als 5 x $10^{6} \mathrm{cpm}$ sein. Bis zur Hybridisierung wurde die Sonde bei $-20{ }^{\circ} \mathrm{C}$ gelagert.

\subsubsection{Northern Blot}

Zur gelelektrophoretischen Auftrennung von RNA für einen Northern Blot wurden spezielle Formaldehyd-haltige Agarosegele verwendet. Formaldehyd denaturiert sowohl die RNASekundärstruktur, so daß die RNA-Moleküle ihrer Größe nach aufgetrennt werden, als auch eventuell vorhandene RNasen.

Für ein Formaldehydgel wurden $3 \mathrm{~g}$ Agarose in $150 \mathrm{ml} \mathrm{H}_{2} \mathrm{O}$ aufgeschmolzen und, nach Abkühlung auf $70{ }^{\circ} \mathrm{C}, 33 \mathrm{ml}$ Formaldehyd und $20 \mathrm{ml} 10$ x MEN Puffer zugegeben. Der gesamte Ansatz wurde zum Gießen eines einzigen Gels von ca. 15 x $15 \mathrm{~cm}$ eingesetzt. Je Geltasche wurden 15-20 $\mu \mathrm{g}$ gesamt-RNA aufgetragen. Die Geltaschen faßten dabei ein Volumen von $90 \mu 1$, so daß je nach RNA-Konzentration der im Folgenden beschriebene Probenansatz unter Beibehaltung der Volumenverhältnisse an die RNA-Konzentration angepaßt werden konnte. Um das Probenvolumen in allen Geltaschen gleich zu halten, wurden dabei alle Proben durch Auffüllen mit $\mathrm{H}_{2} \mathrm{O}$ oder Aufkonzentration der RNA durch eine Ethanolfällung (2.9.4) an die jeweils niedrigst- oder höchstkonzentrierte Probe angeglichen. Die eingesetzte RNA wurde vor dem Pipettieren $5 \mathrm{~min}$ bei $65^{\circ} \mathrm{C}$ resuspendiert, um eine möglichst hohe Homogenität der Lösung zu erreichen.

$\begin{array}{lll}\text { Probenansatz: } & 9 \mu \mathrm{l} & \text { RNA } \\ & 12 \mu \mathrm{l} & \text { deionisiertes Formamid } \\ 3 \mu \mathrm{l} & \text { Formaldehyd } \\ 3 \mu \mathrm{l} & \text { Blaumarker } \\ 3 \mu \mathrm{l} & 10 \times \text { MEN Puffer }\end{array}$


Blaumarker: Bromphenol-Blau-Stammlösung:Ethidiumbromid (10 mg/ml) (17:3)

Bromphenol-Blau-Stammlösung: 0,25 \% (w/v) Bromphenol-Blau, 0,25 \% (w/v) Xylen Zyanol FF, 40 \% (w/v) Saccharose

Die Proben wurden zur Denaturierung der RNA 5 min bei $65{ }^{\circ} \mathrm{C}$ inkubiert und dann auf das Gel aufgetragen. Anschließend wurden die Geltaschen mit 1 x MEN Puffer gefüllt, der auch als Laufpuffer diente. Dazu wurde die Gelkammer mit ca. $600 \mathrm{ml} 1$ x MEN gerade bis zur Geloberkante gefüllt, so daß die Geloberfläche trocken blieb. Die Gelelektrophorese wurde für ca. 2,5 h bei $130 \mathrm{~V}$ durchgeführt. Dabei mußte bei Verwendung von zwei Reihen Geltaschen beachtet werden, daß Ethidiumbromid sich entgegengesetzt zur RNA im Gel bewegt. Das Fotografieren des Gels (DIANA III; Raytest, Straubenhardt) zur Überprüfung der Auftrennung und Quantifizierung der aufgetragenen RNA mußte deshalb durchgeführt werden, bevor das Ethidiumbromid aus der einen Geltaschenreihe die Proben in der anderen Gelhälfte vollkommen überdeckte.

Nach der Elektrophorese wurden die Taschen des Gels abgeschnitten und das Gel gegebenenfalls in zwei Hälften zerschnitten, wenn zwei Reihen Geltaschen vorhanden waren. Dann wurde das Gel luftblasenfrei mit der Oberseite nach unten auf ein mit 20 x SSC angefeuchtetes Stück Whatman 3 MM Papier gelegt, dessen Enden in 20 x SSC tauchten. Auf das Gel wurde die zuvor in $\mathrm{H}_{2} \mathrm{O}$ angefeuchtete und dann 20 min in 20 x SSC äquilibrierte Nylonmembran (Hybond XL; Amersham Biosciences, Freiburg) ebenfalls luftblasenfrei aufgelegt. Eine Ecke der Membran war zur späteren Orientierung abgeschnitten worden. Auf die Membran kamen noch luftblasenfrei 3 Lagen mit 20 x SSC angefeuchtetes Whatman 3 MM Papier, dann wurde rings um das Gel mit Zellophanfolie oder Parafilm ausgelegt um zu verhindern, daß Blotpuffer durch herabhängendes Papier am Gel vorbei gesaugt werden konnte. Zuletzt wurden auf den Blotaufbau ca. $5 \mathrm{~cm}$ hoch Papierhandtücher gleichmäßig aufgeschichtet und mit einem Gewicht von ca. $2 \mathrm{~kg}$ beschwert. Der Transfer der RNA auf die Nylonmembran erfolgte über Nacht.

Am folgenden Tag wurde der Blot abgebaut und die Membran 5 min in 2 x SSC gewaschen um eventuelle Gelreste zu entfernen. Die RNA wurde durch eine $10 \mathrm{sec}$ UV-Belichtung in einem UV-Fixierungsofen (Bio-Link BLX; Biometra, Göttingen) an der Membran fixiert und der Transfer unter UV Licht überprüft. Zur Absättigung der freien Bindungsplätze auf der Nylonmembran wurde dann $45 \mathrm{~min}$ bei $65^{\circ} \mathrm{C}$ in Hybridisierungspuffer prähybridisiert. Danach erfolgte die Zugabe der zuvor hergestellten Sonde (2.11.1), die 5 min bei $95{ }^{\circ} \mathrm{C}$ denaturiert und dann direkt in den Hybridisierungspuffer pipettiert wurde. Die Hybridisierung 
erfolgte bei $65{ }^{\circ} \mathrm{C}$ über Nacht. Danach wurde zweimal 20 min in $2 \times$ SSC, 0,1\% SDS und einmal $20 \mathrm{~min}$ in $0,5 \mathrm{x}$ SSC, $0,1 \%$ SDS gewaschen. Der letzte Waschschritt war durch die geringere Salzkonzentration im Puffer stringent, d.h. die Sonde sollte nur an mRNAs mit hoher Sequenzhomologie gebunden bleiben. Von der Prähybridisierung bis zum Waschen der Membran wurden alle Arbeitsschritte in verschraubbaren Glasröhren mit ca. $4 \mathrm{~cm}$ Durchmesser in einem Hybridisierungsofen (OV5; Biometra, Göttingen) durchgeführt.

Nach dem letzten Waschen wurde die Membran luftgetrocknet, in eine Plastiktüte eingeschweißt und ein Phosphoimager-Screen mit der lichtempfindlichen Seite auf ihre RNASeite aufgelegt. Je nach Höhe der Restradioaktivität wurde der Screen für $2 \mathrm{~h}$ bis über Nacht exponiert. Die Signale wurden mit einem Fujifilm FLA-3000 Phosphoimager (Fuji Photo Film, Düsseldorf) detektiert und mit den Bildbearbeitungsprogrammen BASReader und Aida Image Analyzer v3.24 (beide Raytest, Straubenhardt) ausgewertet.

10 x MEN Puffer:

$$
\begin{array}{ll}
200 \mathrm{mM} & \text { MOPS } \\
80 \mathrm{mM} & \text { Natriumacetat } \\
10 \mathrm{mM} & \text { EDTA } \\
\text { pH 7,0 mit NaOH einstellen }
\end{array}
$$

20x SSC: $\quad 3 \mathrm{M} \quad \mathrm{NaCl}$

0,3 M Natriumcitrat $\mathrm{pH} 7,0$

Hybridisierungspuffer:

$\begin{array}{ll}5 \mathrm{x} & \text { SSC } \\ 5 \mathrm{x} & \text { Denhardt's }\end{array}$

Denhardt's (100 x):

$\begin{array}{ll}2 \%(\mathrm{w} / \mathrm{v}) & \text { Ficoll } 400 \\ 2 \%(\mathrm{w} / \mathrm{v}) & \text { PVP } \\ 2 \%(\mathrm{w} / \mathrm{v}) & \text { BSA (entfettet) } \\ 0,5 \%(\mathrm{w} / \mathrm{v}) & \text { SDS }\end{array}$




\subsection{2 cDNA-Synthese}

Die reverse Transkription (RT) von mRNA-Vorlagen in cDNA („copy DNA”) Kopien ermöglicht es, indirekt RNA als Ausgangspunkt einer PCR (2.13.2) zu verwenden (= RTPCR) und so bestimmte mRNA-Spezies spezifisch nachzuweisen oder die transkribierte Sequenz eines Gens frei von Introns zu erhalten. Ein an das PolyA-Ende von eukaryontischen mRNA bindender $\mathrm{dT}_{20}$-Primer dient dabei als unspezifischer Primer für die Reverse Transcriptase:

$3 \mu \mathrm{g}$ RNA und $1 \mu 1 \mathrm{dT}_{20}$-Primer $(50 \mu \mathrm{M})$ wurden mit $\mathrm{H}_{2} \mathrm{O}$ auf $12,8 \mu 1$ aufgefüllt und RNASekundärstrukturen durch Inkubation für $5 \mathrm{~min}$ bei $65{ }^{\circ} \mathrm{C}$ denaturiert. Die Probe wurde wieder auf Eis gestellt und $2 \mu 110 \mathrm{mM}$ dNTPs, $4 \mu 15$ x RT-Puffer, 0,5 $\mu 1$ RNase-Inhibitor und 0,7 $\mu 1$ M-MuLV-Reverse Transcriptase (alle MBI, Vilnius, Litauen) zugegeben. Die RT-Reaktion erfolgte für $1 \mathrm{~h}$ bei $37^{\circ} \mathrm{C}$. Anschließend wurde die Reverse Transcriptase $5 \mathrm{~min}$ bei $95{ }^{\circ} \mathrm{C}$ inaktiviert. Das Produkt der RT-Reaktion ist nur ein einzelner DNA-Strang (Erststrang). Die Erststrang-cDNA reicht aber als Matrize für eine RT-PCR aus, bei der dann Primer für beide Polymerisationsrichtungen vorhanden sind, so daß der zweite DNA-Strang synthetisiert werden kann. Je 1-4 $\mu 1$ RT-Ansatz wurden als Matrize in einer PCR eingesetzt.

\subsection{Auf der Polymerase-Kettenreaktion basierende Methoden}

Das Prinzip der Polymerase-Kettenreaktion (PCR, Mullis \& Faloona 1987) ist die Verwendung von hitzestabilen DNA-Polymerasen für einen zyklischen Reaktionsablauf, in dem eine DNA-Vorlage (Matrize) immer wieder thermisch denaturiert und mit sequenzspezifischen Oligonukleotiden (Primern) hybridisiert wird (Annealing), die der Polymerase als Startpunkt für die Synthese des komplementären DNA-Stranges (Elongation) dienen. Da die DNA dabei exponentiell vervielfacht wird ist es im Prinzip möglich, aus einem einzigen Ausgansmolekül innerhalb von 25-35 Reaktionszyklen mehr als $10^{6}$ Kopien herzustellen. Über die Basenpaarung der Primer mit der Vorlage ist dieser Vorgang außerordentlich spezifisch und es wird so möglich, extrem seltene Moleküle, wie bestimmte mRNA-Spezies (eigentlich cDNA-Spezies) gezielt nachzuweisen und analysierbare Mengen davon herzustellen. 


\subsubsection{Kriterien bei der Ableitung von synthetischen Oligonukleotiden (Primern)}

Bei der Auswahl von Primern für die PCR muß zwischen spezifischen und degenerierten Primern unterschieden werden. Spezifische Primer können immer dann benutzt werden, wenn die genaue Sequenz der zu amplifizierenden DNA bekannt ist. Sie sollten aus 20-30 Nukleotiden bestehen, einen ausgewogenen G/C-Gehalt von 40-60\% besitzen und mit einem $\mathrm{G}$ oder $\mathrm{C}$ enden. Zudem sollten die Primer, die jeweils zusammen in einer PCR eingesetzt werden, eine ähnliche Schmelz-Temperatur haben. Dies ist die Temperatur, bei der sich die Primer von der Ziel-DNA ablösen. Sie kann nach folgender Formel berechnet werden:

$$
\mathrm{T}_{\mathrm{m}}=69,3+0,41 \times[\% \mathrm{G} / \mathrm{C}]-650 / \text { Primerlänge }
$$

In der Regel wurden Primer so gewählt, daß sie eine Schmelztemperatur zwischen 55 und 63 ${ }^{\circ} \mathrm{C}$ hatten. Außerdem mußten die Primer so beschaffen sein, daß sie eine geringe Tendenz zur Bildung von Sekundärstrukturen und zur Hybridisierung miteinander besaßen. Dies wurde mit den Computerprogrammen „foldrna“ und „bestfit“ des Wisconsin Package der Genetics Computer Group (GCG), Madison, USA getestet.

Degenerierte Primer dienen zur Amplifikation von noch nicht bekannten DNA-Sequenzen, von denen bereits verwandte Sequenzen bekannt sind, z.B. weitere Mitglieder einer Genfamilie, oder Homologe aus anderen Pflanzenarten. Ihre Sequenz muß aus konservierten Regionen proteinkodierender DNA-Bereiche abgeleitet werden, da nur dort eine ausreichend große Ähnlichkeit zwischen den bereits bekannten und den neuen DNA-Sequenzen zu erwarten ist. Zunächst mußten dazu die bereits bekannten Aminosäure-Sequenzen von AAPProteinen miteinander verglichen werden, um konservierte Regionen $\mathrm{zu}$ finden. Aus der Aminosäuresequenz dieser konservierten Regionen wurde dann eine Nukleotidsequenz rückübersetzt. Da der genetische Code degeneriert ist, ist diese Rückübersetzung selbst dann nicht eindeutig, wenn die betreffende Aminosäure-Sequenz zu $100 \%$ konserviert ist. Es bleiben in der Regel einige Positionen im Primer, an denen 2, 3 oder 4 verschiedene Nukleotide stehen können (= degenerierter Primer). 7-8 zu 100 \% konservierte Aminosäuren sind notwendig, um einen Primer von 21-24 Nukleotiden Länge abzuleiten. Außerdem sollten diese im günstigsten Fall Aminosäuren mit einem geringen Degenerationsgrad des genetischen Codes beinhalten (z.B. Methionin, Tryptophan) und nicht die von jeweils sechs Basentripletts kodierten Aminosäuren Arginin, Leucin oder Serin. Im Prinzip sollten für einen degenerierten Primer dieselben Kriterien gelten wie oben für spezifische Primer angeführt, aufgrund der begrenzten Anzahl geeigneter konservierter Aminosäure-Sequenzen ist es aber 
in der Regel nicht möglich, diese Vorgaben einzuhalten. Außerdem kann die Schmelztemperatur wegen der variablen Nukleotidpositionen nur näherungsweise berechnet werden. An diesen Postionen kann entweder eines der in Frage kommenden Nukleotide zufällig eingebaut werden, so daß der degenerierte Primer eigentlich ein Primergemisch darstellt. Oder variable Nukleotidpositionen werden durch Inosin (I) ersetzt, das mit allen vier Basen der DNA paaren kann. Die in dieser Arbeit verwendeten degenerierten Primer sind am Ende mit einem „i” bezeichnet, wenn es sich um Inosin-Primer handelt (Tab 2.1). Alle verwendeten Primer wurden von der Firma MWG, Göttingen bezogen mit Ausnahme der nicht für die PCR verwendeten Oligonukleotide ANTI-1 und ANTI-2 (Carl Roth, Karlsruhe) $(2.17 .1)$

Tab. 2.1: Oligonukleotidprimer. $\mathrm{I}=$ Inosin; $\mathrm{M}=\mathrm{A}, \mathrm{C} ; \mathrm{N}=\mathrm{A}, \mathrm{C}, \mathrm{G}, \mathrm{T}$ (beliebige Base); $\mathrm{R}=$ A, $\mathrm{G}$ (Purinbase); $\mathrm{S}=\mathrm{G}, \mathrm{C} ; \mathrm{W}=\mathrm{A}, \mathrm{T} ; \mathrm{Y}=\mathrm{C}, \mathrm{T}$ (Pyrimidinbase).

\begin{tabular}{|c|c|c|}
\hline Bezeichnung & Sequenz $\left(5^{\prime} \rightarrow 3^{\prime}\right)$ & Verwendung \\
\hline \multicolumn{3}{|c|}{ allgemeine Primer } \\
\hline 5' RACE & \begin{tabular}{|lllllllll} 
GGC & CAC & GCG & TCG & ACT & AGT & ACG & GGI & IGG \\
GII & GGG & IIG & & & \\
\end{tabular} & 5' RACE Ankerprimer \\
\hline AP & 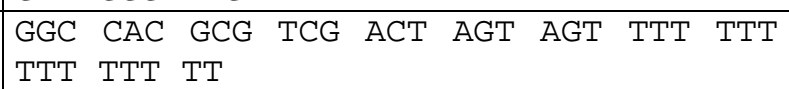 & 3' RACE Ankerprimer \\
\hline $\mathrm{dT}_{20}$ & \begin{tabular}{|l} 
TTT TTT TTT TTT TTT TTT TT \\
\end{tabular} & Primer für Reverstranskription \\
\hline PKecgus3 & CCG GCT TTC TTG TAA CGC & $\begin{array}{l}\text { Test-PCR von Promotor-GUS- } \\
\text { Konstrukten }\end{array}$ \\
\hline M13 rev & AGC GGA TAA CAA TTT CAC ACA GGA & Sequenzierungsprimer \\
\hline pMal-seqf & CCG CAG ATG TCC GCT TTC TGG & $\begin{array}{l}\text { Sequenzierungsprimer für pMal-c2X } \\
\text { Konstrukte }\end{array}$ \\
\hline T7 Promotor & TAA TAC GAC TCA CTA TAG GG & Sequenzierungsprimer \\
\hline T7 Terminator & GCT AGT TAT TGC TCA GCG G & Sequenzierungsprimer \\
\hline UAP & GGC CAC GCG TCG ACT AGT AG & 3’ RACE Adapterprimer \\
\hline \multicolumn{3}{|c|}{ genspezifische Primer für Ubiquitin } \\
\hline ubifor & ATG CAG ATY TTT GTG AAG AC & RT-PCR-Positivkontrolle \\
\hline ubirev & ACC ACC ACG RAG ACG GAG & RT-PCR-Positivkontrolle \\
\hline \multicolumn{3}{|c|}{ degenerierte Primer } \\
\hline CKAA1i & GGI GTI YTI WSI YTI GCI TGG GC & Identifizierung von BnAAPs \\
\hline CKAA2 & GGN AAR MGN AAY TAY ACN TAY ATG & Identifizierung von BnAAPs \\
\hline CKAA2i & GGI AAR MGI AAY TAY ACI TAY ATG & Identifizierung von BnAAPs \\
\hline CKAA4ri & CCR AAI GCI GCR TAI CC & Identifizierung von BnAAPs \\
\hline \multicolumn{3}{|c|}{ genspezifische Primer für $B n A A P 1$} \\
\hline A1-3R-1 & AAG TTT TGT GGG AGT ATC AAC CAC C & 3. RACE \\
\hline A1-3R-2C & GAG CAA GTT TTG TGG GAG TAT CAA C & 3' RACE \\
\hline A1-5R-1C & ATC AGA TTC CCA TAC TGT GCC AC & 5' RACE \\
\hline A1-5R-2 & AGA TCG AAC GTC CAT ATA CGT G & 5' RACE \\
\hline A1TskNf & 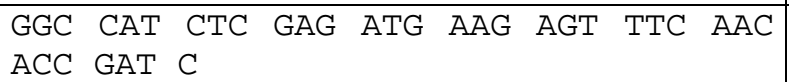 & $\begin{array}{l}\text { Klonierung des offenen Leserasters, } \\
\text { Xhol Schnittstelle }\end{array}$ \\
\hline A1TskNr & $\begin{array}{l}\text { GGC CAT CTG CAG TCA CTC ATG GAT AGT } \\
\text { CCG GA G }\end{array}$ & $\begin{array}{l}\text { Klonierung des offenen Leserasters, } \\
\text { Pstl Schnittstelle }\end{array}$ \\
\hline BA1f1 & ATT ACA CGT ATA TGG ACG TTG TTC G & $\begin{array}{l}\text { Klonierung einer } \\
\text { Hybridisierungssonde, Sequenzierung }\end{array}$ \\
\hline BA1r1 & CCA CAT AAG ATG TAG AAG AAA GTG G & $\begin{array}{l}\text { Klonierung einer } \\
\text { Hybridisierungssonde, Sequenzierung }\end{array}$ \\
\hline
\end{tabular}

(Fortsetzung auf der nächsten Seite) 
Tab. 2.1: Oligonukleotidprimer. (Fortsetzung)

\begin{tabular}{|c|c|c|}
\hline \multicolumn{3}{|c|}{ genspezifische Primer für BnAAP2 } \\
\hline BA2f1 & GGT GCT GAG GTT GGC GTG GGC & Klonierung einer Hybridisierungssonde \\
\hline BA2r1 & GCG GCG CAG CCC ATT GAG CC & Klonierung einer Hybridisierungssonde \\
\hline \multicolumn{3}{|c|}{ genspezifische Primer für BnAAP6 } \\
\hline A6TskNf & $\begin{array}{llllll}\text { GGC } & \text { CAT CTC GAG ATG GAG AAA AAG AGC } \\
\text { ATG } & \text { TTC ATT G }\end{array}$ & $\begin{array}{l}\text { Klonierung des offenen Leserasters, } \\
\text { Xhol Schnittstelle }\end{array}$ \\
\hline A6TskNr & 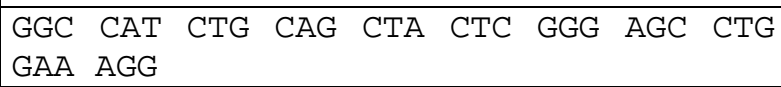 & $\begin{array}{l}\text { Klonierung des offenen Leserasters, } \\
\text { Pstl Schnittstelle }\end{array}$ \\
\hline ANTI-1 & 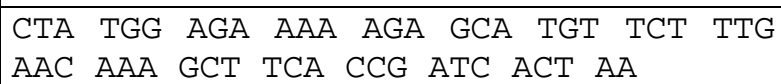 & $\begin{array}{l}\text { Klonierung des Nterm Peptids in } \\
\text { pMAL-c2X }\end{array}$ \\
\hline ANTI-2 & $\begin{array}{lllllllll}\text { AGC } & \text { TTT } & \text { AGT } & \text { GAT } & \text { CGG } & \text { TGA } & \text { AGC } & \text { TTT } & \text { GTT } \\
\text { CAA } & \text { TGA } & \text { ACA } & \text { TGC } & \text { TCT } & \text { TTT } & \text { TCT } & \text { CCA } & \text { TAG } \\
\text { AGC } & \text { T } & & & & & & & \\
\end{array}$ & $\begin{array}{l}\text { Klonierung des Nterm Peptids in } \\
\text { pMAL-c2X }\end{array}$ \\
\hline BA6f2 & GTC TCT CCA TCG CCA AAG TGG & $\begin{array}{l}\text { Klonierung einer } \\
\text { Hybridisierungssonde, Sequenzierung }\end{array}$ \\
\hline BA6r2 & ATC ATT GCT ACA ACA GCC GTA AC & $\begin{array}{l}\text { Identifizierung von BnAAPs, } \\
\text { Klonierung einer } \\
\text { Hybridisierungssonde, Sequenzierung }\end{array}$ \\
\hline BAA3-1 & GGC CAG ATA ACA AGT TTA TTA CAG G & 3' RACE \\
\hline BAA3-2 & GTA TCA GCT TGT TTA GAT TGG TTT GG & 3' RACE \\
\hline BAA5-1 & GAT TGT TAT TCC AAT CAG ATT CCC G & $5^{\prime}$ RACE \\
\hline BAA5-2 & AGC CAA TCC ACA TAA CAT CAC TTT TC & 5' RACE \\
\hline P6f2 & CTC TTT CCT TTA TGG CCT ATT CC & Promotorsequenzierung \\
\hline P6f3 & TTT ACC GGA AAT GTA TTA TTT TTA ACG & Promotorsequenzierung \\
\hline P6r2 & ACT TTA GTG GGC AAA ATC AAT ATC G & Promotorsequenzierung \\
\hline P6r3 & ATA GTT GAC TTT TCC AAA AGT CTG C & Promotorsequenzierung \\
\hline walk1 & $\begin{array}{|lllllllll|}\text { TTT } & \text { TCT } & \text { CCA } & \text { TAG } & \text { ATA } & \text { GAT } & \text { TGC } & \text { CTT } & \text { TCT } \\
\text { GC } & & & & & & & & \\
\end{array}$ & "Genome walking" \\
\hline walk2 & 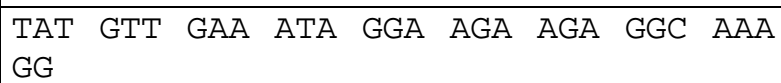 & "Genome walking" \\
\hline
\end{tabular}

\subsubsection{Polymerase-Kettenreaktion}

PCR-Amplifikationen wurden in verschiedenen Thermocyclern mit beheizbarem Deckel (TGradient Thermocycler; Biometra, Göttingen; Mastercycler personal und Mastercycler gradient; Eppendorf Gerätebau, Hamburg) durchgeführt, die z.T. Temperaturgradienten innerhalb der Thermoblocks gestatteten. Ein Standardansatz $(25 \mu \mathrm{l})$ bestand aus folgenden Komponenten:

\begin{tabular}{|c|c|}
\hline $2,5 \mu 1$ & 10 x Taq-Puffer (100 mM Tris/HCl pH 9,0, 500 mM KCl) \\
\hline $1-3,5 \mu 1$ & $25 \mathrm{mM} \mathrm{MgCl}_{2}$ (Endkonzentration 1-3,5 mM) \\
\hline $0,5 \mu 1$ & $10 \mathrm{mM}$ dNTPs \\
\hline $0,5 \mu 1$ & 5'-Primer $(10 \mathrm{pmol} / \mu \mathrm{l})$ \\
\hline $0,5 \mu 1$ & 3'-Primer $(10 \mathrm{pmol} / \mu \mathrm{l})$ \\
\hline $1 \mu 1$ & DNA-Matrize \\
\hline $0,5 \mu 1$ & 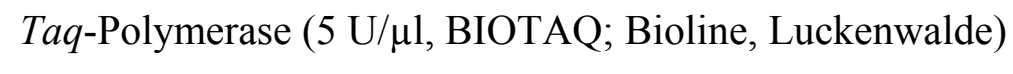 \\
\hline ad $25 \mu 1$ & $\mathrm{H}_{2} \mathrm{O}$ \\
\hline
\end{tabular}


Standard-Programmierung:

$\begin{array}{ll}94{ }^{\circ} \mathrm{C} & 1 \mathrm{~min} \text { (Denaturierung) } \\ 94{ }^{\circ} \mathrm{C} & 1 \mathrm{~min} \text { (Denaturierung) } \\ \left(\mathrm{T}_{\mathrm{m}}-3\right){ }^{\circ} \mathrm{C} & 1 \mathrm{~min} \text { (Annealing) } \\ 72{ }^{\circ} \mathrm{C} & 1 \mathrm{~min} \text { (Elongation) }\end{array}$

Dieser Zyklus wurde $30 \mathrm{x}$ wiederholt.

$72^{\circ} \mathrm{C} \quad 10 \mathrm{~min}($ terminale Elongation)

Diese Bedingungen wurden je nach Art der Primer und der zu amplifizierenden Matrize optimiert: Wurde kein Produkt erhalten, so wurde die Spezifität der PCR verringert, bei unerwünschten Nebenprodukten wurde sie erhöht. Die Annealing-Temperatur wurde zunächst $3{ }^{\circ} \mathrm{C}$ niedriger als die Schmelztemperatur der Primer gewählt, konnte aber zur Erhöhung der Spezifität höher oder zur Verringerung niedriger eingestellt werden. Bei Thermoblocks mit einstellbarem Temperaturgradient konnte innerhalb einer PCR die optimale Temperatur ermittelt werden. Die $\mathrm{MgCl}_{2}$-Konzentration wurde zwischen $1 \mathrm{mM}$ (spezifischer) und 3,5 $\mathrm{mM}$ (unspezifischer) variiert. Die Elongationszeit war abhängig von der Länge der Matrize, es wurde für die Taq-Polymerase eine Elongationszeit von ca. $1 \mathrm{~kb} / \mathrm{min}$ veranschlagt. Weiterhin konnte die Primerkonzentration auf $100 \mathrm{pmol} / \mu 1$ und die Zyklenzahl auf 35 erhöht werden, wenn mit den Standard-Bedingungen kein Produkt erhalten wurde. Wurde mit spezifischen Primern kein Produkt oder ein starker Hintergrund unspezifischer Nebenprodukte erhalten, so wurde das PCR-Produkt z.T. reamplifiziert, indem $1 \mu \mathrm{l}$ als Matrize in einer weiteren PCR z.B. mit spezifischeren Amplifikationsbedingungen - eingesetzt wurden. Bei einer RT-PCR, bei der ein cDNA-Erststrang als Matrize diente, wurde die Matrizenmenge auf bis zu $4 \mu 1$ erhöht.

Zwei stärkere Abwandlungen des Standard-Protokolls waren die „Touch Down” PCR und die „Inverse Touch Down” PCR (Knop 2001). Bei diesen PCR-Methoden wurde die AnnealingTemperatur zunächst ca. $10{ }^{\circ} \mathrm{C}$ über oder unter der endgültigen Temperatur eingestellt, die dann im Laufe von etwa 10 Zyklen mit $1{ }^{\circ} \mathrm{C} /$ Zyklus erreicht und für weitere 20-25 Zyklen beibehalten wurde. Beim „Touch Down“ wurde die Annealing-Temperatur von oben kommend allmählich verringert und so die PCR mit extrem spezifischen Bedingungen begonnen, um Nebenprodukte zu vermeiden, die dann allmählich unspezifischer wurden nachdem das gewünschte Produkt bereits angereichert war. Beim „Inverse Touch Down“ 
wurde umgekehrt zunächst eine sehr unspezifische, niedrige Annealing-Temperatur gewählt, um bei schwierigen PCRs überhaupt Produkt zu erhalten, und dann langsam die Spezifität erhöht.

Anstelle von Taq-Polymerase aus Thermophilus aquaticus wurde „SAWADY Pwo-DNAPolymerase" aus Pyrococcus woesei (PeqLab, Erlangen) verwendet, wenn eine geringe Fehlerrate bei der Elongation entscheidend war, wie bei PCR-Produkten die für die Veröffentlichung in den Datenbanken oder zur funktionellen Expression der kodierten Proteine (2.15) dienen sollten. Pwo-Polymerase hat eine $3^{\prime} \rightarrow 5^{\prime}$ Exonuklease KorrekturleseFunktion und dadurch eine zehnfach höhere Genauigkeit (Fehlerrate etwa $2 \times 10^{-3}$ ) als TaqPolymerase. Entspechend den anderen Reaktionsoptima wurden die PCR-Bedingungen angepaßt: Die Elongation fand bei $68^{\circ} \mathrm{C}$ statt $72{ }^{\circ} \mathrm{C}$ statt, $\mathrm{Mg}^{2+}$ Ionen wurden als $\mathrm{MgSO}_{4}$ an Stelle von $\mathrm{MgCl}_{2}$ zugegeben. Die Enzymmenge pro $25 \mu$ l-Ansatz betrug 2,5 U. Wegen der langsameren Elongationsrate von $P$ wo-Polymerase wurden die Elongationszeiten zunächst verdoppelt und z.T. sogar vervierfacht. Dabei ist von Vorteil, daß das Enzym deutlich hitzestabiler ist als Taq-Polymerase (Halbwertszeit bei $100{ }^{\circ} \mathrm{C} 1 \mathrm{~h}$ im Gegensatz zu $5 \mathrm{~min}$ ). Aufgrund der $3^{\prime} \rightarrow 5^{\prime}$ Exonulease-Aktivität kann Pwo-Polymerase Primer und Matrize abbauen. Der PCR-Ansatz mußte deshalb in zwei Teilen hergestellt werden, von denen der eine Polymerase, Puffer und $\mathrm{Mg}^{2+}$ enthielt, der andere Matrize und Primer. Beide wurden erst unmittelbar vor dem Reaktionsstart gemischt und dann sofort in den bereits heißen Thermoblock des PCR-Gerätes gestellt. Ein Nachteil von Pwo-Polymerase ist auch, daß durch die $3^{\prime} \rightarrow 5^{\prime}$ Exonukleasefunktion keine A-Überhänge wie bei Taq-Polymerase erzeugt werden und somit eine T/A-Klonierung (2.14.4) nicht möglich ist. Entsprechend mußten Primer mit geeigneter Restriktionsschnittstelle verwendet werden. Alle PCR-Produkte wurden durch TEA-Agarose-Gelelektrophorese (2.10.1) von 1-5 $\mu 1$ Aliquots analysiert.

\subsubsection{Kolonie-PCR}

Die Polymerase-Kettenreaktion erlaubt auch, Bakterienkolonien schnell und sequenzspezifisch auf das Vorhandensein eines Plasmids mit dem gewünschten Insert zu untersuchen. Vorteile gegenüber der Plasmid-Mini-Präparation (2.9.3.1) mit anschließendem Restriktionsverdau (2.14.1) sind dabei die schnellere Durchführung und der v.a. bei großen Probenzahlen geringere Arbeitsaufwand, die Sequenzspezifität und die Möglichkeit, durch geeignete Primerwahl gleichzeitig die Richtung der Insertion zu bestimmen. Dazu müssen ein im Insert bindender und ein Vektor-spezifischer Primer kombiniert werden, so daß ein PCR- 
Produkt nur dann gebildet werden kann, wenn die Insertion so erfolgt ist, daß die 3' Enden beider Primer in entgegengesetzte Richtungen weisen.

Für eine Kolonie-PCR wurden $25 \mu$ S Standard PCR-Ansätze (2.13.2) ohne Matrizen-DNA angesetzt. Dann wurden im Anschluß an eine Transformation (2.14.6) gewachsene Bakterienkolonien mit sterilen Zahnstochern gepickt. Mit dem Zahnstocher wurde zuerst ein PCR-Ansatz und anschließend eine Übernacht-Kultur mit LB-Medium und geeignetem Antibiotikum (2.2.3) angeimpft. Diese Kulturen konnten am nächsten Tag für Plasmid-MiniPräparationen der anhand der Kolonie-PCR als positiv identifizierten Kolonien verwendet werden. Die angeimpften PCR-Ansätze wurden dem unter 2.13.2 beschriebenen Programm in einem Thermocykler unterzogen, wobei aber der anfängliche Denturierungsschritt auf 5 min verlängert wurde, um die Bakterienzellen zu lysieren und ihre Plasmide freizusetzen. Die PCR-Produkte wurden durch TEA-Agarose-Gelelektrophorese (2.10.1) analysiert.

\subsubsection{Amplifikation von cDNA-Enden (RACE)}

Wenn mittels PCR mit degenerierten Primern (2.13.1) eine bisher unbekannte cDNA-Sequenz amplifiziert worden ist, so handelt es sich dabei normalerweise nur um eine unvollständige cDNA. Die zur Primer-Ableitung verwendeten konservierten Aminosäuresequenzen liegen nur selten an den Enden des offenen Leserasters und selbst dann fehlen der Sequenz die untranslatierten 5' und 3' Enden der ursprünglichen mRNA-Sequenz. Durch die RACETechnik (,,rapid amplification of $\underline{\text { cDNA }}$ ends“, Frohman et al. 1988) ist es möglich, diese fehlenden Enden über spezielle RT-PCR-Techniken zu erhalten. Die Schwierigkeit liegt dabei darin, daß nur an jeweils einem Ende des gewünschten PCR-Produktes die Ableitung von Primern aus dem bereits bekannten Teil der Sequenz möglich ist. Beim 3' RACE wird deshalb das PolyA-Ende der mRNA als zweite Primeranlagerungsstelle genutzt, beim 5' RACE muß ein entsprechendes Homooligomer, in diesem Fall PolyC, erst erzeugt werden. Bei beiden RACE-Techniken werden zur Erhöhung der Spezifität jeweils 2 sequenzspezifische Primer in aufeinanderfolgenden Polymerase-Reaktionen verwendet, von denen der zweite näher am zu amplifizierenden Ende, also innerhalb des zuerst erhaltenen Fragmentes liegt. Dieser zweite Primer wird als „,nested“ Primer bezeichnet. 


\subsubsection{Identifizierung des Transkriptions-Endpunktes durch 3' RACE}

Das 3' RACE beginnt mit einer speziellen RT-Reaktion (2.12), bei der nicht der normalerweise verwendete $\mathrm{dT}_{20}$ Primer, sondern der sogenannte Ankerprimer AP verwendet wurde. Dieser besitzt neben dem zur PolyA-Sequenz komplementären PolyT-Abschnitt eine Sequenz (Adaptersequenz) zu der ein zweiter Primer UAP komplementär ist (Tabelle 2.1). Auf diese Weise kann bei der nachfolgenden PCR die Verwendung des unspezifischen $\mathrm{dT}_{20}$ Primers umgangen werden. Verwendet wurde Gesamt-RNA aus einem Gewebe, in dem die gewünschte mRNA stark exprimiert war (sofern bekannt). Die cDNA-Synthese wurde folgendermaßen durchgeführt:

2-3 $\mu$ g Gesamt-RNA wurden mit 2,5 $\mu$ l Primer AP (100 pmol/ $\mu \mathrm{l})$ versetzt, das Volumen mit $\mathrm{H}_{2} \mathrm{O}$ auf $10 \mu \mathrm{l}$ aufgefüllt und der Ansatz 5 min bei $65^{\circ} \mathrm{C}$ inkubiert um die Sekundärstrukturen der RNA aufzubrechen. Anschließend wurde die Probe zurück auf Eis gestellt, so daß sich der Primer anlagern konnte. Anschließend wurden $2 \mu 110 \mathrm{mM}$ dNTPs, 2,25 $\mu 1 \mathrm{H}_{2} \mathrm{O}, 0,75 \mu \mathrm{l}$ RNase-Inhibitor, $4 \mu 15$ x RT-Puffer und $1 \mu$ l M-MuLV-Reverse Transcriptase (alle von MBI, Vilnius, Litauen) zugegeben, so daß das gesamte Volumen des Ansatzes $20 \mu \mathrm{l}$ betrug. Die RT-Reaktion erfolgte für $1 \mathrm{~h}$ bei $42^{\circ} \mathrm{C}$.

Die so erhaltene Erststrang-cDNA wurde in einer ersten PCR als Matrize eingesetzt:

$\begin{array}{ll}2 \mu \mathrm{l} & \text { RT-Ansatz } \\ 5 \mu \mathrm{l} & 10 \times \text { Taq-Puffer (100 mM Tris/HCl pH 9,0,500 mM KCl) } \\ 3 \mu \mathrm{l} & 25 \mathrm{mM} \mathrm{MgCl}_{2} \text { (Endkonzentration 1-3,5 mM) } \\ 1 \mu \mathrm{l} & 10 \mathrm{mM} \mathrm{dNTPs} \\ 1 \mu \mathrm{l} & \text { Primer UAP }(100 \mathrm{pmol} / \mu \mathrm{l}) \\ 1 \mu \mathrm{l} & \text { erster sequenzspezifischer Primer (100 pmol/ } \mu \mathrm{l}) \\ 1 \mu \mathrm{l} & \text { Taq-Polymerase }(5 \mathrm{U} / \mu 1, \text { BIOTAQ; Bioline, Luckenwalde) } \\ \operatorname{ad} 50 \mu \mathrm{l} & \mathrm{H}_{2} \mathrm{O}\end{array}$


Thermocycler-Programmierung:

$\begin{array}{ll}94{ }^{\circ} \mathrm{C} & 1 \mathrm{~min} \text { (Denaturierung) } \\ 94{ }^{\circ} \mathrm{C} & 30 \mathrm{sec} \text { (Denaturierung) } \\ 58^{\circ} \mathrm{C} & 30 \mathrm{sec} \text { (Annealing) } \\ 72^{\circ} \mathrm{C} & 2 \mathrm{~min} \text { (Elongation) }\end{array}$

Dieser Zyklus wurde $35 \mathrm{x}$ wiederholt.

$72{ }^{\circ} \mathrm{C} \quad 10 \mathrm{~min}$ (terminale Elongation)

Die PCR-Produkte wurden durch Agarose-Gelelektrophorese (2.10.1) überprüft. Häufig erhielt man mehrere Produkte. Wenn sich darunter ein DNA-Fragment der erwarteten Größe befand, schloß sich zur Erhöhung der Spezifität eine weitere PCR an:

\begin{tabular}{|c|c|}
\hline $1 \mu 1$ & Produkt aus PCR 1 \\
\hline $5 \mu 1$ & $10 \times$ Taq-Puffer (100 mM Tris/HCl pH 9,0, $500 \mathrm{mM} \mathrm{KCl)}$ \\
\hline $3 \mu 1$ & $25 \mathrm{mM} \mathrm{MgCl}_{2}$ (Endkonzentration 1-3,5 mM) \\
\hline $1 \mu 1$ & $10 \mathrm{mM} \mathrm{dNTPs}$ \\
\hline $1 \mu 1$ & Primer UAP $(100 \mathrm{pmol} / \mu \mathrm{l})$ \\
\hline $1 \mu 1$ & zweiter sequenzspezifischer (,nested“) Primer $(100 \mathrm{pmol} / \mu \mathrm{l})$ \\
\hline $1 \mu 1$ & 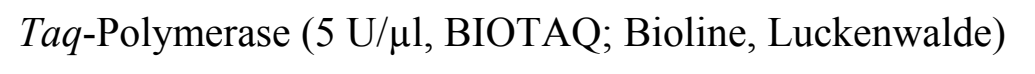 \\
\hline $50 \mu 1$ & $\mathrm{H}_{2} \mathrm{O}$ \\
\hline
\end{tabular}

Die Thermocycler-Programmierung entsprach der bei der ersten PCR. Die Produkte der ersten und zweiten PCR wurden in einer Agarose-Gelelektrophorese miteinander verglichen. Aufgrund der Position der Bindungsstelle des zweiten (,nested“) Primers innerhalb des mit dem ersten Primer amplifizierten Fragmentes sollte das Produkt der zweiten PCR geringfügig kleiner sein als das der ersten. Außerdem sollte die Anzahl der unspezifisch mitamplifizierten Banden nach der zweiten PCR geringer sein. Geeignete PCR-Fragmente wurden durch eine präparative Agarose-Gelelektrophorese und anschließende Gelelution (2.10.2) gereinigt und zur Sequenzierung (2.13.6) in den Vektor pGEM-T Easy ligiert (2.14.4). 


\subsubsection{Identifizierung des Transkriptions-Startpunktes durch 5' RACE}

Auch das 5' RACE beginnt mit einer speziellen RT-Reaktion (2.12). Da in diesem Fall nicht vom 3' Ende der mRNA her, sondern aus dem kodierenden Sequenzbereich her revers transkribiert werden soll, kann bereits für die RT ein genspezifischer Primer verwendet werden. Die Annealing-Temperatur liegt dadurch wesentlich höher als bei einem $\mathrm{dT}_{20}$ Primer und die cDNA Synthese wurde mit einer besonderen hitzestabilen Reversen Transcriptase durchgeführt, die bei Temperaturen bis zu $65{ }^{\circ} \mathrm{C}$ aktiv ist („Thermoscript ${ }^{“}$ Kit; Invitrogen, Karlsruhe). Außerdem konnte durch die Verwendung eines spezifischen Primers bereits bei der RT-Reaktion der zweite, „nested“ Primer bereits in der sich anschließenden PCR verwendet und auf eine zweite PCR verzichtet werden. Wie beim 3' RACE wurde GesamtRNA aus einem Gewebe, in dem die gewünschte mRNA stark exprimiert war verwendet (sofern bekannt).

Für die cDNA-Synthese wurden die folgenden Komponenten in ein Eppendorfgefäß pipettiert: $3 \mu \mathrm{g}$ Gesamt RNA und 0,5 $\mu$ d des ersten sequenzspezifischen Primers (100 pmol/ $\mu \mathrm{l}$ ) wurden mit $\mathrm{H}_{2} \mathrm{O}$ auf $10 \mu \mathrm{l}$ aufgefüllt und RNA-Sekundärstrukturen 5 min bei $65^{\circ} \mathrm{C}$ denaturiert. Die Probe wurde zur Primerbindung auf Eis gestellt und $1 \mu \mathrm{H}_{2} \mathrm{O}, 2 \mu 10 \mathrm{mM}$ dNTPs, $1 \mu 1100$ mM DTT, $1 \mu \mathrm{l}$ „RNase out“ RNase-Inhibitor, $4 \mu 15$ x RT Puffer und $1 \mu 1$ Thermoscript RT (1 U/ $\mu$ l) hinzugefügt (alle Komponenten von Invitrogen, Karlsruhe). Die RT-Reaktion erfolgte für $1 \mathrm{~h}$ bei $55^{\circ} \mathrm{C}$.

Da am 5' Ende der mRNA, d.h. dem 3' Ende der Erststrang-cDNA keine als Primerbindungsstelle verwendbare PolyA-Sequenz vorhanden ist, mußte im nächsten Schritt eine vergleichbare Struktur synthetisch hergestellt werden. Dies geschah durch das Enzym Terminale Desoxynukleotid-Transferase (TdT), das an freie 3' Enden von DNA Matrizenunabhängig in zufälliger Reihenfolge Nukleotide anhängt (Roychoudhury et al. 1976). Wird dem Enzym nur ein einziges Desoxynukleotid angeboten, so entsteht ein Homooligomer. Dazu mußten zunächst die im RT-Ansatz noch vorhandenen dNTPs entfernt werden. Der RTAnsatz wurde deshalb mit einem Kit („CONCERT Rapid Purificaton System“; Invitrogen, Karlsruhe) gereinigt. Doppelsträngige Nukleinsäuren (in diesem Fall ein Hybrid-Doppelstrang aus mRNA und Erststrang-cDNA) binden dabei selektiv in Gegenwart hoher Salzkonzentrationen an eine Kieselgelsäule während die freien Nukleotide die Säule passieren. Die cDNA wurde mit $50 \mu 1$ auf $65^{\circ} \mathrm{C}$ erwärmtem 1 x TdT Puffer eluiert.

Zur 3' Verlängerung der cDNA wurde dCTP verwendet, da die G-C Basenpaarung mit drei Wasserstoffbrücken stabiler ist als die A-T Bindung mit nur zwei und somit bei der PCR höhere Annealing-Temperaturen und eine größere Spezifität erreicht werden können. Für die 
TdT-Reaktion wurden zum Eluat der Reinigungssäule 1,5 $\mu 1 \mathrm{H}_{2} \mathrm{O}, 1,5 \mu 11 \mathrm{mM}$ dCTP, $1 \mu 15$ $\mathrm{x}$ TdT Puffer und $1 \mu 1$ (19 U) Terminale Transferase (Promega, Mannheim) hinzugegeben und 30 min bei $37^{\circ} \mathrm{C}$ inkubiert. $2 \mu \mathrm{l}$ der TdT-Reaktion wurden anschließend für eine PCR eingesetzt:

\begin{tabular}{|c|c|}
\hline $2 \mu 1$ & TdT-Ansatz \\
\hline $5 \mu 1$ & 10 x Taq-Puffer (100 mM Tris/HCl pH 9,0, $500 \mathrm{mM} \mathrm{KCl)}$ \\
\hline $3 \mu 1$ & $25 \mathrm{mM} \mathrm{MgCl}_{2}$ (Endkonzentration 1-3,5 mM) \\
\hline $1 \mu 1$ & $10 \mathrm{mM}$ dNTPs \\
\hline $1 \mu 1$ & zweiter sequenzspezifischer (,nested“) Primer $(100 \mathrm{pmol} / \mu \mathrm{l})$ \\
\hline $1 \mu l$ & 5' RACE Primer $(100 \mathrm{pmol} / \mu \mathrm{l})$ \\
\hline$\mu 1$ & 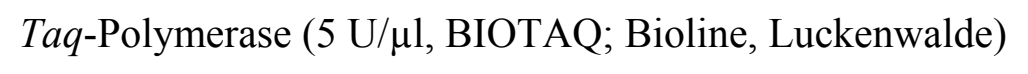 \\
\hline $50 \mu 1$ & $\mathrm{H}_{2} \mathrm{O}$ \\
\hline
\end{tabular}

Thermocycler-Programmierung:

$\begin{array}{ll}94{ }^{\circ} \mathrm{C} & 1 \mathrm{~min} \text { (Denaturierung) } \\ 94{ }^{\circ} \mathrm{C} & 30 \mathrm{sec} \text { (Denaturierung) } \\ 58^{\circ} \mathrm{C} & 30 \mathrm{sec} \text { (Annealing) } \\ 72{ }^{\circ} \mathrm{C} & 90 \mathrm{sec} \text { (Elongation) }\end{array}$

Dieser Zyklus wurde $40 \mathrm{x}$ wiederholt.

$72{ }^{\circ} \mathrm{C} \quad 10 \mathrm{~min}($ terminale Elongation)

Der für die PCR verwendete 5' RACE Primer (Tabelle 2.1) war kein reiner PolyG-Primer, da die Bindung eines solchen Primers an das PolyC-Ende der cDNA so stabil wäre, daß die Denaturierung bei $30 \mathrm{sec} 94{ }^{\circ} \mathrm{C}$ nur unvollständig abläuft. Die Sequenz des 5' RACE Primers enthielt deshalb einige Inosin-Basen, die die Bindung etwas abschwächen und die AnealingTemperatur des Primers senken. Die PCR-Produkte wurden im Agarose-Gel untersucht und geeignete Fragmente aus dem Gel eluiert (2.10.2) und zur Sequenzierung (2.13.6) in pGEM-T Easy ligiert (2.14.4). 


\subsubsection{Amplifikation von Promotoren durch „Genome Walking“}

Bei einem sogenannten „Genome Walking” identifiziert man noch unbekannte genomische DNA-Sequenzen anhand bekannter benachbarter Sequenzen. Insbesondere kann durch ein „Genome Walking” von einem als cDNA-Sequenz bekannten Gen ausgehend dessen Promotorregion identifiziert werden. Eine Möglichkeit, ein „Genome Walking” durchzuführen basiert auf der Polymerase-Kettenreaktion. Ähnlich wie beim RACE wird dazu ein Primer verwendet dessen 3' Ende nach Anlagerung an den bekannten Sequenzabschnitt auswärts in chromosomale Sequenzbereiche weist. Am anderen, noch unbekannten Ende der zu amplifizierenden Sequenz muss, analog der Synthese eines PolyC-Endes am 3' cDNAEnde beim 5' RACE, erst eine Bindungsstelle für einen zweiten spezifischen Primer geschaffen werden. Dazu wird in diesem Fall allerdings kein Homooligomer an das DNAEnde synthetisiert. Da bei genomischer DNA als Ausgangsmaterial eine wesentlich höhere Spezifität der Primerbindung erforderlich ist, wird stattdessen ein kurzes doppelsträngiges DNA-Stück mit definierter Sequenz an die DNA ligiert. Zur Durchführung des „Genome Walking” wurde der „Universal Genome Walker Kit“ der Firma Clontech, Heidelberg verwendet. Das Protokoll dieses Kits besteht aus zwei Teilen, der Konstruktion einer „Genome Walker Library“ und der eigentlichen „Genome Walking“ PCR.

\subsubsection{Herstellung einer „Genome Walker Library“}

Die „Genome Walker Library” besteht aus 5 unterschiedlichen Gemischen von Fragmenten genomischer DNA, die jeweils mit einem anderen glatt schneidenden Restriktionsenzym erzeugt worden sind und an den Enden einen Adapter für die Primerbindung besitzen. Diese Fragmente dienen als Matrize für die ,genome walking” PCR, so daß sich mit demselben Primerpaar (genspezifischer Primer + Adapterprimer) je nach Lage der Schnittstellen im Gen oder seiner Sequenzumgebung aus jedem Fragmentgemisch unterschiedlich lange Produkte ergeben.

Für die Konstruktion der „Genome Walker Library“ wurde eine große Menge sehr sauberer genomischer DNA benötigt, die nach dem unter 2.9.2 dargestellten Verfahren aus jungen Rapsblättern isoliert wurde. Die Qualität der DNA wurde vor ihrer Weiterverwendung überprüft: Es wurde eine Agarose-Gelelektrophorese (2.10.1) durchgeführt, bei der wegen der Größe der genomischen DNA 0,7 \% Agarose in TEA verwendet wurde. Da die DNA für die Kostruktion der „Genome Walker Library” mit Restriktionsenzymen in unterschiedliche Gemische von Fragmenten zerschnitten werden sollte, war wichtig, daß sie nicht bereits bei 
der Isolation durch Scherkräfte fragmentiert worden war. Dies war im Gel an einer klar abgegrenzten einzelnen Bande, die oberhalb der größten Markerbande bei ca. $50 \mathrm{~kb}$ lief, und dem Fehlen von Schmier in der Gelspur feststellbar. Weiterhin wurde durch einen Testverdau mit DraI überprüft, ob die DNA mit Polysacchariden kontaminiert war, die die Restriktion stören. Dazu wurden $5 \mu 1$ DNA, 11,4 $\mu 1 \mathrm{H}_{2} \mathrm{O}, 2 \mu 110$ x Puffer B ${ }^{+}$und 1,6 $\mu 1$ DraI (10 U/ $\mu 1$; MBI, Vilnius, Litauen) vorsichtig gemischt und über Nacht bei $37{ }^{\circ} \mathrm{C}$ inkubiert. Am darauffolgenden Tag wurden $5 \mu 1$ des Reaktionsansatzes in einem 0,7\% Agarosegel aufgetrennt. Es sollte ein gleichmäßiger Schmier in der ganzen Gelspur und mit gerader Lauffront (nicht bogenförmig zu einem „Smiling” verzogen) sichtbar sein und möglichst nur geringe Reste der unsprünglichen $50 \mathrm{~kb}$-Bande.

Hatte die genomische DNA eine geeignete Qualität, so wurde sie für die Konstruktion der „Genome Walker Library“ mit den fünf glatt schneidenden Restriktionsenzymen DraI, EcoRV, PvuII, ScaI und StuI verdaut. Jeder Restriktionsansatz bestand aus folgenden Komponenten:

$\begin{array}{ll}25 \mu 1 & \text { genomische DNA }(0,1 \mu \mathrm{g} / \mu \mathrm{l}) \\ 8 \mu \mathrm{l} & \text { Restriktionsenzym }(10 \mathrm{U} / \mu \mathrm{l}) \\ 10 \mu \mathrm{l} & 10 \mathrm{x} \text { Puffer } \\ 57 \mu \mathrm{l} & \mathrm{H}_{2} \mathrm{O}\end{array}$

Die Ansätze wurden vorsichtig gemischt und bei $37{ }^{\circ} \mathrm{C}$ inkubiert. Nach $2 \mathrm{~h}$ wurde nochmals bei geringer Geschwindigkeit für 5-10 sec gevortext und dann über Nacht bei $37{ }^{\circ} \mathrm{C}$ weiter inkubiert. Am darauffolgenden Tag wurde die Vollständigkeit der Verdaus durch Gelelektrophorese von je $5 \mu 1$ Restriktionsansatz in einem 0,7 \% Agarosegel überprüft. Die 50 kb-Bande der intakten genomischen DNA sollte verschwunden sein. Die fragmentierte genomische DNA wurde anschließend von den noch vorhandenen Enzymen durch eine Phenolextraktion gereinigt (2.9.5). Dazu wurden $\mathrm{zu}$ jedem Reaktionsgefäß $95 \mu 1$ Phenol:Chloroform (1:1) gegeben, kurz gemischt und anschließend 5 min zur Phasentrennung zentrifugiert. Der wässrige Überstand wurde in ein neues $1,5 \mathrm{ml}$ Reaktionsgefäß überführt und mit $95 \mu$ Chloroform extrahiert. Wiederum wurde kurz gemischt und zur Phasentrennung zentrifugiert. Der wässrige Überstand wurde abgenommen und auf Eis mit 2 Vol. kaltem 99,6 \% Ethanol, 0,1 Vol. 3 M Na-Oxalacetat pH 4,5 und $20 \mu \mathrm{g}$ Glycogen gemischt. Die DNA wurde für 10 min pelletiert und der Überstand verworfen. Das Pellet wurde mit kaltem 75 \% Ethanol gewaschen und nochmals $5 \mathrm{~min}$ abzentrifugiert. Nach der Entfernung des 
Überstandes wurde das Pellet an der Luft getrocknet und dann in $20 \mu 1$ TE-Puffer $(10 \mathrm{mM}$ Tris/HCl pH 7,5, 0,1 mM EDTA) resuspendiert. Um die Menge verbliebener DNA abzuschätzen, wurde $1 \mu$ jedes Restriktionsansatzes in einem 0,7 \% Agarosegel aufgetrennt. Als nächstes erfolgte die Ligation des „Genome Walker Adaptors“ and die Enden der Restriktionsfragmente.

„Genome Walker Adaptor“ (im Kit enthalten):

5'-GTAATACGACTCACTATAGGGCACGCGTGGTCGACGGCCCGGGCTGGT-3' 3'- $\mathrm{H}_{2} \mathrm{~N}-\mathrm{CCCGACCA}-5^{\prime}$

Die Aminogruppe am freien 3' Ende des kürzeren Stranges verhindert bei der „Genome Walking“ PCR eine Kettenverlängerung in dieser Richtung, so daß die Adapter Primer 1 und 2 (s. nächster Abschnitt) nur an solche Fragmente binden können, bei denen von einem sequenzspezifischen Primer aus ein zum längeren Strang des „Genome Walker Adaptors“ komplementärer Strang synthetisiert wurde. Auf diese Weise wird verhindert, daß bei der PCR über den beidseitig vorhandenen Adaptor alle Fragmente in der „Genome Walker Library“ unspezifisch mitamplifiziert werden.

Zusammensetzung der Ligationsansätze:

\author{
$4 \mu \mathrm{l} \quad$ gereinigter Restriktionsansatz \\ $1,9 \mu \mathrm{l}$ Genome Walker Adaptor $(25 \mu \mathrm{M})$ \\ $1,6 \mu 15 \mathrm{x}$ Ligationspuffer \\ $0,5 \mu 1$ T4 DNA-Ligase $(1 \mathrm{U} / \mu \mathrm{l})$
}

Neben der Ligation der Restriktionsansätze wurde in einem 6. Ansatz als Positivkontrolle menschliche genomische DNA eingesetzt, die bereits mit PvuII fragmentiert im Kit mitgeliefert wurde. Die Ansätze wurden vorsichtig gemischt und über Nacht bei $15{ }^{\circ} \mathrm{C}$ inkubiert. Am folgenden Tag wurde die Reaktion durch eine Inkubation für 5 min bei $70{ }^{\circ} \mathrm{C}$ gestoppt. Abschließend wurde jeder Ligationsansatz durch Zugabe von $72 \mu 1$ TE-Puffer auf $80 \mu 1$ Gesamtvolumen aufgefüllt. 


\subsubsection{2 „Genome Walking“ PCR}

Analog zum 3' RACE (2.13.4.1) besteht das „Genome Walking" aus zwei aufeinanderfolgenden PCR-Amplifikationen mit unterschiedlichen Primerpaaren (jeweils ein genspezifischer und ein zum Adapter komplementärer Primer), wobei das zweite Primerpaar innerhalb des zuerst amplifizierten Fragmentes bindet („nested“ Primer). Auf diese Weise wird die Spezifität des „genome walking“ erhöht. Die Adaptor-Primer waren im Kit enthalten, während die genspezifischen Primer selbst abgeleitet werden mußten.

\section{Adapter Primer 1 (AP1): 5'-GTAATACGACTCACTATAGGGC-3'}

Adapter Primer 2 (AP2): 5'-ACTATAGGGCACGCGTGGT-3'

Aufgrund der hohen Komplexität der genomischen DNA-Matrize mußten die genspezifischen Primer eine besonders hohe Spezifität besitzen. Es wurden deshalb lange (26-60 Nt) Oligonukleotide mit einer Schmelztemperatur von ca. $67^{\circ} \mathrm{C}$ ausgewählt. Weitere Kriterien für die Primerauswahl waren, daß sie so weit wie möglich am 5'Ende der bekannten cDNASequenz binden, nicht miteinander überlappen und einen G/C-Gehalt von 40-60\% besitzen sollten. Von den letzten sechs Positionen am 3' Ende sollten nicht mehr als 3 Nukleotide ein G oder C sein.

Die Ansätze für die erste PCR-Reaktion setzten sich wie folgt zusammen:

$\begin{array}{ll}37,8 \mu \mathrm{l} & \mathrm{H}_{2} \mathrm{O} \\ 5 \mu \mathrm{l} & 10 \mathrm{x} \text { Tth Puffer } \\ 1 \mu \mathrm{l} & 10 \mathrm{mM} \text { dNTPs } \\ 2,2 \mu \mathrm{l} & 25 \mathrm{mM} \text { Magnesiumacetat } \\ 1 \mu \mathrm{l} & \text { erster genspezifischer Primer }(10 \mathrm{pmol} / \mu \mathrm{l}) \\ 1 \mu \mathrm{l} & \text { Primer AP1 (10 pmol } / \mu \mathrm{l}) \\ 1 \mu \mathrm{l} & 50 \times \text { Advantage Tth Polymerase Mix (Clontech, Heidelberg) } \\ 1 \mu \mathrm{l} & \text { „Genome Walker Library" (1-5) } \\ 50 \mu \mathrm{l} & \text { Gesamtvolumen }\end{array}$


Thermocycler-Programmierung:

$\begin{array}{ll}94{ }^{\circ} \mathrm{C} & 25 \mathrm{sec} \text { (Denaturierung) } \\ 72{ }^{\circ} \mathrm{C} & 3 \mathrm{~min} \text { (Annealing + Elongation) }\end{array}$

Dieser Zyklus wurde $7 \mathrm{x}$ wiederholt.

$94{ }^{\circ} \mathrm{C} \quad 25 \mathrm{sec}$ (Denaturierung)

$67^{\circ} \mathrm{C} \quad 3 \mathrm{~min}$ (Annealing + Elongation)

Dieser Zyklus wurde 32 x wiederholt.

$67^{\circ} \mathrm{C} \quad 7 \mathrm{~min}$ (terminale Elongation)

Die PCR wurde mit den sechs Ligationsansätzen (5 Restriktionen und eine Positivkontrolle) und einer im Kit mitgelieferten fertigen „Control Library“ aus genomischer menschlicher DNA durchgeführt. Für die Kontrollansätze mit menschlicher DNA als (Ligationskontrolle und fertige „Control Library“) wurde ein anderer, ebenfalls im Kit enthaltener genspezifischer Primer verwendet, der im Gen des „tissue Plaminogen Activator“ (tPA) bindet und ein PCRProdukt von ca. 1,5 kb ergibt. Außerdem wurden als Negativkontrolle je ein Ansatz ohne Matrizen-DNA mit AP1 und mit PCP1 angesetzt. Der verwendete „Advantage Tth Polymerase Mix“ (Clontech, Heidelberg) enthält eine thermostabile DNA-Polymerase mit besonders großer Elongationsreichweite aus Thermus thermophilus und eine geringe Beimischung einer DNA-Polymerase mit $3^{\prime} \rightarrow 5^{\prime}$ Korrekturleseaktivität. Außerdem sind Tth Polymerase bindende Antikörper enthalten, die das Enzym bis zum ersten Denaturierungsschritt inaktiv halten.

Jeweils $8 \mu$ l der PCR-Reaktionen wurden in einem 1 \% Agarosegel analysiert (2.10.1). Sofern die erwartete $1,5 \mathrm{~kb}$ Bande in den Positivkontrollen, keine PCR-Produkte in den Negativkontrollen und amplifizierte DNA-Fragmente in den „Genome Walker Library“ Ansätzen sichtbar waren, wurde mit der zweiten PCR-Reaktion fortgefahren. Dazu wurde $1 \mu 1$ der ersten PCR-Reaktion wurde mit $49 \mu 1 \mathrm{H}_{2} \mathrm{O}$ verdünnt und davon $1 \mu \mathrm{l}$ als eingesetzt: 


$\begin{array}{ll}37,8 \mu \mathrm{l} & \mathrm{H}_{2} \mathrm{O} \\ 5 \mu \mathrm{l} & 10 \mathrm{x} \text { Tth Puffer } \\ 1 \mu \mathrm{l} & 10 \mathrm{mM} \text { dNTPs } \\ 2,2 \mu \mathrm{l} & 25 \mathrm{mM} \text { Magnesiumacetat } \\ 1 \mu \mathrm{l} & \text { zweiter (,nested”) genspezifischer Primer }(10 \mu \mathrm{M}) \\ 1 \mu \mathrm{l} & \text { Primer AP2 (10 } \mu \mathrm{M}) \\ 1 \mu \mathrm{l} & 50 \mathrm{x} \text { Advantage Tth Polymerase Mix (Clontech, Heidelberg) } \\ 1 \mu \mathrm{l} & \text { Produkt aus erster PCR (1:50 verdünnt) } \\ 50 \mu \mathrm{l} & \text { Gesamtvolumen }\end{array}$

Thermocycler-Programmierung:

$94{ }^{\circ} \mathrm{C} \quad 25 \mathrm{sec}$ (Denaturierung)

$72{ }^{\circ} \mathrm{C} \quad 3 \mathrm{~min}$ (Annealing + Elongation)

Dieser Zyklus wurde $5 \mathrm{x}$ wiederholt.

$94{ }^{\circ} \mathrm{C} \quad 25 \mathrm{sec}$ (Denaturierung)

$67{ }^{\circ} \mathrm{C} \quad 3 \min ($ Annealing + Elongation)

Dieser Zyklus wurde $20 \mathrm{x}$ wiederholt.

$67^{\circ} \mathrm{C} \quad 7 \mathrm{~min}$ (terminale Elongation)

$5 \mu \mathrm{l}$ der PCR-Produkte der zweiten PCR wurden zur Analyse in einem $1 \%$ Agarosegel aufgetrennt. Amplifikationsprodukte geeigneter Größe (für pflanzliche Promotoren in diesem Fall ca. $2 \mathrm{~kb}$ ) wurden durch eine präparative Gelelektrophorese und anschließende Elution der DNA (2.10.2) aufgereinigt, kloniert (2.14) und sequenziert (2.13.6).

\subsubsection{DNA-Sequenzierung}

Die DNA-Sequenzierung erfolgte nach der Didesoxymethode von Sanger et al. (1977). Dazu wurden mit dRhodamin markierte Didesoxynukleotide benutzt („ABI PRISM dRhodamine Terminator Cycle Sequencing Ready Reaction Kit“; PerkinElmer Life Sciences, Jügesheim). Die verschiedenen markierten ddNTPs haben Absorptions- und Emissionsspektren von 450$650 \mathrm{~nm}$. Die Kettenverlängerungsreaktion erfolgte nach dem Prinzip einer PCR durch zyklische Wiederholung von Dentaurierungs-, Primeranlagerungs- und Elongationsschritten. 
Die Komponenten eines Sequenzierungsansatzes waren:

$\begin{array}{ll}2 \mu \mathrm{l} & \text { „Terminator Ready Reaction Mix“ (im Kit enthalten) } \\ 300-600 \mathrm{ng} & \text { Plasmid-DNA } \\ 0,5 \mu \mathrm{l} & \text { Sequenzierungs-Primer }(10 \mathrm{pmol} / \mu \mathrm{l}) \\ \text { ad } 10 \mu \mathrm{l} & \mathrm{H}_{2} \mathrm{O}\end{array}$

Thermocycler-Programmierung:

$\begin{array}{ll}96{ }^{\circ} \mathrm{C} & 10 \mathrm{sec} \text { (Denaturierung) } \\ 50{ }^{\circ} \mathrm{C} & 5 \mathrm{sec} \text { (Annealing) } \\ 60{ }^{\circ} \mathrm{C} & 4 \mathrm{~min} \text { (Elongation) }\end{array}$

Dieser Zyklus wurde $25 \mathrm{x}$ wiederholt.

Als Sequenzierungs-Primer dienten meist in der Nähe der Klonierungsstelle liegende Sequenzabschnitte der verwendeten Vektoren (T7 Promotor, T7 Terminator, M13 rev, pMalseqf; Tab. 2.1), zum Teil aber auch Insert-spezifische Primer bei der Sequenzierung großer DNA-Fragmente.

Im Anschluß an die Kettenverlängerungsreaktion mußten nicht eingebaute dRhodaminddNTPs durch eine Ethanolfällung entfernt werden. Dazu wurden zu $10 \mu$ PCR-Ansatz $1 \mu 1$ 1,5 M Natriumacetat $\mathrm{pH} \geq 8,0,250 \mathrm{mM}$ EDTA und $36 \mu 1$ 99,6 \% Ethanol gegeben und gut gemischt. Die Probe wurde für $2 \mathrm{~h}$ auf Eis inkubiert, danach für 15 min zentrifugiert und der Überstand entfernt. Das (in der Regel nicht mit bloßen Auge erkennbare) Pellet wurde mit $100 \mu 175 \%$ Ethanol gewaschen. Nach einer weiteren Zentrifugation für 10 min wurde der Überstand verworfen und das Pellet 1 min bei $90{ }^{\circ} \mathrm{C}$ getrocknet. Danach wurde es in $20 \mu 1$ „Template Suppression Reagent“ (PerkinElmer Life Sciences, Jügesheim) gelöst und 2 min bei $95{ }^{\circ} \mathrm{C}$ denaturiert. Bis zur Sequenzierung wurde die Probe auf Eis aufbewahrt. Die chromatographische Auftrennung und Fluoreszenz-Detektion der KettenverlängerungsProdukte erfolgte in einem ABI Prism 310 Genetic Analyzer (PerkinElmer Life Sciences, Jügesheim). Die Auswertbarkeit der Chromatogramme (Leseweite) lag bei etwa 400-500 bp. Wurden längere Sequenzen benötigt, wie zur vollständigen Sequenzierung identifizierter BnAAP-cDNAs und Promotoren, so wurde die Kettenverlängerungsreaktion und Analyse der Produkte nicht selbst durchgeführt, sondern der Vektor mit dem zu sequenzierenden Insert und gegebenenfalls dem Sequenzierungs-Primer an die Firma Seqlab, Göttingen verschickt, wo Leseweiten über 800 bp erreicht werden konnten. Die erhaltenen Nukleotidsequenzen wurden mit denen schon bekannter Gene verglichen (2.18.1). 


\subsection{Klonierungsmethoden}

\subsubsection{Restriktionsverdau von DNA-Fragmenten}

Das sequenzspezifische Schneiden von doppelsträngiger DNA durch Restriktionsenzyme diente dazu, Vektoren für die Aufnahme eines Inserts zu linearisieren, die Enden von Insert und/oder Vektor für eine Ligation vorzubereiten, unerwünschte Sequenzabschnitte aus Plasmiden zu entfernen, sowie dazu, ein Insert aus einem Vektor herauszuschneiden um seine Größe zu überprüfen (2.10.1) oder es als Sonde in einer Hybridisierung zu verwenden (2.11). Insbesondere besitzt der routinemäßig für T/A-Klonierungen (2.14.4) verwendete Vektor pGEM-T Easy auf beiden Seiten der Insertionsstelle eine EcoRI-Schnittstelle. Der Erfolg einer Klonierung konnte deshalb auf einfache Weise durch einen Restriktionsverdau mit diesem Enzym getestet werden. Ein Standard-Restriktionsansatz enthielt folgende Komponenten:

$\begin{array}{ll}50 \mathrm{ng} & \text { DNA (z.B. Plasmid-Mini-Präparation) } \\ 2 \mu \mathrm{l} & 10 \times \text { Reaktions-Puffer } \\ 0,5 \mu \mathrm{l} & \text { Restriktionsenzym }(10 \mathrm{U} / \mu \mathrm{l}) \\ \operatorname{ad} 20 \mu \mathrm{l} & \mathrm{H}_{2} \mathrm{O}\end{array}$

Die verwendeten Restriktionsenzyme und ihre Puffer wurden von der Firma MBI, Vilnius, Litauen bezogen. Sollten größere DNA-Mengen quantitativ verdaut werden, wurden entsprechend alle Komponenten des Ansatzes im gleichen Verhältnis zueinander in größeren Mengen eingesetzt. Der Restriktionsansatz wurde $1 \mathrm{~h}$ bei $37{ }^{\circ} \mathrm{C}$ inkubiert und anschließend durch Analyse eines $1 \mu$ l Aliquots in einem Agarosegel überprüft (2.10.1).

\subsubsection{Auffüllen von überstehenden Enden doppelsträngiger DNA-Moleküle}

Zur Ligation von DNA-Fragmenten (2.14.4) mit nicht-komplementären überstehenden (,sticky“) Enden war es teilweise nötig, die Enden in glatte („blunt“) Enden umzuwandeln. Dazu wurde eine Auffüllreaktion mit Klenow DNA-Polymerase durchgeführt. Die Klenow Polymerase ist das große Fragment eines proteolytischen Verdaus der E. coli DNA Polymerase I mit Subtilisin und wird verwendet, weil sie keine $5^{\prime} \rightarrow 3^{\prime}$ Exonukleaseaktivität besitzt. 
Der Ansatz für eine Auffüllreaktion enthielt folgende Komponenten:

$\begin{array}{ll}200 \mathrm{ng} & \text { gereinigte DNA } \\ 4 \mu \mathrm{l} & 10 \mathrm{mM} \text { dNTPs } \\ 4 \mu \mathrm{l} & 10 \mathrm{x} \text { Puffer } \\ 1 \mu \mathrm{l} & \text { Klenow Polymerase (2 U/ } \mu \mathrm{l} ; \text { MBI, Vilnius, Litauen) } \\ \operatorname{ad} 40 \mu \mathrm{l} & \mathrm{H}_{2} \mathrm{O}\end{array}$

Die Reaktion erfolgte für $20 \min$ bei $37^{\circ} \mathrm{C}$.

\subsubsection{Alkalische Phosphatase-Behandlung}

Um bei einer Ligation (2.14.4) die Rezirkularisierung eines für die Klonierung durch einen Restriktionsverdau linearisierten Plasmides zu verhindern und so die Wahrscheinlichkeit des Einbaus des gewünschten Inserts zu erhöhen, konnte das Plasmid mit alkalischer Phosphatase behandelt werden. Dieses Enzym entfernt die 5' Phosphatreste an den Enden eines DNADoppelstrangs, die von der T4 DNA Ligase als Substrat benötigt werden. Die Ligation eines Inserts mit intakten 5' Phosphatresten an das Vektorende kann weiterhin erfolgen. Die alkalische Phosphatase-Behandlung war v.a. bei der verhältnismäßig ineffektiven Ligation von DNA-Strängen mit glatten (,blunt“") Enden vorteilhaft. Bei linearisierten Plasmiden, deren Enden deutlich verschieden waren (z.B. ein 5' Überhang auf der einen und ein 3' Überhang auf der anderen Seite) und bei für eine T/A-Klonierung vorbereitetem pGEM-T Easy (2.14.4) war dieser Arbeitsschritt unnötig.

Zur alkalischen Phosphatase-Behandlung eines linearisierten Plasmids wurde 0,1 Vol. $10 \mathrm{x}$ Dephosphorylierungspuffer und 1 U alkalische Phosphatase (Roche, Mannheim) in die DNALösung oder direkt in den Restriktionsansatz gegeben. Es folgte eine Inkubation für $30 \mathrm{~min}$ bei $37{ }^{\circ} \mathrm{C}$. Vor der Verwendung des so behandelten Plasmids in einer Ligation mußten die Restriktionsenzyme und die Phosphatase durch Phenol/Chloroform-Reinigung (2.9.5) entfernt werden. Bei der Lagerung der Phosphatase war darauf zu achten, daß sie nicht kälter als bei 4 ${ }^{\circ} \mathrm{C}$ gelagert wurde, da sie durch Einfrieren relativ schnell inaktiv wurde.

\subsubsection{Ligation von DNA}

Mit der DNA Ligase aus dem Bacteriophagen T4 können lineare doppelsträngige DNAMoleküle miteinander verknüpft werden, wenn die Enden entweder beide überstehend (,sticky”) und (zumindest teilweise) zueinander komplementär oder beide glatt („,blunt”) sind. 
Außerdem muß zumindest an einem Doppelstrangende eine freie 5' Phosphatgruppe und am anderen eine freie 3' Hydroxygruppe vorhanden sein. Die Ligation wurde benutzt, um PCRProdukte (2.13.2) oder durch Resttriktionsverdau (2.14.1) aus einem DNA-Molekül ausgeschnittene Fragmente (Insert) in ein linearisiertes Plasmid (Vektor) einzufügen. In der Regel wurden sowohl das Insert als auch der Vektor zuvor durch eine Gelelution (2.10.2) gereinigt. Für PCR-Produkte, die mit den thermostabilen DNA Polymerasen Taq oder Tth synthetisiert wurden, konnte die sogenannte T/A-Klonierung genutzt werden, da diese PCRProdukte an ihren 3' Enden ein überhängendes A besitzen: Der Klonierungsvektor pGEM-T Easy (Promega, Mannheim) wird fertig linearisiert geliefert und besitzt überhängende T's an seinen freien 3' Enden, so daß Taq/Tth-PCR-Produkte direkt hinein ligiert werden können.

Für eine Ligation wurden 0,5 $\mu 1$ Plasmid, $5 \mu 12$ x T4-DNA-Ligase-Puffer, $1 \mu 1$ T4-DNALigase (Promega, Mannheim) und bis zu 3,5 $\mu$ l Insert-DNA gemischt, mit $\mathrm{H}_{2} \mathrm{O}$ auf $10 \mu \mathrm{l}$ aufgefüllt und bei $15{ }^{\circ} \mathrm{C}$ über Nacht inkubiert. Das Verhältnis von Insert zu Vektor sollte dabei mindestens 10:1 betragen. $5 \mu \mathrm{l}$ des Ansatzes wurden für die Transformation (2.14.6) verwendet, der Rest wurde für eine mögliche zweite Transformation bei $-20{ }^{\circ} \mathrm{C}$ gelagert.

\subsubsection{Herstellung chemokompetenter $\boldsymbol{E}$. coli Zellen}

Zur Vermehrung und Analyse eines rekombinanten Plasmids wurde dieses zunächst in E. coli Zellen der Linien DH5 $\alpha$ oder XL-I Blue transformiert. Es standen dabei zwei Methoden für die Herstellung kompetenter Zellen zur Verfügung: Die Methode nach Inoue et al. (1990) lieferte hochkompetente Zellen, die für die Transformation schwieriger Ligationen mit geringer Insertionsrate verwendet wurden. Da der Arbeitsaufwand dieser Methode relativ hoch war, wurden alternativ kompetente Zellen nach der Rubidiumchlorid-Methode hergestellt. Dieses Protokoll ist schnell durchführbar und liefert kompetente Zellen deren Transformationsraten ausreichend für Standard-Ligationen und Retransformationen mit Plasmid-Mini-Präparationen sind. Frisch hergestellte kompetente Zellen wurden jeweils durch Transformation (2.14.6) mit $1 \mu$ l Plasmid-Maxi-Präparation bzw. $1 \mu 1$ sterilem $\mathrm{H}_{2} \mathrm{O}$ auf ihre Transformationsrate und auf Kontamination mit Antibiotikum-resistenten Bakterien getestet.

\subsubsection{Herstellung kompetenter Zellen nach der Rubidiumchlorid-Methode}

Von einer LB-Platte (2.2.3) wurde von einer einzelnen Kolonie eine Vorkultur in $3 \mathrm{ml}$ LBFüssigmedium angeimpft und über Nacht bei $37^{\circ} \mathrm{C}$ unter Schütteln inkubiert. Von dieser Vorkultur wurden am folgenden Tag 1-3 ml als Inokulum für eine $50 \mathrm{ml}$ Flüssigkultur in LB- 
Medium verwendet. Diese wurde bis zu einer $\mathrm{OD}_{600}$ von 0,8 unter Schütteln bei $37{ }^{\circ} \mathrm{C}$ inkubiert. Danach wurde 15 min auf Eis inkubiert und anschließend die Kultur in ein $50 \mathrm{ml}$ Röhrchen dekantiert und die Zellen 10 min bei $4{ }^{\circ} \mathrm{C}$ und $3.500 \mathrm{Upm}$ sedimentiert (Centrifuge 5810 R; Eppendorf Gerätebau, Hamburg). Der Mediums-Überstand wurde abgegossen und die Zellen in $16 \mathrm{ml}$ Puffer RF-1 resuspendiert. Es folgte eine weitere Inkubation auf Eis für 1 h. Danach wurden die Zellen wiederum $10 \mathrm{~min}$ bei $4{ }^{\circ} \mathrm{C}$ und $3.500 \mathrm{Upm}$ sedimentiert, der RF1 Puffer abgegossen und das Bakterienpellet vorsichtig in $4 \mathrm{ml}$ Puffer RF-2 resuspendiert ohne zu vortexen. Nach 15 min Inkubation auf Eis wurden die Zellen in $200 \mu$ Aliquots abgefüllt, in flüssigem Stickstoff schockgefroren und bis zur Verwendung bei $-80{ }^{\circ} \mathrm{C}$ gelagert.

Puffer RF-1:

$\begin{array}{ll}100 \mathrm{mM} & \mathrm{RbCl} \\ 50 \mathrm{mM} & \mathrm{MnCl}_{2} \\ 15 \mathrm{mM} & \mathrm{CaCl}_{2} \\ 30 \mathrm{mM} & \text { Kaliumacetat } \\ 15 \%(\mathrm{w} / \mathrm{v}) & \text { Glycerin } \\ \text { pH 5,8 mit 0,2 } \mathrm{M} \text { Essigsäure einstellen } \\ \text { sterilfiltrieren }\end{array}$

Puffer RF-2:

$\begin{array}{ll}10 \mathrm{mM} & \mathrm{RbCl} \\ 100 \mathrm{mM} & \mathrm{CaCl}_{2} \\ 10 \mathrm{mM} & \mathrm{MOPS} \\ 15 \%(\mathrm{w} / \mathrm{v}) & \text { Glycerin } \\ \text { pH } 6,8 \text { mit } \mathrm{NaOH} \text { einstellen } \\ \text { sterilfiltrieren }\end{array}$

2.14.5.2 Herstellung kompetenter Zellen nach Inoue et al. (1990)

Bei dieser Methode wurden bereits beim Ansetzen der Medien und auch für die Bakterienkulturen nur Glasgefäße verwendet, die zuerst mit $\mathrm{H}_{2} \mathrm{O}$ und dann leer autoklaviert worden waren, um eventuelle Spuren von Detergentien zu beseitigen. Es wurde eine $5 \mathrm{ml}$ Vorkultur von E. coli DH5 $\alpha$ oder XL-I Blue in SOC-Medium in einem $50 \mathrm{ml}$ Gefäß über Nacht bei $37{ }^{\circ} \mathrm{C}$ geschüttelt. Am folgenden Tag wurden mit der geamten Vorkultur $200 \mathrm{ml}$ SOC-Medium in einem 21 Erlenmeyer-Kolben angeimpft und bei $18{ }^{\circ} \mathrm{C}$ bis zu einer $\mathrm{OD}_{600}$ 
von 0,4-0,6 wachsen gelassen. Dann wurde die Bakterienkultur auf vier $50 \mathrm{ml}$ Röhrchen aufgeteilt und bei $4.000 \mathrm{Upm}$ und $4{ }^{\circ} \mathrm{C}$ für $10 \mathrm{~min}$ abzentrifugiert (Centrifuge $5810 \mathrm{R}$; Eppendorf Gerätebau, Hamburg). Alle weiteren Arbeitsschritte erfolgten auf Eis. Die Bakterienpellets wurden in je $15 \mathrm{ml}$ kaltem Transformationspuffer resuspendiert und $15 \mathrm{~min}$ auf Eis inkubiert. Anschließend wurden je $30 \mathrm{ml}$ Suspension in einem $50 \mathrm{ml}$ Röhrchen vereinigt und die Zellen wiederum $10 \mathrm{~min}$ bei $4.000 \mathrm{Upm}$ und $4{ }^{\circ} \mathrm{C}$ pellettiert. Beide Pellets wurden wieder in je $15 \mathrm{ml}$ Transformationspuffer resuspendiert und unter stetigem Mischen zu jeder Suspension langsam $525 \mu 1$ DMSO gegeben. Nach einer Inkubation für 5 min auf Eis wurden die Bakteriensuspensionen in $200 \mu$ Portionen aliquotiert und in flüssigem Stickstoff schockgefroren. Die Lagerung erfolgte bei $-80^{\circ} \mathrm{C}$.

Transformationspuffer:

$\begin{array}{ll}10 \mathrm{mM} & \text { PIPES } \\ 15 \mathrm{mM} & \mathrm{CaCl}_{2} \\ 250 \mathrm{mM} & \mathrm{KCl} \\ \mathrm{pH} 6,7 \mathrm{mit} \mathrm{KOH} \text { einstellen } \\ \text { ad } 55 \mathrm{mM} \quad \mathrm{MnCl}_{2} \\ \text { sterilfiltrieren }\end{array}$

SOC-Medium:

$\begin{array}{ll}20 \mathrm{~g} / 1 & \text { Select Pepton } 140 \\ 5 \mathrm{~g} / 1 & \text { Hefe-Extrakt } \\ 10 \mathrm{ml} / 1 & 1 \mathrm{M} \mathrm{NaCl} \\ 2,5 \mathrm{ml} / 1 & 1 \mathrm{M} \mathrm{KCl} \\ 10 \mathrm{~min} \text { autoklavieren, anschließend hinzufügen: } \\ 10 \mathrm{ml} / 1 & 1 \mathrm{M} \mathrm{MgCl}_{2} \text { (sterilfiltriert) } \\ 10 \mathrm{ml} / 1 & 1 \mathrm{M} \mathrm{MgSO}_{4} \text { (sterilfiltriert) } \\ 10 \mathrm{ml} / 1 & 2 \mathrm{M} \mathrm{Glukose} \mathrm{(sterilfiltriert)}\end{array}$

\subsubsection{Chemische Transformation von $E$. coli}

$200 \mu$ kompetente Zellen wurden langsam auf Eis aufgetaut. Dann wurden $5 \mu 1$ Ligationsansatz (2.14.4) oder $1 \mu$ l Plasmid-Präparation (2.9.3) zugegeben, gemischt und 30 min auf Eis inkubiert. Es folgte ein Hitzeschock für $30 \mathrm{sec}$ bei $42{ }^{\circ} \mathrm{C}$. Der Ansatz wurde 
zurück auf Eis gestellt und $1 \mathrm{ml}$ SOC-Medium (2.14.5.2) zugegeben. Danach wurden die Bakterien für $1 \mathrm{~h}$ bei $37^{\circ} \mathrm{C}$ inkubiert.

Die transformierten Zellen wurden nun auf LB-Agar-Platten mit geeignetem Antibiotikum (2.2.3) ausgestrichen. Die Platten wurden dann bei $37{ }^{\circ} \mathrm{C}$ über Nacht inkubiert, so daß die transformierten Zellen Kolonien bilden konnten. Die Vektoren pGEM-T Easy und pMALc2X ermöglichten eine Blau/Weiß-Selektion (Sambrook et al. 1989): Die Klonierungsstelle liegt im lacZ Gen, das das Enzym $\beta$-Galactosidase kodiert. Durch Induktion des lacZPromotors mit Isopropyl- $\beta$-D-Thiogalactopyranosid (IPTG) wird $\beta$-Galactosidase gebildet und Bakterienkolonien sind in der Lage, aus dem im Medium enthaltenen synthetischen Substrat 5-Brom-4-Chlor-3-Indolyl- $\beta$-D-Galactopyranosid (X-Gal) einen blauen Farbstoff freizusetzen. Bakterienzellen, die bei der Transformation einen leeren Vektor erhalten haben, erscheinen dadurch blau. Bei einer gelungenen Ligation wird das lacZ Gen durch das Insert unterbrochen und die $\beta$-Galactosidase somit inaktiviert. Positive Transformanten bilden daher weiße Kolonien. Bei sehr kleinen Inserts von nur einigen hundert Basenpaaren (z.B. bei der Klonierung von RACE-Produkten, 2.13.4) konnte allerdings gelegentlich die Inaktivierung der $\beta$-Galactosidase ineffizient sein, so daß alle Kolonien blau waren. Zur Blau/WeißSelektion wurde auf LB-Ampicillin-Platten ausgestrichen, denen zusätzlich $100 \mathrm{mM}$ IPTG und X-Gal (2\% (w/v) in DMF) Stammlösungen in jeweils 1:500 Verdünnung zugesetzt waren. Die IPTG und X-Gal Lösungen waren sterilfiltriert und wurden nach dem Autoklavieren zum Medium hinzugefügt.

\subsubsection{Herstellung elektrokompetenter Agrobacterium tumefaciens Zellen}

Zur Präparation von kompetenten Agrobacterium tumefaciens Zellen wurde eine $3 \mathrm{ml}$ Vorkultur (YEB-Medium mit entsprechenden Antibiotika, 2.2.3) mit einer Einzelkolonie eines A. tumefaciens Stammes angeimpft und über Nacht bei $28^{\circ} \mathrm{C}$ im Roller inkubiert. Am darauffolgenden Tag wurden mit $2 \mathrm{ml}$ dieser Kultur $50 \mathrm{ml}$ YEB-Medium angeimpft und unter Schütteln bei $28^{\circ} \mathrm{C}$ für ca. $4 \mathrm{~h}$ bis zu einer $\mathrm{OD}_{600}$ von 0,5 angezogen. Nach der Sedimentation der Bakterienzellen für $5 \mathrm{~min}$ bei $4.300 \mathrm{Upm}$ und $4{ }^{\circ} \mathrm{C}$ (Centrifuge $5810 \mathrm{R}$; Eppendorf Gerätebau, Hamburg) wurde das Pellet in $10 \mathrm{ml} \mathrm{0,15} \mathrm{M} \mathrm{NaCl-Lösung} \mathrm{resuspendiert.} \mathrm{Nach}$ einer weiteren Zentrifugation wurde das Zellsediment in $1 \mathrm{ml}$ eiskalter $75 \mathrm{mM} \mathrm{CaCl}$-Lösung resuspendiert und in $200 \mu 1$ Aliquots in flüssigem Stickstoff eingefroren. Die Zellen wurden bei $-80{ }^{\circ} \mathrm{C}$ gelagert. 


\subsubsection{Elektroporation von Agrobacterium tumefaciens}

Agrobacterium tumefaciens wurde durch Elektroporation transformiert. Dazu wurden $30 \mu 1$ kompetente Agrobakterien (2.14.7) auf Eis aufgetaut und mit $3 \mu \mathrm{l}$ des zu transformierenden Plasmids vermischt. Der Ansatz wurde für $1 \mathrm{~h}$ auf Eis inkubiert und anschließend in eine Spezialküvette gegeben, gemischt und in die Elektroporationsapparatur (Gene pulser II Pulse Controller Plus; BioRad, München) gestellt. Der Pulser wurde auf 2,5 V/ 200 k $\Omega / 25 \mu \mathrm{F} / 4,6$ msec eingestellt. Es wurde ein einmaliger Strompuls ausgelöst und die Küvette danach sofort auf Eis gestellt und $1 \mathrm{ml}$ SOC-Medium (2.14.5.2) hinzugefügt. Der Ansatz wurde in ein 1,5 $\mathrm{ml}$ Eppendorfgefäß überführt und für $2 \mathrm{~h}$ bei $28^{\circ} \mathrm{C}$ im Roller inkubiert. Danach wurde die Agrobakterien-Lösung auf YEB-Agarplatten (2.2.3) mit geeigneten Antibiotika ausplattiert und für zwei Tage bei $28^{\circ} \mathrm{C}$ inkubiert.

Positive Kolonien wurden durch Kolonie-PCR (2.13.3) oder, wenn auch eine Sequenzierung erwünscht war, durch Plasmid-Mini-Präparation (2.9.3.3) getestet. Da die Ausbeute v.a. große, in niedriger Kopienzahl vorliegender binärer Vektoren aus Agrobakterien sehr gering ist, mußten für eine Sequenzierung zunächst $5 \mu$ der Plasmid-Präparation in E. coli retransformiert werden (2.14.6). Aus den transformierten E. coli Zellen konnte dann ausreichend Plasmid-DNA für eine Sequenzierung (2.13.6) gewonnen werden. Von den positiven Agrobakterien-Kolonien wurden Glycerinkulturen angelegt (2.14.9).

\subsubsection{Bakteriendauerkultur}

Zur Anlage von Bakteriendauerkulturen positiver Klone wurden 0,2 $\mathrm{ml}$ Glycerin in $2 \mathrm{ml}$ Schraubdeckel-Eppendorfgefäßen autoklaviert. Von einer gut gewachsenen Übernachtkultur mit Antibiotikum wurden $0,8 \mathrm{ml}$ hinzuzugegeben und gut gemischt. Die Glycerinkulturen wurden in flüssigem Stickstoff schockgefroren und bei $-80{ }^{\circ} \mathrm{C}$ aufbewahrt.

\subsubsection{Transformation von Arabidopsis thaliana}

Die Transformation von Arabidopsis thaliana Ökotyp Columbia erfolgte nach der „floral dip“-Methode (Clough \& Bent 1998). Hierzu wurden zunächst Arabidopsis-Pflanzen ca. sechs Wochen unter Langtag-Bedingungen angezogen, da die Pflanzen auf diese Weise eine große Anzahl an Infloreszenzsprossen bildeten. Wenn die meisten Sprosse eine Höhe von 4$10 \mathrm{~cm}$ erreicht hatten, erfolgte die Transformation. 
Hierzu wurde der Agrobakterien-Stamm, der das interessierende Gen in einem passenden binären Vektor enthielt, bei $25-28{ }^{\circ} \mathrm{C}$ in $500 \mathrm{ml}$ YEB-Flüssigmedium (2.2.3) angezogen, das die notwendigen Antibiotika enthielt (normalerweise Kanamycin, und Rifampicin). Nach Erreichen einer $\mathrm{OD}_{600}$ von 0,6-1,0 wurde die Bakterien-Suspension auf mehrere Gefäße aufgeteilt und für $10 \mathrm{~min}$ bei $4300 \mathrm{Upm}$ abzentrifugiert (Centrifuge $5810 \mathrm{R}$; Eppendorf Gerätebau, Hamburg). Die Pellets wurden in frisch angesetzter, unsteriler $5 \%(\mathrm{w} / \mathrm{v})$ Saccharose-Lösung resuspendiert, wieder vereinigt und die $\mathrm{OD}_{600}$ der Suspension mit Saccharose-Lösung auf 0,6-0,8 eingestellt. Diese Bakterien-Suspension wurde in ein breithalsiges Becherglas überführt und als ein mildes Detergenz $0.05 \%$ (v/v) Silwet L-77 (Lehle Seeds, Round Rock, USA) hinzugegeben.

Zur Transformation wurden die Pflanzen mit ihren Blütenständen in die AgrobakterienSuspension getaucht und für 2-3 sec darin geschwenkt. Die Bakteriensuspension wurde dabei ständig langsam gerührt. Nachdem die Pflanzen abgetrocknet waren (ca. 1 h), wurden sie wieder zurück in die Klimakammer gestellt, und blieben noch für einen Tag unter einer Schutzhaube um ein zu schnelles Eintrocknen des Bakterienfilms zu verhindern. Danach wurden die Arabidopsis-Pflanzen normal weiter angezogen und nach ca. 3-4 Wochen die Samen geerntet. Von diesen konnten bis zu $1 \%$ transgen sein.

Die Selektion der aus den Samen angezogenen Pflanzen erfolgte je nach verwendetem Vektor (2.2.4): Bei pCAMBIA3300-Konstrukten, die eine Resistenz gegen Glufosinat („BASTA“) trugen, wurden die Samen zur Keimung auf Komposterde ausgelegt. Ca. 3 Wochen nach der Keimung wurden die jungen Pflanzen mit einer $10 \mathrm{mM}$ „BASTA”-Lösung (Agrevo, Düsseldorf) besprüht. Nach 3-4 Tagen verfärbten sich daraufhin die untransformierten Pflanzen gelblich und starben ab, wohingegen sich transgene Arabidopsis-Pflanzen unbeeinflußt weiterentwickelten.

Bei pBI101.3-Konstrukten diente eine vektorkodierte Kanamycin-Resistenz zur Selektion. Dazu wurden die Samen zunächst durch eine Behandlung mit Natriumhypochlorid oberflächensterilisiert. Die Sterilisation erfolgte unter einer Sterilbank. Etwa $50 \mu 1$ Samen wurden in ein Eppendorfgefäß gefüllt und $3 \mathrm{~min}$ in Natriumhypochlorid-Lösung (6-14\% aktives Chlor, Sigma-Aldrich, Steinheim) geschüttelt. Nach dem Abzentrifugieren der Samen und dem Abnehmen des Hypochlorids erfolgte eine weitere Wäsche für 3 min in $70 \%$ Ethanol. Die Samen wurden erneut abzentrifugiert und der Ethanol abgenommen. Anschließend wurde dreimal für $5 \mathrm{~min}$ mit sterilem $\mathrm{H}_{2} \mathrm{O}$ gewaschen. Mit dem letzten Waschwaser wurden die Samen danach direkt auf eine Selektionsplatte mit MS-Km Medium (2.2.3) plattiert. Einige Zeit nach der Keimung waren nichttransgene Pflanzen an ihren 
bleichen Keimblättern und dem gehemmten Wachstum erkennbar. Sobald die Selektion deutliche Unterschiede zwischen transgenen und nichttransgenen Pflanzen zeigte, wurden die Transformanden auf Komposterde überführt.

\subsection{Funktionelle Expression von Membranproteinen in Xenopus Oocyten}

Diese Arbeiten wurden im Labor von PD Dr. Christine Struck in der Abteilung für Phytopathologie der Universität Konstanz durchgeführt und die genaue Durchführung ist in der Literatur beschrieben (Voegele et al. 2001). Die offenen Leseraster der betreffenden Gene wurden in den Vektor pBF1 kloniert (2.14). Das pBF1-Plasmid kodiert für eine 40 Nukleotide lange PolyA-Sequenz stromabwärts der Klonierungsstelle, die für eine effiziente Expression von Membrantransportproteinen in Xenopus Oocyten notwendig ist (Boorer et al. 1996). Von den Plasmidkonstrukten wurde in vitro cRNA transkribiert („mMessage mMachine Kit”; Ambion, Huntingdon, England). $30 \mathrm{ng}$ cRNA wurden in operativ aus einem XenopusWeibchen entfernte Oocyten mikroinjiziert. Zur Negativkontrolle wurden Oocyten mit Wasser injiziert. Bis zu den elektrophysiologischen Untersuchungen wurden die Oocyten 5-6 Tage zur Regeneration bei $16{ }^{\circ} \mathrm{C}$ in Barth-Medium $(88 \mathrm{mM} \mathrm{NaCl}, 1 \mathrm{mM} \mathrm{KCl}, 0,41 \mathrm{mM}$ $\mathrm{CaCl}_{2}, 2,5 \mathrm{mM} \mathrm{NaHCO} 3,0,33 \mathrm{mM} \mathrm{Ca}\left(\mathrm{NO}_{3}\right)_{2}, 0,82 \mathrm{mM} \mathrm{MgSO} 4,7,5 \mathrm{mM}$ Tris/HCl pH 7,4) mit je $10 \mu \mathrm{g} / \mathrm{ml}$ Penicillin und Streptomycin gehalten. Diese Vorbereitungen wurden von C. Struck durchgeführt.

Nach der Regeneration der Oocyten und Expression des Transportproteins konnten durch Substrattransport hervorgerufene Änderungen des Membranpotentials in vivo über eine injizierte Mikroelektrode gemessen werden. Ei 
kein negatives Membranpotential gemessen, oder es näherte sich relativ schnell $0 \mathrm{mV}$ an. In diesem Fall wurde die Messung abgebrochen. War das Membranpotential für ca. 2 min stabil oder sank sogar, so wurde mit der Messung begonnen. Über ein Ventilsystem konnte dazu die die Meßkammer durchspülende Flüssigkeit geändert werden. Zuerst wurde die Meßzelle mit Transportmedium $\mathrm{pH} 5,0$ äquilibriert, was bereits $\mathrm{zu}$ einem leichten Anstieg des Membranpotentials führte. Dann wurde die gewünschte Aminosäure (5, 0,5 oder $0,1 \mathrm{mM}$ in Transportmedium $\mathrm{pH}$ 5,0) eingeleitet. Wenn das Substrat transportiert wurde, führte dies zu einer starken anfänglichen Depolarisation, die dann wieder zurückging und sich bei einem positiveren Membranpotential stabilisierte. Ein typischer Meßverlauf ist in Abb. 3.7 im Ergebnisteil dargestellt. Die Potentialdifferenz zwischen der Inkubation in Transportmedium pH 5,0 ohne und mit Aminosäure wurde bestimmt und relativ zur Referenzaminosäure Alanin gesetzt. Nach jeder Einzelmessung wurde die Oocytenmembran durch Spülen mit Transportmedium pH 7,5 regeneriert. War bei diesem Schritt kein Absinken des Membranpotentials feststellbar, so wurde die Oocyte verworfen. Mit einer einzelnen Oocyte konnten nacheinander etwa 3-20 verschiedene Aminosäuren oder Konzentrationen gemessen werden. Die Meßelektrode konnte mehrfach verwendet werden. Sie wurde aus der nicht mehr benötigten Ooycte gezogen und vor der nächsten Mikroinjektion sowohl unter dem Binokular als auch durch eine Widerstandsmessung auf Intaktheit und mögliche Verstopfungen untersucht. Nicht mehr benötigten Oocyten wurden zur Proteinisolation aufgeschlossen (2.6) und die Proteine später für SDS-Polyacrylamid-Gelelektrophorese (2.8.1) und Western-Blots (2.17.2) verwendet.

\subsection{Nachweis der Promotoraktivität durch einen histochemischen GUS-Test}

Die Aktivität und Gewebespezifität von Promotoren kann durch die Fusion mit sogenannten Reportergenen analysiert werden. Für pflanzliche Systeme ist das GUS Reportergen gebräuchlich, welches das bakterielle Enzym $\beta$-Glucuronidase (GUS) kodiert. Das GUSProtein wird in transgenen Pflanzen i.d.R. problemlos in aktiver Form exprimiert. Durch die $\beta$-Glucuronidase wird aus dem synthetischen Substrat 5-Brom-4-Chlor-3-Indolyl- $\beta$-DGlucuronat (X-Gluc) ein blauer Farbstoff freigesetzt. Das Gewebe transgener Pflanzen, die ein Konstrukt enthalten, bei dem GUS unter Kontrolle des zu untersuchenden Promotors steht, kann mit einer X-Gluc Lösung infiltiert und so die Promotoraktivität anhand der Blaufärbung sichtbar gemacht werden.

Zur Färbung wurde eine modifizierte Methode nach Jefferson et al. (1987) verwendet. X-Gluc Stammlösung wurde 1:50 in GUS-Waschpuffer verdünnt und das zu untersuchende 
Pflanzenmaterial wurde unter Vakuum mit dieser Lösung infiltriert. Dazu wurde an einen Exsikkator mit einer Wasserstrahlpumpe solange immer wieder Unterdruck angelegt und zwischendurch belüftet bis keine Luftblasen mehr aufstiegen und das vollständig infiltrierte Pflanzenmaterial in der Lösung zu Boden sank. Dem Waschpuffer wurden dazu 3-10 mM Kaliumferricyanit und Kaliumferrocyanit in gleichen Teilen zugesetzt, um die spontane Oxidation des möglicherweise im Gewebe diffundierenden X-Gluc und damit eine unspezifische Hintergrundfärbung zu vermeiden. Zur Entwicklung der GUS-Färbung wurden die Proben bei $37{ }^{\circ} \mathrm{C}$ inkubiert. Dies geschah im Dunkeln, da X-Gluc lichtempfindlich ist. Die Inkubation konnte je nach Stärke der Promotoraktivität für einige Stunden bis zu mehreren Tagen fortgesetzt werden. Gestoppt wurde die Färbungsreaktion durch Überführen der Proben in GUS-Fixativ, worin sie für $1 \mathrm{~h}$ inkubiert wurden. Anschließend wurden zur besseren Visualisierung der Färbung die pflanzlichen Farbstoffe (v.a. Chlorophyll) aus dem Gewebe extrahiert. Dies geschah durch einstündige Inkubation in $75 \%$ Ethanol, gefolgt von einer Inkubation über Nacht in 99,6 \% Ethanol. Am nächsten Tag wurden die Proben zur Lagerung wieder in $75 \%$ Ethanol überführt und waren so lange Zeit haltbar.

GUS-Waschpuffer:

$$
\begin{array}{ll}
50 \mathrm{mM} & \mathrm{Na}_{2} \mathrm{HPO}_{4} / \mathrm{NaH}_{2} \mathrm{PO}_{4} \mathrm{pH} \mathrm{6,8} \\
1 \mathrm{mM} & \text { EDTA } \\
0,1 \%(\mathrm{v} / \mathrm{v}) & \text { Tween } 20 \\
3-20 \mathrm{mM} & \mathrm{K}_{4}\left[\mathrm{Fe}(\mathrm{CN})_{6}\right] \times 3 \mathrm{H}_{2} \mathrm{O} \\
3-20 \mathrm{mM} & \mathrm{K}_{3}\left[\mathrm{Fe}(\mathrm{CN})_{6}\right]
\end{array}
$$

X-Gluc Stammlösung: $\quad 100 \mathrm{mM}$ X-Gluc in DMF

$$
\begin{aligned}
& \text { GUS-Fixativ: } \\
& \qquad \begin{array}{ll}
50 \%(\mathrm{v} / \mathrm{v}) & \text { Ethanol } \\
10 \%(\mathrm{v} / \mathrm{v}) & \text { Essigsäure } \\
5 \%(\mathrm{v} / \mathrm{v}) & \text { Formaldehyd }
\end{array}
\end{aligned}
$$

\subsection{Immunologische Methoden}

Mit immunologischen Methoden werden Proteine spezifisch identifiziert und lokalisiert. Dazu werden zunächst Antikörper gegen das untersuchte Protein benötigt, mit denen dann in Western-Blots bzw. durch Immunolokalisation das gewebespezifische Vorkommen des 
Proteins nachgewiesen werden kann. In dieser Arbeit wurde dies für das BnAAP6-Protein durchgeführt.

\subsubsection{Herstellung von polyklonalen Antikörpern}

Für den immunologischen Nachweis des BnAAP6 Proteins sollte ein polyklonaler Antikörper hergestellt werden. Dazu wurden zunächst als Antigene geeignete Peptidabschnitte des Proteins ausgewählt. Als Kriterien dienten dabei zuerst eine möglichst hohe Variabilität der entsprechenden Region innerhalb der AAP-Transporterfamilie und die Lage außerhalb einer Transmembranhelix. Entsprechende Sequenzen wurden weiterhin auf ihre mögliche Antigenizität hin untersucht, die z.B. durch die Anzahl der Ladungen, das Vorhandensein oder Fehlen potentieller Glykosylierungsstellen und die wahrscheinliche Ähnlichkeit der Tertiärstruktur im vollständigen Protein und im Oligopeptid bestimmt wird. Zusätzlich wurde von der Firma Pineda Antikörper-Service (Berlin) eine Epitopanalyse durchgeführt. Es ergaben sich zwei möglicherweise geeignete Sequenzen: Der N-Terminus (Nterm) von BnAAP6 wies die höchste Antigenizität und geringste Homologie zu verwandten Proteinen auf. Eine weitere als Seq5 bezeichnete Sequenz, die mit hoher Wahrscheinlichkeit in einer intrazellulären Schleife der Polypeptidkette liegt wies eine hohe Antigenizität aber auch Homologie zu anderen AAPs auf:

\section{Nterm:MEKKSMFIEQSFTDH(K)*}

\section{Seq5: QSAKRWPDNKFITGE}

* der letzte Lysin (K)-Rest wurde bei der Konstruktion des MBP-BnAAP6-Nterm Fusionsproteins (s.u.) weggelassen.

Zur Antikörpergewinnung wurden zwei verschiedene Strategien verfolgt. Zuerst wurden zwei Oligonukleotide synthetisiert (Carl Roth, Karlsruhe), die den beiden Strängen der für das Peptid Nterm kodierenden DNA-Sequenz entsprachen (ANTI-1 und ANTI-2, Tab. 2.1). Diese Oligonukleotide wurden zu doppelsträngiger DNA zusammengelagert und in den mit SacI und HindIII linearisierten (2.14.1) Vektor pMAL-c2X ligiert (2.14.4). Dadurch wurde das kodierte Peptid im korrekten Leseraster C-terminal an Maltose-Bindeprotein (MBP) aus $E$. coli fusioniert. Zum Annealing wurden je $1 \mu$ l Oligonukleotid (100 pmol/ $\mu \mathrm{l})$ mit $10 \mu 15 \mathrm{x}$ PNK-Puffer (Promega, Mannheim) und $38 \mu \mathrm{H}_{2} \mathrm{O}$ gemischt und der Ansatz zunächst für 2 min bei $85{ }^{\circ} \mathrm{C}$ denaturiert. Danach erfolgte das Annealing bei $65{ }^{\circ} \mathrm{C}$ für 5 min und eine Inkubation bei $37{ }^{\circ} \mathrm{C}$ ebenfalls für $15 \mathrm{~min}$. Die zusammengelagerten Oligos wurden 
anschließend durch das Anfügen von Phosphatresten an die freien 5' Enden für die Ligation vorbereitet: $3,5 \mu 1$ angelagerte Oligonukleotide wurden mit $2 \mu 15$ x PNK-Puffer, 0,5 $\mu 1$ T4 Polynukleotidkinase (PNK) (19 U/ $\mu$ l; Promega, Mannheim), 0,5 $\mu 110 \mathrm{mM}$ ATP und 3,5 $\mu 1$ $\mathrm{H}_{2} \mathrm{O}$ gemischt und für $1 \mathrm{~h}$ bei $37{ }^{\circ} \mathrm{C}$ inkubiert. In zwei separaten Ligationsansätzen mit unterschiedlichen Insert/Vektor-Verhältnissen wurden je $1 \mu 1$ angelagerte phosphorylierte Oligonukleotide entweder mit 0,25 $\mu \mathrm{l}$ (ca. 0,125 $\mu \mathrm{g}$ ) Vektor und 2,75 $\mu 1 \mathrm{H}_{2} \mathrm{O}$ oder mit $1 \mu \mathrm{l}$ (ca. $0,5 \mu \mathrm{g}$ ) Vektor und $2 \mu 1 \mathrm{H}_{2} \mathrm{O}$ versetzt und $5 \mathrm{~min}$ bei $65^{\circ} \mathrm{C}$ inkubiert. Anschließend wurde

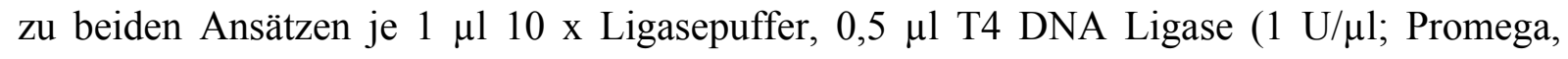
Mannheim) und 4,5 $\mu 1 \mathrm{H}_{2} \mathrm{O}$ gegeben. Die Ligation erfolgte über Nacht bei $15{ }^{\circ} \mathrm{C}$.

Die Ligationsansätze wurden zur Expression des Fusionsproteins in E. coli BL21 (DE3) transformiert (2.14.6) und die Expression mit $1 \mathrm{mM}$ IPTG in einer Bakterienkultur induziert. Aus den Bakterienzellen wurde das Gesamtprotein isoliert (2.6) und in einer SDS-PAGE mit Gesamtprotein aus BL21 (DE3) Zellen ohne Vektor verglichen (2.8.1). Eine nur in Fusionsprotein exprimierenden Zellen auftretende deutliche Bande in der erwarteten Größe von $45 \mathrm{kDa}$ wurde in einer präparativen SDS-PAGE mit anschließender KCl-Färbung und Gelelution (2.8.4) aufgereinigt. Das erhaltene Protein wurde zur Immunisierung von Kaninchen verwendet.

Ein deutlicher Nachteil dieser Methode bestand darin, daß das Verhältnis von antigenem Peptid zu Trägerprotein nur 1:1 betrug, so daß ein großer Teil der erhaltenen polyklonalen Antikörper gegen MBP und nicht BnAAP6 gerichtet war. Es wurden deshalb außerdem die Peptide Nterm und Seq5 synthetisch hergestellt und über einen zusätzlichen C- (Nterm) bzw. N-terminalen (Seq5) Cysteinrest mit KLH (Keyhole Limpid Hemocyanine) als Trägerprotein chemisch gekoppelt. Über eine chemische Kopplung konnten jeweils mehrere antigene Peptidmoleküle an ein Trägerproteinmolekül gebunden werden. Auch mit diesen KLHFusionsproteinen wurden Kaninchen immunisiert.

Bei allen drei Antigenen wurden jeweils drei Kaninchen mit $200 \mu \mathrm{g}$ Protein injiziert und nach 30 Tagen mit weiteren $100 \mu \mathrm{g}$ Protein erneut injiziert (geboostet). Antiserenproben (1,5 ml) wurden am 1. (= Präimunserum), 30., 61., 90. und 120. (nur KLH-Antigene) Tag nach der Erstinjektion entnommen. Die mit MBP-Antigen immunisierten Kaninchen wurden am 120. Tag, die mit KLH-Antigenen immunisierten Tiere am 150. Tag getötet und ausgeblutet. Die Gesamtmenge gewonnenen Immunserums betrug etwa $75 \mathrm{ml}$. Je $50 \mathrm{ml}$ der anti-KLH-NtermImmunseren wurden über eine Affinitätssäule (Peptid Nterm gekoppelt an Sepharose 4B) gereinigt (monospezifische Fraktionen). Die Synthese der Nterm und Seq5 Peptide, 
Immunisierung der Kaninchen und Affinitätsreinigung der Antiseren wurde von der Firma Pineda Antikörper-Service (Berlin) durchgeführt.

\subsubsection{Western-Blot}

Analog zum Southern und Northern Blot für DNA bzw. RNA wird beim Western Blot ein einzelnes Protein spezifisch in einem Gemisch nachgewisen, das zuvor gelektrophoretisch aufgetrennt und zur Fixierung auf eine Membran übertragen (geblottet ) wurde. Der Nachweis erfolgt in diesem Fall durch spezifische Antikörper.

Die Protein-Proben wurden zuerst durch eine SDS-PAGE (2.8.1) aufgetrennt, danach wurde das Sammelgel abeschnitten und das Trenngel in die Western-Blot-Apparatur eingespannt. Sowohl die SDS-PAGE als auch das Blotten erfolgten dabei in einer Mini Protean 3 Kammer (BioRad, München). In einer Spannhalterung wurden in der Reihenfolge, die in der Blotkammer später der Flußrichtung von der Kathode (-) zur Anode (+) entsprach, ein Tuch, ein Filterpapier, das Gel, eine entsprechend zugeschnittene Nitrozellulosemembran (Hybond; Amersham Biosciences, Freiburg), ein weiteres Filterpapier und noch ein Tuch übereinandergelegt. (Tücher und Filterpapiere waren im Mini Protean 3 System enthalten). Die Halterung wurde geschlossen und in die Blotkammer gesteckt. Filter und Nitrozellulosemembran waren vorher mit Blotpuffer angefeuchtet worden und der gesamte Aufbau erfolgte in Blotpuffer, um Luftblasen zwischen den Schichten zu vermeiden. Der Transfer erfolgte in der mit Blotpuffer gefüllten Kammer für 50 min und $60 \mathrm{~V}$ bei maximaler Stromstärke (Consort E 865; Scie-Plas, Southam, England). Zur Kühlung wurde in die Kammer ein eisgefülltes Kühlaggregat gestellt.

$\begin{array}{lll}\text { Blotpuffer: } & 25 \mathrm{mM} & \text { Tris (pH nicht eingestellt) } \\ & 192 \mathrm{mM} & \text { Glycin } \\ & 20 \%(\mathrm{v} / \mathrm{v}) & \text { Methanol }\end{array}$

Zur Überprüfung des Transfers wurde die Nitrozellulosemembran anschließend in PonceauRot Färbelösung angefärbt. Diese fixiert gleichzeitig die Proteine. Dazu wurde die Membran 2 min in die Färbelösung gelegt und dann 3-4 x mit $\mathrm{H}_{2} \mathrm{O}$ gespült, bis die Proteine als rote Banden sichtbar waren. Die Größenstandard-Banden wurden mit einem Kugelschreiber markiert. Die Ponceau-Färbung ist reversibel und durch weiteres Spülen mit Wasser wurde die Membran weitestgehend wieder entfärbt. Letzte Reste von Ponceau-Rot verschwanden dann während den nachfolgenden Inkubationen. 
Ponceau-Rot Färbelösung:

$$
\begin{array}{ll}
2 \%(\mathrm{w} / \mathrm{v}) & \text { Ponceau S } \\
3 \%(\mathrm{w} / \mathrm{v}) & \text { Trichloressigsäure }
\end{array}
$$

Als nächstes wurde die Nitrozellulosemembran für mindestens $2 \mathrm{~h}$ bis über Nacht in Blockpuffer auf einem Kippschüttler (Polymax 1040; Heidolph, ORT) inkubiert um überschüssige Bindungskapazitäten abzusättigen. Das Blocken erfolgte bei RT oder bei $4{ }^{\circ} \mathrm{C}$, wenn über Nacht inkubiert wurde. Erst danach wurde 45 min bei RT mit primärem (proteinspezifischem) Antikörper inkubiert. Zur Verringerung von Hintergrundsignalen erfolge auch diese Inkubation in (frischem) Blockpuffer; der Antikörper wurde in einer Verdünnung von 1:500 eingesetzt. Anschließend wurde der Blot einmal kurz und viermal für $4 \mathrm{~min}$ in TBS-T gewaschen, um nicht oder unspezifisch gebundene IgG-Moleküle zu entfernen. Als sekundärer Antikörper diente Peroxidase-gekoppeltes Protein A (EIA Grade Protein A-Horseradish Peroxidase Conjugate; BioRad, München) 1:3.000 in TBS-T verdünnt. Protein A aus dem Bakterium Staphylococcus aureus bindet unspezifisch an WirbeltierImmunglobuline (Boyle \& Reis 1987). Auch diese Inkubation erfolgte für 45 min bei RT. Danach wurde nochmals einmal kurz und dreimal für 4 min mit TBS-T und schließlich einmal für 10 min mit TBS gewaschen.

TBS: $\quad 50 \mathrm{mM} \quad$ Tris/ $\mathrm{HCl} \mathrm{pH} \mathrm{7,5}$

$$
150 \mathrm{mM} \quad \mathrm{NaCl}
$$

TBS-T: $\quad 0,1 \%(\mathrm{v} / \mathrm{v}) \quad$ Triton-X-100

$$
\text { in TBS }
$$

Blockpuffer: $3 \%(w / v) \quad$ Trockenmilchpulver (Carl Roth, Karlsruhe) in TBS-T

Der Nachweis des primären Antikörpers und damit des gesuchten Proteins erfolgte über die an das Protein A gebundene Peroxidase. Sie katalysiert unter alkalischen Bedingungen die Oxidation von Luminol durch $\mathrm{H}_{2} \mathrm{O}_{2}$, wodurch Luminol zur Lichtemission angeregt wird. Verstärkt wird diese Reaktion durch Phenole. Die Halbwertszeit der Reaktion beträgt ca. 1 h. Diese Methode wird als „Enhanced Chemiluminescence“ (ECL) bezeichnet. Die Lichtemission kann schließlich durch das Auflegen eines Filmes detektiert werden. 
Die Nitrozellulosemembran wurde mit der Proteinseite nach oben auf eine Glasplatte gelegt und darauf frisch zusammengemischte ECL-1 und ECL-2 Lösung (1:1) (Amersham Biosciences, Freiburg) gegeben. Nach 1 min wurde die Flüssigkeit durch Abgießen und seitliches Absaugen mit Zellstoff wieder entfernt und die Membran luftblasenfrei mit Haushaltsfolie bedeckt. Anschließend wurde sofort für 1 min ein Film (Hyperfilm; Amersham Biosciences, Freiburg) aufgelegt. Je nach der Signalstärke auf diesem Film wurden ein oder mehrere weitere Filme mit angepaßten Expositionszeiten von $10 \mathrm{sec}$ bis $\mathrm{zu} 1 \mathrm{~h}$ aufgelegt. Die Filmentwicklung erfolgte in einem Optima Typ TR (MS Laborgeräte, Wiesloch).

\subsubsection{Immunohistochemischer Nachweis von Proteinen in Gewebeschnitten}

\subsubsection{Einbettung von Pflanzengewebe in Methacrylat}

Blätter von jungen, in $4 \mathrm{mM} \mathrm{NO}_{3}^{-}$-Hydrokulturlösung angezogenen Brassica napus Pflanzen der Sorte Lirajet wurden geerntet und mit einer frischen Rasierklinge in ca. 1 x $5 \mathrm{~mm}$ große Stücke zerteilt. Ca. 30-40 solcher Gewebestücke wurden in $3 \mathrm{ml}$ Fixierungslösung (Ethanol:Essigsäure 3:1, v/v) in einem Exsikkator infiltriert, an den ein Wasserstrahlvakuum angelegt wurde. Dieses wurde so lange beibehalten, bis keine Luftblasen mehr aus den Proben aufstiegen. Die Fixierungslösung wurde erneuert und die Proben für $1 \mathrm{~h}$ bei Raumtemperatur inkubiert. Anschließend wurde dreimal 30 min und dann über Nacht mit $75 \%$ techn. Ethanol, 1 mM DTT gewaschen. Am nächsten Tag erfolgte die Entwässerung der Proben über eine Ethanolreihe. Hierzu wurde das Gewebe jeweils 20 min mit 80, 85, 90, 95 \% techn. Ethanol, 1 mM DTT und anschließend zweimal 20 min mit 99,6 \% Ethanol, 1 mM DTT behandelt. Danach wurde der Ethanol schrittweise bei $4{ }^{\circ} \mathrm{C}$ durch Methacrylat-Mix ersetzt:

\begin{tabular}{lll}
\hline Dauer & Lösung & Mischungsverhältnis \\
\hline über Nacht & Methacrylat-Mix:Ethanol & $1: 2(\mathrm{v} / \mathrm{v})$ \\
$6 \mathrm{~h}$ & Methacrylat-Mix:Ethanol & $1: 1(\mathrm{v} / \mathrm{v})$ \\
über Nacht & Methacrylat-Mix:Ethanol & $2: 1(\mathrm{v} / \mathrm{v})$ \\
über Nacht & Methacrylat-Mix & \\
$6 \mathrm{~h}$ & Methacrylat-Mix & \\
über Nacht & Methacrylat-Mix & \\
\hline
\end{tabular}

Zur Polymerisation wurden die Proben in ultradünne, zur Hälfte mit Methacrylat-Mix gefüllte 0,2 ml PCR-Reaktionsgefäße überführt und mit einer Präpariernadel positioniert. Das 
Auspolymerisieren erfolgte für $18 \mathrm{~h}$ bei $4{ }^{\circ} \mathrm{C}$ durch Bestrahlung der Proben von unten mit UV-Licht (310 nm, ca. $10 \mathrm{~cm}$ Abstand).

\author{
Methacrylat-Mix: $75 \%(\mathrm{v} / \mathrm{v}) \quad$ Butyl-Methacrylat \\ $25 \%(\mathrm{v} / \mathrm{v}) \quad$ Methyl-Methacrylat \\ $0,5 \%(\mathrm{w} / \mathrm{v}) \quad$ Ethylbenzoin \\ $10 \mathrm{mM} \quad$ DTT \\ vor jedem Gebrauch 15 min mit $\mathrm{N}_{2}$ entgasen
}

\title{
2.17.3.2 Herstellung von Dünnschnitten
}

Von den in Methacrylat eingebetteten Objekten wurden an einem Ultramikrotom (Ultracut R; Fa. Leica, Bensheim) mit Glasmessern $2 \mu \mathrm{m}$ dicke Schnitte angefertigt. Diese wurden auf Poly-L-Lysin beschichtete Objektträger (Histobond; Fa. Marienfeld, Lauda-Königshofen) aufgebracht. Das Antrocknen erfolgte bei $40{ }^{\circ} \mathrm{C}$. In diesem Zustand konnten die Schnitte für nahezu unbegrenzte Zeit bei $4{ }^{\circ} \mathrm{C}$ gelagert werden.

\subsubsection{Behandlung der Schnitte mit Antikörpern und Fluoreszenzfarbstoffen}

Die Objektträger mit den Schnitten wurden in ein Becherglas gestellt und zum Entfernen des Methacrylats für 2 min in Aceton inkubiert. Die Rehydrierung erfolgte in einer Ethanolserie $(100,70,30 \%)$ mit Inkubationszeiten von je $30 \mathrm{sec}$. Anschließend wurden die Objektträger für $30 \mathrm{sec}$ in TBS-Puffer und dann für $45 \mathrm{~min}$ in Blockpuffer stehen gelassen. Die Objektträger wurden nun auf der Unterseite gut abgetrocknet und auf die Schnitte Deckgläschen plaziert, die durch an den Ecken angebrachte Knetgummi-Stückchen etwas Abstand zum darunterliegenden Objektträger besaßen. In diesen Spalt wurde der primäre Antikörper in einer Verdünnung von 1:500 in Blockpuffer pipettiert. Die Inkubation erfolgte bei $4^{\circ} \mathrm{C}$ über Nacht.

Am folgenden Tag wurden die Deckgläschen entfernt und die Objektträger in Bechergläsern dreimal für 10 min mit Blockpuffer gewaschen. Es folgte eine Inkubation für $1 \mathrm{~h}$ mit dem sekundären Antikörper. Dies war Anti-Rabbit IgG-Fluorescein Isothiocyanat (FITC)-Isomer 1-Konjugat (Sigma-Aldrich, Steinheim) 1:300 verdünnt mit Blockpuffer. Da der Fluoreszenzfarbstoff FITC lichtempfindlich ist, fand die Inkubation und anschließende Wäsche im Dunkeln statt. Die nicht gebundenen Antikörper wurden durch eine Wäsche für fünfmal $5 \mathrm{~min}$ in Blockpuffer entfernt. Um alle Reste des Trockenmilchpulvers von den 
Objektträgern zu beseitigen, folgten noch drei weitere Waschschritte in $\mathrm{H}_{2} \mathrm{O}$. Zum schnelleren Trocknen der Proben wurden die Objektträger zum Abschluß kurz in 99,6 \% Ethanol getaucht. Zuletzt wurde ein Wassertropfen auf den Objektträger gegeben und die Schnitte mit Deckgläschen bedeckt. Die FITC-Fluoreszenz wurde durch Betrachtung der Schnitte in einem Fluoreszenz-Mikroskop mit Videokamera (BX51; Olympus, Hamburg) detektiert. Die Anregung erfolgte bei $450-490 \mathrm{~nm}$.

TBS:

$$
\begin{array}{ll}
50 \mathrm{mM} & \text { Tris/ } \mathrm{HCl} \mathrm{pH} 7,5 \\
150 \mathrm{mM} & \mathrm{NaCl}
\end{array}
$$

Blockpuffer: $1 \%(\mathrm{w} / \mathrm{v}) \quad$ Trockenmilchpulver (Carl Roth, Karlsruhe) in TBS

\subsection{Computergestützte Analyseverfahren}

\subsubsection{Sequenzanalyse von DNA und Proteinen}

Für die Suche und den Vergleich von öffentlich zugänglichen Sequenzen wurden die GenBank (http://www.ncbi.nlm.nih.gov, „BLAST“, Altschul et al. 1990) und die Datenbank des EMBL (http://www.embl-heidelberg.de/Services/index.html) genutzt. Bei der EMBLDatenbank erfolgte auch die Veröffentlichung der in dieser Arbeit isolierten Sequenzen.

Die Analyse von DNA- und Proteinsequenzen erfolgte im wesentlichen mit der Version 9.1 des Wisconsin Package der Genetics Computer Group (GCG), Madison, USA. Hierzu gehören u.a. Programme, mit denen Nukleotid- oder Aminosäure-Sequenzen paarweise verglichen (bestfit, gap) oder sogenannte Alignments von Sequenzgruppen erstellt werden können (pileup) und ein Programm (map), das Nukleotidsequenzen in Aminosäuresequenzen übersetzt und Restriktionsschnittstellen identifiziert. Nähere Beschreibungen der einzelnen Funktionen sind unter der Internet-Adresse http://gcg.gwdg.de abrufbar. Zur Untersuchung der Proteinsequenz auf mögliche zelluläre Lokalisationssignale dienten:

1. PSORT (http://psort.ims.u-tokyo.ac.jp)

2. TARGETP 1.0 (http://www.cbs.dtu.dk/services/TargetP) 
Zur Untersuchung von Promotorsequenzen auf mögliche Bindungsstellen für Transkriptionsfaktoren wurden drei verschiedene Online-Resourcen genutzt:

1. TRANSFAC (http://transfac.gbf.de/TRANSFAC)

2. TFSEARCH (http://pdap1.trc.rwcp.or.jp/research/db/TFSEARCH.html)

3. PROMOTER SCAN II (http://www.molbiol.ox.ac.uk/promoterscan.htm)

\subsubsection{Untersuchungen zur Proteinstruktur}

Neben der reinen Primärstruktur sind Informationen über die Sekundär- bzw. Tertiärstruktur von Proteinen sehr wichtig, da von diesen auf mögliche Funktionen und Eigenschaften geschlossen werden kann. Hier war v.a. die Analyse von putativen transmembranen $\alpha$-Helices wichtig.

Als Online-Resource wurde das Programm PredictProtein (http://www.emblheidelberg.de/predictprotein) genutzt. Zur Erstellung von Hydropathie-Diagrammen diente der Protein Hydrophilicity Search and Comparison Server des Weizmann Institute of Science, Israel (http://bioinformatics.weizmann.ac.il/hydroph/index.html). Desweiteren wurden diverse Proteinanalyse-Programme des Wisconsin Package der Genetics Computer Group (GCG) verwendet.

\subsection{Statistische Auswertung der Experimente}

Angegeben wurden entweder Ergebnisse, die den typischen Verlauf aller durchgeführten Experimente wiedergeben oder zusammengefaßte Ergebnisse. Im letzteren Fall wurde der arithmetische Mittelwert \pm Standardabweichung angegeben. Die Anzahl der durchgeführten Experimente (n) betrug mindestens 3, wenn dieses nicht anders im Text beschrieben ist.

Mittelwert $=\frac{\Sigma \text { Einzelmessungen }}{\text { Anzahl der Einzelmessungen (n) }}$

$S D=\sqrt{\frac{\sum_{i=1}^{n}\left(x_{i}-x\right) I}{n-1}}$ 


\section{Ergebnisse}

\subsection{Feldversuche zur Variabilität der Stickstoffnutzung und -verteilung in B. napus}

Zur Untersuchung der Variabilität der Stickstoffnutzung bei Raps wurden von 1999-2002 doppelt haploide (DH-) Linien aus einer Kreuzung der Winterrapssorten Apex und Mohican, sowie die beiden Elternsorten unter zwei verschiedenen Stickstoffbedingungen $\left(\mathrm{N}_{0}=0\right.$ und $\mathrm{N}_{240}=240 \mathrm{~kg} \mathrm{~N} \mathrm{ha}^{-1} \mathrm{a}^{-1}$ ) angebaut. DH-Linien wurden verwendet, weil sie für jedes Allel homozygot sind. In den Anbauperioden 1999/2000 und 2000/2001 wurden 45 DH-Linien verglichen, 2001/2002 acht (DH4, 5, 15, 18, 28, 29, 33 und 42). Diese acht DH-Linien waren aufgrund ihres extremen Verhaltens bezüglich verschiedener, aus züchterischer Sicht interessanter Merkmale ausgewählt worden. Die Elternsorten waren in allen drei Anbaujahren unter den Versuchspflanzen. Von jeder Linie und beiden N-Düngungsstufen wurden je zwei Versuchsreihen angelegt. In den Blättern wurden die Gesamt-Aminosäuregehalte, Nitratreduktaseaktivitäten (NRA) und Nitratgehalte bestimmt. Daten zum Proteingehalt der Samen der Versuchspflanzen wurden freundlicherweise von Prof. Becker (Institut für Pflanzenbau und Pflanzenzüchtung der Universität Göttingen) zur Verfügung gestellt.

Tabelle 3.1 faßt die Ergebnisse der Feldversuche zusammen. Die Proteingehalte im Samen variierten zwischen 12,9 und $16,8 \%{ }_{\mathrm{TG}}$ bei $\mathrm{N}_{0}$ und zwischen 17,8 und $21,3 \%$ TG bei $\mathrm{N}_{240}$, mit Mittelwerten von 14,8 \pm 0,8 bzw. 19,2 $\pm 0,9 \%$ TG. Die Blatt-Aminosäuregehalte lagen zwischen 4,8-17 $\left(\mathrm{N}_{0}\right)$ und 12-24 $\mu$ mol $\mathrm{g}_{\mathrm{FG}}^{-1}\left(\mathrm{~N}_{240}\right)$ mit Mittelwerten von 9,9 \pm 3,2 $\left(\mathrm{N}_{0}\right)$ und $16,4 \pm 2,5 \mu \mathrm{mol} \mathrm{g}_{\mathrm{FG}}^{-1}\left(\mathrm{~N}_{240}\right)$. Blattproben von bei $\mathrm{N}_{0}$-Bedingungen gewachsenen Pflanzen wiesen Nitratreduktaseaktivitäten von 11-47 $\mathrm{nmol}_{\mathrm{FG}^{-1}} \mathrm{~min}^{-1}$ auf (Mittelwert 25,7 \pm 9,3). Bei den $\mathrm{N}_{240}$-Pflanzen lagen diese Werte in einem Bereich von 27-99 $\mathrm{nmol} \mathrm{g}_{\mathrm{FG}}{ }^{-1} \mathrm{~min}^{-1}$, mit einem Mittelwert von 60,6 $\pm 15,5$. Die Blatt-Nitratgehalte dieser Pflanzen variierten zwischen 8 und $19 \mu \mathrm{mol} \mathrm{g}_{\mathrm{FG}}{ }^{-1}$ (Mittelwert: 14,6 $\pm 3,8$ ). Bei den $\mathrm{N}_{0}$-Pflanzen wurden Nitratgehalte von $<0,1$ bis $3 \mu \mathrm{mol} \mathrm{g}_{\mathrm{FG}}{ }^{-1}$ gemessen, mit einem Mittelwert von $0,1 \pm 0,1 \mu \mathrm{mol}_{\mathrm{FG}}{ }^{-1}$.

Tabelle 3.1 (nächste Seite): Ergebnisse der Feldversuche zur Stickstoffnutzung bei Winterraps. Blatt-Aminosäuregehalt, Blatt-Nitratreduktaseaktivität und Samen-Proteingehalt sind jeweils als Mittelwerte über alle Anbaujahre angegeben. Durch Fettdruck und graue Hinterlegung hervorgehobene Werte sind Mittelwerte aus drei, die nicht hervorgehobenen Daten Mittelwerte aus zwei Jahren. Gesamtmittelwerte für alle Sorten \pm Standardabweichungen. 
Tab. 3.1: Ergebnisse der Feldversuche. (Legende auf S. 93)

\begin{tabular}{|c|c|c|c|c|c|c|c|c|}
\hline \multirow[t]{2}{*}{ Linie } & \multicolumn{2}{|c|}{$\begin{array}{l}\text { Aminosäuregehalt } \\
\text { im Blatt } \\
\left(\mu \mathrm{mol} \mathrm{g}_{\mathrm{FG}}^{-1}\right)\end{array}$} & \multicolumn{2}{|c|}{$\begin{array}{l}\text { Nitratreduktase- } \\
\text { Aktivität im Blatt } \\
\left(\mathrm{nmol} \mathrm{g}{ }_{\mathrm{FG}}^{-1} \mathrm{~min}^{-1}\right)\end{array}$} & \multicolumn{2}{|c|}{$\begin{array}{l}\text { Nitratgehalt } \\
\text { im Blatt } \\
\left(\mu \mathrm{mol} \mathrm{g}{ }_{\mathrm{FG}}{ }^{-1}\right)\end{array}$} & \multicolumn{2}{|c|}{$\begin{array}{c}\text { Proteingehalt im } \\
\text { Samen } \\
\left.\text { (\% }{ }_{\mathrm{TG}}\right)\end{array}$} \\
\hline & $\mathbf{N}_{0}$ & $\mathbf{N}_{240}$ & $\mathbf{N}_{0}$ & $\mathrm{~N}_{240}$ & $\mathrm{~N}_{0}$ & $\mathbf{N}_{240}$ & $\mathbf{N}_{0}$ & $\mathbf{N}_{240}$ \\
\hline DH 1 & 9,5 & 15,0 & 28,9 & 49,0 & $<0,1$ & 12,4 & 13,8 & 18,0 \\
\hline DH 2 & 5,7 & 13,0 & 23,6 & 77,3 & $<0,1$ & 11,3 & 14,4 & 18,9 \\
\hline DH 3 & 5,3 & 14,0 & 26,4 & 59,3 & $<0,1$ & 13,5 & 13,8 & 17,8 \\
\hline DH 4 & 9,6 & 16,0 & 23,7 & 55,3 & $<0,1$ & 14,5 & 12,9 & 17,8 \\
\hline DH 5 & 13,5 & 16,0 & 31,4 & 28,0 & 0,2 & 19,1 & 15,4 & 19,0 \\
\hline DH 6 & 8,5 & 12,0 & 23,3 & 56,7 & $<0,1$ & 11,8 & 13,6 & 17,8 \\
\hline DH 7 & 9,8 & 18,0 & 14,8 & 68,1 & $<0,1$ & 21,4 & 15,7 & 20,0 \\
\hline DH 8 & 14,3 & 17,0 & 46,7 & 79,0 & 0,1 & 10,3 & 15,0 & 19,0 \\
\hline DH 9 & 9,6 & 21,0 & 11,3 & 74,1 & $<0,1$ & 16,0 & 14,6 & 18,3 \\
\hline DH 10 & 13,0 & 17,0 & 36,5 & 76,6 & $<0,1$ & 13,0 & 14,3 & 19,5 \\
\hline DH 11 & 4,8 & 13,0 & 45,9 & 62,6 & $<0,1$ & 7,6 & 14,6 & 18,8 \\
\hline DH 13 & 6,0 & 16,0 & 25,4 & 61,3 & $<0,1$ & 17,4 & 15,5 & 20,8 \\
\hline DH 14 & 6,7 & 17,0 & 16,3 & 79,2 & $<0,1$ & 12,1 & 15,6 & 20,0 \\
\hline DH 15 & 17,0 & 20,0 & 38,3 & 46,6 & 0,1 & 10,9 & 16,1 & 20,9 \\
\hline DH 16 & 8,4 & 15,0 & 30,9 & 69,6 & $<0,1$ & 11,0 & 14,0 & 17,8 \\
\hline DH 17 & 5,3 & 20,0 & 27,2 & 48,4 & $<0,1$ & 18,0 & 15,1 & 19,6 \\
\hline DH 18 & 10,8 & 16,0 & 21,0 & 49,6 & $<0,1$ & 18,9 & 14,5 & 19,0 \\
\hline DH 19 & 7,3 & 16,0 & 22,4 & 59,3 & 0,1 & 14,9 & 14,8 & 18,6 \\
\hline DH 25 & 17,0 & 14,0 & 23,7 & 68,6 & 0,2 & 18,8 & 15,8 & 19,8 \\
\hline DH 27 & 10,7 & 25,0 & 20,2 & 39,6 & $<0,1$ & 14,2 & 16,8 & 21,3 \\
\hline DH 28 & 13,3 & 22,0 & 30,7 & 74,5 & 0,2 & 10,5 & 14,7 & 19,7 \\
\hline DH 29 & 10,5 & 19,0 & 23,2 & 65,8 & $<0,1$ & 15,8 & 13,7 & 18,4 \\
\hline DH 30 & 14,6 & 17,0 & 19,6 & 68,4 & $<0,1$ & 11,2 & 16,0 & 19,7 \\
\hline DH 31 & 11,5 & 14,0 & 26,5 & 47,9 & $<0,1$ & 18,0 & 14,5 & 18,4 \\
\hline DH 32 & 6,7 & 19,0 & 35,0 & 59,4 & 0,1 & 8,6 & 13,6 & 18,4 \\
\hline DH 33 & 11,5 & 16,0 & 29,3 & 36,7 & 0,1 & 15,3 & 14,0 & 18,6 \\
\hline DH 34 & 12,8 & 17,0 & 31,1 & 98,9 & $<0,1$ & 17,4 & 15,2 & 19,5 \\
\hline DH 35 & 11,3 & 16,0 & 36,2 & 55,5 & 0,1 & 12,0 & 15,6 & 19,9 \\
\hline DH 36 & 7,7 & 13,0 & 20,7 & 75,2 & $<0,1$ & 17,9 & 14,6 & 18,4 \\
\hline DH 37 & 10,0 & 15,0 & 22,7 & 48,8 & 0,1 & 18,8 & 14,7 & 19,6 \\
\hline DH 40 & 6,0 & 14,0 & 28,5 & 65,9 & $<0,1$ & 17,0 & 14,7 & 18,7 \\
\hline DH 41 & 6,8 & 16,0 & 38,5 & 82,6 & 0,1 & 17,9 & 14,1 & 18,2 \\
\hline DH 42 & 12,8 & 18,0 & 52,1 & 54,5 & 0,1 & 12,6 & 15,9 & 20,0 \\
\hline DH 43 & 10,1 & 11,0 & 16,2 & 51,3 & 0,1 & 17,5 & 15,1 & 19,5 \\
\hline DH 44 & 9,3 & 13,0 & 28,6 & 69,3 & 0,1 & 28,8 & 14,6 & 18,9 \\
\hline DH 45 & 6,2 & 12,0 & 16,0 & 72,6 & 0,1 & 12,2 & 14,8 & 18,5 \\
\hline DH 47 & 8,3 & 14,0 & 32,7 & 27,2 & 0,1 & 12,5 & 14,0 & 18,4 \\
\hline DH 48 & 7,4 & 15,0 & 19,7 & 63,2 & 0,1 & 13,5 & 15,4 & 19,8 \\
\hline DH 49 & 7,8 & 22,0 & 42,6 & 57,2 & 0,2 & 11,5 & 15,1 & 20,1 \\
\hline DH 50 & 10,7 & 16,0 & 36,1 & 38,3 & 0,1 & 14,1 & 15,7 & 20,1 \\
\hline DH 52 & 10,1 & 15,0 & 13,8 & 69,3 & 0,3 & 12,7 & 15,3 & 19,7 \\
\hline DH 53 & 13,8 & 19,0 & 37,7 & 67,4 & 0,1 & 13,1 & 14,9 & 20,0 \\
\hline DH 59 & 11,9 & 14,0 & 15,6 & 48,3 & 0,1 & 12,0 & 15,1 & 20,7 \\
\hline DH 69 & 5,6 & 12,0 & 22,2 & 48,9 & 0,1 & 14,9 & 13,7 & 18,8 \\
\hline DH 70 & 11,0 & 13,0 & 35,0 & 49,9 & 0,1 & 12,4 & 16,2 & 20,6 \\
\hline Apex & 12,3 & 17,0 & 34,8 & 73,8 & 0,1 & 18,5 & 14,5 & 19,7 \\
\hline Mohican & 14,8 & 18,0 & 50,1 & 41,9 & 0,2 & 11,1 & 14,1 & 18,4 \\
\hline Mittelwert & $9,9 \pm 3,2$ & $16,1 \pm 3,0$ & $28,4 \pm 9,8$ & $60,0 \pm 14,8$ & $0,1 \pm 0,1$ & $14,6 \pm 3,8$ & $14,8 \pm 0,8$ & $19,2 \pm 0,9$ \\
\hline
\end{tabular}


Eine höhere Stickstoffversorgung führte bei allen untersuchten Rapslinien zu einem Anstieg in jedem getesteten Parameter des Stickstoffhaushalts. Außerdem nahm bei höherem NAngebot die Standardabweichung aller Parameter relativ zum Mittelwert ab, d.h. die relative Variabilität zwischen den Sorten war geringer.

Alle gemessenen Parameter wurden jeweils paarweise durch lineare Regression auf mögliche Zusammenhänge getestet (Tab. 3.2). Dabei zeigte sich lediglich für die Proteingehalte im Samen bei $\mathrm{N}_{0}$ und $\mathrm{N}_{240}$ ein Zusammenhang mit einem Bestimmtheitsmaß von $\mathrm{r}^{2}=0,72$. Das heißt, daß im Mittel Sorten, die bei niedriger N-Versorgung mehr Protein im Samen akkumulierten, dies auch bei hoher N-Versorgung taten. Für den Nitrat- und Aminosäuregehalt sowie die NRA in den Blättern ergab sich kein Zusammenhang zwischen $\mathrm{N}_{0}$ und $\mathrm{N}_{240}$. Diese Parameter veränderten sich also in verschiedenen Sorten sehr unterschiedlich in Reaktion auf ein erhöhtes Stickstoffangebot.

Tabelle 3.2: Korrelationen zwischen Parametern des Stickstoffhaushalts. Die Korrelationen zwischen verschiedenen gemessen Parametern wurden jeweils durch lineare Regression analysiert. Die rechten zwei Spalten zeigen die Ergebnisse für den reduzierten Datensatz aus den in allen drei Anbaujahren getesteten Sorten. Angegeben sind Steigung (m) und Bestimmungsmaß $\left(\mathrm{r}^{2}\right)$ für jede Regression. Der einzige signifikante Zusammenhang ist durch Fettdruck und graue Hinterlegung hervorgehoben.

\begin{tabular}{|c|c|c|c|c|c|}
\hline \multirow{2}{*}{ Faktor } & \multirow{2}{*}{ Variable } & \multicolumn{2}{|c|}{ alle Linien } & \multicolumn{2}{|c|}{8 DH- \& Elternlinien } \\
\hline & & m & $r^{2}$ & m & $r^{2}$ \\
\hline Aminosäuregehalt $_{\mathrm{N} 0}$ & Nitratreduktaseaktivität $_{\mathrm{N} 0}$ & 0,1 & 0,08 & 0,1 & 0,40 \\
\hline Aminosäuregehalt ${ }_{\mathrm{N} 240}$ & Nitratreduktaseaktivität $_{\mathrm{N} 240}$ & 0,0 & 0,05 & 0,1 & 0,28 \\
\hline Aminosäuregehalt $_{\mathrm{N} 0}$ & Nitratgehalt $_{\mathrm{N} 0}$ & 0,3 & 0,51 & 19,0 & 0,37 \\
\hline Aminosäuregehalt ${ }_{\mathrm{N} 240}$ & Nitratgehalt $_{\mathrm{N} 240}$ & 0,1 & 0,01 & $-0,4$ & 0,53 \\
\hline Nitratreduktaseaktivität $_{\mathrm{N} 0}$ & Nitratgehalt $_{\mathrm{N} 0}$ & 0,1 & 0,01 & 49,7 & 0,11 \\
\hline Nitratreduktaseaktivität $_{\mathrm{N} 240}$ & Nitratgehalt $_{\mathrm{N} 240}$ & 0,4 & 0,01 & $-0,7$ & 0,02 \\
\hline Proteingehalt $_{\mathrm{N} O}$ & Aminosäuregehalt $_{\mathrm{N} 0}$ & 0,1 & 0,12 & 0,3 & 0,54 \\
\hline Proteingehalt $_{\mathrm{N} 240}$ & Aminosäuregehalt ${ }_{\mathrm{N} 240}$ & 0,1 & 0,14 & 0,2 & 0,26 \\
\hline Proteingehalt $_{\mathrm{N} 0}$ & Nitratreduktaseaktivität $_{\mathrm{N} 0}$ & 0,0 & 0,00 & 0,0 & 0,27 \\
\hline Proteingehalt $_{\mathrm{N} 240}$ & Nitratreduktaseaktivität $_{\mathrm{N} 240}$ & 0,0 & 0,01 & 0,0 & 0,03 \\
\hline Proteingehalt $_{\mathrm{N} O}$ & Nitratgehalt $_{\mathrm{N} 0}$ & 3,6 & 0,06 & 5,8 & 0,17 \\
\hline Proteingehalt $_{\mathrm{N} 240}$ & Nitratgehalt $_{\mathrm{N} 240}$ & 0,0 & 0,00 & $-0,1$ & 0,07 \\
\hline Aminosäuregehalt ${ }_{\mathrm{N} 240}$ & Aminosäuregehalt $_{\mathrm{N} 0}$ & 0,3 & 0,09 & 0,5 & 0,24 \\
\hline Nitratreduktaseaktivität $_{\mathrm{N} 240}$ & Nitratreduktaseaktivität $_{\mathrm{NO}}$ & $-0,2$ & 0,01 & $-0,2$ & 0,02 \\
\hline Nitratgehalt $_{\mathrm{N} 240}$ & Nitratgehalt $_{\mathrm{N} 0}$ & $-3,0$ & 0,00 & $-7,1$ & 0,02 \\
\hline Proteingehalt $_{\mathrm{N} 240}$ & Proteingehalt $_{\mathrm{N} 0}$ & 1,0 & 0,72 & 0,8 & 0,78 \\
\hline
\end{tabular}


Auch untereinander zeigten die verschiedenen Parameter des Stickstoffmetabolismus keine signifikanten Abhängigkeiten: Der Aminosäuregehalt der Blätter hing weder von der NAssimilationsrate (NRA) noch vom Nitratgehalt ab. Auch die Nitratreduktaseaktivität war nicht abhängig vom Nitratgehalt der Blätter. Der Proteingehalt im Samen war weder bei $\mathrm{N}_{0}$ noch bei $\mathrm{N}_{240}$ signifikant von den drei anderen Parametern beeinflußt.

Da die Auswirkungen jahresabhängiger Klima-Unterschiede mögliche Zusammenhänge zwischen den gemessenen Größen des Stickstoffhaushalts überdecken könnten, wurden dieselben Regressionsanalysen auch nur für die Daten der zehn in allen drei Jahren angebauten Sorten (acht DH-Linien und die Elternsorten) durchgeführt. Die Ergebnisse sind ebenfalls in Tabelle 3.2 dargestellt. In fast allen Fällen erhöhte sich durch die Einschränkung des Datensatzes das Bestimmtheitsmaß $\mathrm{r}^{2}$ der Regression, aber auch hier war nur für die Proteingehalte der Samen bei $\mathrm{N}_{0}$ und $\mathrm{N}_{240}$ ein signifikanter Zusammenhang auszumachen. Zumindest als Tendenz ist erkennbar, daß bei $\mathrm{N}_{0}$ der Proteingehalt im Samen mit dem Aminosäuregehalt im Blatt ansteigt (Abb. 3.1) und bei $\mathrm{N}_{240}$ die Nitrat- und Aminosäuregehalte des Blattes negativ korrelieren.

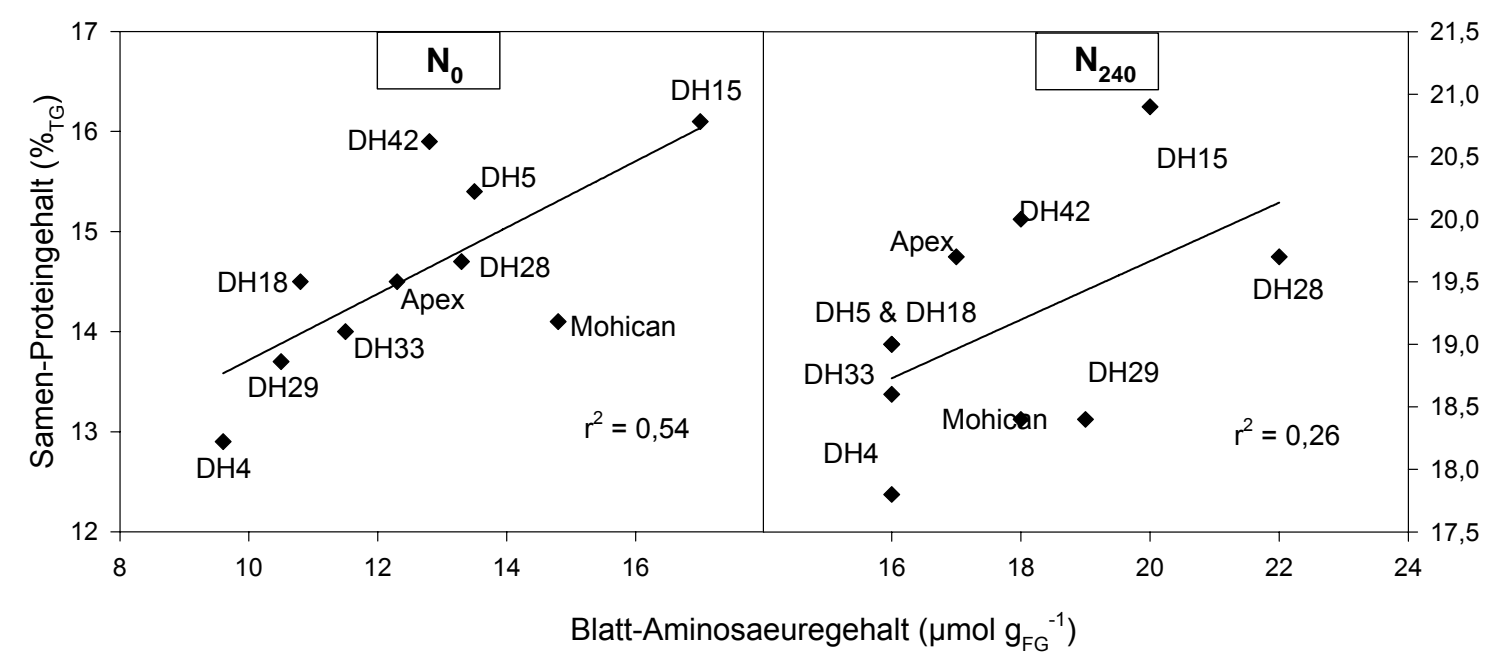

Abb. 3.1: Samen-Proteingehalt in Abhängigkeit vom Blatt-Aminosäuregehalt. Dargestellt sind die Daten der acht ausgewählten DH-Linien und zwei Elternsorten, die in allen drei Versuchsjahren angebaut wurden. Regressionsgeraden und Bestimmtheitsmaße sind eingezeichnet. 
Zur Beurteilung einzelner Sorten erlaubt eine graphische Auftragung der $\mathrm{N}_{240^{-}}$gegen die $\mathrm{N}_{0^{-}}$ Werte für jeden Parameter eine Zuordnung zu einer von vier Kategorien (Kessel 2000): Neffiziente Sorten liegen bei niedriger N-Versorgung über dem Sortendurchschnitt, Nineffiziente darunter. N-responsive Sorten reagieren auf ein erhöhtes N-Angebot mit einer verstärkten N-Akkumulation bzw. stärkerer Nitratreduktaseaktivität und weisen Werte größer als der Mittelwert auf. Nicht N-responsive Sorten bleiben bei $\mathrm{N}_{240}$ unter dem Mittel. Unter diesem Gesichtspunkt sagt eine signifikante Korrelation in der Regressionsanalyse aus, daß bezüglich dieses Parameters fast alle Sorten in die Kategorien ineffizient/nicht N-responsiv oder effizient/N-responsiv fallen. Bei einer nicht signifikanten Korrelation der $\mathrm{N}_{0}$ und $\mathrm{N}_{240^{-}}$ Werte sind auch einige Sorten bei geringer N-Versorgung effizient, reagieren aber unterdurchschnittlich auf eine erhöhte N-Düngergabe, während andere Sorten so extrem auf die höhere Stickstoffmenge reagieren daß sie bei $\mathrm{N}_{0}$ unter dem Sortendurchschnitt liegen und bei $\mathrm{N}_{240}$ darüber. Diese Zusammenhänge sind in Abb. 3.2 (S. 98) dargestellt. Es zeigte sich dabei, daß die Hälfte der in allen Anbauperioden untersuchten zehn Linien bezüglich der NEffizienz eine große Konstanz aufwies und in allen vier getesteten Parametern dasselbe Verhalten zeigte (Tab. 3.3).

Tabelle 3.3: Reaktion ausgewählter Rapssorten auf ein erhöhtes Stickstoffangebot. Einteilung der Rapssorten in ineffiziente/effiziente und nicht $\mathrm{N}$-responsive/N-responsive Sorten nach Abb. 3.2. Konstantes Verhalten in allen vier Parametern ist durch graue Hinterlegung und Fettdruck hervorgehoben.

\begin{tabular}{|c|c|c|c|c|}
\hline & $\begin{array}{c}\text { Nitratgehalt im } \\
\text { Blatt }\end{array}$ & NRA im Blatt & $\begin{array}{l}\text { Aminosäuregehalt } \\
\text { im Blatt }\end{array}$ & $\begin{array}{c}\text { Proteingehalt im } \\
\text { Samen }\end{array}$ \\
\hline \multirow{2}{*}{ DH4 } & ineffizient & ineffizient & ineffizient & ineffizient \\
\hline & nicht N-responsiv & N-responsiv & nicht N-responsiv & nicht N-responsiv \\
\hline DH5 & $\begin{array}{c}\text { effizient } \\
\mathrm{N} \text {-responsiv }\end{array}$ & $\begin{array}{c}\text { ineffizient } \\
\text { nicht N-responsiv }\end{array}$ & $\begin{array}{c}\text { effizient } \\
\text { nicht } \mathrm{N} \text {-responsiv }\end{array}$ & $\begin{array}{c}\text { effizient } \\
\text { nicht } \mathrm{N} \text {-responsiv }\end{array}$ \\
\hline \multirow[t]{2}{*}{ DH15 } & effizient & effizient & effizient & effizient \\
\hline & nicht N-responsiv & nicht N-responsiv & $\mathrm{N}$-responsiv & $\mathrm{N}$-responsiv \\
\hline \multirow{2}{*}{ DH18 } & ineffizient & ineffizient & ineffizient & ineffizient \\
\hline & $\mathrm{N}$-responsiv & nicht N-responsiv & nicht N-responsiv & nicht N-responsiv \\
\hline DH28 & $\begin{array}{c}\text { effizient } \\
\text { nicht } \mathrm{N} \text {-responsiv }\end{array}$ & $\begin{array}{c}\text { ineffizient } \\
\mathrm{N} \text {-responsiv }\end{array}$ & $\begin{array}{c}\text { effizient } \\
\mathrm{N} \text {-responsiv }\end{array}$ & $\begin{array}{c}\text { effizient } \\
\mathrm{N} \text {-responsiv }\end{array}$ \\
\hline \multirow{2}{*}{ DH29 } & ineffizient & ineffizient & ineffizient & ineffizient \\
\hline & N-responsiv & $\mathrm{N}$-responsiv & $\mathrm{N}$-responsiv & nicht N-responsiv \\
\hline \multirow{2}{*}{ DH33 } & ineffizient & ineffizient & ineffizient & ineffizient \\
\hline & N-responsiv & nicht N-responsiv & nicht N-responsiv & nicht N-responsiv \\
\hline DH42 & $\begin{array}{c}\text { ineffizient } \\
\text { nicht N-responsiv }\end{array}$ & $\begin{array}{c}\text { effizient } \\
\mathrm{N} \text {-responsiv }\end{array}$ & $\begin{array}{c}\text { effizient } \\
\mathrm{N} \text {-responsiv }\end{array}$ & $\begin{array}{c}\text { effizient } \\
\mathrm{N} \text {-responsiv }\end{array}$ \\
\hline Apex & $\begin{array}{c}\text { ineffizient } \\
\mathrm{N} \text {-responsiv }\end{array}$ & $\begin{array}{c}\text { effizient } \\
\mathrm{N} \text {-responsiv }\end{array}$ & $\begin{array}{c}\text { ineffizient } \\
\text { nicht N-responsiv }\end{array}$ & $\begin{array}{c}\text { ineffizient } \\
\mathrm{N} \text {-responsiv }\end{array}$ \\
\hline Mohican & $\begin{array}{c}\text { effizient } \\
\text { nicht N-responsiv }\end{array}$ & $\begin{array}{c}\text { effizient } \\
\text { nicht N-responsiv }\end{array}$ & $\begin{array}{c}\text { effizient } \\
\mathrm{N} \text {-responsiv }\end{array}$ & $\begin{array}{c}\text { ineffizient } \\
\text { nicht N-responsiv }\end{array}$ \\
\hline
\end{tabular}



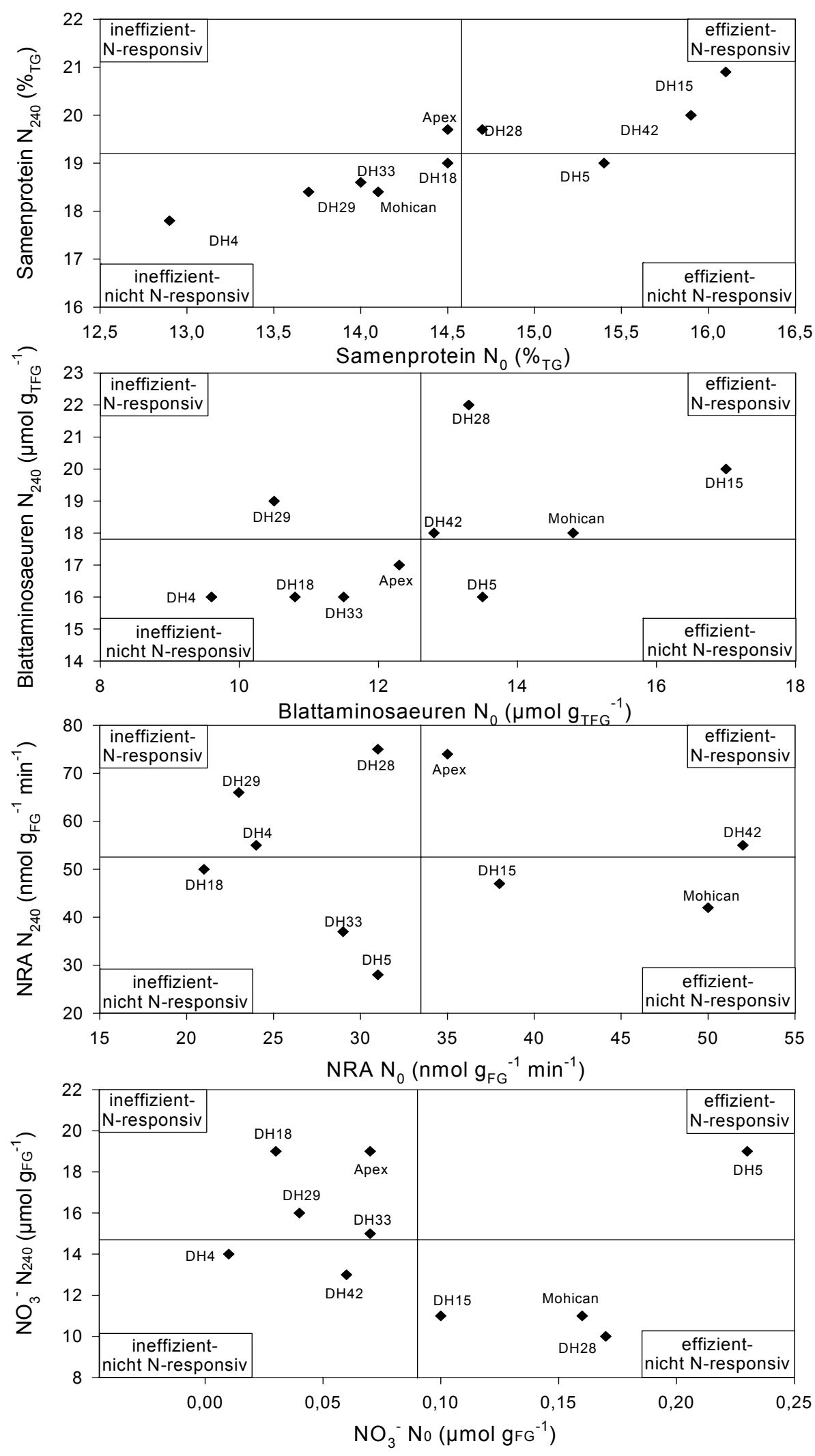

Abb. 3.2: Klassifizierung von Rapssorten anhand ihres $\mathbf{N}$-Stoffwechsels. Die zehn in allen Anbauperioden getesten Rapslinien wurden für jeden gemessenen Parameter anhand ihres Verhaltens bei $\mathrm{N}_{0}$ und $\mathrm{N}_{240}$ in vier Kategorien eingeteilt (siehe Text). Senkrechte Linien repräsentieren Gesamtmittelwerte aller zehn Linien. Datenpunkte repräsentieren dreijährige Mittelwerte einzelner Sorten. 


\subsection{Aminosäurekonzentrationen in subzellulären Kompartimenten von Mesophyllzellen}

Die Konzentrationen verschiedener, für den N-Metabolismus wichtiger Metabolite in den Kompartimenten Zytosol, Vakuole und Chloroplast von Mesophyllzellen aus Rapsblättern der Sorte Lirajet wurden durch nichtwässrige Fraktionierung und anschließende HPLC-Analyse bestimmt. Es wurden sehr kleine, aber bereits voll ergrünte Blätter, voll ausgewachsene grüne Blätter und bereits deutlich blaßgelbe, seneszierende Blätter untersucht, die im folgenden als ,jung“, „mittelalt“ und ,alt“ bezeichnet werden. Die Pflanzen wurden hydroponisch mit 0,5 $\mathrm{mM}$ Nitrat (,0,5 mM Nitrat-Pflanzen“) oder $4 \mathrm{mM}$ Nitrat (,4 mM Nitrat-Pflanzen“) in der Nährlösung als einziger N-Quelle angezogen.

Für jede Pflanzenart und jedes Gewebe müssen die Bedingungen der DichtegradientenZentrifugation neu optimiert werden. Als Auftrennungskriterium dient die Verteilung der Markerenzyme im Gradienten. Die NADPH-abhängige Glycerinaldehyd-3-Phosphat Dehydrogenase (GAP-DH), das plastidäre Markerenzym, sollte dabei am stärksten in den obersten, z.T. durch ihren Plastidengehalt deutlich grün gefärbten Gradientenfraktionen aktiv sein und in der untersten, farblosen Fraktion fehlen. Die Aktivität des vakuolischen Makerenzyms saure Phosphatase (bzw. $\alpha$-Mannosidase) sollte dagegen hauptsächlich in den unteren Fraktionen nachweisbar sein. Die Phosphoenolpyruvat-Carboxylase $\left(\mathrm{PEP}_{\mathrm{CX}}\right)$, Marker für das Zytosol, sollte sich auf den gesamten Gradienten verteilen, mit maximalen Aktivitäten in den mittleren Fraktionen. Es wurden jeweils so viele Fraktionierungen durchgeführt, bis für jedes Blattalter und jede N-Stufe drei Gradienten mit einer ausreichend guten Auftrennung der Markerenzyme zur Verfügung standen. Die optimierten Dichtestufen und die Verteilung der Markerenzyme in den verwendeten Gradienten sind in Anhang 8.1 dargestellt. Die im folgenden angegebenen Metabolitenkonzentrationen sind Mittelwerte aus jeweils drei Gradienten. Um die Konzentrationen aus der Verteilung der Gradientenfraktionen von $\mu$ mol $\mathrm{g}_{\mathrm{FG}}{ }^{-1}$ in die Konzentrationen in subzellulären Kompartimenten (in $\mathrm{mM}$ ) umzurechnen, wurden folgende Volumina zugrunde gelegt: Vakuole: $600 \mu \mathrm{lg}_{\mathrm{FG}}{ }^{-1}$; Chloroplast: $70 \mu 1 \mathrm{~g}_{\mathrm{FG}}{ }^{-1}$; Zytosol: $40 \mu \mathrm{g}_{\mathrm{FG}}{ }^{-1}$. Die Werte sind Mittelwerte der entsprechenden Volumina aus Spinat, Gerste und Kartoffel (Winter et al. 1993, 1994, Leidreiter et al. 1995).

Tabellen 3.4 und 3.5 (S. 101-102) stellen die Ergebnisse der nichtwässrigen Fraktionierung dar. Unter den Kohlenhydraten waren die Hexosen Glukose und Fruktose überwiegend in der Vakuole verteilt, Saccharose trat hauptsächlich im Zytosol auf. Die Hexosekonzentrationen erreichten maximal ca. $60 \mathrm{mM}$, Saccharose ca. $180 \mathrm{mM}$. Mit dem Blattalter nahmen die Konzentrationen dieser Zucker tendenziell etwas ab. Zwischen den Kohlenhydratkonzentrationen bei 0,5 und $4 \mathrm{mM}$ Nitrat im Anzuchtmedium bestanden keine signifikanten 
Unterschiede. Die organische Säure Malat fand sich überwiegend in der Vakuole, wo ihre Konzentration bis zu $150 \mathrm{mM}$ betrug und bei $0,5 \mathrm{mM}$ Nitrat-Pflanzen mit dem Blattalter zunahm. Bei den 4 mM Nitrat-Pflanzen war keine derartige Tendenz feststellbar.

Die Ammoniumkonzentrationen waren in allen Kompartimenten und Blattaltern niedrig, sowohl bei $0,5 \mathrm{mM}$ als auch bei $4 \mathrm{mM}$ Nitrat im Anzuchtmedium. Die höchsten Werte von bis zu 6,3 mM im Zytosol, 4,4 mM im Chloroplasten und 3,6 $\mathrm{mM}$ in der Vakuole traten bei den 0,5 mM Nitrat-Pflanzen auf, bei den $4 \mathrm{mM}$ Nitrat-Pflanzen war $\mathrm{NH}_{4}{ }^{+}$häufig gar nicht nachweisbar. Nitrat war wie Malat vor allem in der Vakuole kompartimentiert, im Zytosol und Chloroplasten blieb seine Konzentration meist unter $10 \mathrm{mM}$. Höhere Werte traten bei jungen Blättern von $4 \mathrm{mM}$ Nitrat-Pflanzen auf. Die Nitratkonzentration in der Vakuole stieg bei $0,5 \mathrm{mM}$ Nitrat im Medium mit dem Blattalter an und war mit maximal 18,1 mM (alte Blätter) signifikant niedriger als bei allen Blattaltern von $4 \mathrm{mM}$ Nitrat-Pflanzen. Bei den Pflanzen mit $4 \mathrm{mM} \mathrm{NO}_{3}{ }^{-}$im Medium zeigte die vakuoläre Nitratkonzentration keinen klaren Trend mit dem Blattalter: Wie im Zytosol und im Chloroplasten fand sich bei jungen Blättern auch in der Vakuole eine besonders hohe Nitratkonzentration von 161,2 mM, bei mittelalten und alten Blättern blieb die Konzentration dann auf einem niedrigeren Niveau von etwa 60-70 $\mathrm{mM}$ konstant.

Aminosäuren waren über alle drei Kompartimente verteilt, mit annähernd gleichen Gesamtkonzentrationen im Zytosol und im Chloroplasten (unter Berücksichtigung der Standardabweichungen) und deutlich niedrigeren Werten in der Vakuole. In allen Kompartimenten und bei beiden N-Versorgungsstufen nahm die AminosäureGesamtkonzentration mit dem Blattalter tendenziell ab, wobei sowohl bei $4 \mathrm{mM}$ als auch bei 0,5 mM Nitrat auch alte Blätter noch signifikante Mengen enthielten. Zytosolische Aminosäurekonzentrationen blieben bei beiden N-Stufen unter 200 mM. Bei 4 mM Nitrat im Medium waren signifikant erhöhte Aminosäurewerte nur in der Vakuole feststellbar. Die maximale Gesamtkonzentration betrug dort in jungen Blättern $60 \mathrm{mM}$, gegenüber $<10 \mathrm{mM}$ in 0,5 mM Nitrat-Pflanzen. Im Verlauf des Rückgangs der Aminosäure-Gesamtkonzentration mit dem Blattalter glichen sich die Werte bei alten Blättern wieder denen der 0,5 mM NitratPflanzen an. Abb. 3.3 (S. 103) faßt die Aminosäurekonzentrationen in den untersuchten subzellulären Kompartimenten nochmals zusammen.

Tab. 3.4 \& 3.5 (folgende Seiten): Metabolitkonzentrationen in Mesophyllzellen aus Blättern von bei 0,5 bzw. $4 \mathrm{mM} \mathrm{NO}_{3}{ }^{-}$hydroponisch angezogenen Rapspflanzen. Alle Werte in $\mathrm{mM}$. Angegeben sind Mittelwerte aus drei Gradienten \pm Standardabweichungen. Wenn keine Standardabweichungen angegeben sind, lagen Meßwerte nur für 1-2 Gradienten vor. GABA: $\gamma$-Aminobuttersäure. 
Tab. 3.4: Ergebnisse der nichtwässrigen Fraktionierung von bei $0,5 \mathrm{mM} \mathrm{NO}_{3}^{-}$ hydroponisch angezogenen Rapspflanzen

\begin{tabular}{|c|c|c|c|c|c|c|c|c|c|c|c|c|c|c|c|c|c|c|c|c|c|c|c|c|c|c|c|}
\hline \multirow{3}{*}{ 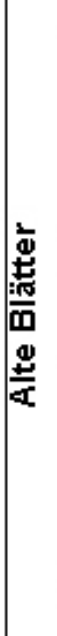 } & 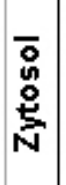 & $\begin{array}{l}\frac{\omega}{\omega} \\
+1 \\
\frac{\omega}{\sigma} \\
\frac{\sigma}{\sigma}\end{array}$ & $\begin{array}{l}\infty \\
= \\
+1 \\
\infty \\
\overline{-}\end{array}$ & 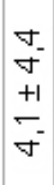 & $\begin{array}{l}\infty \\
- \\
+1 \\
\infty \\
\infty\end{array}$ & $\begin{array}{l}\square \\
\infty \\
+1 \\
0 \\
\cdots \\
\cdots\end{array}$ & $\begin{array}{l}\infty \\
\infty \\
+1 \\
\infty \\
\cdots\end{array}$ & $\begin{array}{l}L 5 \\
\square \\
+1 \\
\square \\
-\end{array}$ & $\bar{\sigma}$ & $\begin{array}{l}\widetilde{v} \\
\square^{\circ} \\
+1 \\
\stackrel{v}{\square} \\
\square\end{array}$ & $\frac{\infty}{-1}$ & $\begin{array}{l}w \\
\infty \\
+1 \\
m \\
m^{-}\end{array}$ & $\begin{array}{c}5 \\
\sigma \\
+1 \\
N- \\
N\end{array}$ & $\begin{array}{c}\bar{\sigma} \\
+1 \\
\bar{\sigma} \\
\bar{\sigma}\end{array}$ & $\begin{array}{l}\infty \\
\sigma^{\circ} \\
+1 \\
\text { J- } \\
\square\end{array}$ & $\begin{array}{l}\mathscr{0} \\
0 \\
+1 \\
0 \\
0\end{array}$ & $\begin{array}{l}\simeq \\
\sim \\
+1 \\
\infty \\
- \\
-\end{array}$ & 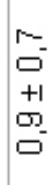 & $\begin{array}{l}- \\
+1 \\
\sigma\end{array}$ & $\begin{array}{c}\widetilde{v} \\
\square \\
+1 \\
\stackrel{v}{\sigma} \\
\square\end{array}$ & $\begin{array}{c}\underset{\infty}{\infty} \\
\stackrel{\infty}{\infty} \\
+1 \\
\stackrel{\infty}{\infty}\end{array}$ & $\begin{array}{l}\omega \\
0 \\
+1 \\
\infty \\
\sigma^{-}\end{array}$ & $\begin{array}{l}\infty \\
+ \\
+ \\
\sigma \\
\infty\end{array}$ & $\begin{array}{l}0 \\
0 \\
0 \\
+1 \\
0 \\
- \\
0\end{array}$ & $\begin{array}{l}\infty \\
\infty \\
+1 \\
\sim \\
\infty \\
5 \\
-1\end{array}$ & $\begin{array}{l}\checkmark \\
\sigma^{-} \\
+1 \\
\cdots \\
\cdots\end{array}$ & $\bar{L}$ \\
\hline & 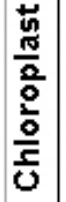 & $\begin{array}{l}0 \\
+1 \\
\square \\
0 \\
\varrho\end{array}$ & $\begin{array}{l}0 \\
\sigma \\
+1 \\
0 \\
0 \\
-1\end{array}$ & $\begin{array}{l}\square \\
\square \\
+1 \\
0 \\
\omega \\
\omega\end{array}$ & $\begin{array}{l}m \\
\square \\
+1 \\
m \\
0 \\
\square\end{array}$ & $\frac{1}{5}$ & $\begin{array}{l}\bar{L} \\
+1 \\
\sigma \\
\sigma\end{array}$ & $\begin{array}{l}\widetilde{v} \\
\mathfrak{b}^{\prime} \\
+1 \\
\cdots \\
\mathfrak{b}^{\prime}\end{array}$ & $\stackrel{\text { }}{-}$ & $\begin{array}{l}\square^{口} \\
\square^{\prime} \\
+1 \\
\square^{\prime} \\
\square^{\prime}\end{array}$ & $\begin{array}{l}\text { J. } \\
\text { - } \\
+1 \\
\text { v- } \\
-\end{array}$ & $\begin{array}{l}m- \\
b-1 \\
+1 \\
-\end{array}$ & $\begin{array}{l}\cdots \\
+1 \\
0 \\
- \\
-\end{array}$ & 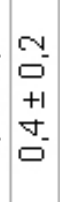 & $\begin{array}{l}5 \\
\sigma \\
+1 \\
\text { J- } \\
\sigma\end{array}$ & $\begin{array}{l}5 \\
\square \\
+1 \\
\sigma\end{array}$ & $\begin{array}{l}\checkmark \\
\square \\
+1 \\
0 \\
\square \\
\square\end{array}$ & $\begin{array}{l}m \\
\sigma \\
+1 \\
v \\
\sigma \\
\sigma\end{array}$ & $\begin{array}{l}5 \\
+1 \\
+ \\
\sigma\end{array}$ & $\begin{array}{c}\mathrm{N} \\
\square \\
+1 \\
\mathrm{v} \\
\square\end{array}$ & $\begin{array}{l}\text { N } \\
\stackrel{0}{-} \\
+1 \\
m \\
0 \\
\frac{0}{q}\end{array}$ & 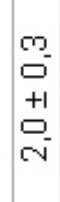 & $\begin{array}{l}\widetilde{-} \\
- \\
+1 \\
\widetilde{V} \\
-\end{array}$ & $\begin{array}{l}J \\
5 \\
+1 \\
0 \\
0\end{array}$ & $\begin{array}{l}c \\
\sim \\
+1 \\
+\infty \\
\infty \\
\infty\end{array}$ & $\begin{array}{l}\infty \\
\square \\
+1 \\
\infty \\
-\end{array}$ & $\begin{array}{l}\infty \\
- \\
+1 \\
0 \\
-\end{array}$ \\
\hline & $\begin{array}{l}\frac{\omega}{0} \\
\stackrel{0}{J} \\
\text { J } \\
\end{array}$ & $\begin{array}{l}\bar{\sigma} \\
+1 \\
\sigma \\
\sigma\end{array}$ & $\begin{array}{l}\sigma \\
\sigma \\
+1 \\
\sigma- \\
-\end{array}$ & $\begin{array}{l}m \\
\square \\
+1 \\
+1 \\
0 \\
\square\end{array}$ & $\begin{array}{l}5 \\
\square \\
+1 \\
\sigma\end{array}$ & $\begin{array}{l}\mathrm{N} \\
b^{v} \\
+1 \\
\square \\
\square\end{array}$ & $\begin{array}{l}L \\
\square \\
+1 \\
\infty \\
\square \\
\square\end{array}$ & $\begin{array}{l}\text { 口् } \\
b^{\prime} \\
+1 \\
\text { 吕 } \\
\square^{\prime}\end{array}$ & $\begin{array}{l}\square \\
\square \\
\text { 口 } \\
+1 \\
\square \\
\square\end{array}$ & 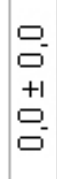 & 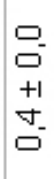 & $\begin{array}{l}\bar{\sigma} \\
+1 \\
\cdots \\
\sigma \\
\sigma\end{array}$ & $\begin{array}{l}\widetilde{c} \\
\sigma \\
+1 \\
\infty \\
\sigma\end{array}$ & $\begin{array}{c}\bar{\sigma} \\
+1 \\
\sim \\
\sigma \\
\sigma\end{array}$ & $\begin{array}{l}\bar{\sigma} \\
+1 \\
0 \\
\sigma\end{array}$ & 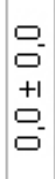 & 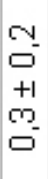 & $\begin{array}{l}5 \\
\square \\
+1 \\
0 \\
\sigma\end{array}$ & $\begin{array}{l}\bar{\sigma} \\
+1 \\
\bar{\sigma}\end{array}$ & $\begin{array}{l}口 \\
\square^{\prime} \\
+1 \\
g^{\prime} \\
\square^{\prime}\end{array}$ & $\begin{array}{l} \pm \\
+1 \\
+\infty \\
\infty\end{array}$ & $\begin{array}{l}\checkmark \\
\sigma^{-} \\
+1 \\
\checkmark \\
\sigma^{-} \\
\sigma\end{array}$ & $\begin{array}{l}J \\
m \\
+1 \\
5 \\
\sigma \\
\sigma\end{array}$ & $\begin{array}{l}\infty \\
\infty \\
+1 \\
\sim \\
v \\
v\end{array}$ & 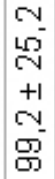 & $\begin{array}{l}\infty \\
0 \\
+1 \\
-\infty \\
-\infty\end{array}$ & $\begin{array}{l}\text { 믐 } \\
\text { +1 } \\
\stackrel{-}{\sigma} \\
\square\end{array}$ \\
\hline \multirow{3}{*}{ 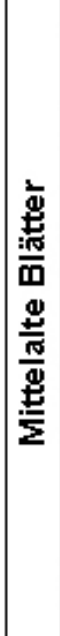 } & 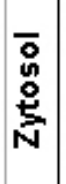 & 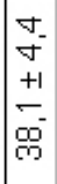 & $\stackrel{\square}{\square}$ & 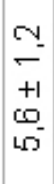 & $\begin{array}{l}m \\
\sigma \\
+1 \\
\vdots \\
\square \\
\sigma\end{array}$ & $\begin{array}{l}0 \\
\square \\
+1 \\
\omega \\
\square \\
\square\end{array}$ & $\begin{array}{l}m \\
\cdots \\
+1 \\
- \\
m-\end{array}$ & 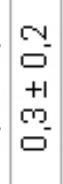 & $\begin{array}{c}\bar{\sigma} \\
\sigma \\
+1 \\
\omega \\
\sigma\end{array}$ & $\begin{array}{l}\sigma^{-} \\
+1 \\
\text { J. } \\
\sigma^{\prime}\end{array}$ & $\begin{array}{l}\widetilde{v} \\
\square \\
+1 \\
w \\
\sim \\
\sim\end{array}$ & 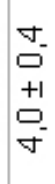 & $\begin{array}{l}m \\
-3 \\
+1 \\
m \\
-\end{array}$ & $\begin{array}{l}\sigma^{\prime} \\
\sigma^{\prime} \\
\cdots \\
\sigma^{-1}\end{array}$ & $\begin{array}{l}\widetilde{N} \\
\square \\
+1 \\
\infty \\
\varrho^{\prime}\end{array}$ & $\begin{array}{l}\stackrel{v}{a} \\
\square \\
+1 \\
m \\
\square\end{array}$ & 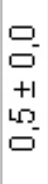 & $\begin{array}{l}5 \\
\square \\
+1 \\
\sigma\end{array}$ & $\begin{array}{l}= \\
+1 \\
+ \\
\sigma\end{array}$ & $\begin{array}{c}\sigma \\
\sigma \\
+1 \\
\sigma \\
\sigma\end{array}$ & $\begin{array}{c}0 \\
\infty \\
+1 \\
\infty \\
\infty \\
\infty\end{array}$ & $\begin{array}{l}\widetilde{V} \\
-1 \\
+1 \\
0 \\
\omega\end{array}$ & $\frac{\square}{\frac{\square}{+1}}$ & 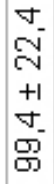 & $\begin{array}{l}\cdots \\
+1 \\
\infty \\
0 \\
0\end{array}$ & $\begin{array}{l}\square \\
\square \\
+1 \\
0 \\
-\end{array}$ & ס \\
\hline & 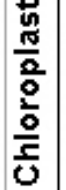 & $\begin{array}{c}\sigma \\
+1 \\
\infty \\
\infty \\
\infty\end{array}$ & $\begin{array}{l}0 \\
\square \\
+1 \\
\infty \\
0 \\
\checkmark\end{array}$ & $\begin{array}{l}\square \\
\square+1 \\
+1 \\
5- \\
m\end{array}$ & 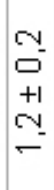 & $\begin{array}{l}\widetilde{V} \\
- \\
+1 \\
m \\
m\end{array}$ & $\begin{array}{c}\square \\
- \\
+1 \\
\infty \\
-\end{array}$ & $\begin{array}{l}\bar{\sigma} \\
\text { 口 } \\
+1 \\
\text { J } \\
\sigma^{\prime}\end{array}$ & $\begin{array}{l}\bar{\sigma} \\
+1 \\
\text { व. } \\
\sigma^{-}\end{array}$ & $\begin{array}{c}\bar{\sigma} \\
+1 \\
\sim \\
\square \\
\square\end{array}$ & 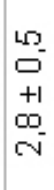 & $\begin{array}{l}m \\
0 \\
+1 \\
m- \\
-\end{array}$ & $\begin{array}{l}\infty \\
\sigma \\
+1 \\
0 \\
\sigma \\
\sigma\end{array}$ & $\begin{array}{c}\bar{\sigma} \\
\sigma^{-} \\
+1 \\
\nabla \\
\sigma\end{array}$ & $\begin{array}{l}5 \\
\sigma \\
+1 \\
\text { J- } \\
\sigma\end{array}$ & $\begin{array}{l}\sigma \\
\sigma \\
+1 \\
\sim \\
\sigma\end{array}$ & $\begin{array}{l}5 \\
\square \\
+1 \\
0 \\
0 \\
\end{array}$ & $\begin{array}{l}\sigma \\
\square \\
+1 \\
\sim \\
\sigma\end{array}$ & $\begin{array}{l}\text { 믐 } \\
+1 \\
+ \\
=\end{array}$ & $\begin{array}{l}\square \\
\square \\
+1 \\
\square^{\prime} \\
\square^{\prime}\end{array}$ & $\begin{array}{c}3 \\
\infty \\
+1 \\
0 \\
0 \\
8\end{array}$ & $\begin{array}{l}\cdots \\
b \\
+1 \\
\sigma^{\prime} \\
m^{\prime}\end{array}$ & $\begin{array}{l}\infty \\
0 \\
+1 \\
\sigma \\
\infty \\
\infty\end{array}$ & $\begin{array}{l}\text { 믐 } \\
\square+1 \\
\stackrel{+}{\circ} \\
\square\end{array}$ & $\begin{array}{l}\stackrel{\square}{-} \\
\stackrel{+1}{-} \\
\omega^{-}\end{array}$ & $\begin{array}{l}{ }^{N} \\
\square \\
+1 \\
- \\
-\end{array}$ & $\begin{array}{l}\square \\
\stackrel{\square}{-} \\
+1 \\
\stackrel{-}{-}\end{array}$ \\
\hline & 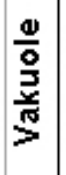 & $\begin{array}{l}\nabla \\
\sigma \\
+1 \\
\checkmark \\
v \\
v\end{array}$ & $\begin{array}{l}- \\
\square \\
+1 \\
0 \\
0\end{array}$ & $\begin{array}{l}5 \\
\square \\
+1 \\
\vdots \\
\sigma\end{array}$ & $\begin{array}{l}\square \\
\square \\
+1 \\
0 \\
\square \\
\square\end{array}$ & $\begin{array}{c}\bar{\sigma} \\
+1 \\
0 \\
\sigma^{-}\end{array}$ & $\begin{array}{c}\square \\
\square \\
+1 \\
\cdots \\
\square\end{array}$ & $\begin{array}{c}\square \\
\square \\
+1 \\
\square \\
\square\end{array}$ & $\begin{array}{l}\square \\
\square \\
+1 \\
\square \\
\square\end{array}$ & $\begin{array}{l}\square \\
\square \\
+1 \\
\square \\
\square\end{array}$ & $\begin{array}{l}\square \\
\square \\
+1 \\
+ \\
0 \\
\square\end{array}$ & 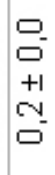 & $\begin{array}{l}\text { 号 } \\
+1 \\
\frac{-1}{\sigma}\end{array}$ & $\begin{array}{c}\sigma^{-} \\
+1 \\
\sigma^{-}\end{array}$ & 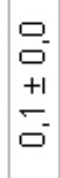 & 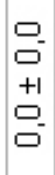 & $\begin{array}{l}\square^{-} \\
+1 \\
\square^{\prime} \\
\square^{-}\end{array}$ & 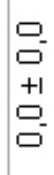 & $\begin{array}{l}\text { 号 } \\
+1 \\
\text { +1 } \\
-\end{array}$ & $\begin{array}{l}\square \\
\square^{\prime} \\
+1 \\
\square^{\prime} \\
\square^{\prime}\end{array}$ & $\begin{array}{l}\infty \\
0 \\
0 \\
+1 \\
0 \\
0 \\
0\end{array}$ & $\begin{array}{l}\square \\
0 \\
0 \\
+1 \\
\infty \\
0 \\
0\end{array}$ & $\begin{array}{l}\infty \\
\infty \\
+1 \\
\omega \\
\infty \\
\infty\end{array}$ & 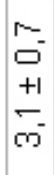 & $\begin{array}{l}\square \\
\check{\square} \\
+1 \\
+ \\
0 \\
g \\
0\end{array}$ & $\begin{array}{l}\widetilde{N} \\
\sim \\
+1 \\
\sim \\
\simeq \\
\simeq\end{array}$ & $\begin{array}{l}5 \\
\square \\
+1 \\
0 \\
-\end{array}$ \\
\hline \multirow{3}{*}{ 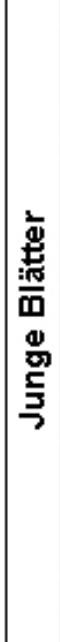 } & $\begin{array}{l}\bar{D} \\
\text { On } \\
\stackrel{5}{5} \\
\text { N }\end{array}$ & $\left|\begin{array}{c}\infty \\
- \\
+1 \\
\omega \\
\sigma \\
0\end{array}\right|$ & $\begin{array}{l}J \\
\square \\
+1 \\
0 \\
\square \\
\square\end{array}$ & $\begin{array}{l}0 \\
\square \\
+1 \\
\stackrel{-1}{-} \\
\frac{1}{\square}\end{array}$ & $\begin{array}{l}0 \\
\square \\
+1 \\
0 \\
0 \\
0\end{array}$ & 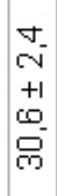 & $\begin{array}{c}\omega \\
\sigma \\
+1 \\
\infty \\
-\end{array}$ & $\begin{array}{l}\infty \\
\sigma^{-} \\
+1 \\
0 \\
0\end{array}$ & $\begin{array}{l}\bar{\sigma} \\
+1 \\
\bar{\sigma} \\
\bar{\sigma}\end{array}$ & $\begin{array}{l}\text { 口. } \\
\square \\
+1 \\
\square \\
\square\end{array}$ & 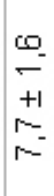 & $\begin{array}{l}\sigma_{-} \\
+1 \\
\sigma^{\prime} \\
\sigma\end{array}$ & $\begin{array}{l}m- \\
+1 \\
0 \\
0 \\
-\end{array}$ & $\begin{array}{l}\text { 口 } \\
\square \\
+1 \\
\text { 口́ } \\
\square\end{array}$ & $\begin{array}{l}L \\
\sigma^{2} \\
+1 \\
\text { J- } \\
\sigma^{\prime}\end{array}$ & $\begin{array}{l}5 \\
\square \\
+1 \\
\sigma\end{array}$ & $\begin{array}{l}\text { v } \\
\square \\
+1 \\
0 \\
0 \\
\square\end{array}$ & $\begin{array}{l}5 \\
\square \\
+1 \\
\sigma\end{array}$ & $\begin{array}{l}- \\
+1 \\
\cdots \\
\cdots \\
-\end{array}$ & $\begin{array}{l}\square \\
\square^{\prime} \\
+1 \\
\square^{\prime} \\
\square^{\prime}\end{array}$ & $\begin{array}{l}\underset{\sigma}{\sigma} \\
+1 \\
\infty \\
\varnothing\end{array}$ & $\begin{array}{l}\nabla \\
\infty \\
+1 \\
- \\
\sigma\end{array}$ & $\begin{array}{l}- \\
\cdots \\
+1 \\
- \\
\cdots\end{array}$ & $\begin{array}{l}0 \\
0 \\
0 \\
+1 \\
0 \\
m \\
m\end{array}$ & $\begin{array}{l}\sigma \\
\infty \\
+1 \\
\infty \\
\sigma\end{array}$ & 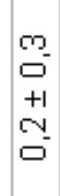 & 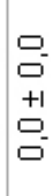 \\
\hline & 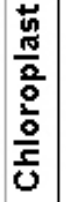 & $\mid \begin{array}{l}\square \\
\infty^{-} \\
+1 \\
\infty \\
\sigma^{-}\end{array}$ & 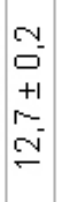 & $\begin{array}{l}\square \\
\frac{\square}{+1} \\
\frac{-1}{-}\end{array}$ & $\begin{array}{l}\bar{\sigma} \\
\sigma \\
+1 \\
\omega \\
\sigma\end{array}$ & $\begin{array}{l}0 \\
- \\
+1 \\
0 \\
\infty\end{array}$ & $\begin{array}{l}m \\
- \\
+1 \\
\sim \\
m\end{array}$ & $\begin{array}{l}0 \\
0 \\
+1 \\
0 \\
0 \\
0\end{array}$ & $\begin{array}{c}\sigma \\
\square \\
+1 \\
0 \\
\square\end{array}$ & $\begin{array}{c}\square \\
\square \\
+1 \\
\omega \\
\square \\
\square\end{array}$ & $\begin{array}{l}0 \\
\square \\
0+1 \\
\sim \\
v \\
v\end{array}$ & $\begin{array}{l}5 \\
\square \\
+1 \\
- \\
-\end{array}$ & $\begin{array}{l}\widetilde{N} \\
\square \\
+1 \\
0 \\
-\end{array}$ & $\begin{array}{c}\bar{\sigma} \\
\bar{\sigma} \\
+1 \\
\omega \\
\sigma\end{array}$ & $\begin{array}{l}\bar{\sigma} \\
+ \\
+1 \\
\square \\
-\end{array}$ & $\begin{array}{l}\square \\
\square \\
\square+1 \\
+1 \\
\square \\
\square\end{array}$ & $\begin{array}{l}- \\
\square \\
+1 \\
\square \\
\square\end{array}$ & $\begin{array}{l}- \\
\square \\
+1 \\
0 \\
\sigma \\
\sigma\end{array}$ & $\begin{array}{l}\square \\
\stackrel{-}{-} \\
+1 \\
\text { g. } \\
\square\end{array}$ & $\begin{array}{c}\square \\
\sigma^{\prime} \\
+1 \\
\square \\
\sigma^{-}\end{array}$ & 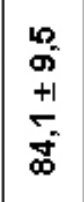 & $\begin{array}{l}\nabla \\
- \\
+1 \\
\sim \\
L\end{array}$ & $\frac{\widetilde{V}}{-}$ & $\begin{array}{l}3 \\
\square \\
+1 \\
\vdots \\
\vdots \\
0\end{array}$ & $\begin{array}{l}m \\
\cdots \\
+1 \\
\cdots \\
\cdots\end{array}$ & 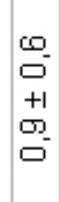 & $\begin{array}{l}\nabla_{-} \\
\sigma_{-}\end{array}$ \\
\hline & $\begin{array}{l}\frac{\omega}{0} \\
\stackrel{0}{J} \\
\text { J } \\
\end{array}$ & $\begin{array}{l}\infty \\
0 \\
+1 \\
\infty \\
\infty\end{array}$ & $\begin{array}{l}\sigma \\
\square \\
+1 \\
\stackrel{-}{2} \\
-\end{array}$ & $\begin{array}{l}\square \\
\square \\
+1 \\
+1 \\
\square \\
\square\end{array}$ & $\begin{array}{l}\square \\
\square \\
+1 \\
0 \\
b^{\prime}\end{array}$ & $\begin{array}{l}{ }^{N} \\
\square \\
+1 \\
-- \\
-\end{array}$ & $\begin{array}{l}\sigma \\
\sigma \\
+1 \\
\omega \\
\square \\
\sigma\end{array}$ & $\begin{array}{l}\sigma \\
\square \\
+1 \\
\square \\
\square\end{array}$ & $\begin{array}{l}\square \\
\square \\
+1 \\
\square \\
\square\end{array}$ & $\begin{array}{c}\square \\
\square \\
+1 \\
\square \\
\square \\
\square\end{array}$ & $\begin{array}{l}5 \\
\square \\
+1 \\
0 \\
0 \\
\sigma\end{array}$ & $\begin{array}{l}- \\
\sigma \\
+1 \\
\sigma_{-}\end{array}$ & 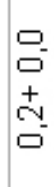 & 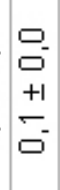 & 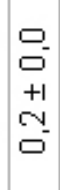 & $\begin{array}{l}\text { 머 } \\
\square \\
+1 \\
\stackrel{+}{\circ} \\
\square\end{array}$ & 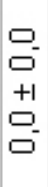 & $\begin{array}{l}\text { 口. } \\
\square \\
+1 \\
\square \\
\square \\
\square\end{array}$ & $\begin{array}{l}\text { 号 } \\
+1 \\
\text { +1 } \\
-\end{array}$ & $\begin{array}{l}\square \\
b^{\prime} \\
+1 \\
\square^{\prime} \\
\square^{\prime}\end{array}$ & $\underset{+\infty}{\stackrel{0}{\sigma}}$ & 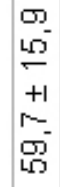 & $\begin{array}{l}\sigma \\
\infty \\
\sigma \\
+1 \\
\checkmark \\
\sigma \\
\sigma\end{array}$ & $\begin{array}{l}\cdots \\
-1 \\
+1 \\
\infty \\
\infty\end{array}$ & $\begin{array}{l}\infty \\
\infty \\
\omega \\
+1 \\
\cdots \\
\cdots \\
\infty\end{array}$ & $\begin{array}{c}\infty \\
- \\
+1 \\
\infty \\
-\end{array}$ & $\begin{array}{l}= \\
+\infty \\
\infty \\
\infty\end{array}$ \\
\hline$\underline{E}$ & & 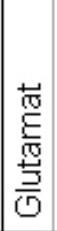 & 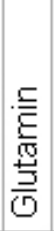 & 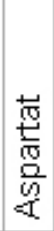 & $\begin{array}{l}\frac{5}{0} \\
\frac{10}{0} \\
\frac{0}{0} \\
\frac{1}{10}\end{array}$ & $\frac{5}{\frac{5}{5}}$ & $\frac{\frac{5}{0}}{\mathscr{Y}}$ & 旁 & $\stackrel{\frac{5}{\omega}}{\beth}$ & 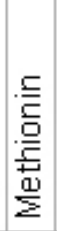 & 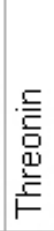 & 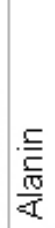 & $\frac{.5}{\frac{5}{N 0}}$ & 秕 & $\begin{array}{l}\underline{\underline{O}} \\
\underline{\underline{a}} \\
\underline{\underline{b}} \\
\underline{\underline{b}}\end{array}$ & 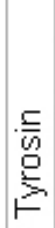 & 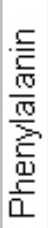 & 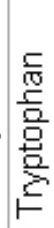 & 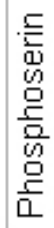 & $\begin{array}{l}\leq 1 \\
0 \\
01 \\
0\end{array}$ & 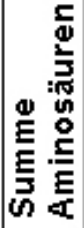 & 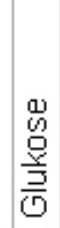 & $\begin{array}{l}\text { 岁 } \\
\text { 号 } \\
\text { 学 } \\
\text { 는 }\end{array}$ & 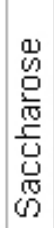 & $\frac{\pi}{\frac{\pi}{00}}$ & 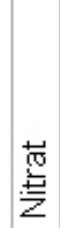 & : \\
\hline
\end{tabular}


Tab. 3.5: Ergebnisse der nichtwässrigen Fraktionierung von bei $4 \mathrm{mM} \mathrm{NO}_{3}$ hydroponisch angezogenen Rapspflanzen

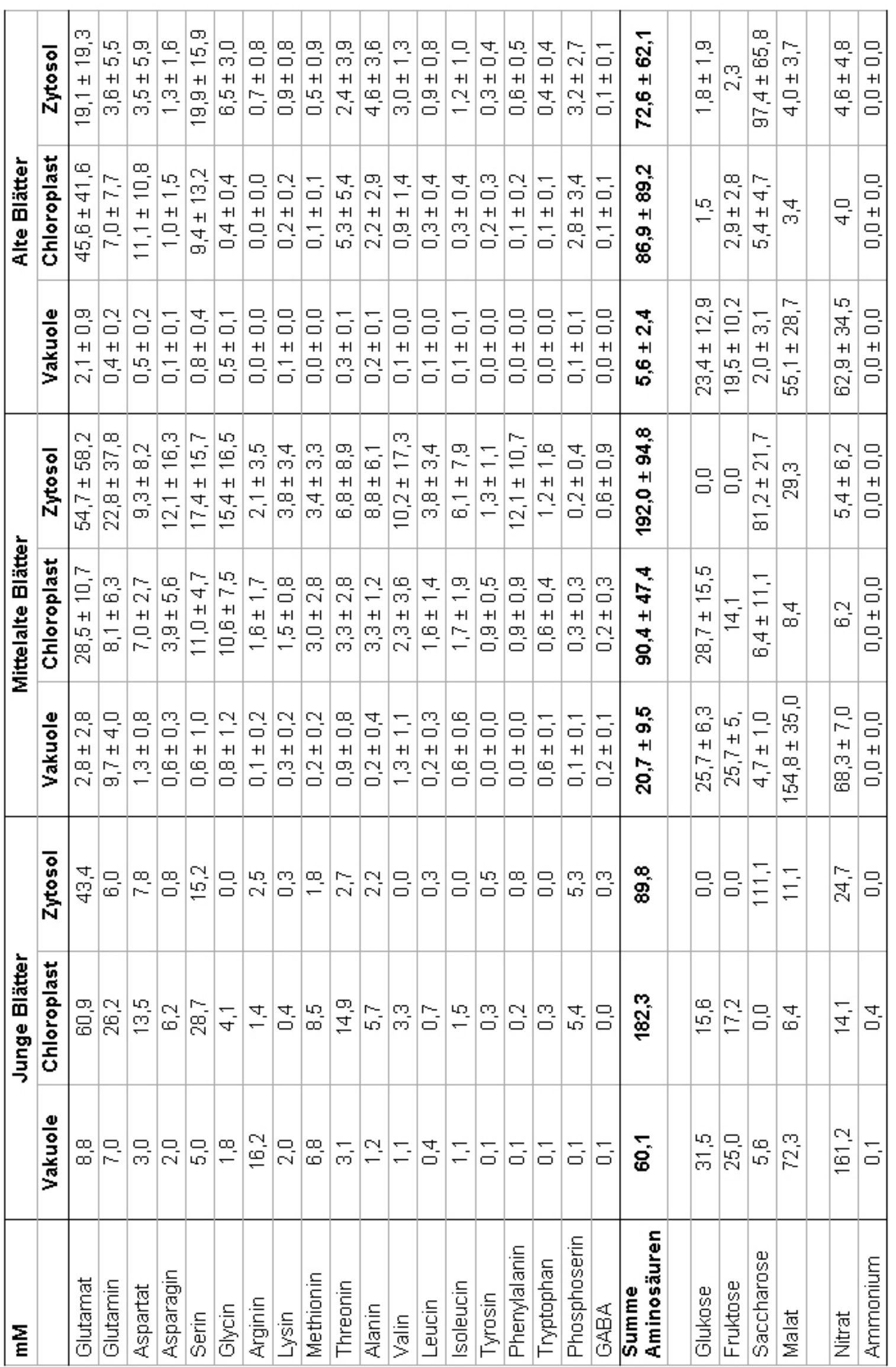




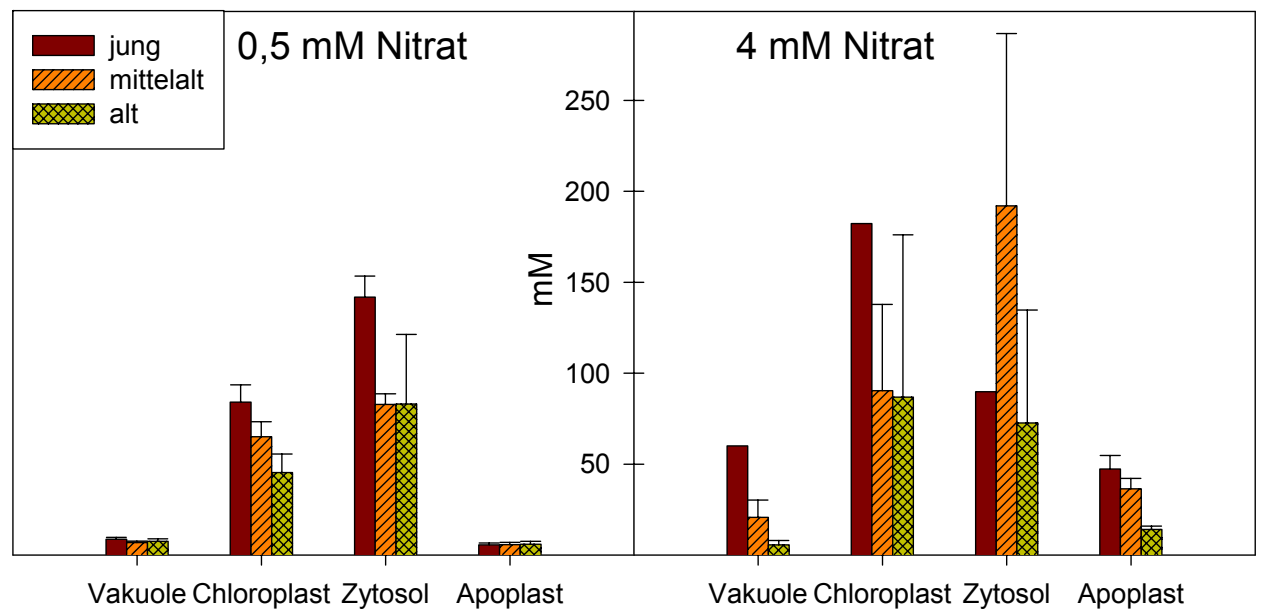

Abb. 3.3: Aminosäurekonzentrationen in subzellulären Kompartimenten verschieden alter Rapsblätter. $0,5 \mathrm{mM}$ und $4 \mathrm{mM}$ Nitrat: N-Konzentration in der Nährlösung. Die Abbildung kombiniert die Ergebnisse der nichtwässrigen Fraktionierung (3.2) mit denen der apoplastischen Infiltrationsexperimente (3.3).

\subsection{Aminosäurekonzentrationen im Apoplasten und Vergleich der Aminosäure- Zusammensetzung in den untersuchten Kompartimenten}

Zur Ergänzung der Daten aus der nichtwässrigen Fraktionierung und, um die tatsächlichen Substratkonzentrationen für Aminosäuretransporter bei der apoplastischen Phloembeladung zu ermitteln, wurde die Aminosäurekonzentration im Apoplast bestimmt (Tab. 3.6 und Abb. 3.3). Bei mit 0,5 mM Nitrat in der Nährlösung angezogenen Pflanzen blieb die apoplastische Aminosäure-Gesamtkonzentration während der Blattentwicklung konstant niedrig bei etwa 56 mM. Das entspricht einem Konzentrationsgefälle von 10-40fach gegenüber dem Zytosol der Mesophyllzellen (Tab. 3.4 und 3.5, Abb. 3.3.). Im Apoplasten junger Blätter von $4 \mathrm{mM}$ Nitrat-Pflanzen fanden sich dagegen mit 47,3 \pm 7,4 mM etwa zehnfach höhere Werte und entsprechend nur ein ein- bis vierfacher Konzentrationsgradient zum umgebenden Gewebe. Anders als bei den 0,5 mM Nitrat-Pflanzen nahm die apoplastische Aminosäurekonzentration hier mit dem Blattalter ab. Alte Blätter enthielten noch etwa doppelt so viele Aminosäuren im Apoplasten wie bei $0,5 \mathrm{mM}$ Nitrat in der Nährlösung. Bei beiden N-Versorgungsstufen entspricht die jeweilige Gesamtkonzentration von Aminosäuren im Apoplasten in etwa der in der Vakuole. 
Tab. 3.6: Apoplastische Aminosäurekonzentrationen in Blättern von hydroponisch mit 0,5 $\mathrm{mM}$ und $4 \mathrm{mM}$ Nitrat im Medium angezogenen Rapspflanzen. Angegeben sind Mittelwerte \pm Standardabweichungen $(n=6)$. GABA: $\gamma$-Aminobuttersäure.

\begin{tabular}{|l|c|c|c|c|c|c|}
\hline \multirow{2}{*}{$\mathbf{m M}$} & \multicolumn{3}{|c}{$\mathbf{0 , 5} \mathbf{~ m M ~ N i t r a t}$} & \multicolumn{3}{c|}{$\mathbf{4 ~ m M ~ N i t r a t}$} \\
\cline { 2 - 7 } & jung & mittelalt & alt & jung & mittelalt & alt \\
\hline Glutamat & $0,8 \pm 0,2$ & $0,9 \pm 0,4$ & $1,3 \pm 0,2$ & $10,4 \pm 1,7$ & $8,0 \pm 1,5$ & $2,8 \pm 0,8$ \\
\hline Glutamin & $0,2 \pm 0,1$ & $0,7 \pm 0,3$ & $0,4 \pm 0,0$ & $12,3 \pm 2,1$ & $9,9 \pm 1,0$ & $4,3 \pm 0,7$ \\
\hline Aspartat & $0,9 \pm 0,3$ & $0,9 \pm 0,3$ & $1,6 \pm 0,6$ & $10,2 \pm 2,1$ & $7,0 \pm 1,5$ & $1,8 \pm 0,4$ \\
\hline Asparagin & $0,1 \pm 0,0$ & $0,1 \pm 0,1$ & $0,1 \pm 0,1$ & $0,9 \pm 0,3$ & $0,6 \pm 0,1$ & $0,2 \pm 0,0$ \\
\hline Serin & $0,9 \pm 0,3$ & $0,7 \pm 0,2$ & $0,4 \pm 0,1$ & $5,1 \pm 1,3$ & $2,8 \pm 0,5$ & $1,6 \pm 0,3$ \\
\hline Glycin & $0,8 \pm 0,2$ & $0,4 \pm 0,1$ & $0,2 \pm 0,1$ & $0,6 \pm 0,2$ & $0,9 \pm 0,2$ & $1,1 \pm 0,5$ \\
\hline Arginin & $0,1 \pm 0,0$ & $0,1 \pm 0,1$ & $0,1 \pm 0,0$ & $0,3 \pm 0,2$ & $0,2 \pm 0,1$ & $0,0 \pm 0,0$ \\
\hline Lysin & $0,1 \pm 0,0$ & $0,1 \pm 0,0$ & $0,1 \pm 0,0$ & $0,2 \pm 0,1$ & $0,3 \pm 0,1$ & $0,1 \pm 0,0$ \\
\hline Histidin & $0,1 \pm 0,0$ & $0,1 \pm 0,0$ & $0,1 \pm 0,0$ & $0,1 \pm 0,1$ & $0,2 \pm 0,0$ & $0,1 \pm 0,0$ \\
\hline Methionin & $0,0 \pm 0,0$ & $0,1 \pm 0,0$ & $0,1 \pm 0,1$ & $0,1 \pm 0,0$ & $0,1 \pm 0,0$ & $0,0 \pm 0,0$ \\
\hline Threonin & $0,3 \pm 0,1$ & $0,2 \pm 0,1$ & $0,2 \pm 0,1$ & $2,7 \pm 0,7$ & $2,0 \pm 0,4$ & $0,5 \pm 0,1$ \\
\hline Alanin & $0,4 \pm 0,2$ & $0,3 \pm 0,1$ & $0,4 \pm 0,1$ & $1,8 \pm 0,3$ & $1,7 \pm 0,4$ & $1,0 \pm 0,1$ \\
\hline Valin & $0,0 \pm 0,0$ & $0,2 \pm 0,1$ & $0,2 \pm 0,1$ & $0,7 \pm 0,1$ & $0,6 \pm 0,1$ & $0,2 \pm 0,0$ \\
\hline Leucin & $0,2 \pm 0,0$ & $0,2 \pm 0,1$ & $0,2 \pm 0,1$ & $0,3 \pm 0,1$ & $0,3 \pm 0,1$ & $0,1 \pm 0,0$ \\
\hline Isoleucin & $0,1 \pm 0,0$ & $0,1 \pm 0,1$ & $0,1 \pm 0,0$ & $0,5 \pm 0,1$ & $0,4 \pm 0,1$ & $0,2 \pm 0,0$ \\
\hline Tyrosin & $0,1 \pm 0,0$ & $0,1 \pm 0,0$ & $0,1 \pm 0,0$ & $0,1 \pm 0,1$ & $0,1 \pm 0,0$ & $0,0 \pm 0,0$ \\
\hline Phenylalanin & $0,1 \pm 0,0$ & $0,1 \pm 0,0$ & $0,1 \pm 0,1$ & $0,2 \pm 0,1$ & $0,2 \pm 0,1$ & $0,1 \pm 0,0$ \\
\hline Tryptophan & $0,1 \pm 0,0$ & $0,1 \pm 0,0$ & $0,1 \pm 0,0$ & $0,1 \pm 0,1$ & $0,1 \pm 0,0$ & $0,0 \pm 0,0$ \\
\hline Phosphoserin & $0,1 \pm 0,0$ & $0,1 \pm 0,0$ & $0,1 \pm 0,0$ & $0,2 \pm 0,1$ & $0,2 \pm 0,1$ & $0,0 \pm 0,0$ \\
\hline GABA & $0,1 \pm 0,0$ & $0,1 \pm 0,1$ & $0,2 \pm 0,0$ & $0,6 \pm 0,0$ & $0,8 \pm 0,3$ & $0,2 \pm 0,1$ \\
\hline Summe & $\mathbf{5 , 6} \pm \mathbf{1 , 1}$ & $\mathbf{5 , 7} \pm \mathbf{1 , 3}$ & $\mathbf{5 , 9} \pm \mathbf{1 , 6}$ & $\mathbf{4 7 , 3} \pm \mathbf{7 , 4}$ & $\mathbf{3 6 , 4} \pm \mathbf{5 , 8}$ & $\mathbf{1 4 , 1} \pm \mathbf{1 , 8}$ \\
\hline
\end{tabular}

Um in den untersuchten Kompartimenten die Aminosäurezusammensetzung vergleichen zu können, wurden ihre prozentualen Anteile an der jeweiligen Gesamtkonzentration berechnet (Tab. 3.7). Für Prolin liegen keine Daten vor, da diese Aminosäure mit der verwendeten Derivatisierungsmethode nicht meßbar ist. Die Konzentration von Cystein lag in der Regel unter der Nachweisgrenze. Bei der nichtwässrigen Fraktionierung liegen auch für Histidin keine Daten vor, da diese Aminosäure abhängig von der Säulencharge meistens nicht von Glutamin getrennt werden konnte. In einzelnen Proben zeigte sich aber, daß die HistidinKonzentration sehr niedrig war. 
Tab. 3.7: Prozentuale Anteile einzelner Aminosäuren an der GesamtAminosäurekonzentration in verschiedenen Kompartimenten von Mesophyllzellen und im Apoplast von Rapsblättern. Alle Werte in \% der Gesamtkonzentration im jeweiligen Kompartiment. Bei der nichtwässrigen Fraktionierung wurde kein Histidin gemessen. 0,5 mM und $4 \mathrm{mM}$ Nitrat bezeichnen die $\mathrm{NO}_{3}{ }^{-}$-Konzentrationen in den hydroponischen Medien. Vak.: Vakuole, Chl.: Chloroplast, Zyt.: Zytosol, Apo.: Apoplast, GABA: $\gamma$-Aminobuttersäure, ND: nicht detektiert.

\begin{tabular}{|c|c|c|c|c|c|c|c|c|c|c|c|c|}
\hline \multirow{2}{*}{$\begin{array}{l}0,5 \mathrm{mM} \\
\text { Nitrat }\end{array}$} & \multicolumn{4}{|c|}{ junge Blätter } & \multicolumn{4}{|c|}{ mittelalte Blätter } & \multicolumn{4}{|c|}{ alte Blätter } \\
\hline & $\begin{array}{l}\text { Vak. } \\
\text { (\%) }\end{array}$ & $\begin{array}{l}\text { Chl. } \\
\text { (\%) }\end{array}$ & $\begin{array}{l}\text { Zyt. } \\
\text { (\%) }\end{array}$ & $\begin{array}{c}\text { Apo. } \\
\text { (\%) }\end{array}$ & $\begin{array}{l}\text { Vak. } \\
\text { (\%) }\end{array}$ & $\begin{array}{l}\text { Chl. } \\
\text { (\%) }\end{array}$ & $\begin{array}{l}\text { Zyt. } \\
(\%)\end{array}$ & $\begin{array}{c}\text { Apo. } \\
(\%)\end{array}$ & $\begin{array}{l}\text { Vak. } \\
\text { (\%) }\end{array}$ & $\begin{array}{l}\text { Chl. } \\
\text { (\%) }\end{array}$ & $\begin{array}{l}\text { Zyt. } \\
\text { (\%) }\end{array}$ & $\begin{array}{l}\text { Apo. } \\
\text { (\%) }\end{array}$ \\
\hline Glutamat & 32,1 & 43,8 & 43,4 & 14,1 & 34,8 & 50,6 & 46,0 & 16,2 & 25,4 & 35,4 & 16,9 & 21,9 \\
\hline Glutamin & 13,2 & 15,1 & 0,2 & 3,8 & 11,8 & 7,4 & 2,1 & 12,1 & 14,2 & 4,2 & 38,3 & 6,1 \\
\hline Aspartat & 7,6 & 9,6 & 10,0 & 16,0 & 9,9 & 11,6 & 6,7 & 15,6 & 10,1 & 11,8 & 5,0 & 26,4 \\
\hline Asparagin & 3,6 & 3,0 & 0,2 & 2,0 & 4,2 & 1,8 & 0,4 & 2,5 & 1,2 & 0,7 & 4,0 & 1,9 \\
\hline Serin & 12,8 & 9,9 & 21,6 & 16,9 & 11,3 & 11,2 & 17,5 & 12,8 & 5,7 & 8,1 & 8,4 & 6,5 \\
\hline Glycin & 5,2 & 3,8 & 0,9 & 14,4 & 4,8 & 2,5 & 8,6 & 7,6 & 7,5 & 20,5 & 8,8 & 3,4 \\
\hline Arginin & 4,3 & 0,6 & 0,6 & 1,9 & 4,2 & 0,6 & 0,3 & 1,9 & 0,5 & 0,7 & 1,6 & 1,5 \\
\hline Lysin & 1,6 & 0,8 & 0,1 & 2,5 & 1,5 & 0,6 & 0,6 & 2,0 & 0,0 & 3,5 & 0,1 & 1,8 \\
\hline Histidin & $N D$ & ND & $N D$ & 1,9 & $N D$ & $N D$ & $N D$ & 1,4 & $N D$ & $N D$ & $N D$ & 1,2 \\
\hline Methionin & 1,8 & 0,5 & 0,0 & 0,7 & 0,9 & 0,3 & 0,5 & 1,4 & 0,1 & 0,1 & 0,2 & 2,2 \\
\hline Threonin & 5,4 & 5,0 & 5,4 & 4,6 & 4,6 & 4,3 & 3,0 & 3,9 & 5,8 & 3,1 & 2,5 & 3,6 \\
\hline Alanin & 4,2 & 1,7 & 6,3 & 7,2 & 3,5 & 2,6 & 4,8 & 5,7 & 3,2 & 3,7 & 4,0 & 6,0 \\
\hline Valin & 2,6 & 2,1 & 1,3 & 0,4 & 1,7 & 1,4 & 1,5 & 3,9 & 7,3 & 4,0 & 3,3 & 3,6 \\
\hline Leucin & 0,8 & 0,6 & 0,0 & 3,8 & 0,9 & 0,7 & 0,9 & 2,8 & 2,7 & 1,0 & 2,5 & 2,6 \\
\hline Isoleucin & 2,0 & 1,1 & 0,3 & 2,5 & 1,7 & 0,6 & 0,8 & 2,6 & 4,4 & 0,9 & 0,5 & 2,1 \\
\hline Tyrosin & 0,4 & 0,4 & 0,1 & 1,5 & 0,6 & 0,3 & 0,3 & 1,5 & 0,2 & 0,3 & 0,7 & 1,2 \\
\hline Phenylalanin & 0,5 & 0,4 & 0,2 & 2,1 & 0,7 & 0,4 & 0,6 & 1,8 & 3,5 & 1,0 & 1,9 & 1,8 \\
\hline Tryptophan & 0,5 & 0,3 & 0,1 & 1,2 & 0,7 & 0,3 & 0,2 & 1,1 & 6,4 & 0,4 & 1,0 & 1,5 \\
\hline Phosphoserin & 1,2 & 1,1 & 9,3 & 1,0 & 2,1 & 2,7 & 5,1 & 0,9 & 1,5 & 1,5 & 0,1 & 1,9 \\
\hline GABA & 0,3 & 0,1 & 0,0 & 1,4 & 0,4 & 0,0 & 0,1 & 2,1 & 0,2 & 0,5 & 0,3 & 2,6 \\
\hline \multirow{2}{*}{$\begin{array}{l}4 \mathrm{mM} \\
\text { Nitrat }\end{array}$} & \multicolumn{4}{|c|}{ junge Blätter } & \multicolumn{4}{|c|}{ mittelalte Blätter } & \multicolumn{4}{|c|}{ בalte Blätter } \\
\hline & $\begin{array}{l}\text { Vak. } \\
\text { (\%) }\end{array}$ & $\begin{array}{l}\text { Chl. } \\
\text { (\%) }\end{array}$ & $\begin{array}{l}\text { Zyt. } \\
(\%)\end{array}$ & $\begin{array}{c}\text { Apo. } \\
\text { (\%) }\end{array}$ & $\begin{array}{l}\text { Vak. } \\
\text { (\%) }\end{array}$ & $\begin{array}{l}\text { Chl. } \\
\text { (\%) }\end{array}$ & $\begin{array}{l}\text { Zyt. } \\
\text { (\%) }\end{array}$ & $\begin{array}{l}\text { Apo. } \\
\text { (\%) }\end{array}$ & $\begin{array}{l}\text { Vak. } \\
(\%)\end{array}$ & $\begin{array}{l}\text { Chl. } \\
\text { (\%) }\end{array}$ & $\begin{array}{l}\text { Zyt. } \\
\text { (\%) }\end{array}$ & $\begin{array}{l}\text { Apo. } \\
\text { (\%) }\end{array}$ \\
\hline Glutamat & 14,6 & 33,4 & 48,3 & 21,9 & 13,8 & 31,5 & 28,5 & 21,9 & 37,9 & 52,5 & 26,3 & 19,7 \\
\hline Glutamin & 11,6 & 14,4 & 6,6 & 25,9 & 46,8 & 9,0 & 11,9 & 27,3 & 6,7 & 8,1 & 5,0 & 30,2 \\
\hline Aspartat & 5,0 & 7,4 & 8,6 & 21,5 & 6,4 & 7,8 & 4,8 & 19,4 & 9,7 & 12,8 & 4,9 & 12,4 \\
\hline Asparagin & 3,4 & 3,4 & 0,9 & 1,9 & 3,1 & 4,4 & 6,3 & 1,6 & 1,6 & 1,1 & 1,8 & 1,2 \\
\hline Serin & 8,3 & 15,7 & 16,9 & 10,8 & 2,9 & 12,2 & 9,0 & 7,8 & 13,9 & 10,8 & 27,4 & 11,5 \\
\hline Glycin & 3,0 & 2,3 & 0,0 & 1,3 & 3,7 & 11,7 & 8,0 & 2,5 & 8,2 & 0,5 & 9,0 & 7,4 \\
\hline Arginin & 27,0 & 0,8 & 2,8 & 0,6 & 0,6 & 1,8 & 1,1 & 0,7 & 0,7 & 0,0 & 0,9 & 0,3 \\
\hline Lysin & 3,4 & 0,2 & 0,3 & 0,5 & 1,3 & 1,6 & 2,0 & 0,7 & 1,1 & 0,2 & 1,2 & 0,4 \\
\hline Histidin & $N D$ & $N D$ & $N D$ & 0,2 & $N D$ & $N D$ & $N D$ & 0,5 & $N D$ & $N D$ & $N D$ & 0,4 \\
\hline Methionin & 11,4 & 4,6 & 2,0 & 0,3 & 1,0 & 3,3 & 1,8 & 0,3 & 0,5 & 0,1 & 0,7 & 0,2 \\
\hline Threonin & 5,2 & 8,2 & 3,0 & 5,7 & 4,3 & 3,7 & 3,5 & 5,4 & 6,0 & 6,1 & 3,4 & 3,8 \\
\hline Alanin & 1,9 & 3,1 & 2,4 & 3,7 & 1,1 & 3,7 & 4,6 & 4,8 & 4,0 & 2,5 & 6,3 & 6,9 \\
\hline Valin & 1,8 & 1,8 & 0,0 & 1,5 & 6,3 & 2,5 & 5,3 & 1,7 & 2,4 & 1,0 & 4,1 & 1,2 \\
\hline Leucin & 0,6 & 0,4 & 0,4 & 0,7 & 1,0 & 1,8 & 2,0 & 0,7 & 1,4 & 0,4 & 1,3 & 0,4 \\
\hline Isoleucin & 1,9 & 0,8 & 0,0 & 1,0 & 2,9 & 1,9 & 3,2 & 1,2 & 2,5 & 0,3 & 1,6 & 1,1 \\
\hline Tyrosin & 0,2 & 0,2 & 0,5 & 0,3 & 0,1 & 1,0 & 0,7 & 0,3 & 0,5 & 0,2 & 0,4 & 0,2 \\
\hline Phenylalanin & 0,1 & 0,1 & 0,9 & 0,4 & 0,1 & 1,0 & 6,3 & 0,5 & 0,8 & 0,2 & 0,8 & 0,4 \\
\hline Tryptophan & 0,2 & 0,1 & 0,0 & 0,3 & 3,0 & 0,7 & 0,6 & 0,3 & 0,4 & 0,1 & 0,5 & 0,3 \\
\hline Phosphoserin & 0,2 & 2,9 & 5,9 & 0,4 & 0,6 & 0,3 & 0,1 & 0,4 & 1,4 & 3,2 & 4,4 & 0,1 \\
\hline GABA & 0,1 & 0,0 & 0,3 & 1,2 & 0,8 & 0,2 & 0,3 & 2,1 & 0,5 & 0,1 & 0,1 & 1,7 \\
\hline
\end{tabular}


Beim Vergleich der Kompartimente, zunächst nur innerhalb der Mesophyllzellen, zeigte sich, daß Glutamat mit bis zu 52,5 \% Anteil fast überall die dominierende Aminosäure war, häufig gefolgt von Glutamin (bis zu 46,8 \%) oder dem Photorespirations-Intermediat Serin (bis zu 27,4 \%). In der Vakuole junger Blätter von $4 \mathrm{mM}$ Nitrat-Pflanzen dominierte die sonst eher seltene Aminosäure Arginin (27,0 \% Anteil), allerdings lag in diesem Fall nur ein Meßwert vor. Glutamat war stets zumindest die zweithäufigste Aminosäure. Neben Glutamat, Glutamin und Serin erreichten auch Glycin (bis 20,5 \%), ebenfalls ein Intermediat der Photorespiration, und Aspartat (bis 12,8 \%) relativ hohe Anteile an der Gesamt-Aminosäurekonzentration. Unter den übrigen Aminosäuren waren Methionin (bis zu 11,4) sowie Threonin und Alanin mit in der Regel $>2 \%$ Anteil am häufigsten, gefolgt von Valin, Asparagin und Isoleucin. Die aromatischen Aminosäuren Tryptophan, Phenylalanin und Tyrosin waren am seltensten, Tyrosin machte nie mehr als $1 \%$ aller Aminosäuren aus.

Bei den 0,5 mM Nitrat-Pflanzen nahmen im Zytosol alter Blätter die relativen Anteile der häufigen Aminosäuren Glutamat, Aspartat, Serin und Alanin, sowie von Threonin und Phosphoserin ab. Die Anteile von Glutamin, Asparagin, Glycin, Arginin, Valin, Leucin, Isoleucin, Tyrosin, Phenylalanin und Tryptophan stiegen dagegen an. Tendenziell wurden seltenere Aminosäuren häufiger und es fand eine Umverteilung von den Säuren Glutamat und Aspartat zu den Amiden Glutamin und Asparagin statt. Bei den 4 mM Nitrat-Pflanzen waren solche Tendenzen nicht deutlich erkennbar. Auch hier nahmen die zytosolischen Anteile von Glutamat und Aspartat mit dem Blattalter ab. Die deutlichsten Zunahmen zeigten sich bei Serin, Glycin und Alanin, wogegen seltenere Aminosäuren eher in den mittelalten Blättern die höchsten Anteile erreichten und dann zu den alten Blättern hin wieder prozentual abnahmen. Im Apoplasten gehörte Glutamat ebenfalls stets zu den häufigsten Aminosäuren, war aber im Gegensatz zum Zellinneren nur in einem Fall dominierend. Bei 0,5 mM Nitrat im Medium waren bei jungen Blättern Serin und Aspartat am häufigsten, bei mittelalten und alten Blättern Glutamat und Aspartat. Bei $4 \mathrm{mM}$ Nitrat war dagegen stets Glutamin dominierend und Glutamat stellte die zweithäufigste Aminosäure dar.

Bei den 0,5 mM Nitrat-Pflanzen war die Zunahme von Glutamin mit dem Blattalter im Apoplasten weniger deutlich als im Zytosol, und Glutamat und Aspartat nahmen anteilsmäßig zu während sie im Zytosol relativ weniger wurden. Bis auf Methionin, Valin und Tryptophan nahmen auch die Anteile der anderen Aminosäuren im Apoplasten mit dem Blattalter ab. Bei $4 \mathrm{mM}$ Nitrat war im Apoplasten für Glutamin, Glycin und Alanin eine Zunahme des relativen Anteils mit dem Blattalter feststellbar, die bei Glycin und Alanin auch einer zytosolischen Zunahme entsprach. Der Anteil von Histidin an den apoplastischen Aminosäuren nahm 
ebenfalls mit dem Blattalter zu, während Aspartat, Asparagin, Arginin, Threonin, Valin und Leucin abnahmen.

\subsection{Identifizierung von Brassica napus Aminosäuretransportern}

Um die Phloembeladung mit Aminosäuren in Rapsblättern auf molekularer Ebene zu untersuchen, wurden cDNA-Fragmente von Brassica napus Aminosäuretransportern durch PCR bzw. RT-PCR identifiziert. Dazu wurden Kombinationen spezifischer und degenerierter Primer verwendet. Der spezifische Primer BA6r2 (Tab. 2.1) war aus einem B. napus „Expressed Sequence Tag“ (EST) mit 86,5 \% Homologie zu AtAAP6 abgeleitet (Sohn et al. 1995, GenBank Acc. No. H07512). Degenerierte Primer wurden anhand eines Vergleichs von elf Aminosäuretransportern aus Arabidopsis thaliana, Tomate (Lycopersicon esculentum) und Ricinus communis abgeleitet. Dazu wurden Bereiche mit vollständig konservierter Aminosäuresequenz in eine Nukleotidsequenz rückübersetzt (Knop 1998). Zusätzlich wurden entsprechende degenerierte Primer mit Inosin an variablen Nukleotidpositionen, an denen alle vier Basen möglich waren, verwendet (CKAA1i, CKAA2i, CKAA4ri; Tab. 2.1). Die durch PCR bzw. RT-PCR erhaltenen partiellen cDNAs wurden in pGEM-T Easy kloniert und sequenziert. cDNA-Fragmente, die eine Homologie zu Arabidopsis AAPs aufwiesen, wurden durch 5' und 3' RACE vervollständigt. Die Benennung der BnAAP-Gene erfolgte nach dem jeweils nächstverwandten Arabidopsis-Gen.

Tab. 3.8: Homologie von Aminosäuretransportern aus B. napus und A. thaliana. Angegeben sind die Sequenzidentität („Identity“) und Sequenzähnlichkeit („Similarity“) auf Aminosäureebene in Prozent. Die für den Sequenzvergleich verwendete Sequenz von BnAAP2 ist unvollständig. Die jeweils größten Homologien zu Arabidopsis-Transportern sind durch Fettdruck und graue Hinterlegung hervorgehoben.

\begin{tabular}{|c|c|c|c|c|c|c|c|c|c|c|c|}
\hline & $\%$ & $\begin{array}{l}\text { Bn } \\
\text { AAP2 }\end{array}$ & $\begin{array}{l}\text { Bn } \\
\text { AAP6 }\end{array}$ & $\begin{array}{l}\text { At } \\
\text { AAP1 }\end{array}$ & $\begin{array}{l}\text { At } \\
\text { AAP2 }\end{array}$ & $\begin{array}{l}\text { At } \\
\text { AAP3 }\end{array}$ & $\begin{array}{l}\text { At } \\
\text { AAP4 }\end{array}$ & $\begin{array}{l}\text { At } \\
\text { AAP5 }\end{array}$ & $\begin{array}{l}\text { At } \\
\text { AAP6 }\end{array}$ & $\begin{array}{l}\text { At } \\
\text { AAP7 }\end{array}$ & $\begin{array}{l}\text { At } \\
\text { AAP8 }\end{array}$ \\
\hline \multirow{3}{*}{ 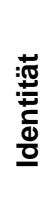 } & BnAAP1 & \multirow[t]{3}{*}{55,7} & 75,1 & 91,1 & 57,3 & 58,9 & 59,1 & 57,5 & 73,8 & 51,0 & 77,7 \\
\hline & BnAAP2 & & 59,8 & 56,9 & 93,5 & 74,0 & 87,0 & 65,0 & 57,5 & 45,3 & 52,4 \\
\hline & BnAAP6 & & & 75,8 & 60,0 & 59,9 & 59,5 & 58,5 & 91,9 & 51,6 & 69,6 \\
\hline \multirow{3}{*}{ 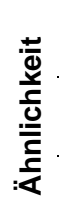 } & BnAAP1 & \multirow[t]{3}{*}{65,9} & 81,0 & 94,4 & 67,8 & 69,9 & 69,1 & 67,9 & 80,7 & 60,7 & 85,4 \\
\hline & BnAAP2 & & 70,3 & 67,1 & 94,3 & 82,1 & 89,8 & 74,0 & 68,0 & 59,6 & 63,8 \\
\hline & BnAAP6 & & & 83,2 & 70,1 & 70,0 & 69,4 & 68,6 & 93,9 & 61,7 & 77,7 \\
\hline
\end{tabular}




\subsubsection{BnAAP1}

Eine partielle cDNA (616 bp) von BnAAPl wurde durch RT-PCR mit den degenerierten Primern CKAA2i und CKAA4ri (Tab. 2.1) und zweifache Reamplifikation erhalten. Als Matrize diente Erststrang-cDNA aus Gesamt-RNA junger Blätter der Rapssorte Lirajet. Das 5' cDNA-Ende wurde durch 5' RACE mit den Primern A1-5R-1C und A1-5R-2 erhalten. Für das 3' RACE wurde zunächst eine Voramplifikation mit dem Primer BA1f1 und dem unspezifischen $\mathrm{dT}_{20}$ Primer durchgeführt. Die Primer für die eigentlichen 3' RACE PCRs waren A1-3R-1 und A1-3R-2C. Die vollständige kodierende Sequenz wurde durch PCR mit den Primern A1TskNf und A1TskNr und einer $3^{\prime} \rightarrow 5^{\prime}$ korrekturlesenden Pwo DNAPolymerase erhalten und über XhoI und Pst $\mathrm{I}$ Restriktionsschnittstellen in den Primern direktional in den Vektor pBF1 kloniert. Das daraus resultierende Plasmid p1ORF ist im Anhang in Abb. 8.3 abgebildet. Aus dem in Xenopus-Oozyten funktionell exprimierten Klon (3.5) wurde die kodierende Sequenz über NcoI und $P v u$ II ausgeschnitten und in den E. coliExpressionsvektor pET-15b ligiert. Der Vektor wurde dafür mit XhoI linearisiert, die überstehenden Enden durch Klenow DNA-Polymerase aufgefüllt und der N-terminale HisTag durch einen NcoI-Verdau entfernt. Dieses Konstrukt wurde für eine vollständige beidseitige Sequenzierung durch die Firma Seqlab, Göttingen verwendet. Die Sequenzierungsprimer waren T7 Promotor, T7 Terminator (beide vektorspezifisch), BA1f1, A1-3R-1, BA1r1 und A1-5R-1C (alle genspezifisch). Die vollständige cDNA-Sequenz von $B n A A P 1$ ist mit der Accession No. AJ565847 in den Datenbanken hinterlegt und findet sich in Anhang 8.2 dieser Arbeit.

Die cDNA von BnAAP1 ist inklusive 3' PolyA-Ende 1739 bp lang und kodiert von bp 91 bis 1548 ein Polypeptid aus 485 Aminosäuren mit einem kalkulierten Molekulargewicht von 53,1 kDa. Die Sequenzidentität des offenen Leserasters mit AtAAPl beträgt 88,6 \% auf Nukleotidund 91,1 \% auf Aminosäureebene, die Sequenzähnlichkeit auf Aminosäureebene ist 94,4 \% (Tab. 3.8, Abb. 3.6). Im Verlauf dieser Arbeit wurde von Noiraud et al. 2002 eine partielle cDNA von BnAAPl in den Datenbanken hinterlegt (Acc. No. AY188953). Dieses 552 bpFragment weist zu dem hier beschriebenen Vollängenklon eine Sequenzidentität von 96,2 \% auf Nukleotidebene auf.

Die PredictProtein-Strukturvorhersage (http://www.embl-heidelberg.de/predictprotein; Rost 1996) ergab für BnAAP1 elf potentielle Transmembranhelices mit dem N-Terminus im Zytosol und dem C-Terminus außerhalb der Zelle (Abb. 3.4). An den Aminosäurepositionen 104 und 226 wurden zwei mögliche N-Glykosylierungsstellen gefunden, wobei die erstere nach der Strukturvorhersage in einer intrazellulären Schleife, die zweite aber in einem 
extrazellulären Proteinbereich liegt. Außerdem wurden verschiedene mögliche Phosphorylierungs- und N-Myristoylierungsstellen erkannt. Eine Analyse der der potentiellen zellulären Lokalisation von BnAAP1 mit dem Programm PSORT (http://psort.ims.utokyo.ac.jp) ergab die Plasmamembran als wahrscheinlichste zelluläre Lokalisation. Das Programm TargetP (http://www.cbs.dtu.dk/services/TargetP; Emanuelsson et al. 2000) sagt voraus, daß das Protein nicht in Mitochondrien oder Chloroplasten lokalisiert ist und nicht aus der Zelle sekretiert wird.

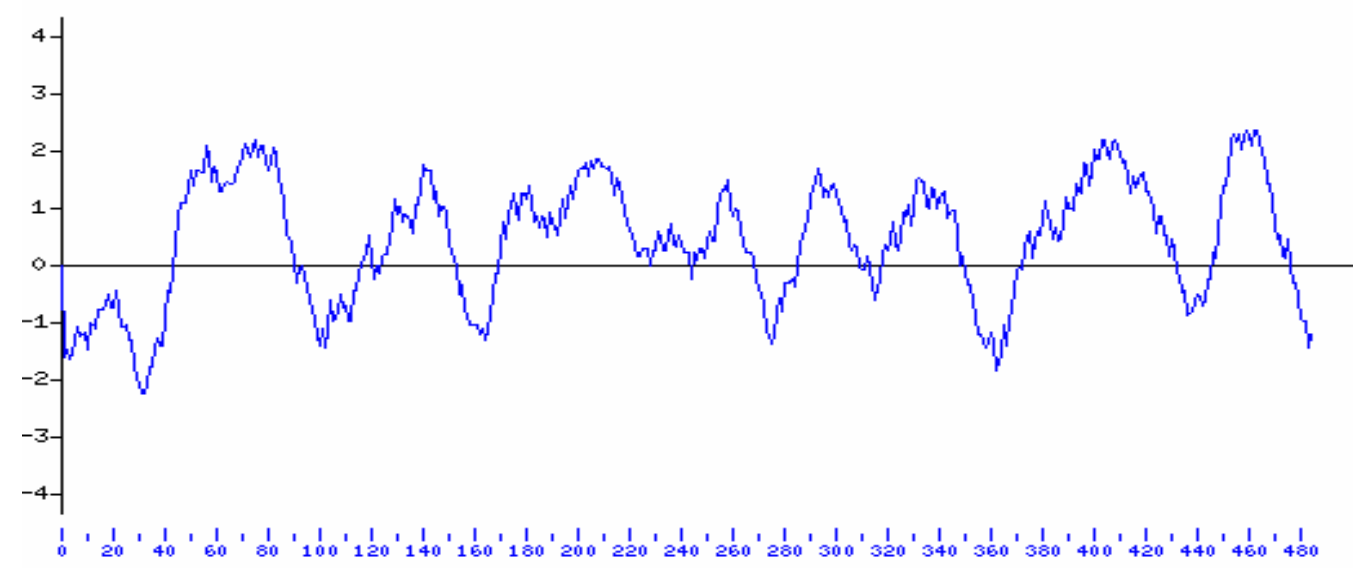

Abb. 3.4: Hydropathie-Analyse von BnAAP1 . Die X-Achse gibt die Position in der Aminosäuresequenz an, die Y-Achse den Kyte-Doolitle-Wert (Kyte \& Doolittle 1982). Positive Werte zeigen hydrophobe Bereiche an. Die Abbildung wurde mit dem Protein Hydrophilicity Search and Comparison Server des Weizmann Institute of Science, Israel erstellt (http://bioinformatics.weizmann.ac.il/hydroph/index.html).

\subsubsection{BnAAP6}

Von BnAAP6 wurde zunächst eine partielle cDNA (888 bp) durch RT-PCR mit den Primern CKAA2 und BA6r2 (Tab. 2.1) und einmalige Reamplifikation erhalten. Ausgangsmaterial war Erststrang-cDNA aus Gesamt-RNA ausgewachsener Blätter einer Kreuzung der Rapssorten Bristol x Mansholts. Die cDNA-Enden wurden durch 5' RACE mit den Primern BAA5-1 und BAA5-2 und 3' RACE mit den Primern BAA3-1 und BAA3-2 erhalten. Wie bei $B n A A P 1$ wurde die vollständige kodierende Sequenz durch PCR mit einer $3^{\prime} \rightarrow 5^{\prime}$ korrekturlesenden Pwo DNA-Polymerase amplifiziert (Primer A6TskNf und A6TskNr) und über in den Primersequenzen enthaltene XhoI und PstI Restriktionsschnittstellen zunächst direktional in den Vektor pBF1 kloniert, wodurch das Plasmid p6ORF erhalten wurde (Abb. 
8.3, im Anhang). Nach Verifikation der Funktionalität des Genprodukts durch Expression in Xenopus-Oozyten (3.5) wurde der entsprechende Klon über NcoI und PvuII ausgeschnitten und zur vollständigen beidseitigen Sequenzierung in pET-15b kloniert wie oben beschrieben. Die Sequenzierung erfolgte mit den Primern T7 Promotor, T7 Terminator (beide vektorspezifisch), BA6f2, BAA3-1, BA6r2 und BAA5-2 (alle genspezifisch). Die vollständige cDNA-Sequenz von BnAAP6 ist mit der Accession No. AJ565848 in den Datenbanken hinterlegt und findet sich im Anhang 8.3 dieser Arbeit.

Die gesamte BnAAP6 cDNA inklusive PolyA-Ende ist 1697 bp lang und kodiert von bp 65 bis 1510 ein Polypeptid aus 481 Aminosäuren mit einem kalkulierten Molekulargewicht von $52,8 \mathrm{kDa}$. Die Sequenzidentität des offenen Leserasters mit AtAAP1 beträgt $88,1 \%$ auf Nukleotid- und 91,9 \% auf Aminosäureebene, die Sequenzähnlichkeit auf Aminosäureebene ist 93,9 \% (Tab. 3.8, Abb. 3.6). Die Sequenzidentität mit dem zur Primerableitung verwendeten EST von Sohn et al. 1995 (175 bp, Acc. No. H07512) beträgt 96,0 \%. Die vollständigen cDNAs von BnAAP6 und BnAAP1 besitzen eine Sequenzidentität von 65,1\% auf Nukleotid- und von 75,1 \% auf Aminosäureebene. Die Sequenzähnlichkeit auf Aminosäureebene beträgt 81,0 \% (Tab. 3.8).

Eine Strukturvorhersage (PredictProtein, http://www.embl-heidelberg.de/predictprotein; Rost 1996) ergab für das BnAAP6-Protein elf potentielle Transmembranhelices mit dem NTerminus im Zytosol und dem C-Terminus außerhalb der Zelle (Abb. 3.5). BnAAP6 hat zwei mögliche N-Glykosylierungsstellen (Aminsäuren 100 und 186), von denen die erste in einer putativen zytosolischen Schleife und die zweite am intrazellulären Ende einer Transmembranhelix liegt. Außerdem wurden verschiedene mögliche Phosphorylierungs- und N-Myristoylierungsstellen erkannt. Eine Analyse der möglichen zellulären Lokalisation von BnAAP6 ergab mit dem Programm PSORT (http://psort.ims.u-tokyo.ac.jp) die höchste Wahrscheinlichkeit für die Plasmamembran und mit dem Programm TargetP (http://www.cbs.dtu.dk/services/TargetP; Emanuelsson et al. 2000), daß das Protein nicht in Mitochondrien oder Chloroplasten lokalisiert ist und nicht aus der Zelle sekretiert wird. 


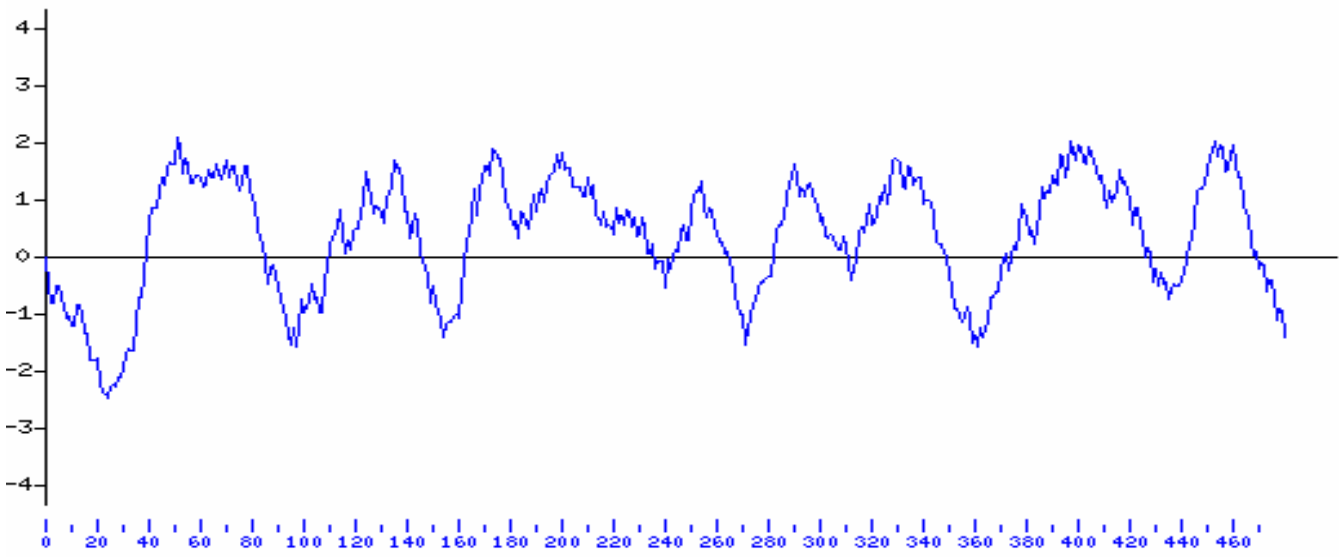

Abb. 3.5: Hydropathie-Analyse von BnAAP6. Die X-Achse gibt die Position in der Aminosäuresequenz an, die Y-Achse den Kyte-Doolitle-Wert (Kyte \& Doolittle 1982). Positive Werte zeigen hydrophobe Bereiche an. Die Abbildung wurde mit dem Protein Hydrophilicity Search and Comparison Server des Weizmann Institute of Science, Israel erstellt (http://bioinformatics.weizmann.ac.il/hydroph/index.html).

\subsubsection{BnAAP2}

Ein 730 bp langes cDNA-Fragment von BnAAP2 wurde durch PCR und einmalige Reamplifikation mit den degenerierten Primern CKAA1i, CKAA4ri (Tab. 2.1) aus einer einmal amplifizierten cDNA-Bank aus reifenden Brassica napus Schoten (Fulda et al. 1997) erhalten. Die Sequenzierung des klonierten Fragments ergab, daß bei der PCR beidseitig CKAA4ri an die Matrize gebunden hatte. Die Sequenzidentität dieses Fragments zu AtAAP2 betrug 86,7 \% auf Nukleotid- und 93,5 \% auf Aminosäureebene, die Sequenzähnlichkeit auf Aminosäureebene 94,3 \%. Die Sequenzidentität zu BnAAP1 und BnAAP6 war 59,7 bzw. 60,2 \% auf Nuleotid- und 55,7 bzw. 59,8 \% auf Aminosäureebene. Die Sequenzähnlichkeit auf Aminosäureebene betrug zwischen BnAAP2 und BnAAP1 65,9 \% und zwischen BnAAP2 und BnAAP6 70,3 \% (Tab. 3.8). Im Verlaufe dieser Promotionsarbeit wurde von Noiraud et al. 2002 die Sequenz eines 558 bp cDNA-Fragments von BnAAP2 in die Datenbanken eingegeben (Acc. No. AY188954). Dieses Fragment deckt einen ca. 120 bp weiter 5' liegenden Bereich des BnAAP2 Gens ab als die hier beschriebene Teilsequenz. Die Sequenzidentität beider Fragmente im überlappenden Bereich beträgt $87,8 \%$ auf Nukleotidebene. 
Abb. 3.6: Sequenzvergleich der Aminosäuretransporter BnAAP1 und BnAAP6 aus B. napus mit homologen Proteinen aus Arabidopsis. Graue Hinterlegung zeigt Sequenzidentität zwischen den homologen Transportern aus B. napus und A. thaliana an, schwarze Hinterlegung Sequenzidentität aller vier Proteine. In dieser Darstellungsweise sind Sequenzübereintimmungen der B. napus bzw. der A. thaliana AAPs untereinander nicht markiert und auch nicht Übereinstimmungen von drei der vier Proteine. Lücken wurden eingefügt, um die AAP1- und AAP6-Sequenzen optimal zur Deckung zu bringen.

BNAAP1 1 M... KSFNTDQHGHSAAESGDVYAMSDPTKNVDDDGREKRTGTWLTASAHIITAVIGSGV AtAAP1 1 M...KSFNTEGHNHSTAESGDAYTVSDPTKNVDEDGREKRTGTWLTASAHIITAVIGSGV BNAAP6 1 ME. KKSMFIEQSFTDHK.SGDMN . . . . . . KNFDDDGRQKRTGTWMTGSAHIITAVIGSGV AtAAP6 1 MEKKKSMFVEQSFPEHE. IGDTN . . . . . KNFDEDGRDKRTGTWMTGSAHIITAVIGSGV

BnAAP1 58 LSLAWAIAQLGWIAGTLILIIFSFITYFTSTMLADCYRAPDPLTGKRNYTYMDVVRSYLG 117 ATAAP1 58 LSLAWAIAQLGWIAGTSILLIFSFITYFTSTMLADCYRAPDPVTGKRNYTYMDVVRSYLG 117 BNAAP6 53 LSLAWAIAQLGWVAGPAVLMAFSFITYFTSTMLADCYRSPDPVTGKRNYTYMEVVRSYLG 112 AtAAP6 54 LSLAWAIAQLGWVAGPAVLMAFSFITYFTSTMLADCYRSPDPVTGKRNYTYMEVVRSYLG 113

BnAAP1 118 GRKVQLCGVAQYGNLIGITVGYTITASISLVAIGKANCYHNKGHHADCTISNYPYMAAFG 177 ATAAP1 118 GRKVQLCGVAQYGNLIGVTVGYTITASISLVAVGKSNCFHDKGHTADCTISNYPYMAVFG 177 BNAAP6 113 GRKVMLCGLAQYGNLIGITIGYTITASISMVAVKRSNCFHKNGHNVKCSTSNTPFMIIFA 172 ATAAP6 114 GRKVQLCGLAQYGNLIGITIGYTITASISMVAVKRSNCFHKNGHNVKCATSNTPFMIIFA 173

BnAAP1 178 IIQILLSQIPNFHKLSFLSLMAAVMSFAYASIGIGLAIATVAGGKV.GKTNMTGTVVGVD 236 AtAAP1 178 IIQVILSQIPNFHKLSFLSIMAAVMSFTYATIGIGLAIATVAGGKV. GKTSMTGTAVGVD 236 BNAAP6 173 CIQIVLSQIPNFHNLSWLSILAAVMSFSYASIGIGLSIAKVAGGGVHARTALTGVTVGVD 232 AtAAP6 174 IIQIILSQIPNFHNLSWLSILAAVMSFCYASIGVGLSIAKAAGGGEHVRTTLTGVTVGID 233

BnAAP1 237 VTAAQKIWRSFQAVGDIAFAYAYATVLIEIQDTLRSS.PAENKAMKRASFVGVSTTTFFY 295 ATAAP1 237 VTAAQKIWRSFQAVGDIAFAYAYATVLIEIQDTLRSS.PAENKAMKRASLVGVSTTTFFY 295 BNAAP6 233 VTGSEKVWRTFQAVGDIAFAYAYSTVLIEIQDTLKASPPSENKAMKRASLVGVSTTTFFY 292 AtAAP6 234 VSGAEKIWRTFQAIGDIAFAYAYSTVLIEIQDTLKAGPPSENKAMKRASLVGVSTTTFFY 293

BnAAP1 296 ILCGCLGYAAFGNKAPGDFLTNFGFYEPFWLIDFANACIAFHLIGAYQVFAQPIFQFVEK 355 AtAAP1 296 ILCGCIGYAAFGNNAPGDFLTDFGFFEPFWLIDFANACIAVHLIGAYQVFAQPIFQFVEK 355 BnAAP6 293 MLCGCVGYAAFGNNAPGNFLTGFGFYEPFWLIDFANVCIAVHLVGAYQVFCQPIFQFVES 352 AtAAP6 294 MLCGCVGYAAFGNDAPGNFLTGFGFYEPFWLIDFANVCIAVHLIGAYQVFCQPIFQFVES 353

BnAAP1 356 KCNRNWPDNKFITSEYSVNIPFLGKFSINLFRLVWRTAYVVITTLVAMIFPFFNAILGLI 415 AtAAP1 356 KCNRNYPDNKFITSEYSVNVPFLGKFNISLFRLVWRTAYVVITTVVAMIFPFFNAILGLI 415 BNAAP6 353 QSAKRWPDNKFITGEYKMNVPCGGDFGISLFRLVWRTSYVVVTAVVAMIFPFFNDFLGLI 412 AtAAP6 354 QSAKRWPDNKFITGEYKIHVPCCGDFSINFLRLVWRTSYVVVTAVVAMIFPFFNDFLGLI 413

BnAAP1 416 GAASFWPLTVYFPVEMHIAQTKVKKYSSRWIGLKMLCWVCLIVSLLAAAGSIAGLISSVK 475 AtAAP1 416 GAASFWPLTVYFPVEMHIAQTKIKKYSARWIALKTMCYVCLIVSLLAAAGSIAGLISSVK 475 BnAAP6 413 GAASFWPLTVYFPIEMHIAQKNMKKFSFTWTWLKILSWACFLVSLVAAAGSVQGLIQSLK 472 AtAAP6 414 GAASFWPLTVYFPIEMHIAQKKIPKFSFTWTWLKILSWTCFIVSLVAAAGSVQGLIQSLK 473 
Da es nicht gelang, das BnAAP2 cDNA-Fragment mit den genspezifischen Primern BA2f1 und BA2r1 erneut über eine RT-PCR zu amplifizieren und 5' und 3' RACE PCR-Reaktionen keine Produkte lieferten, wurde $B n A A P 2$ in dieser Arbeit nicht weiter untersucht. Die Sequenz des 730 bp cDNA Fragments ist in Anhang 8.5 dieser Arbeit enthalten.

\subsection{Elektrophysiologische Untersuchungen zur Substratspezifität von BnAAP1 und BnAAP6 durch funktionelle Expression in Xenopus Oozyten}

Um die Funktionalität der identifizierten B. napus AAP-Gene in vivo zu testen, wurden die von ihnen kodierten Transportproteine in Oozyten des Krallenfrosches Xenopus laevis exprimiert. Dazu wurden die offenen Leseraster von BnAAP1 und BnAAP6 vom Start- bis zum Stopcodon durch PCR mit einer korrekturlesenden Pwo DNA-Polymerase und Primern mit XhoI und PstI Schnittstellen (A1TskNf und A1TskNr bzw. A6TskNf und A6TskNr, Tab. 2.1) amplifiziert. Die in den Primern enthaltenen Schnittstellen erlaubten anschließend, die DNA-Fragmente direktional in den Vektor pBF1 (W. Frommer, Tübingen) zu klonieren, der einen T7 Promotor, eine 40 Nukleotide lange Poly-A-Sequenz, und einen T7 TranskriptionsTerminator enthält. Von diesen Konstrukten, p1ORF und p6ORF (Abb. 8.3, im Anhang), wurden durch in vitro Transkription mit T7 RNA-Polymerase cRNAs hergestellt und zur Expression in die Oozyten injiziert. Als Negativkontrolle wurden einige Oozyten mit Wasser statt cRNA-Lösung injiziert. Die Messung der Aufnahme von Aminosäuren in die Oozyten erfolgte indirekt über das Membranpotential der Zellen, das durch eine in die Oozyte injizierte Mikroelektrode und eine Referenzelektrode in der umgebenden Waschlösung abgenommen wurde (s. 2.15).

Bei den Wasser-injizierten Kontrolloozyten bewirkte keine der getesteten Aminosäuren eine Veränderung des Membranpotentials. Dagegen führte die Additition von $5 \mathrm{mM}, 0,5 \mathrm{mM}$ oder 0,1 mM einer proteinogenen Aminosäure bei allen BnAAPl- oder BnAAP6-injizierten Oocyten zu einer Membrandepolarisation, deren Intensität von der Aminosäure und ihrer Konzentration abhing. Abb. 3.7 zeigt die Depolarisation derselben BnAAPl-injizierten Oozyte durch drei verschiedene Konzentrationen von Alanin. Die Stärke der Depolarisation nahm mit der Aminosäurekonzentration zu, allerdings nicht in proportionaler Weise. 

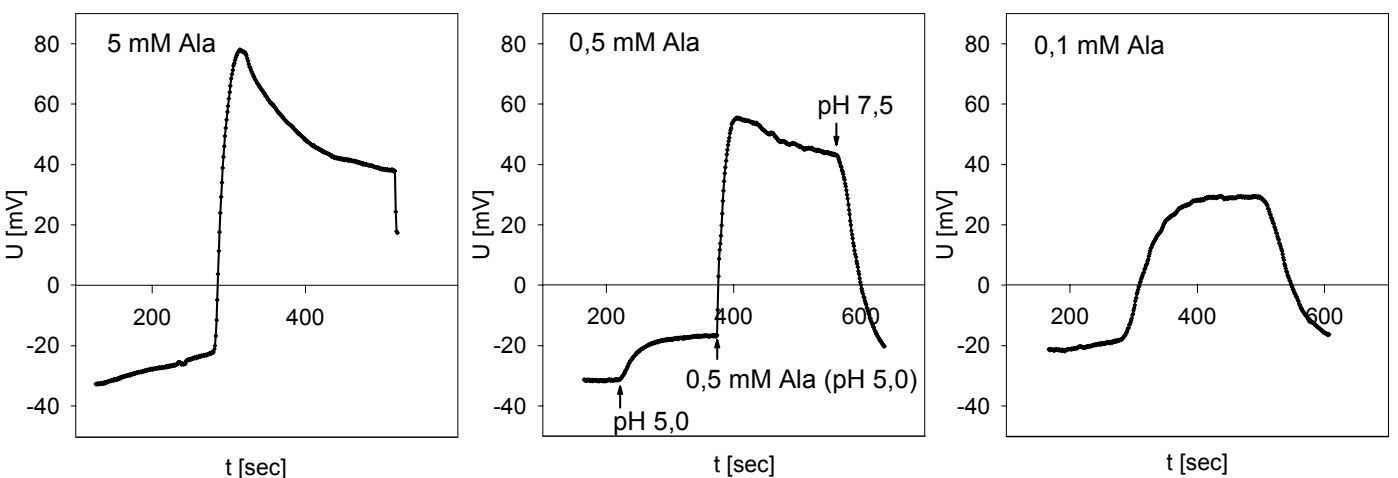

\begin{abstract}
Abb. 3.7: Depolarisation der Membran einer BnAAP1-injizierten Oozyte durch drei verschiedene Konzentrationen von Alanin. Die Änderung des Membranpotentials ist der Aminosäurekonzentration in der Waschlösung nicht direkt proportional. In der mittleren Abbildung sind die Zeitpunkte markiert, an denen die Zusammensetzung der Waschlösung geändert wurde (s. 2.15).
\end{abstract}

Zur Untersuchung der Substratspezifität der Transporter wurden zunächst BnAAPl- und BnAAP6-injizierte Oozyten jeweils mit $5 \mathrm{mM}$ Lösungen aller proteinogenen Aminosäuren (ausgenommen Cystein und Tyrosin) sowie $5 \mathrm{mM} \gamma$-Aminobuttersäure (GABA) getestet. Alle Membranpotentialänderungen wurden relativ zu der durch Alanin erzeugten Depolarisation in Prozent umgerechnet. Dabei wurden wegen der besseren Vergleichbarkeit möglichst viele Aminosäuren pro Oozyte gemessen. Da die Membran der Zellen aber durch die Injektion der Elektrode geschädigt wird und die mehrfachen Depolarisationen und Repolarisationen die Regenerationsfähigkeit der Oozyte erschöpfen, war es meistens nicht möglich, alle Aminosäuren an einer einzigen Zelle zu testen. In diesem Falle wurde für jede neue Oozyte wiederum Alanin als Bezugsgröße gemessen. Für BnAAP1 wurden alle Aminosäuren 2-3 mal bei $5 \mathrm{mM}$ getestet, für BnAAP6 nur einmal, in diesem Fall aber an einer einzigen Oozyte. Die Substratspezifität der Transporter ist in Abb. 3.8 dargestellt.

Sowohl BnAAP1 als auch BnAAP6 transportierten alle angebotenen proteinogenen $(\alpha-)$ Aminosäuren, nicht jedoch die $\gamma$-Aminosäure GABA. Am schlechtesten wurden von beiden Transportern die basischen Aminosäuren Arginin und Lysin transportiert. Deutlich geringere Membrandepolarisationen als Alanin rief bei BnAAP1 und BnAAP6 auch die basische Aminosäure Histidin hervor, sowie bei BnAAP1 die saure Aminosäure Aspartat und bei BnAAP6 die neutrale Aminosäure Valin. Alle übrigen Aminosäuren erzeugten Depolarisationen in einer ähnlichen Größenordnung wie Alanin, einschließlich der aromatischen Aminosäuren Phenylalanin und Tryptophan. 


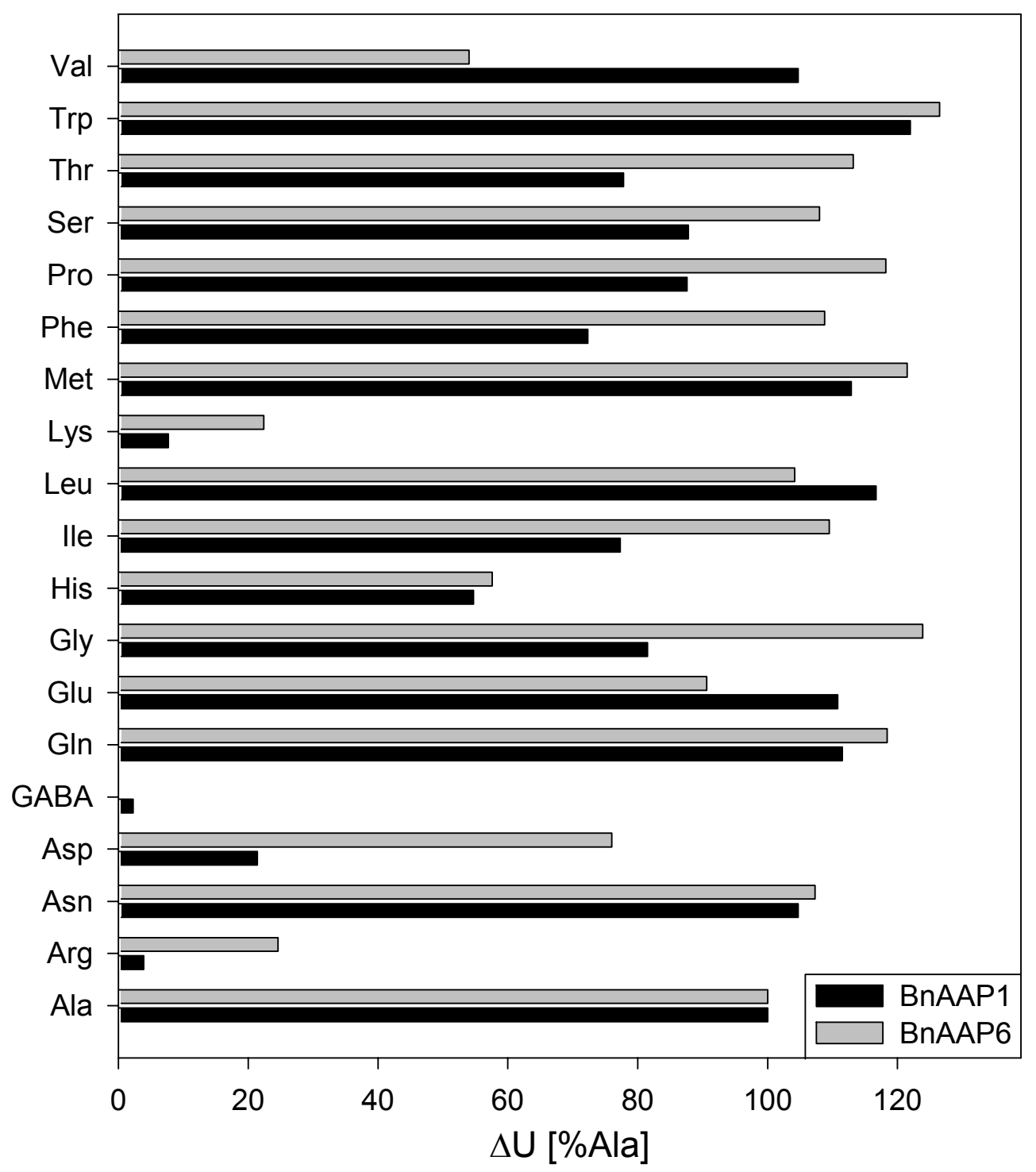

Abb. 3.8: Depolarisation der Membran von BnAAP1- bzw. BnAAP6-injizierten Oozyten in Abhängigkeit von der getesteten Aminosäure. Alle Aminosäuren wurden in $5 \mathrm{mM}$ Konzentration getestet. Die Werte sind jeweils relativ zu Alanin angegeben. Die Aminosäuren sind mit ihrem Drei-Buchstaben-Code bezeichnet. GABA: $\gamma$-Aminobuttersäure. 


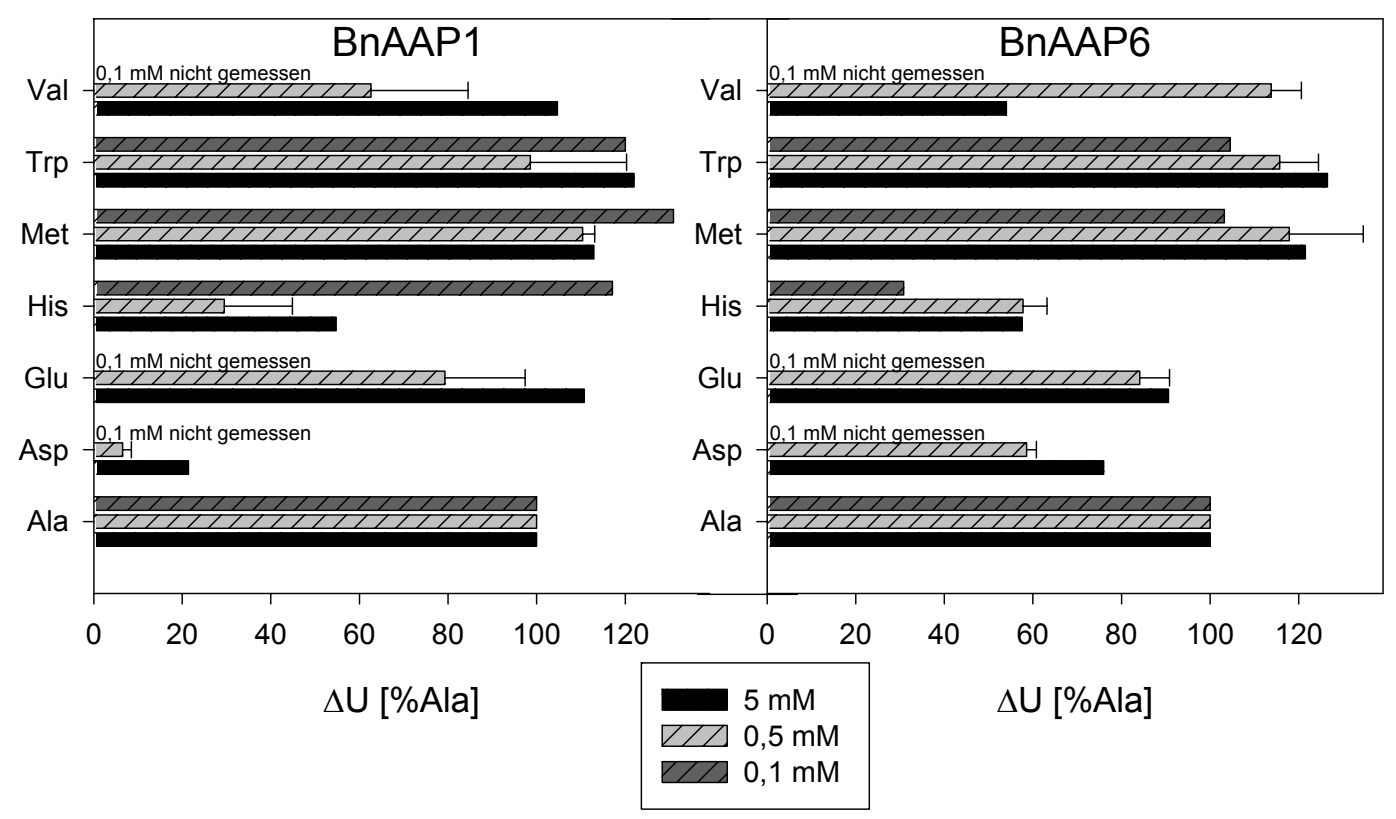

Abb. 3.9: Substratspezifität von BnAAP1 und BnAAP6 in Abhängigkeit von der Substratkonzentration. Alle Werte sind jeweils bezogen auf die durch dieselbe Konzentration von Alanin hervorgerufene Depolarisation. Die Aminosäuren sind mit ihrem Drei-Buchstaben-Code bezeichnet. Für die Messungen bei $5 \mathrm{mM}$ und $0,1 \mathrm{mM}$ ist $\mathrm{n}=1-2$, für $0,5 \mathrm{mM}$ ist $\mathrm{n}=3$. In diesem Fall sind Standardabweichungen als Fehlerbalken dargestellt.

Für insgesamt sieben saure (Aspartat, Glutamat), basische (Histidin), neutrale (Alanin, Methionin und Valin) und aromatische (Tryptophan) Aminosäuren wurde die Substratspezifität bei je drei Konzentrationen, $0,1 \mathrm{mM}, 0,5 \mathrm{mM}$ und $5 \mathrm{mM}$, bestimmt. Um unabhängige Experimente zu erhalten, wurden zahlreiche Oozyten verwendet und jeweils nur einige Aminosäuren und Konzentrationen mit jeder Zelle gemessen. Als Bezugsgröße diente in jeder Meßreihe die entsprechende Konzentration von Alanin (Abb. 3.9). Alle bei 0,1 mM getesteten Aminosäuren wurden von BnAAP1 und BnAAP6 transportiert. Eine Veränderung gegenüber der relativen Depolarisation bei $5 \mathrm{mM}$ zeigte sich nur für Histidin und Valin. Bei BnAAP1 erzeugten $5 \mathrm{mM}$ Histidin 54,7 \% der durch $5 \mathrm{mM}$ Alanin hervorgerufenen Membran-Depolarisation, 0,1 mM Histidin aber 117,1\% des Wertes für 0,1 mM Alanin. Bei BnAAP6 riefen $5 \mathrm{mM}$ Valin 54,0\% der Depolarisation bei $5 \mathrm{mM}$ Alanin hervor, 0,5 $\mathrm{mM}$ Valin aber $113,8 \pm 6,8 \%$ der Depolarisation bei 0,5 mM Alanin. 


\subsection{Untersuchungen zur Expression von BnAAP1 und BnAAP6 in der Pflanze}

Parallel zur vorliegenden Arbeit wurde im Rahmen einer Diplomarbeit die organspezifische Expression von BnAAPl und BnAAP6 anhand von Northern Blot-Analysen und RT-PCR untersucht (Kassner 2003). Im Folgenden werden darüber hinausgehende weitere Experimente zur Genexpression beschrieben: die Untersuchung der Promotoraktivität von BnAAP6 mittels einer GUS-Reportergenfusion, die Herstellung polyklonaler Antikörper gegen BnAAP6 für eine Immunolokalisation des Proteins und die Analyse der Expression beider Gene im Verlauf der Blattentwicklung auf mRNA-Ebene. Für alle Experimente wurde Winterraps der Sorte Lirajet verwendet.

\subsubsection{Untersuchung einer BnAAP6-Promotor-Reportergenfusion}

Ein 2310 bp Promotor-Fragment von BnAAP6 wurde durch Genome Walking mit den Primern walk1 und walk2 (Tab. 2.1) aus einer PvuII-Walking-Bibliothek amplifiziert. Das PCR-Produkt wurde in pGEM-T Easy kloniert und mit den Primern T7 Promotor, M13 rev (vektorspezifisch), P6f2, P6f3, P6r2 und P6r3 (promotorspezifisch) vollständig beidseitig durchsequenziert. Die Sequenz ist mit der Accession No. AJ580452 in den Datenbanken hinterlegt und findet sich in Anhang 8.4 dieser Arbeit.

Der BnAAP6-Promotor weist keinerlei signifikante Homologie zu irgendeiner Sequenz in den Datenbanken auf, insbesondere nicht zur Promotorsequenz von AtAAP6 (Sequenzidentität 40,4 \%). Es sind keine genau den Konsensus-Sequenzen TATA $\frac{\mathrm{A}}{\mathrm{T}} \mathrm{A}^{\mathrm{A}} / \mathrm{T}$ bzw. GG ${ }_{\mathrm{T}} \mathrm{CAATCT}$ entsprechenden TATA- (Hogness-) und CAAT-Boxen vorhanden, aber ein Vorhersageprogramm für eukaryotische Promotoren (Promoter predictor, Reese 2001; http://www.fruitfly.org/seq_tools/promoter.html) sagt aufgrund typischer Promotorelemente den tatsächlichen Transkriptionsstart auf fünf Nukleotide genau voraus. Eine Suche in der TRANSFAC-Datenbank (Heinemeyer et al. 1998) mit dem Programm TFSEARCH (http://molsun1.cbrc.aist.go.jp/research/db/TFSEARCH) ergab nur eine signifikante Homologie zu bekannten Transkriptionsfaktor-Bindungsstellen: Die Basenpaare 938-951 der BnAAP6-Promotor-Sequenz enthalten eine potentielle Bindungsstelle für das Protein SBF-1, das eine Silencer-Region im Promotor der Chalcon-Synthase von Phaseolus vulgaris bindet, eines Schlüsselenzyms der Flavonoid-Biosynthese (Lawton et al. 1991).

Zur Analyse der Funktion des BnAAP6-Promotors in der Pflanze wurde eine Fusion mit dem Reportergen GUS hergestellt, das für eine bakterielle $\beta$-Glucuronidase kodiert. Dazu wurde der in pGEM-T Easy klonierte Promotor mit EcoRI wieder aus dem Vektor ausgeschnitten 
und nach einer Auffüll-Reaktion über glatte Enden in den mit SmaI linearisierten binären Vektor pBI101.3 ligiert. Dieses Konstrukt (p6P-GUS-Km, Abb. 8.4, im Anhang) wurde zunächst in E. coli transformiert, um das Insert und die Insertionsrichtung durch Sequenzierung zu überprüfen. Mit einem Klon des gewünschten Konstruktes wurden anschließend Agrobakterien transformiert, die zur Pflanzentransformation dienten. Sowohl $B$. napus als auch $A$. thaliana wurden transformiert. Aus der Rapstransformation wurden keine transgenen Planzen erhalten. Transgene Arabidopsis-Pflanzen der T1-Generation wiesen bei Vorversuchen GUS-Aktivität in den Blattadern auf. Das pBI101.3-Plasmid trägt eine Kanamycin-Resistenz, die eine Selektion der Keimlinge auf Agar-Platten notwendig macht. Das aus der Transformation erhaltene Saatgut war mit einem extrem hartnäckigen Schimmelpilz kontaminiert, der sich auch durch Verschärfung der Bedingungen der Oberflächensterilisation bis hin zum Abtöten der Arabidopsis-Samen nicht entfernen ließ. Das gesamte erhaltene Samenmaterial und auch das aus einer zweiten Transformation wurde verbraucht, ohne das es gelang, pilzfreie Agarplatten zu erhalten.
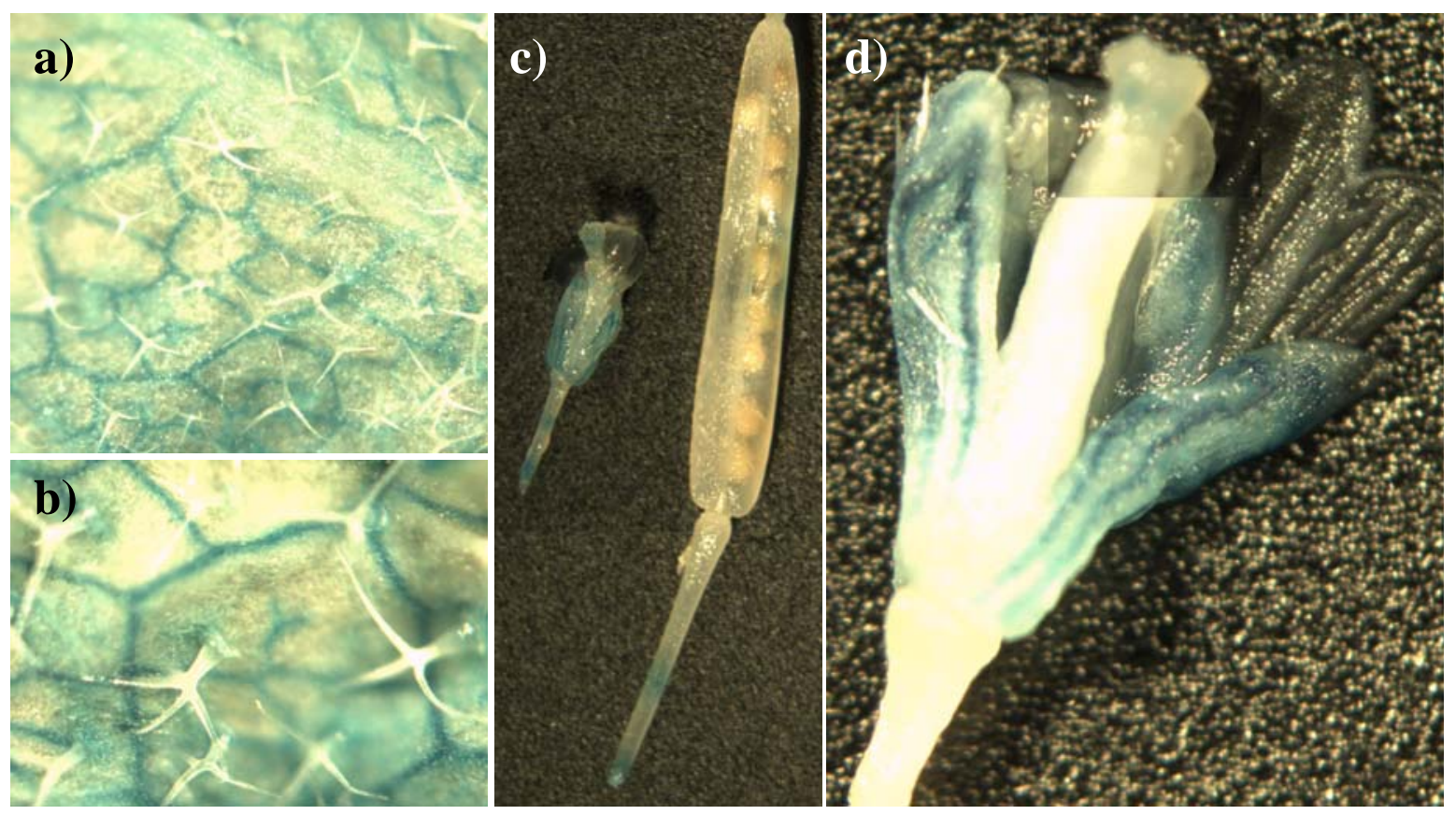

Abb. 3.10: Aktivität des BnAAP6-Promotors in transgenen Arabidopsis-Pflanzen. Material von transgenen Pflanzen wurde $2 \mathrm{~h}$ mit GUS-Färbelösung in Gegenwart von 10 $\mathrm{mM}$ Ferro/Ferricyanid gefärbt und anschließend mit Ethanol gebleicht. a) und b) SourceBlatt (Details). c) Blüte und Schote. d) Vergrößerte Ansicht der Blüte aus c). Eine zweite Aufnahme der Narbe ist für bessere Tiefenschärfe eingefügt. 
Um die Gefahr von Pilzkontaminationen zu verringern, wurde ein neues Konstrukt hergestellt, das eine Selektion mit dem Herbizid Glufosinat („BASTA“) ermöglicht. Dadurch konnten die Arabidopsis-Samen auf Erde statt auf Agarplatten ausgesäht und selektioniert werden. Ein weiterer Vorteil ist, daß „BASTA“ eine deutlich stringentere Selektion ermöglicht als Kanamycin. Von Nachteil für die spätere GUS-Färbung des Pflanzenmaterials ist allerdings, daß die Anzucht auf Erde durch die geringere Luftfeuchtigkeit gegenüber geschlossenen Agarplatten zwar den Pilzbefall reduziert, bei den Pflanzen aber auch zu einer stärker ausgeprägten Cuticula führt, die die Infiltration mit Färbelösung erschwert. Zur Umklonierung wurde der BnAAP6-Promotor mitsamt dem GUS-Reportergen durch Restriktion mit EcoRI und HindIII aus p6P-GUS-Km ausgeschnitten. Der Vektor pCAMBIA3300, der die „BASTA“-Resistenzkassette trägt, wurde ebenfalls mit diesen zwei Enzymen linearisiert, wodurch zugleich der auf dem Plasmid enthaltene CaMV 35S-Promotor herausgeschnitten wurde. Durch Ligation der BnAAP6-Promotor-GUS-Kassette in pCAMBIA3300 wurde das Plasmid p6P-GUS-BASTA erhalten (Abb. 8.4, im Anhang), das für eine erneute Arabidopsis-Transformation verwendet wurde. Es wurden transgene Pflanzen der T2-Generation erhalten und für GUS-Färbungen verwendet. Im Zeitraum dieser Arbeit war es nicht mehr möglich, umfangreichere Versuche mit den Pflanzen der nächsten Generation (T3) durchzuführen.

Alle getesteten Promotor-GUS-Pflanzen wiesen eine starke Färbung der Blattadern von Source-Blättern auf. Diese Färbung erstreckte sich auf Blattadern aller Ordnungen mit Ausnahme der Mittelrippe und war bereits nach 2 Stunden deutlich sichtbar (Abb. 3.10a und b). Auch die Leitgefäße der Blütenkelchblätter zeigten GUS-Aktivität, nicht jedoch die Kronbätter (Abb. 3.10c und d). In manchen Pflanzen war außerdem eine leichte Färbung der Narbe (Abb. 3.10d) feststellbar. Die Schoten (Abb. 3.10c) und die Sproßachse nahe der Infloreszenz wiesen keine Färbung auf. Die Diffusion des Substrats X-Gluc war durch Zugabe von $10 \mathrm{mM}$ Ferro/Ferricyanid zur Färbelösung minimiert.

\subsubsection{Herstellung von BnAAP6-spezifischen polyklonalen Antikörpern}

Um eine zellspezifische Immunolokalisation des nativen BnAAP6 Proteins zu ermöglichen wurden polyklonale Antikörper gegen zwei Peptidfragmente des Transporters hergestellt. Ausgewählt wurden dazu der N-Terminus (Nterm, Aminosäure 1-16) und eine Sequenz aus einer putativen intrazellulären Schleife (Seq5, Aminosäure 353-367) des Polypeptids. Beide wiesen in einer von der Fa. Pineda Antikörperservice, Berlin durchgeführten Epitopanalyse gute antigene Eigenschaften auf. 
In einem ersten Ansatz zur Antikörperherstellung wurden die zwei synthetischen Oligonukleotide ANTI-1 und ANTI-2 (Tab. 2.1) miteinander hybridisiert. Das dabei gebildete doppelsträngige DNA-Fragment kodiert für das Nterm Epitop und wurde in den mit HindIII und ScaI linearisierten Vektor pMal-c2X ligiert. Dadurch entsteht eine C-terminale translationale Fusion des Nterm Polypetids an das Trägerprotein MBP (Maltose Bindeprotein). Die Ligation im korrekten Leseraster wurde durch Sequenzierung mit dem vektorspezifischen Primer pMal-seqf überprüft und das gewünschte Konstrukt in E. coli BL21 (DE3) transformiert. Dort wurde das MBP-Nterm Fusionsprotein überexprimiert und anschließend durch präparative SDS-PAGE aus den lysierten Bakterienzellen aufgereinigt. Mit je $300 \mu$ g Fusionsprotein wurden von der Fa. Pineda Antikörperservice drei Kaninchen immunisiert, von denen eins etwa einen Monat später starb. Die aus den übrigen beiden Kaninchen erhaltenen Antiseren erbrachten in Western Blot Experimenten aufgrund starker Kreuzreaktionen keine befriedigenden Ergebnisse und wurden nicht weiter verwendet. Das MBP-Nterm Fusionsprotein diente aber bei der weiteren Antikörperherstellung als Positivkontrolle in Western Blots.

In einem zweiten Ansatz wurden Antiseren gegen die synthetisch hergestellten Oligopeptide Nterm und Seq5 hergestellt, die chemisch an das Trägerprotein KLH (Keyhole Limpid Hemocyanine) gekoppelt waren. Durch die chemische Koppelung an das Trägerprotein können im Gegensatz zur gentechnischen Herstellung eines Fusionsproteins mehrere Epitope an jedes Trägermolekül gekoppelt werden. Die Peptidsynthese, chemische Koppelung an KLH und Immunisierung von je drei Kaninchen wurden wiederum von der Fa. Pineda Antikörperservice durchgeführt. Auch hier starb eines der drei mit Nterm-KLH immunisierten Tiere nach kurzer Zeit. Von den übrigen fünf Antiseren erwies sich Nterm-1 (aus Tier 1 der Nterm-KLH Immunisierung) als unbrauchbar, da eine sehr starke Kreuzreaktivität mit allen getesteten Blockmitteln auftrat. Die verbleibenden vier Antiseren Nterm-2, Seq5-1, Seq5-2 und Seq5-3 wurden in Western Blots auf ihre Spezifität getestet.

Als Positivkontrolle zur Erkennung des BnAAP6 Proteins dienten dabei sowohl die in Abschnitt 3.5 beschriebenen BnAAP6-exprimierenden Xenopus Oozyten als auch BnAAP6exprimierende E. coli Rosetta-Zellen. Für die E. coli-Expression wurde das bereits für die Sequenzierung verwendete pET15b-BnAAP6 Konstrukt (3.4.2) verwendet. Die Proteinexpression erfolgte für 10 Tage bei $15{ }^{\circ} \mathrm{C}$, da die Expression eukaryotischer Membranproteine in Bakterienzellen bei höheren Temperaturen oft das Wachstum der Bakterienkolonie verhindert. In Lysaten BnAAP6-exprimierender Bakterienzellen war in silbergefärbten SDS-Polyacrylamidgelen keine Proteinbande nachweisbar, die in 
untransformierten Kontrollzellen fehlte. Dennoch zeigten alle vier Antiseren in Western Blots eine nur in den BnAAP6-exprimierenden Zellen auftretende Bande bei ca. $43 \mathrm{kDa}$ (Abb. 3.11a). Das ist ca. $10 \mathrm{kDa}$ kleiner als das vorrausgesagte Molekulargewicht des BnAAP6Proteins. Integrale Membranproteine laufen in SDS-Polyacrylamidgelen häufig schneller als globuläre Proteine mit dem gleichen Molekulargewicht (Sauer \& Tanner 1984). Eine 43 kDa Bande wurde auch in BnAAP6-injizierten Oozyten, aber nicht in Wasser-injizierten Kontrolloozyten gefunden (Abb. 3.11b). Das Nterm-2 Antiserum erkannte außerdem das MBP-Nterm Fusionsprotein (Abb. 3.11c).

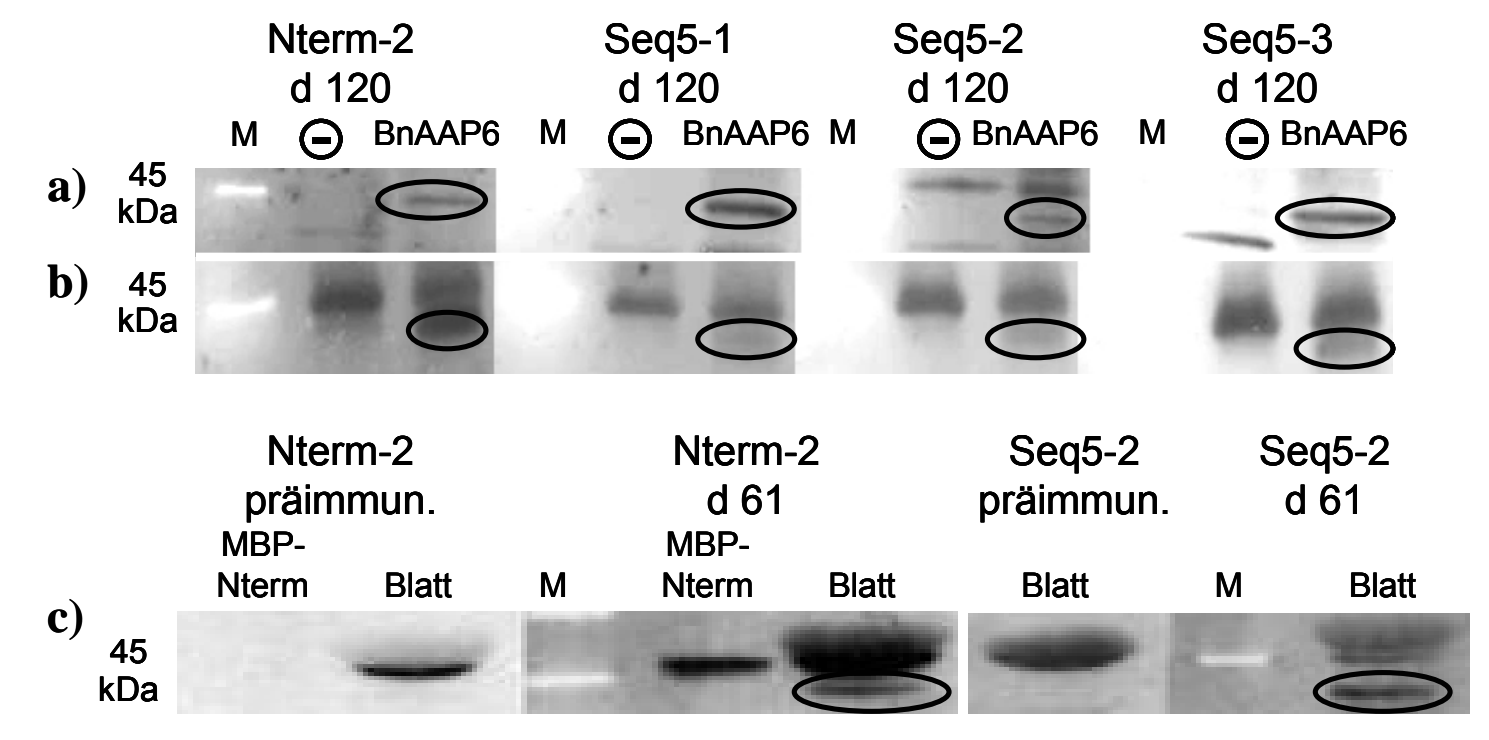

Abb. 3.11: Test von polyklonalen Antikörpern gegen BnAAP6. Western Blots mit a) BnAAP6-exprimierenden E. coli Rosetta-Zellen, b) BnAAP6-exprimierenden Xenopus Oozyten und c) Pflanzenproben. d: Tage seit Erstimmunisierung, M: Größenstandard, Minuszeichen: Negativkontrolle (untransformierte E. coli Zellen bzw. Wasser-injizierte Oozyten), BnAAP6: BnAAP6-exprimierende E. coli Zellen oder Oozyten, MBP-Nterm: MBP-Nterm Fusionsprotein als Positivkontrolle, Blatt: Blatt-Rohextrakt. Die 43 kDa-Bande von BnAAP6 ist eingekreist.

In Blatt-Rohextrakten detektierten sowohl gegen Nterm als auch gegen Seq5 gerichtete Antiseren ebenfalls ein Protein mit einem apparenten Molekulargewicht von ca. 43 kDa, das von Präimmunseren der entsprechenden Tiere nicht erkannt wurde (Abb. 3.11c). Allerdings trat auch eine starke Kreuzreaktion mit einem etwa 52 kDA großen Protein auf, bei dem es sich höchstwahrscheinlich um die große Untereinheit der RubisCO handelte. Für eine weitere Überprüfung der Antiseren wurden Plasmamembranfraktionen (PM) aus Rapsblättern angereichert. 


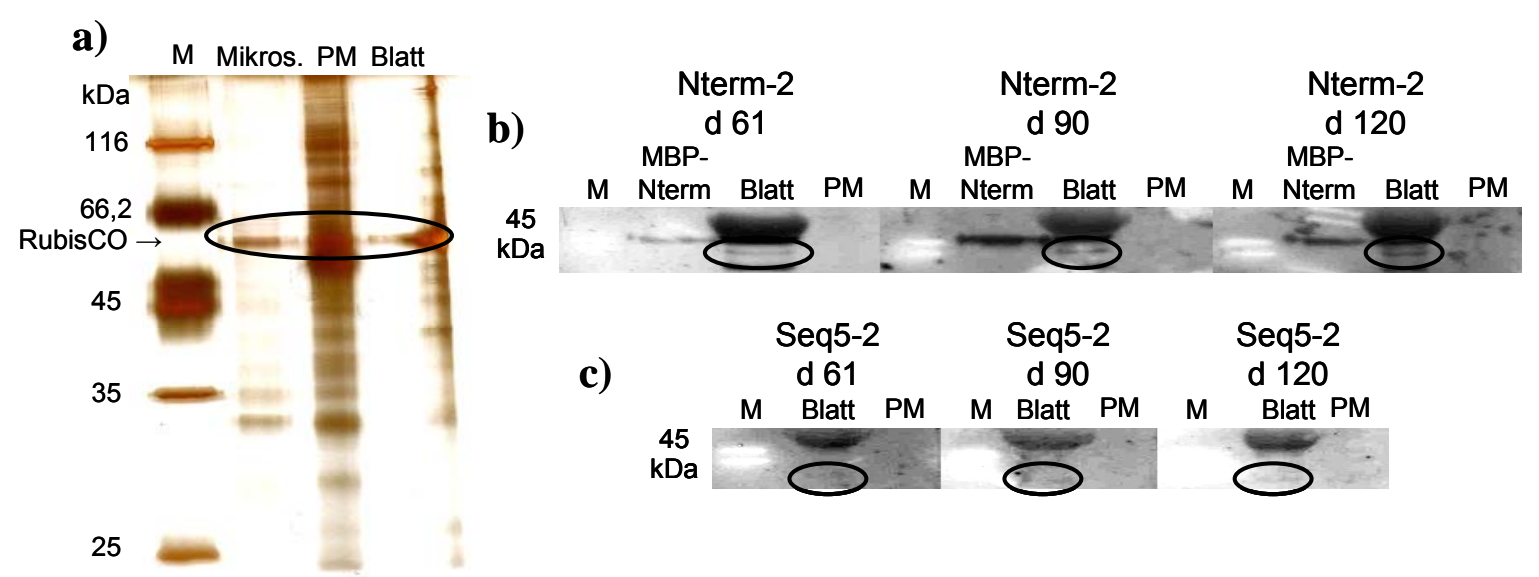

\begin{abstract}
Abb. 3.12: Test von polyklonalen Antikörpern gegen BnAAP6. a) SDS-PAGE von angereicherten Plasmamembranen. b) und c) Western-Blots mit Pflanzenproben. M: Größenstandard, Mikros.: Mikrosomen (Gesamtmembran-Fraktion), PM: Plasmamembran-Fraktion, d: Tage seit Erstimmunisierung, MBP-Nterm: MBP-Nterm Fusionsprotein als Positivkontrolle, Blatt: Blatt-Rohextrakt. Im SDS-Gel ist die große Untereinheit von RubisCO eingekreist, in den Western Blots die 43 kDa-Bande von BnAAP6.
\end{abstract}

Eine hochangereicherte PM-Probe, bei der das Verhältnis der Vanadat-hemmbaren Plasmamembran-ATPase-Aktivität zur ungehemmten Gesamt-ATPase-Aktivität 1,0 betrug, wurde in Western Blots getestet. Keines der Antiseren detektierte das erwartete $43 \mathrm{kDa}$ Protein (Abb. 3.12b und c). Andererseits trat auch keinerlei Kreuzreaktion mit anderen Proteinen auf, insbesondere nicht mit RubisCO, die trotz des hohen Reinheitsgrades noch in der PM-Probe vorhanden war (Abb. 3.12a). Da die PM-Probe insgesamt nur noch einen sehr geringen Proteingehalt aufwies (ca. 0,5 $\mu \mathrm{g} / \mu \mathrm{l}$ ), wurde das BnAAP6-Protein bei der Aufreinigung wahrscheinlich weitgehend verloren. Auch in Gesamtmembran- (Mikrosomen-) Fraktionen war das gesuchte Protein nicht detektierbar.

Die Antiseren Nterm-2 und Seq5-2, die ein deutliches Sinal mit E. coli- und Oozytenproben, aber nur geringe Kreuzreaktivität mit Blatt-Rohextrakten lieferten, wurden schließlich für einen Immunolokalisationsversuch ausgewählt. Dazu wurden $2 \mu \mathrm{m}$-Semidünnschnitte von in Methacrylat eingebetteten jungen Rapsblättern (Lirajet, auf $4 \mathrm{mM}$ Nitrat hydroponisch angezogen) hergestellt. Die Schnitte wurden über Nacht mit dem Primärantiserum inkubiert und gebundene Antikörper anschließend durch einen Fluoreszenzfarbstoff- (FITC-) gekoppelten Sekundärantikörper sichtbar gemacht. Obwohl mit beiden Primärantiseren in manchen Schnitten eine leichte Fluoreszenz im Bereich der Leitbündel erkennbar war, war das Signal zu schwach, um es von der Autofluoreszenz der Xylemgefäße zu unterscheiden. Mit den in dieser Arbeit hergestellten polyklonalen Antikörpern war somit eine zellspezifische Immunolokalisation von BnAAP6 nicht möglich. 


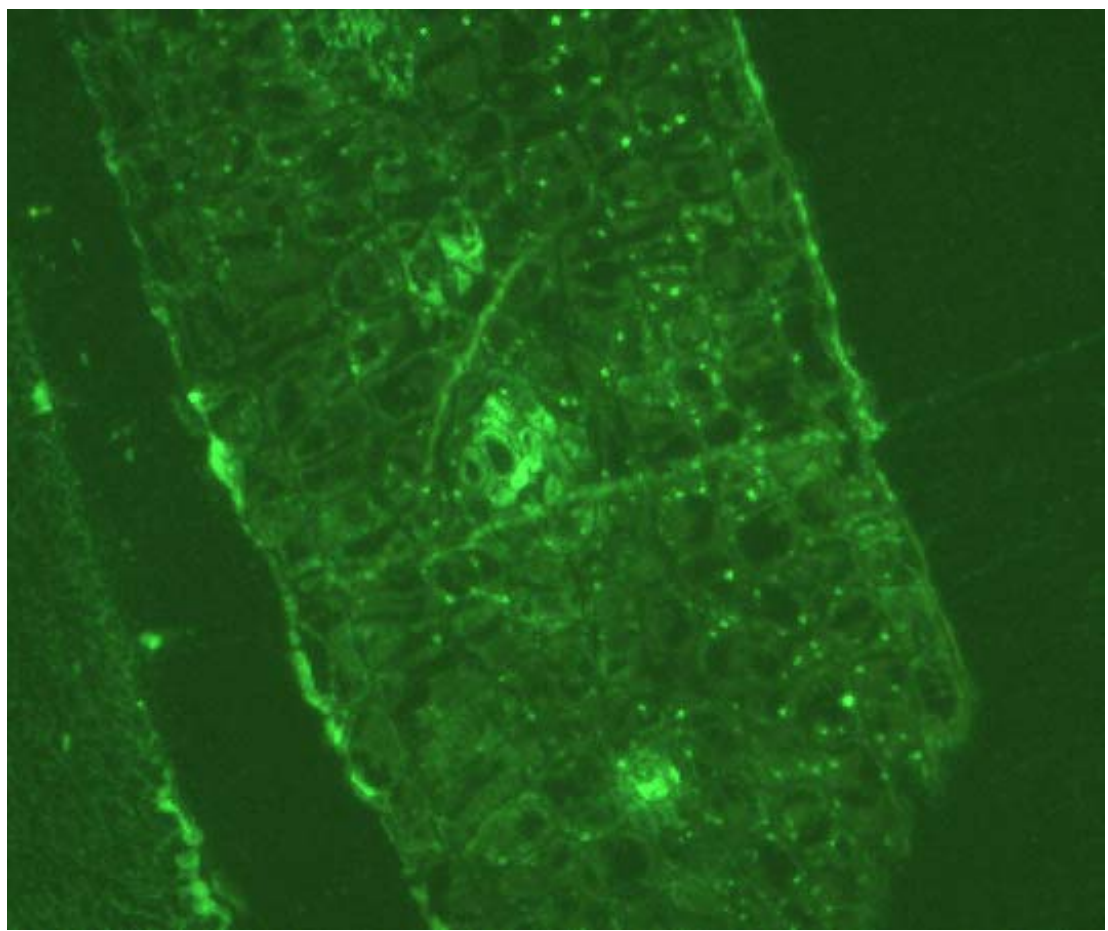

Abb. 3.13: Semidünnschnitt eines Rapsblattes inkubiert mit anti-BnAAP6-Antikörper und fluoreszenzmarkiertem Sekundärantikörper. Querschnitt eines in Methacrylat eingebetteten jungen Rapsblattes (Lirajet). Die Pflanze wurde bei $4 \mathrm{mM} \mathrm{NO}_{3}{ }^{-}$hydroponisch angezogen. Der $2 \mu \mathrm{m}$-Semindünnschnitt wurde über Nacht mit Nterm-2 Antiserum vom 150. Tag nach der Erstimmunisierung und anschließend mehrere Stunden mit Ziege-antiKaninchen IgG-FITC-Konjugat inkubiert. Die Fluoreszenzanregung erfolgte bei 450-490 $\mathrm{nm}$.

\subsubsection{Expression von BnAAP1 und BnAAP6 in verschiedenen Blattaltersstufen}

\subsubsection{BnAAPl}

Die Veränderung der Expression von BnAAP1 und BnAAP6 wurde auf mRNA-Ebene durch Northern Blot-Analysen und RT-PCR untersucht. Dabei wurden folgende Blattaltersstufen von hydroponisch mit $0,5 \mathrm{mM}$ oder $4 \mathrm{mM}$ Nitrat in der Nährlösung angezogenen Rapspflanzen (Lirajet) unterschieden: Die als ,jung“ bezeichneten Blätter waren maximal 2 cm lang und wuchsen an Seitenknospen der ca. 4-5 Wochen alten Pflanzen. „Mittelalte“ Blätter waren ca. 10-15 cm lang und äußerlich vollkommen gesund. „Alte Blätter“ waren bis zu $20 \mathrm{~cm}$ lang und wiesen erste Anzeichen von Ausbleichen und Welken auf. „Braune“ Blätter waren bereits deutlich gelb- bis braungefärbt, zeigten fortgeschrittenes Welken und z.T. eine beginnende Ablösung der Blattstielbasis vom Stengel.

Aufgrund des hohen Polysaccharidgehaltes von Rapsgewebe erwies es sich als schwierig, ausreichend große Mengen von Gesamt-RNA in einer Reinheit zu erhalten, die eine genaue Quantifizierung erlaubte. Häufig waren die zuvor anhand ihrer Absorbtion bei $260 \mathrm{~nm}$ und in 
Testgelen quantifizierten und auf einheitliche RNA-Mengen eingestellten Proben anschließend dennoch deutlich unterschiedlich im RNA-Gehalt (Abb. 3.14a). Außerdem wurden selbst mit bis $\mathrm{zu} 20 \mu \mathrm{g}$ RNA pro Geltasche stets nur sehr schwache Hybridisierungssignale erhalten. Daher wurden zur quantitativen Abschätzung der Transkriptmengen RT-PCR Experimente mit limitierender Zyklenzahl durchgeführt, bei denen die Produktmenge unterhalb des Sättigungsbereiches bleibt und der eingesetzten Matrizenmenge proportional ist. Um Unterschiede in der Qualität der cDNA-Matrizen auszugleichen wurden zunächst RT-PCRs mit Ubiquitin-spezifischen Primern (ubifor, ubirev, Tab. 2.1) durchgeführt. Die Anzahl der RT-PCR Zyklen für die Amplifikation von BnAAP1 oder BnAAP6 wurde dann für jede Probe anhand der Zyklenanzahl gewählt, bei der zuerst Ubiquitin-spezifische Banden sichtbar waren.

a)

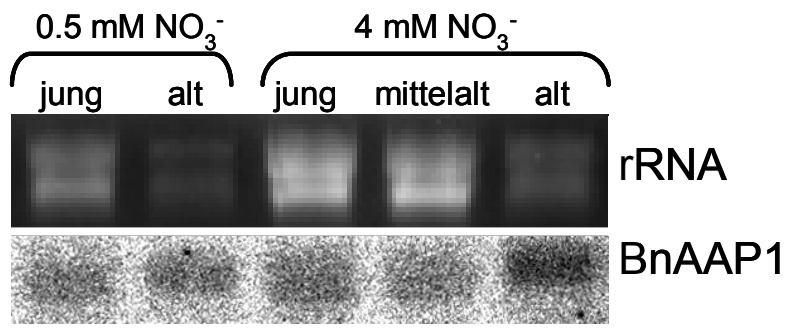

b)

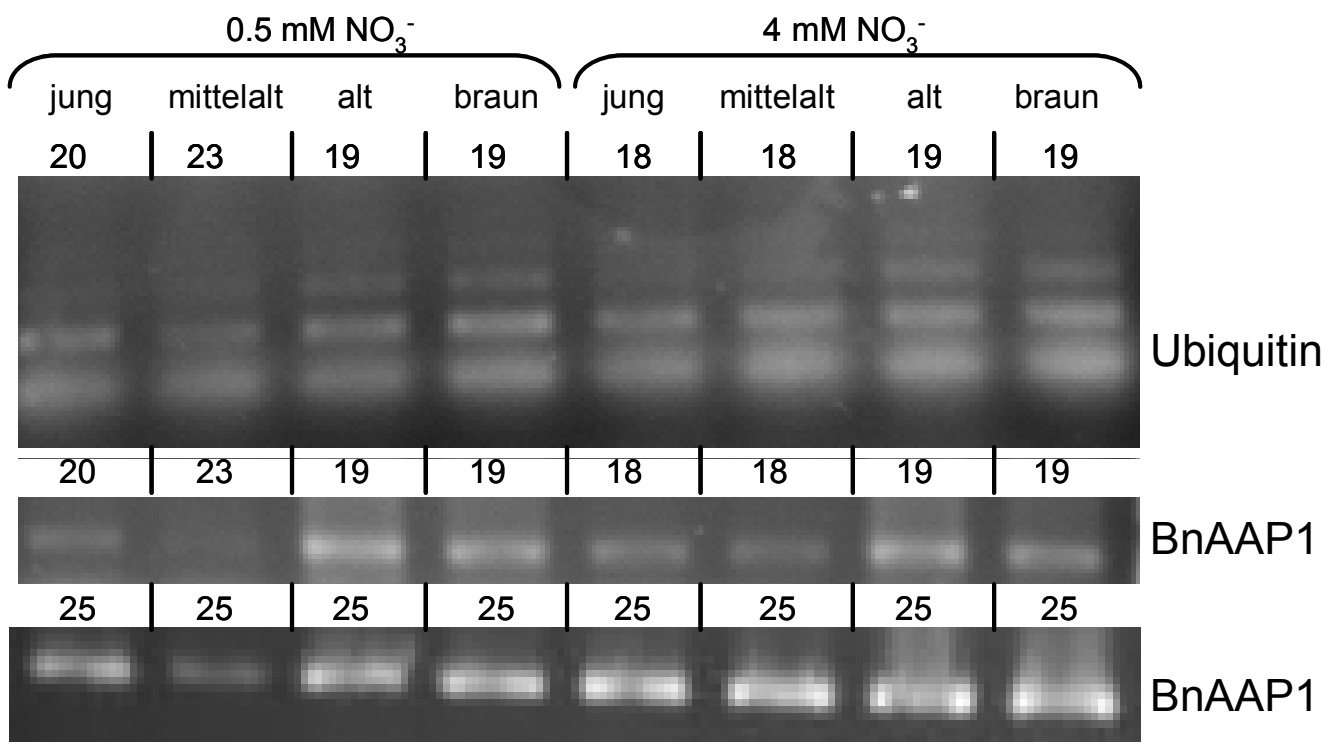

Abb. 3.14: Expression von BnAAP1 in Abhängigkeit vom Blattalter und der $\mathbf{N}$ Versorgung. a) Northern Blot: Gelfoto der 28S rRNA und Hybridisierungsergebnis mit einer 0,5 kb BnAAP1-Sonde. Eingesetzt wurden $20 \mu \mathrm{g}$ Gesamt-RNA je Geltasche. b) RTPCR mit limitierender Zyklenzahl. Zahlen oberhalb der Gelbahnen geben die Anzahl der PCR-Zyklen an. Verwendet wurden die Primer ubifor und ubirev für die Detektion von Ubiquitin-mRNA sowie BA1f1 und BA1r1 für die BnAAPl-Detektion. Je 0,1 Vol. einer RT-Reaktion aus $3 \mu \mathrm{g}$ Gesamt-RNA wuden eingesetzt. 0,5 $\mathrm{mM}$ und $4 \mathrm{mM} \mathrm{NO}_{3}{ }^{-}$: Nitratkonzentration der in hydroponischer Kultur verwendeten Nährlösung. 
Abb. 3.14a zeigt einen typischen Northern Blot bei dem sich die eingesetzten RNA-Mengen im Nachhinein als unterschiedlich erwiesen. Interessanterweise nahm dabei bei beiden $\mathrm{N}$ Stufen die Intensität des Hybridisierungssignals mit dem Blattalter trotz geringerer RNAMengen zu. Die Expression von BnAAPl ging also in alten Blättern nicht zurück, sondern stieg sogar eher an. Allerdings fehlten die älteste Altersstufe (,braun“) sowie die mittelalten Blätter der 0,5 mM Nitrat-Pflanzen in diesem Experiment.

RT-PCR Experimente ergaben übereinstimmende Ergebnisse (Abb. 3.14b). Bei Zyklenzahlen, die in den beginnenden Sättigungsbereich kamen (25 Zyklen, unteres Gelfoto), war BnAAPlmRNA in allen Blattaltern beider N-Stufen nachweisbar. Bei limitierenden Zyklenzahlen (1823 Zyklen, mittleres Gelfoto) wiesen jeweils die Altersstufen „alt“ und „braun“ die stärksten Banden auf. Dabei muß berücksichtigt werden, daß die Proben bereits beim ersten deutlichen Sichtbarwerden von Ubiquitin-Banden (oberes Gelfoto) etwas unterschiedliche Produktmengen ergaben. Insbesondere waren bei der Probe aus mittelalten Blättern der 0,5 mM Nitrat-Pflanzen deutlich mehr PCR-Zyklen notwendig, um Ubiquitin-Banden zu erhalten. Die besonders schwache Amplifikation von BnAAPl in dieser Probe ist deshalb vermutlich auf die niedrige Qualität der cDNA-Matrize zurückzuführen. Insgesamt zeigen die Ergebnisse aber, daß bis zu äußerlich deutlich seneszenten Blättern keine Abnahme der Menge an BnAAPl- mRNA mit dem Blattalter stattfand.

\subsubsection{BnAAP6}

Für BnAAP6 wurden keine verwertbaren Northern Blot-Ergebnisse erhalten. Die Hybridisierungssignale waren so schwach, daß die mRNA nur in den Proben detektierbar war, die am meisten RNA enthielten. Aufgrund der Schwierigkeiten, die RNA genau zu quantifizieren und in allen Proben dieselbe Konzentration einzustellen, war ein Vergleich der Blattalter miteinander nicht möglich.

In RT-PCR Experimenten war auch die mRNA von BnAAP6 in allen Blattaltersstufen nachweisbar (25 Zyklen, Abb. 3.15, unteres Gelfoto). Wie für BnAAPl wurden signifikant schwächere Amplifikationsergebnisse mit der Probe aus mittelalten Blättern der 0,5 mM Nitrat-Pflanzen erhalten, wahrscheinlich aufgrund einer qualitativ schlechteren cDNAMatrize. Die Amplifikation war insgesamt schwächer als bei BnAAP1, so daß alle Zyklenzahlen um eins erhöht werden mußten, um Banden zu erhalten. Bei limitierender Zyklenzahl (mittleres Gelfoto) war eine schwache Abnahme der Menge an BnAAP6-mRNA mit dem Blattalter feststellbar. Im Vergleich dazu zeigten bei den niedrigsten Zyklenzahlen, bei denen Ubiquitin-Banden sichtbar waren (oberes Gelfoto), gerade die ältesten Blattalter 
beider N-Stufen jeweils die stärkste BnAAP6-Amplifikation. Die Ergebnisse zeigen somit, daß die Menge an BnAAP6-mRNA mit dem Blattalter leicht abnahm, aber selbst in äußerlich deutlich seneszenten Blättern war noch Transkript vorhanden.

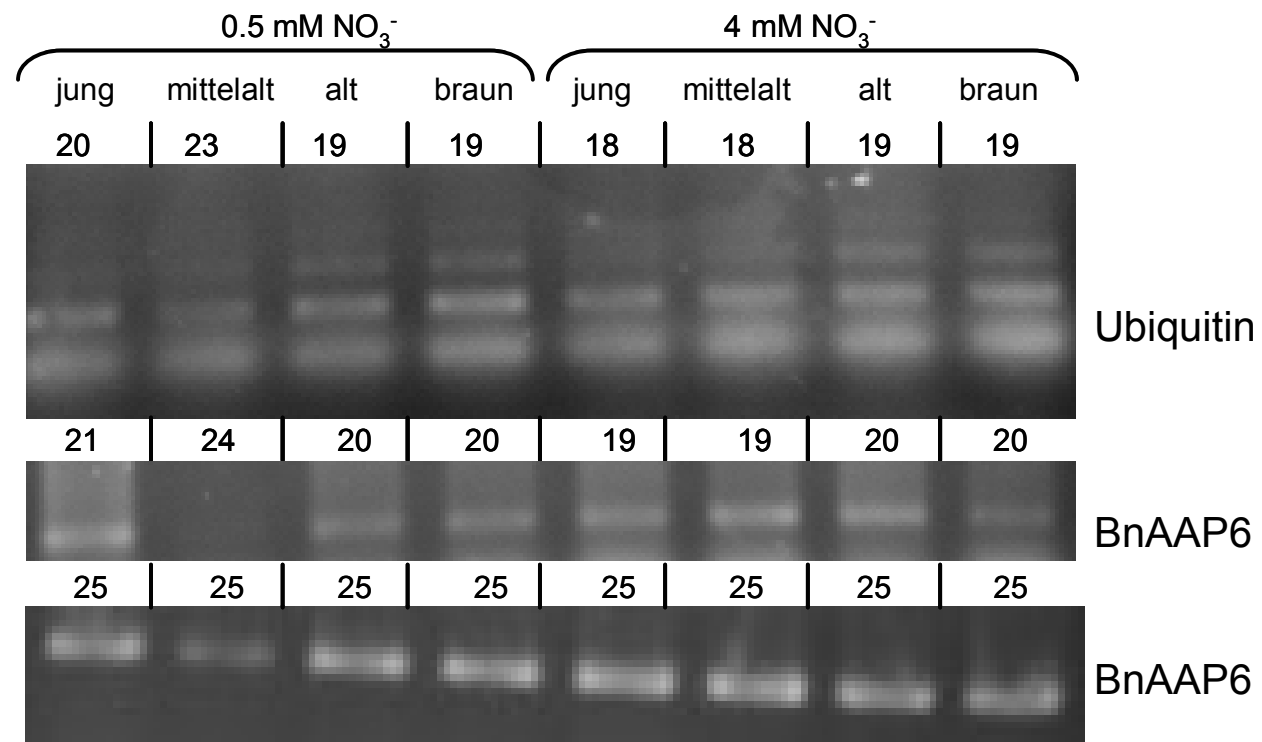

Abb. 3.15: Expression von BnAAP6 in Abhängigkeit vom Blattalter und der NVersorgung. RT-PCR mit limitierender Zyklenzahl. Zahlen oberhalb der Gelbahnen geben die Anzahl der PCR-Zyklen an. Verwendet wurden die Primer ubifor und ubirev für die Detektion von Ubiquitin-mRNA sowie BA6f2 und BA6r2 für die BnAAP6-Detektion. Je 0,1 Vol. einer RT-Reaktion aus $3 \mu \mathrm{g}$ Gesamt-RNA wuden eingesetzt. $0,5 \mathrm{mM}$ und 4 $\mathrm{mM} \mathrm{NO}_{3}{ }^{-}$: Nitratkonzentration der in hydroponischer Kultur verwendeten Nährlösung. 


\section{Diskussion}

\subsection{Variabilität der Stickstoffeffizienz bei Winterraps}

Raps ist in Europa die wichtigste Öl-liefernde Kulturpflanze. Ihr Anbau bringt jedoch Probleme mit sich, da für die aus landwirtschaftlicher Sicht gewünschten Ertragsgrößen der Einsatz sehr hoher N-Düngergaben notwendig ist. Dies verursacht einerseits erhebliche Kosten, andererseits gelangen aus der schnell mineralisierenden Rapsstreu große Mengen anorganischen Stickstoffs ins Grundwasser (Dejoux et al. 1999, Sieling \& Christen 1999, Trinsoutrot et al. 1999, 2000). Die Untersuchung der Stickstoffeffizienz bei Raps ist deshalb von zunehmender ökonomischer und ökologischer Bedeutung. Die vorliegende Arbeit war Teil eines von der Deutschen Forschungsgemeinschaft geförderten Projektes mit dem langfristigen Ziel, Ansätze für eine züchterische oder gentechnische Verbesserung der Stickstoff-Nutzungseffizienz zu finden.

Als Voraussetzung dafür, die N-Effizienz von Raps verbessern zu können, muß zunächst quantifiziert werden, inwieweit dieses komplexe Merkmal des pflanzlichen Stoffwechsels vom Genotyp der Pflanze bzw. von Umwelteinflüssen abhängt. Eine geeignete Methode dazu ist der Vergleich von Kultursorten bei unterschiedlicher Stickstoffversorgung. Für in Kanada angebauten Sommerraps wurden bereits entsprechende Versuche durchgeführt, die ein starke sortenabhängige (und damit eher genotypisch bestimmte) Variabilität der N-Effizienz aufzeigten (Grami \& LaCroix 1977, Yau \& Thurling 1987). Für den in Europa landwirtschaftlich bedeutenderen Winterraps lagen bis $\mathrm{zu}$ diesem DFG-Projekt keine ausführlichen Sortenvergleiche unter Freilandbedingungen vor. Er hat aufgrund der längeren Vegetationszeit, die eine Überwinterungsperiode einschließt, einen ganz anderen Entwicklungsablauf als Sommerraps. Barszcak et al. (1993), Gerath \& Schweiger (1991) und Gerath \& Balko (1995) verglichen verschiedene Winterraps-Sorten in Gefäßversuchen und fanden auch hier z.T. starke Unterschiede in der Reaktion des Samenertrags auf N-Mangel bzw. ein erhöhtes N-Angebot. In vorausgegangen Arbeiten im Rahmen dieses DFG-Projekts (Kessel 2000, Zhou 2000) wurden daher großangelegte Feldversuche mit zahlreichen Winterraps-Sorten an zwei Standorten und während drei Anbauperioden (1996/97-1998/99) durchgeführt. Das Ergebnis dieser Untersuchungen war, daß auch Winterraps bezüglich der Stickstoffeffizienz eine große, sortenabhängige Variabilität aufweist. Um diese genotypische Variabilität genauer zu quantifizieren, wurden in den drei Folgejahren 1999/2000-2001/02 weitere Feldversuche durchgeführt, diesmal aber mit doppel-haploiden (DH-) Linien, die aus 
einer einzigen Kreuzung (Apex $\mathrm{x}$ Mohican) hervorgegangen waren. DH-Linien werden hergestellt, indem man aus Mikrosporen (unreifen Pollenkörnern) in Gewebekultur haploide Embryos erzeugt und mit Colchizin behandelt. In der Pflanzenzüchtung sind DH-Linien von Bedeutung, weil bei ihnen eine Rückkreuzung nicht zu einer Aufspaltung von Merkmalen führt, so daß herausselektionierte Merkmalskombinationen problemlos weiter vermehrt werden können. In dem hier untersuchten Zusammenhang der Sortenvariabilität wurden DHLinien eingesetzt, weil sie für jedes beliebige Allel homozygot sind. Eine Merkmalsaufspaltung zwischen DH-Linien mit einem gemeinsamen genetischen Ursprung, wäre deshalb nach der Mendelschen Genetik ein indirekter Beweis für genetische Ursachen von auftretenden Variationen z.B. in der N-Effizienz. Die in den Feldversuchen 1999-2002 getesteten DH-Linien wurden bezüglich ihres N-Metabolismus physiologisch (Metabolitkonzentrationen, Nitratreduktaseaktivität) und agronomisch (u.a. SamenProteingehalt, Samenertrag) untersucht. In dieser Arbeit wird ihre physiologische Charakterisierung dargestellt.

Tab. 4.1 faßt nochmals die bereits in Tab. 3.1 dargestellten Ergebnisse der Feldversuche zusammen und stellt sie den von Zhou (2000) mit 99 Winterraps-Sorten erhaltenen Daten gegenüber. Unter den getesteten Parametern finden sich kurzfristig variable Größen wie die Nitratreduktaseaktivität ebenso wie langfristig akkumulierte Werte wie der SamenProteingehalt. Trotz der nur halb so großen Anzahl von Linien und Standorten zeigten die DH-Linien in keiner der gemessenen Größen eine geringere Variabilität als die von Zhou 2000 untersuchten, nicht miteinander verwandten Sorten. Ein Teil der hohen Variabilität in beiden Versuchen ist wahrscheinlich auf von Jahr $\mathrm{zu}$ Jahr unterschiedliche klimatische Bedingungen zurückzuführen. Dennoch zeigt der Vergleich der DH-Linien mit den nicht miteinander verwandten Sorten deutlich die starke Beeinflussung der Stickstoffeffizienz durch den Genotyp und damit das bei Winterraps vorhandene züchterische Potential. Daß die Aufspaltung einer einzigen Kreuzung in jeweils homozygote Allelkombinationen eine so hohe Diversität hervorbringt, hängt sicherlich mit der Größe und dem hohen Redundanzgrad des Rapsgenoms zusammen. Diploide Brassica Spezies sind vermutlich durch eine GenomVerdreifachung aus Arabidopsis-ähnlichen Vorfahren entstanden (Lagercrantz 1998, Lukens et al. 2003). Die amphidiploide Kreuzung von Gemüsekohl (B. oleracea) und Rübsen (B. rapa) zu Raps (B. napus) führte nochmals zu einer weiteren Verdoppelung des Genoms. Für diploide Kohlsorten konnte eine sehr rasche Anpassungsfähigkeit an klimatische Standortfaktoren beobachtet werden und dasselbe gilt auch für Raps (Wurr \& Fellows 1998, 
King et al. 1999). Die Variationsfähigkeit eines begrenzten Raps-Genpools bezüglich der NEffizienz, die hier beobachtet wurde, bestätigt diese Anpassungsfähigkeit.

Tab. 4.1: Gegenüberstellung der Daten aus Feldversuchen mit genetisch divergierenden Winterraps-Sorten und mit DH-Linien aus nur einer Kreuzung. NRA: NitratreduktaseAktivität; Stabw: Standardabweichung; k.A.: keine Angabe.

\begin{tabular}{|c|c|c|c|c|c|}
\hline \multirow{4}{*}{$\begin{array}{l}\text { Nitratgehalt im Blatt } \\
\quad\left(\mu \mathrm{mol} \mathrm{g}_{\mathrm{FG}}{ }^{-1}\right)\end{array}$} & \multirow[b]{3}{*}{$\mathrm{N}_{0}$} & \multicolumn{2}{|c|}{$\begin{array}{c}\text { Zhou (2000): } \\
\text { 99 Sorten, } \\
2 \text { Standorte 1996-1999 }\end{array}$} & \multicolumn{2}{|c|}{$\begin{array}{c}\text { diese Arbeit: } \\
45 \text { DH-Linien + } 2 \text { Elternsorten, } \\
1 \text { Standort 1999-2002 }\end{array}$} \\
\hline & & Mittel \pm Stabw. & Spanne & Mittel \pm Stabw & Spanne \\
\hline & & $0,6 \pm 0,4$ & k.A. & $0,1 \pm 0,1$ & $<0,1,-0,2$ \\
\hline & $\mathbf{N}_{240}$ & $18,5 \pm 17,3$ & k.A. & $14,6 \pm 3,8$ & $8-19$ \\
\hline \multirow{2}{*}{$\begin{array}{c}\text { NRA im Blatt } \\
\left(\mathrm{nmol} \mathrm{g} \mathrm{g}_{\mathrm{FG}}^{-1} \mathrm{~min}^{-1}\right)\end{array}$} & $\mathrm{N}_{0}$ & $38,3 \pm 8,0$ & $23,9-62,2$ & $25,7 \pm 9,3$ & $11-47$ \\
\hline & $\mathbf{N}_{240}$ & $59,4 \pm 15,7$ & $39,1-85,8$ & $60,6 \pm 15,5$ & $27-99$ \\
\hline \multirow{2}{*}{$\begin{array}{l}\text { Aminosäuregehalt } \\
\text { im Blatt }\left(\mu \mathrm{mol} \mathrm{g}_{\mathrm{FG}}{ }^{-1}\right)\end{array}$} & $\mathrm{N}_{0}$ & $6,4 \pm 0,4$ & $5,1-9,6$ & $9,9 \pm 3,2$ & $4,8-17,0$ \\
\hline & $\mathbf{N}_{240}$ & $10,3 \pm 3,0$ & $9,9-17,2$ & $16,4 \pm 2,5$ & $12-24$ \\
\hline \multirow{2}{*}{$\begin{array}{l}\text { Proteingehalt im } \\
\left.\text { Samen (\% } \%_{\mathrm{TG}}\right)\end{array}$} & $\mathrm{N}_{0}$ & $18,1 \pm 1,9$ & k.A. & $14,8 \pm 0,8$ & $12,9-16,8$ \\
\hline & $\mathbf{N}_{240}$ & $21,5 \pm 1,2$ & k.A. & $19,2 \pm 0,9$ & $17,8-21,3$ \\
\hline
\end{tabular}

Weiterhin konnte im Feldversuch erwartungsgemäß beobachtet werden, daß alle gemessenen Parameter des Stickstoff-Haushalts bei höherer N-Düngung anstiegen. Dabei nahm von $\mathrm{N}_{0} \mathrm{zu}$ $\mathrm{N}_{240}$ die Variabilität zwischen den Sorten relativ zum Mittelwert in allen Parametern ab. Dieser Effekt ist wahrscheinlich auf eine weitgehende Stickstoffsättigung des Stoffwechsels zurückzuführen. Es ließen sich keine signifikanten Zusammenhänge zwischen den einzelnen N-Stoffwechsel-Kenngrößen feststellen. Zhou (2000) konnte solche Zusammenhänge im Feldversuch ebenfalls nicht nachweisen, fand aber wie hier eine tendenziell positive Korrelation zwischen Aminosäuregehalt im Blatt und Proteingehalt im Samen (Abb. 3.1).

Der einzige signifikante Zusammenhang ergab sich zwischen dem Samenproteingehalt bei $\mathrm{N}_{0}$ und $\mathrm{N}_{240}$. Dieser Wert ist im Gegensatz zu den anderen eine kumulative Größe, die über die Vegetationsperiode langsam aufgebaut wird und kaum kurzzeitigen Fluktuationen unterliegt. Außerdem stellt die Proteineinlagerung in die Samen einen Endpunkt im StickstoffMetabolismus dar während die Nitrat- und Aminosäurepools im Blatt jeweils von verschiedenen konkurrierenden Prozessen (Aufnahme und Assimilation bzw. Synthese, Transport, Proteinbiosynthese und Proteinabbau) beeinflußt werden. Es ist deshalb nicht überraschend, daß sich nur für den Samen-Proteingehalt signifikante Zusammenhänge ergaben.

Die Einteilung der Rapssorten in die vier Kategorien ineffizient/nicht N-responsiv, effizient/nicht N-responsiv, ineffizient/N-responsiv und effizient/N-responsiv (Abb. 3.2) wurde auch von Kessel (2000) für den Samen-Proteingehalt der in den Anbaujahren 1996- 
1999 getesteten Rapslinien durchgeführt. Alle Sorten fielen nur in die zwei Kategorien ineffizient/nicht N-responsiv und effizient/N-responsiv. Dies entspricht der in dieser Arbeit gefundenen positiven Korrelation von Samen-Protein bei $\mathrm{N}_{0}$ und bei $\mathrm{N}_{240}$. Dagegen fanden Gerath \& Balko (1995) drei Typen von Rapssorten: 1) Höchstertrag nur bei höchster Düngungsmenge, 2) Höchstertrag bei mittlerer Düngung, kein weiterer Anstieg bei höchster Düngungsmenge und 3) Höchstertrag bei mittlerer Düngung, Ertragsrückgang bei höchster Düngungsmenge. Allerdings muß beachtet werden, daß der Samen-Proteingehalt nicht dem Ertrag und auch nicht der N-Effizienz selbst entspricht. In verschiedenen Studien wurde gefunden, daß der N-Gehalt des Samens negativ mit dem C-Gehalt, der Samengröße und dem Samenertrag (in kg ha ${ }^{-1}$ ) zusammenhängt (McNeal et al. 1972, Clements 1973, Sattelmacher et al. 1994, Zhou 2000). Sorten mit hohem Samen-Proteingehalt könnten deshalb durchaus trotzdem in die Kategorie 3) nach Gerath \& Balko (1995) fallen. Leider lagen Werte der AG Becker zum Samenertrag und der daraus resultierenden N-Effizienz (Gesamt-N-Gehalt der geernteten Samen geteilt durch die eingesetzte Stickstoffmenge) für die hier beschriebenen Feldversuche noch nicht vor. Insgesamt zeigen die Ergebnisse der Feldversuche, daß Winterraps eine hohe, genetisch bedingte Variabilität der N-Effizienz aufweist, die Möglichkeiten für züchterische und gentechnische Verbesserungen zuläßt.

\subsection{Subzelluläre Konzentrationen und Phloembeladung von Aminosäuren in Raps}

Im Rahmen dieser Arbeit wurden die Aminosäurekonzentrationen in subzellulären Kompartimenten bestimmt, die für die Phloembeladung von Bedeutung sind. Dazu wurden die Nichtwässrige Fraktionierung (Gerhardt \& Heldt 1984) und die ApoplastenInfiltrationstechnik (Lohaus et al. 2001) verwendet. Bei der Nichtwässrigen Fraktionierung wurden neben den Aminosäuren auch andere Metabolite bestimmt. Deren Verteilungsmuster stimmen gut mit der Literatur überein (Riens et al. 1991, Winter et al. 1993, 1994, Lohaus et al. 1995). So waren beispielsweise Malat und Nitrat vor allem in der Vakuole und Saccharose hauptsächlich im Zytosol verteilt. Die Übereinstimmung mit den von anderen Pflanzen bekannten Verhältnissen bestätigen die Zuverlässigkeit dieser Methode.

Die Aminosäurekonzentrationen in allen untersuchten Kompartimenten sind in Abb. 4.1 zusammengefaßt. Innerhalb der Mesophyllzellen waren die höchsten Konzentrationen im Zytosol und im Chloroplasten zu finden. Unter Berücksichtigung der z.T sehr großen Standardabweichungen waren die Aminosäurekonzentrationen dieser zwei Kompartimente vergleichbar. Das für die Zuordnung der Metabolitenkonzentrationen in den nichtwässrigen Fraktionen verwendete Programm Bestfit (Riens et al. 1991) arbeitet numerisch in $1 \%$ 
Schritten. Das bedeutet, daß einem bestimmten Kompartiment nur $0 \%, 1 \%, 2 \%$ usw. eines Metaboliten zugeordnet werden können. Die am Ende der Optimierung erhaltene Zuordnung weist dabei zwangsläufig eine gewisse Fehlerhaftigkeit auf, die in Prozentangaben gering ist. In den daraus errechneten Konzentrationswert geht aber das Volumen des Kompartiments mit ein. Die teilweise hohen Standardabweichungen für Zytosol (40 $\left.\mu 1 \mathrm{~g}_{\mathrm{FG}}{ }^{-1}\right)$ und Chloroplast (70 $\left.\mu 1 \mathrm{~g}_{\mathrm{FG}}{ }^{-1}\right)$ ergeben sich deshalb aus den im Vergleich zur Vakuole $\left(600 \mu 1 \mathrm{~g}_{\mathrm{FG}}{ }^{-1}\right)$ sehr kleinen Volumina dieser Kompartimente (Winter et al. 1993, 1994, Leidreiter et al. 1995). Ein Unterschied von $1 \%$ in der Verteilung eines Metaboliten ergibt hier einen sehr hohen Unterschied in der daraus errechneten Konzentration. Insgesamt stimmt auch die Verteilung der Aminosäuren innerhalb der Zelle weitgehend mit bisherigen Untersuchungen überein (Riens et al. 1991, Lohaus et al. 1995).

\section{$0,5 \mathrm{mM}$ Nitrat}
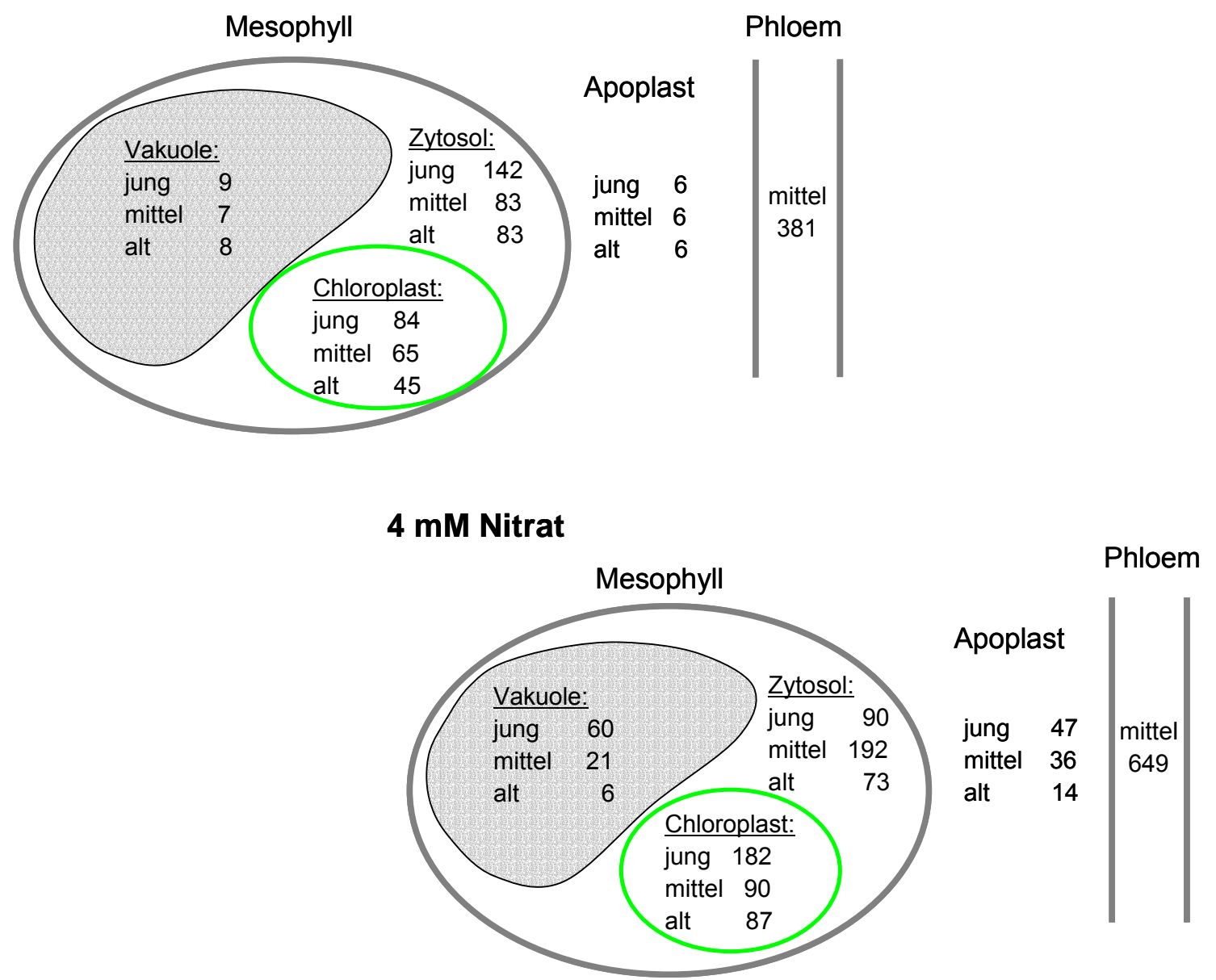

Abb. 4.1: Aminosäurekonzentrationen $(\mathrm{mM})$ in subzellulären Kompartimenten des Rapsblattes. Alle Daten für die Winterraps-Sorte Lirajet. Standardabweichungen wurden aus Platzgründen nicht mit eingezeichnet (siehe Ergebnisteil, Tab. 3.4 und 3.5). jung, mittel, alt: Blattaltersstufen. Phloemsaftdaten aus Zhou 2000 und Lohaus, unveröffentlicht $(0,5$ mM Nitrat: $381 \pm 81 \mathrm{mM}$; 4 mM Nitrat: $649 \pm 146 \mathrm{mM}, \mathrm{n}=3-6$ ). 
Die Mesophyllzellen bei $4 \mathrm{mM}$ Nitrat angezogener Pflanzen zeigten im Vergleich mit bei 0,5 $\mathrm{mM}$ Nitrat angezogenen Pflanzen nur in den Vakuolen junger und mittelalter Blätter signifikant erhöhte Aminosäurekonzentrationen. Wenn sich das erhöhte N-Angebot im Aminosäurepool niederschlug, wurden diese Überschüsse demnach in der Vakuole gespeichert. Berücksichtigt man das wesentlich größere Volumen dieses Kompartiments, so enthielt die Vakuole in jungen Blättern der $4 \mathrm{mM}$ Nitrat-Pflanzen ca. zweimal so viele Aminosäuren wie das Zytosol und die Chloroplasten zusammen. Von jungen zu alten Blättern hin nahm die Konzentration von Aminosäuren in allen Kompartimenten tendenziell ab (Abb. 3.3). Dies war am deutlichsten in der Vakuole der $4 \mathrm{mM}$ Nitrat-Pflanzen feststellbar, bei denen die alten Blätter sich nicht mehr von denen der 0,5 mM Nitrat-Pflanzen unterschieden. Ein großer Teil des durch das hohe N-Angebot erzeugten Aminosäure-Überschusses war am Ende der Blattentwicklung also wieder verschwunden. Dennoch enthielten die Blätter noch ähnlich viele Aminosäuren wie die Source-Blätter anderer Kulturpflanzen (Riens et al. 1991, Lohaus et al. 1994, 1995, 1998).

Der Rückgang der Aminosäurekonzentrationen von den jungen zu den mittelalten Blättern ist wahrscheinlich hauptsächlich auf eine Volumenvergrößerung des Blattes im Verlauf des Blattwachstums zurückzuführen, die sich auf zellulärer Ebene vor allem in einer Vergrößerung der Vakuole niederschlägt (Buchanan et al. 2000). Von den mittelalten zu den alten Blättern spricht der Rückgang der Aminosäurekonzentrationen dagegen eher für einen Abtransport von organischem Stickstoff, da in seneszierenden Blättern die Proteolyse gegenüber der Proteinbiosynthese stark überwiegt (Buchanan-Wollaston 1997). Auch die Zunahme der relativen Anteile verschiedener seltenerer Aminosäuren (Arginin, Leucin, Tyrosin, Phenylalanin, Tryptophan, aber auch Valin) im Zytosol alter Blätter der 0,5 mM Nitrat-Pflanzen spricht für einen steigenden Anteil proteolytisch freigesetzter Aminosäuren am gesamten Pool. Dies wurde von Zhou (2000) auch für die Gesamt-Aminosäuren im Blatt festgestellt. Bei den $4 \mathrm{mM}$ Nitrat-Pflanzen trat dieser Effekt nicht auf, wahrscheinlich war der Beitrag der Protein-Degradation zu dem durch den N-Überschuß sehr großen Aminosäurepool zu gering.

Die in Abb. 4.1 angegebenen Werte für die Konzentration von Aminosäuren im Phloemsaft von Raps (381 bzw. $649 \mathrm{mM}$ ) beruhen auf unveröffentlichen Untersuchungen an mittelalten Blättern der Winterraps-Sorte Lirajet von G. Lohaus. Für weitere Genotypen von B. napus (Sommerraps und Winterraps) und B. carinata (Senf) wurden von Lohaus \& Möllers (2000) ebenfalls sehr hohe Aminosäurekonzentrationen bis zu $500 \mathrm{mM}$ im Phloemsaft gefunden. Andere bisher mit der Aphidentechnik untersuchte Pflanzenarten hatten deutlich geringere 
Phloemsaft-Konzentrationen (Mais: 40-150 mM, Lohaus et al. 1998; Spinat: $180 \mathrm{mM}$, Gerste: $200 \mathrm{mM}$, Lohaus et al. 1995). Dabei besteht eine positive Korrelation zwischen dem Aminosäuregehalt des Phloemsaftes und dem Proteingehalt im Samen (Lohaus \& Möllers 2000). Insgesamt deuten diese Daten darauf hin, daß Raps sehr effizient organischen Stickstoff aus den Source-Blättern verlagert. Um den Abtransport von Aminosäuren aus dem Blatt quantitativ abschätzen zu können, fehlen aber noch Daten zur Flußrate des Phloemstroms sowie vergleichende Analysen des Phloemsaftes auch bei jungen und alten Rapsblättern. Diese Untersuchungen werden dadurch erschwert, daß sich aus Raps mit der Laser-Aphiden-Technik schwieriger Phloemsaft gewinnen läßt als z.B. aus Mais.

Die Konzentration von Aminosäuren im Apoplasten stellt die tatsächliche Substratkonzentration für Aminosäuretransporter in der Plasmamembran der PhloemGeleitzellen dar, die bei apoplastischen Beladern wahrscheinlich die Aufnahme von Aminosäuren ins Phloem katalysieren. Bei 0,5 mM Nitrat in der Nährlösung fanden sich 5-6 mM Aminosäuren im Apoplasten von Rapsblättern aller Altersstufen und bis zu $47 \mathrm{mM}$ Aminosäuren bei 4 mM Nitrat in der Nährlösung (Tab. 3.6, Abb. 4.1). Diese Werte stimmen für die $0,5 \mathrm{mM}$ Nitrat-Pflanzen gut mit Literaturangaben überein, sind aber für die $4 \mathrm{mM}$ Nitrat-Pflanzen ungewöhnlich hoch. So wurden für Vicia faba apoplastische Aminosäurekonzentrationen von 1,5 mM (Asparagin) und $9 \mathrm{mM}$ (Glutamin) gefunden (Delrot 1989), für Gerste und Spinat ca. 3 mM Gesamt-Aminosäuren (Lohaus et al. 1995) und für die Scrophulariaceen Alonsoa meridionalis und Asarina barclaiana 3,7 bzw. 11,8 mM GesamtAminosäuren (Knop et al. 2001). Dies entsprach jeweils Konzentrationsgradienten zum Phloemsaft von 60fach (Lohaus et al. 1995) und 20-30fach (Knop 2001). Für Winterraps der Sorte Lirajet ergaben sich hier ein 64facher Gradient bei den 0,5 mM Nitrat-Pflanzen, und ein 18 facher bei den $4 \mathrm{mM}$ Nitrat-Pflanze. Die Beladung des Phloems erfolgt also auch für Aminosäuren gegen einen hohen Konzentrationsgradienten. In Hefezellen, die pflanzliche Aminosäuretransporter exprimierten, wurden bis zu 450fache Aminosäure-Anreicherungen gegenüber dem Medium beobachtet (Fischer et al. 1995, Frommer et al. 1995).

Die Aminosäurekonzentration im Apoplasten war in allen Blattaltern und N-Stufen deutlich geringer als im Zytosol der Mesophyllzellen. Dies würde einen passiven Ausstrom in den Zellwandraum erlauben, wie er für die apoplastische Phloembeladung teilweise angenommen wird (Laloi et al. 1993, Lalonde et al. 2003). Bei der Betrachtung der AminosäureZusammensetzung in diesen beiden Kompartimenten ist auffällig, daß das Zytosol der Mesophyllzellen und der Apoplast z.T. deutlich voneinander abweichen. Beispielsweise ist bei den 4 mM Nitrat-Pflanzen im Zytosol stets Glutamat häufiger als Glutamin, während das 
Verhältnis im Apoplasten umgekehrt ist. Apoplastische Flüssigkeit enthält häufig höhere Glutamin-Anteile als das Zytosol von Mesophyllzellen (Lohaus et al. 2001), wahrscheinlich durch eine Vermischung mit Xylemsaft, der ebenfalls hohe Anteile von Amidstickstoff aufweist (Lohaus, unveröffentlicht). Bei den 0,5 mM-Pflanzen nimmt der zytosolische Glutamin-Anteil mit dem Blattalter stark zu (Tab. 3.7). Es wurde verschiedentlich gezeigt, daß im Verlauf der Blattseneszenz Isoformen der Glutamin-Synthetase verstärkt exprimiert werden, die wahrscheinlich dazu dienen, beim Abbau stickstoffhaltiger Verbindungen freigesetztes $\mathrm{NH}_{4}^{+}$durch Assimilation in phloemmobile Metaboliten zu überführen (Buchanan-Wollaston 1997 und Zitate darin, Gan \& Amasino 1997). Der zytosolische Anstieg des Glutaminanteils spiegelt sich aber im Apoplasten nicht wieder. Bei den $4 \mathrm{mM}$ Nitrat-Pflanzen war der Gesamt-Aminosäurepool wesentlich größer und wahrscheinlich deshalb der Beitrag der Glutamin-Synthetaseaktivität zur Aminosäure-Zusammensetzung in alten Blättern nicht so ausgeprägt. Da die Phloembeladung von Aminosäuren unspezifisch erfolgt (Riens et al. 1991, Winter et al. 1992) und die Aminosäure-Zusammensetzung im Zytosol der Mesophyllzellen und im Phloemsaft in einem engen Zuammenhang stehen, sollte man eigentlich annehmen, daß sich die starke Veränderung des Glutaminanteils auch im Apoplasten niederschlägt. Andererseits ist nicht anzunehmen, daß die Freisetzung von Aminosäuren in den Zellwandraum vollkommen passiv und unreguliert stattfindet, so daß ein entsprechender Anstieg der Glutaminkonzentration im Apoplasten möglicherweise erst mit einiger Verzögerung bemerkbar würde. Nach wie vor ist die Freisetzung der Metabolite in den Zellwandraum der am wenigsten untersuchte Teilprozeß der apoplastischen Phloembeladung. Eine eingehendere Untersuchung der Zusammenhänge zwischen zellulären, apoplastischen und Phloem-Konzentrationen von transportierten Metaboliten ist zum Verständnis unbedingt notwendig.

\subsection{Charakterisierung von Aminosäuretransportern aus Raps}

Für die apoplastische Beladung des Phloems mit Saccharose konnte an verschiedenen Spezies durch Antisense-Repression bzw. Knockout-Mutanten von $\mathrm{H}^{+}$-Saccharose-Symportern direkt bewiesen werden, daß diese Transporter für die Beladung notwendig sind (Riesmeier et al. 1994, Kühn et al. 1996, Lemoine et al. 1996, Bürkle et al. 1998, Gottwald et al. 2000). Ein entsprechender Beweis auch für Aminosäuretransporter steht bisher noch aus. Dennoch besteht auch für Aminosäuren, die im Phloemsaft keine so starke Anreicherung gegenüber dem Zytosol der Mesophyllzellen wie Saccharose erfahren (Lohaus et al. 1995) ein großer Konzentrationsgradient vom Apoplasten ins Phloem. Die genaue Charakterisierung von 
Aminosäuretransportern v.a. hinsichtlich ihrer Substratspezifität und -affinität sowie ihrer Lokalisation auf zellulärer Ebene ist deshalb für das Verständnis des Stickstofftransports innerhalb der Pflanze unerläßlich.

Im Rahmen dieser Arbeit sollten deshalb Aminosäuretransporter aus Raps identifiziert und charakterisiert werden. Aufgrund ihrer breiten Substratspezifität sind die Transporter der AAP-Familie die wahrscheinlichsten Kandidaten für die unspezifische Beladung des Phloems mit Aminosäuren und wurden für diese Untersuchung ausgewählt. Es gelang, zwei vollständige BnAAP-cDNA-Sequenzen von $\mathrm{zu}$ erhalten, die eine hohe Homologie $\mathrm{zu}$ entsprechenden Genen in Arabidopsis aufweisen. Die Funktionalität beider, nach den homologen Arabidopsis-Proteinen als BnAAP1 und BnAAP6 bezeichneter Transporter konnte durch Expression in Xenopus laevis Oozyten nachgewiesen werden. Dabei zeigten die Raps-AAPs eine sehr ähnliche Substratspezifität wie die verwandten Arabidopsis-Transporter. Wie alle bisher bekannten AAPs (Fischer et al. 2002) transportieren sie alle proteinogenen Aminosäuren (Abb. 3.8). Und wie bei AtAAP1 bzw. AtAAP6 weisen sie eine deutlich geringere Affinität zu basischen als zu neutralen und sauren Aminosäuren auf. BnAAP6 zeigt eine deutlich höhere Affinität zu Aspartat als BnAAP1. Unter den Arabidopsis-Transportern ist ebenfalls AtAAP6 derjenige mit der höchsten Affinität für diese Aminosäure (Fischer et al. 2002, Okumoto et al. 2002). Boorer \& Fischer (1997) konnten zeigen, daß alle Aminosäuren mit Ausnahme von Arginin und Lysin als neutrale Zwitterionen zusammen mit einem Proton transportiert werden. Arginin und Lysin werden als einwertige Kationen ebenfalls zusammen mit einem Proton transportiert. Der Ladungsfluß über die Ooyzentenmembran bei der Aufnahme von Aminosäuren besteht deshalb aus einem $\mathrm{H}^{+}$-Einstrom und einem kompensatorischen $\mathrm{Na}^{+}$-Ausstrom (Towle et al. 1991) und ist der transportierten Aminosäuremenge bei der hier verwendeten Ein-Elektroden-Methode nicht direkt proportional (Abb. 3.7). Ein direkter Vergleich von BnAAP1 und BnAAP6, der zeigen könnte, ob auch BnAAP6 ein hochaffiner Transporter ist, war deshalb nicht möglich.

Ein Unterschied zeigte sich zwischen BnAAP1 und AtAAP1: Der Raps-Transporter zeigte bei Tryptophan-Konzentrationen von $0,1 \mathrm{mM}, 0,5 \mathrm{mM}$ und $5 \mathrm{mM}$ eine ähnliche Affinität wie für Alanin, wogegen AtAAP1 diese Aminosäure nur äußerst ineffizient transportiert (Fischer et al. 2002). Allerdings wird in derselben Veröffentlichung für AtAAP1 der $\mathrm{K}_{0,5}$-Wert für Tryptophan mit 0,6 mM ebenso niedrig angegeben wie für Alanin. Die ansonsten weitgehende Übereinstimmung der Susbtratspezifitäten zwischen den Raps- und ArabidopsisTransportern konnte trotz der nahen Verwandschaft beider Arten nicht ohne weiteres erwartet werden. In Arabidopsis sind z.B. die Gene AtAAP1 und AtAAP 8 durch Verdoppelung eines 
Chromosomenabschnitts entstanden und weisen untereinander eine höhere Homologie auf als zu den anderen AtAAP-Genen (Okumoto et al. 2002). Dennoch transportiert AtAAP8 Aspartat mit hoher Affinität und AtAAP1 nicht.

BnAAP1 und BnAAP6 transportierten alle getesteten Aminosäuren auch bei $0,1 \mathrm{mM}$ Substratkonzentration. Wie die Analyse des Apoplastensaftes gezeigt hat, befindet sich diese Konzentration in einem Bereich, der auch in vivo für die selteneren Aminosäuren anzunehmen ist. Aus den gemessenen Membranpotentialänderungen lassen sich keine MichaelisKonstanten für die Transporter ableiten, dazu wäre eine 2-Elektroden „Voltage Clamp”Messung, die durch konstant halten des Membranpotentials die Messung von Stromflüssen über die Oozytenmembran erlaubt (Miller \& Zhou 2000), oder die Expression der Transporter in Hefe (Frommer \& Ninnemann 1995) notwendig. Die in der Literatur angegebenen $\mathrm{K}_{\mathrm{M}^{-}}$ (bzw. $\mathrm{K}_{0,5^{-}}$) Werte von Aminosäurepermeasen aus Arabidopsis liegen zumeist in der Größenordnung von 0,5-1 mM. Einzelne Aminosäuren werden mit wesentlich geringerer Affinität transportiert, z.B. liegt der $\mathrm{K}_{0,5^{-}}$Wert von AtAAP1, 2, 4 und 6 für Arginin bei über $50 \mathrm{mM}$. Andererseits haben manche Transporter für einzelne Susbtrate auch deutlich höhere Affinitäten. Der $\mathrm{K}_{0,5}$ von AtAAP2 für Tryptophan liegt bei nur $60 \mu \mathrm{M}$ und der hochaffine Transporter AtAAP6 hat allgemein (mit Ausnahme der basischen Aminosäuren) $\mathrm{K}_{0,5}$-Werte zwischen $40 \mu \mathrm{M}$ und 1,6 $\mathrm{mM}$ (Fischer et al. 2002).

Die Bestimmung der Substrataffinität in heterologen Expressionssystemen stellt aber wahrscheinlich eher eine Unterschätzung der tatsächlichen Affinität in der Pflanze dar. Bei elektrogenen Transportern, die die Translokation ihres Substrats gegen einen Konzentrationsgradienten durch das Membranpotential energetisieren (das in diesem Fall durch einen Protonengradienten erzeugt wird), ist auch die Substrataffinität potentialabhängig (Boorer et al. 1996). Bei der Bestimmung des $\mathrm{K}_{0,5}$-Wertes eines Transporters in einem „Voltage Clamp” Experiment mit Xenopus Oozyten wird das Membranpotential der Zelle in der Regel bei -30 bis $-40 \mathrm{mV}$ festgehalten (Miller \& Zhou 2000). In der Pflanze trifft der Transporter dagegen Potentiale von bis $\mathrm{zu}-200 \mathrm{mV}$ an (Meharg \& Blatt 1995), die in Xenopus Oozyten nicht eingestellt werden können, weil bei -150 mV ein endogener $\mathrm{Cl}^{-}$-Kanal geöffnet wird, dessen Aktivität die Effekte heterolog exprimierter Transporter überdeckt (Parker \& Miledi 1988, Kowdley et al. 1994, Miller \& Zhou 2000). Bei kinetischen Experimenten mit transgenen Hefezellen, die einen fremden Transporter exprimieren, wird das Membranpotential normalerweise überhaupt nicht kontrolliert.

Insgesamt deuten die aus der Literatur bekannten $\mathrm{K}_{\mathrm{M}}$-Werte der AAP-Transporter, die im Apoplasten gemessenen Aminosäurekonzentrationen und die Aktivität von BnAAP1 und 6 
bei 0,1 mM Substratkonzentration darauf hin, daß die AAPs sehr wohl in der Lage sind, auch die selteneren Aminosäuren in vivo $\mathrm{zu}$ transportieren. Dies widerspricht ursprünglichen Vermutungen, diese Proteine würden in der Pflanze nur als Transporter für häufige Aminosäuren wie Glutamat und Glutamin fungieren, so daß weitere spezifische Transporter für die seltenen Aminosäuren notwendig wären (Fischer et al. 1998). Um den Transport aller proteinogenen Aminosäuren abzudecken scheinen so zusätzlich nur Transporter für die basischen Aminosäuren notwendig $\mathrm{zu}$ sein, die in Form der „Cationic Amino Acid Transporters“ (CATs, Frommer et al. 1995) und „Lysine and Histidine Transporters“ (LHTs, Chen \& Bush 1997) bereits identifiziert wurden. Welche Bedeutung die „Aromatic and Neutral Amino Acid Transporters“ (ANTs, Chen et al. 2001) für die Phloembeladung mit aromatischen Aminosäuren haben, ist noch unklar.

\subsection{Expression von BnAAP1 und BnAAP6 in der Pflanze}

Für das Verständnis der Funktion von Aminosäuretransportern wie BnAAP1 und BnAAP6 ist die genaue Kenntnis ihrer Lokalisation in der Pflanze und deren zeitlicher Veränderung während des Entwicklungszyklus notwendig. Die Modellpflanze Arabidopsis ist in dieser Hinsicht bereits relativ gut untersucht. Da Arabidopsis und Raps zwar zur gleichen Familie gehören, sich aber physiologisch stark unterscheiden, wurde die organspezifische Expression von BnAAP1 und BnAAP6 in einer parallel zu dieser Arbeit durchgeführten Diplomarbeit (Kassner 2003) anhand von Northern Blots und RT-PCR mit der von AtAAP1 und AtAAP6 verglichen. RT-PCRs mit nicht-limitierender Zyklenzahl zeigten, daß geringfügige Mengen von Transkripten beider Gene überall in der Pflanze vorhanden sind. Bei limitierender Zyklenzahl und in Northern Blots war aber nachweisbar, daß die Expression organspezifisch sehr unterschiedlich war. BnAAPl Transkripte traten v.a. in der Blüte auf, schwächere Hybridisierungssignale ergaben sich auch mit RNA aus dem Stengel. BnAAP6 mRNA war vor allem in Wurzeln nachweisbar, sowie ebenfalls in der Blüte (Tab. 4.2).

Diese Ergebnisse stimmen teilweise mit Arabidopsis überein (Expression von AtAAP6 in Wurzeln), weisen aber auch Unterschiede auf. Die Detektion von beiden mRNAs im Northern Blot war äußerst schwierig aufgrund der wahrscheinlich sehr schwachen Expression der Transporter und dem hohen Polysaccharidgehalt des Rapsgewebes, der die Isolation sauberer RNA beeinträchtigt. Unter Berücksichtigung der basalen Transkription in allen Organen reflektieren die Hybridisierungssignale von BnAAPl im Stengel und von beiden Genen in der Blüte deshalb möglicherweise eher die Qualität der eingesetzten RNA als die Organspezifität der Expression. Unter diesem Gesichtspunkt muß auch beachtet werden, daß BnAAP1 zuerst 
aus RNA junger Blätter isoliert wurde, die im Northern Blot kein Hybridisierungssignal zeigten. AtAAPl ist in Arabidopsis-Schoten nur in den Samen zum Zeitpunkt des herzförmigen Embryostadiums in Northern Blots detektierbar (Hirner et al. 1998). Die Expression von AtAAP6 im Blatt ist auf Sink-Blätter beschränkt und in reifen Blättern stark reduziert (Rentsch et al. 1996). Das Fehlen von Hybridisierungssignalen für BnAAP1 in Schoten bzw. für BnAAP6 in Blättern kann deshalb darauf zurückzuführen sein, daß die Proben für die RNA-Isolation nicht zum Zeitpunkt der stärksten Expression genommen wurden.

Tab. 4.2: Organspezifische Expression von BnAAP1 und BnAAP6 im Vergleich mit homologen Genen aus Arabidopsis. Nach Kassner 2003 (Raps) und Fischer et al. 1998 (Arabidopsis). ++: starke Expression, +: Expression, --: Expression im Northern Blot nicht nachweisbar. *Die Expression von AtAAPl ist auf das Endosperm des Samens beschränkt. **AtAAP6 wird nur in Sink-Blättern exprimiert.

\begin{tabular}{c|c|c|c|c|c}
\hline & Wurzel & Stengel & Blatt & Blüte & Schote \\
\hline BnAAP1 & -- & + & -- & ++ & -- \\
\hline AtAAP1 & -- & -- & -- & -- & $++^{*}$ \\
\hline BnAAP6 & + & -- & -- & ++ & -- \\
\hline AtAAP6 & ++ & -- & $+{ }^{* *}$ & -- & -- \\
\hline
\end{tabular}

Aufgrund ihrer engen Verwandschaft sind einerseits Übereinstimmungen in der organspezifischen und entwicklungsabhängigen Expression von homologen Genen in Raps und Arabidopsis zu erwarten. So ist z.B. die Expression der seneszenzspezifischen Protease SAG12 zwischen beiden Spezies konserviert (Noh \& Amasino 1999b). Andererseits weisen beide Pflanzen völlig verschiedene Wuchsformen und dementsprechend abweichende SinkSource-Verhältnisse auf. Raps ist außerdem durch sein gegenüber Arabidopsis versechsfachtes Genom (Lagercrantz 1998, Lukens et al. 2003) ein genetisch wesentlich komplexerer Organismus. Die mit der Polyploidisierung verbundene Redundanz verringert den Selektionsdruck auf einzelne Allele (Paterson et al. 2001, Osborn et al. 2003) und es ist durchaus möglich, das sich Subtypen der hier untersuchten Transporter mit unterschiedlichen Expressionsmustern herausgebildet haben, die mit den verwendeten Methoden nicht unterscheidbar sind.

Northern Blots und RT-PCR sind über ganze Organe integrierende Methoden, die keine Schlüsse auf die Gewebespezifität der Expression zulassen. Insbesondere bei potentiell Leitbündel-spezifisch exprimierten Genen kann die Intensität des Hybridisierungssignals eher die Dichte von Leitbündelsträngen im Organ reflektieren als das zelluläre Expressionsniveau. 
Für eine genaue Funktionszuweisung ist bei wahrscheinlich an der Phloembeladung beteiligten Transportproteinen außerdem eine Unterscheidung zwischen Xylem- und Phloemexpression notwendig. Wünschenswert wäre eine zellspezifische Lokalisation, da z.B. für die Saccharosetransporter PmSUC2 und PmSUC3 aus Plantago major nachgewiesen wurde, daß SUC2 ausschließlich in den Geleitzellen und SUC3 ausschließlich in den Siebelementen vorkommt (Stadler et al. 1995, Barth et al. 2003). Bei Solanaceen sind dagegen alle bekannten Saccharosetransporter ausschließlich in den Siebröhren zu finden (Kühn et al. 1997, Barker et al. 2000, Weise et al. 2000). Im Rahmen dieser Arbeit wurde deshalb begonnen, das Expressionsmuster von BnAAP6 durch eine PromotorReportergenfusion und durch Immunolokalisation genauer zu charakterisieren.

Transgene Pflanzen, die das $\beta$-Glucuronidase-Reportergen unter der Kontrolle des BnAAP6Promotors exprimierten, wurden nur aus der Transformation von A. thaliana und nicht von $B$. napus erhalten. GUS-Aktivität fand sich in den Leitbündeln von Source-Blättern und Kelchblättern der Blüte, aber nicht im Stengel oder den Schoten (Abb. 3.10). Teilweise wiesen Blüten auch an der Narbe eine Färbung auf, diese war aber nicht konsistent bei allen untersuchten Pflanzen vorhanden und ist wahrscheinlich auf in bestimmten Entwicklungsstadien vorhandene endogene GUS-Aktivität zurückzuführen (Hu et al. 1990). Da die Pflanzen in Erde angezogen wurden, war eine Färbung der Wurzeln nicht praktikabel. Genauere Färbungsexperimente mit vollständigen, auf Agarplatten und unter verschiedenen N-Versorgungsstufen gewachsenen Pflanzen der T3-Generation stehen noch aus. Die GUSFärbung in den Kelchblättern bestätigt das Hybridisierungssignal mit Blüten-RNA in Northern Blots. Bei Arabidopsis ist die Expression von AAPs in den vegetativen Pflanzenteilen ebenfalls auf die Leitbündel beschränkt, allerdings fand sich z.B. AtAAP2Expression im Phloem und AtAAP6-Expression im Xylem-Parenchym (Hirner et al. 1998, Okumoto et al. 2002). Es ist deshalb noch notwendig, die genaue Lokalisation der BnAAP6Promotoraktivität durch mikroskopische Untersuchung GUS-gefärbter Pflanzen festzustellen. Die Promotoraktivität in Source-Blättern scheint sowohl dem Fehlen eines Hybridisierungssignals in Northern Blots $\mathrm{zu}$ widersprechen als auch einer Sink-Blatt spezifischen Expression, wie sie für AtAAP6 gezeigt wurde (Rentsch et al. 1996). Andererseits ist aber die GUS-Färbung gerade wegen ihrer hohen Sensitivität nicht geeignet, anhand der Färbungsintensität zwischen Sink-Blatt- und Source-Blatt-spezifischer Expression zu unterscheiden. Eine basale Transkriptionsaktivität war überall in der Pflanze und auch in allen Blattaltersstufen (4.5.) vorhanden. Sofern diese Expression auf die Leitbündel beschränkt war, war sie dort wahrscheinlich deutlich höher als in Northern Blots erkennbar. 
Auch bei relativ schwacher Promotoraktivität in Source-Blättern könnte die lokal stark begrenzte Akkumulation des farbigen Reaktionsprodukts deshalb zu einer intensiven Färbung der Leitbündel führen.

Die Immunolokalisation von BnAAP6 gelang mit den hergestellten Antiseren nicht, obwohl heterolog in E. coli bzw. Xenopus Oozyten exprimiertes BnAAP6-Protein detektierbar war, sowie in Blattextrakten ein Protein mit einem apparenten Molekulargewicht von ca. 43 kDa, bei dem es sich wahrscheinlich um BnAAP6 handelte. Bisher ist für keinen pflanzlichen Aminosäuretransporter eine Immunolokalisation gelungen, möglicherweise aufgrund des niedrigen Expressionsniveaus oder ungünstiger Epitopeigenschaften der Proteine. Eine erfolgreiche Immunolokalisation wurde für den nah verwandten putativen Auxin-Transporter AUX1 durchgeführt (Swarup et al. 2001). In diesem Fall wurde nicht das AUX1 Protein direkt detektiert, sondern ein translational daran gekoppeltes Hämagglutinin-Epitop. Eine solche Vorgehensweise scheint auch für die AAPs erfolgversprechend, ist aber aufwendig, da die Translationsfusion unter Kontrolle des BnAAP6-Promotors in die Pflanze transformiert werden muß. Alternativ wäre eine Fluoreszenz-Lokalisation mit dem Grün Fluoreszierenden Protein (GFP) unter Kontrolle des BnAAP6-Promotors denkbar. Die direkte Verwendung einer Promotor-GFP Fusion ist allerdings nicht möglich, da GFP zwischen Geleitzellen und Siebelementen transportiert wird und auch im Phloem mobil ist (Imlau et al. 1999). Stattdessen müßte entweder eine translationale BnAAP6-GFP Fusion hergestellt, oder ein durch ein Signalpeptid am Endoplasmatischen Reticulum verankertes GFP-Protein (Wright et al. 2003) verwendet werden.

\subsection{Expression von BnAAP1 und BnAAP6 während der Blattentwicklung}

Unter dem Gesichtspunkt der N-Effizienz von Raps war ein Schwerpunkt der vorliegenden Arbeit die Remobilisation von Aminosäuren aus seneszierenden Blättern. Es sollte daher untersucht werden, ob sich die Expression der identifizierten Aminosäuretransporter im Verlauf der Blattentwicklung veränderte. Aufgrund der Probleme, in Northern Blot-Analysen deutliche und vergleichbare Signale zu erhalten und wegen der für diese Fragestellung zu großen Sensitivität der GUS-Färbungsmethode wurde eine Quantifizierung der Transkriptmengen durch Ubiquitin-standardisierte RT-PCR vorgenommen. Dabei zeigte sich eine leichte Abnahme der Menge an BnAAP6-mRNA mit dem Blattalter (Abb. 3.15). Dies könnte mit dem für AtAAP6 gezeigten Expressionsrückgang beim Sink-Source-Übergang des Blattes übereinstimmen (Rentsch et al. 1996). Eine genauere Analyse der jungen Blätter bezüglich ihres N-Sink- oder N-Source-Status wäre aber für einen direkten Vergleich 
notwendig. Zusätzlich könnte an Keimlingen der BnAAP6-Promotor-GUS-Pflanzen untersucht werden, ob die GUS-Färbung auch in Keimblättern auftritt (die immer als NSource fungieren), bzw. ob sie während der Blattentwicklung zunächst nur in den HauptBlattadern auftritt, bevor die blinden Enden der kleinsten Phloemgefäße fertig entwickelt sind und ihre mit dem Übergang zum Source-Blatt verbundene Funktion in der Phloembeladung aufnehmen (Wright et al. 2003).

Die Menge an BnAAPl-mRNA nahm dagegen nicht mit dem Blattalter ab, sondern eher etwas zu (Abb. 3.14). In der Literatur findet sich bislang kein Nahweis einer verstärkten Expression von Aminosäuretransportern in seneszierenden Blättern. Sakr et al. (1993, 1997) stellten erhöhte Aufnahmeraten an Blattscheiben und Plasmamembran-Vesikeln aus seneszierenden Blättern von Beta vulgaris fest. Sie konnten aber mit einer heterologen AtAAPl-Sonde keine vermehrte Expression endogener Transporter detektieren. Die meisten Studien zu Membrantransport-Proteinen unterscheiden nur zwischen Sink- und Source-Blättern und auch in Transkriptom- und Proteom-Analysen seneszierender Blätter werden keine Aminosäuretransporter erwähnt (Buchanan-Wollaston 1997, Quirino et al. 1999, Yoshida et al. 2001, Bhalerao et al. 2003). Dagegen ist aus verschiedenen Untersuchungen bekannt, daß Glutamin-Synthetasen während der Blattseneszenz verstärkt exprimiert werden, wahrscheinlich um Ammonium, das beim Abbau biologischer Makromoleküle freigesetzt wird, für den Abtransport in organischer Form zu binden (Buchanan-Wollaston 1997 und Zitate darin, Gan \& Amasino 1997). Insbesondere unter dem Gesichtspunkt, daß die Mehrzahl aller Gene während der Blattseneszenz herunterreguliert wird (Gan \& Amasino 1997), ist das zumindest konstante Expressionsniveau von BnAAPl bedeutsam. Weitere Untersuchungen müssen dieses Ergebnis mit der Expression seneszenzspezifischer Markergene wie z.B. BnSAG12 (Noh \& Amasino 1999b) korrelieren. Obwohl möglicherweise nicht die im Blatt hauptsächlich exprimierten AAP-Gene identifiziert wurden, zeigen die Ergebnisse insgesamt, daß Raps auch in seneszierenden Blättern noch Aminosäuretransporter exprimiert.

\subsection{Möglichkeiten zur gentechnischen Verbesserung der Stickstoffeffizienz von Raps}

Der übergeordnete Gesichtspunkt, unter dem in dieser Arbeit der Abtransport von Aminostickstoff aus Rapsblättern untersucht wurde, war die Frage nach Möglichkeiten einer gentechnischen Verbesserung der Stickstoffeffizienz. Nach Duncan \& Baligar (1990) wird die N-Effizienz einer Pflanze im wesentlichen von drei Faktoren beeinflußt: 1) Der Aktivität der Enzyme des primären Stickstoffmetabolismus, 2) der Mobilisation und Translokation stickstoffhaltiger Verbindungen und 3) der Speicherung N-haltiger Verbindungen. Diese drei 
Aspekte lassen sich in etwa gleichsetzen mit 1) der Stickstoffassimilation, 2) dem Stickstofftransport und 3) der Sink-Stärke stickstoffspeichernder Organe. Entsprechend sind dies potentielle Ansatzpunkte für gentechnische Veränderungen, die im Folgenden diskutiert werden.

Verschiedene Studien haben bereits gezeigt, daß bei Raps die Stickstoffassimilation nicht limitierend für die N-Effizienz ist: Raps nimmt Stickstoff effizienter auf als viele andere Kulturpflanzen (Lainé et al. 1993, Dejoux et al. 2000) und ist überdies in der Lage, die NAufnahmekapazität der Wurzeln schnell an einen erhöhten Stickstoff-Bedarf des Sposses anzupassen (Lainé et al. 1995). Durch seine Effizienz in der Stickstoffaufnahme eignet er sich sogar als „catch crop“, d.h. um mineralischen Stickstoff im Bodenprofil aufwärts zu transportieren. Im Rahmen dieses DFG-Projektes wurden transgene Rapspflanzen hergestellt, die die plastidäre oder zytosolische Glutaminsynthetase oder eine bakterielle Asparaginsynthetase überexprimierten, sowie Linien, in denen die plastidäre Glutaminsynthetase durch ein Antisense-Konstrukt ausgeschaltet war (Wallbraun 1997). Keine dieser Modifikationen führte zu signifikanten Veränderungen im Metabolitgehalt der Blätter, im Proteingehalt der Samen oder im N-Ernte-Index (Seiffert 2000, Zhou 2000). Dagegen berichteten Lam et al. (2003) von erhöhten Proteingehalten in Samen von Arabidopsis-Pflanzen, die konstitutiv die Asparaginsynthetase ASN1 überexprimierten. Bei Arabidopsis sind die Samen im Gegensatz zu Raps sehr proteinarm, so daß sich ein solcher Effekt zwangsläufig deutlicher ausprägt.

Winterraps unterscheidet sich von den meisten anderen Kulturpflanzen darin, daß die Pflanze ihre Blätter bereits während der Blüte nahezu vollständig abwirft. Reifende Samen erhalten einen großen Teil ihres Stickstoffs aus der Proteolyse und Aminosäure-Remobilisation seneszierender Blätter (Crawford et al. 1982, Thorne 1985, Feller \& Keist 1986, Frommer et al. 1994b). Bei Raps gehen jedoch mit dem Blattabwurf große Mengen an N verloren, die als Vorernteverluste bezeichnet werden. Diese N-Verluste treten sogar bei extensiver Düngung auf (Lickfett et al. 1994). Sie können Größenordnungen von $16 \mathrm{~kg} \mathrm{~N} \mathrm{ha}^{-1}$ (Aniol 1994) bis 25 $\mathrm{kg} \mathrm{N} \mathrm{ha}{ }^{-1}$ (Schjoerring 1995) haben und $15 \%$ des gesamten Stickstoffs in der Pflanze ausmachen (Rossato et al. 2001). Dies führte zu der Annahme, daß bei Raps der Abtransport von Aminosäuren aus seneszierenden Blättern limitierend für die Stickstoff-Remobilisation sein könnte.

Im Rahmen dieser Arbeit konnte gezeigt werden, daß auch seneszierende Rapsblätter noch Aminosäuretransporter mit breiter Substratspezifität besitzen und einen davon möglicherweise sogar verstärkt exprimieren. Die Analyse der Aminosäurekonzentrationen in 
subzellulären Kompartimenten der Blätter ergab, daß Aminosäureüberschüsse in jungen Blättern stark gedüngter Pflanzen zunächst in der Vakuole gespeichert werden. Diese Aminosäuren werden zu einem großen Teil wieder mobilisiert, so daß sich die intrazellulären Aminosäurekonzentrationen alter Blätter von bei $0,5 \mathrm{mM}$ und bei $4 \mathrm{mM}$ Nitrat gewachsenen Pflanzen nicht wesentlich unterschieden. Dennoch haben seneszierende Rapsblätter immer noch vergleichbare Aminosäuregehalte wie Source-Blätter anderer Nutzpflanzen. Zusammen mit den Daten von Lohaus \& Möllers (2000) sowie Lohaus (unpubliziert) zum Aminosäuregehalt des Phloemsaftes zeigte sich, daß Raps Aminosäuren im Phloem stärker gegenüber dem Zytosol der Mesophyllzellen anreichert als andere Kulturpflanzen und insgesamt sehr viel Aminostickstoff transportiert. Der Aminosäuregehalt des Phloemsaftes korreliert positiv mit dem Proteingehalt der Samen (Lohaus \& Möllers 2000). Alle diese Ergebnisse weisen stark darauf hin, daß die ungenügende Remobilisation von Stickstoff aus den seneszierenden Blättern nicht auf einen ineffizienten Transport zurückzuführen ist.

Es stellt sich außerdem die Frage, inwieweit der Stickstofftransport direkt gentechnisch beeinflußbar ist. Angesichts der Vielzahl von Aminosäuretransportern in Arabidopsis ist durchaus denkbar, daß die Pflanze in der Lage ist, die Überexpression oder Ausschaltung einzelner Gene durch eine Gegenregulation von Transportern mit überlappender Substratspezifität auszugleichen. Dabei könnte z.B. die mögliche Funktion von Glutamat als pflanzliches Signalmolekül eine Rolle spielen (Lam et al. 1998, Kang \& Turano 2003). Der polyploide Raps hat in dieser Hinsicht wahrscheinlich noch flexiblere Anpassungsmöglichkeiten als Arabidopsis. Hinzu kommt, daß gerade bei der Beladung des Samens teilweise signifikante Mengen organischen Stickstoffs auch in Form von kurzen Peptiden transportiert werden (Stacey et al. 2002, Miranda et al. 2003), so daß möglicherweise auch der Peptidtransport gentechnisch modifiziert werden müßte. Dennoch gibt es einige Ergebnisse die darauf hindeuten, daß der Stickstofftransport beeinflußbar ist. Die Antisense-Inhibierung von StAAPl in Kartoffeln führte zu einem verringerten Gehalt freier Aminosäuren in den Knollen, obwohl das Gen blattspezifisch exprimiert ist (Koch et al. 2003). Arabidopsis AtAAP6- und AtANT1-Knockout-Mutanten zeigten eine veränderte Zusammensetzung der Aminosäuren im Phloemsaft und im Fall von AtAAP6 auch eine verringerte Konzentration (Hunt et al. 2003 und Hunt, mündliche Mitteilung). Diese Effekte könnten dadurch erklärbar sein, daß die große Anzahl von pflanzlichen Aminosäuretransportern kein Anzeichen von Redundanz ist, sondern jeder Transporter aufgrund seines zeitlich und räumlich genau regulierten Vorkommens spezifische Aufgaben in der Pflanze erfüllt (Fischer et al. 2002, Okumoto et al. 2002). 
Um die Stickstoffeffizienz zu verbessern, wäre aber wahrscheinlich die Überexpression und nicht die Ausschaltung bestimmter Transporter erforderlich. Während man bei einer Antisense-Repression oder Knockout-Mutanten durch die globale Ausschaltung des Gens automatisch auch seine lokale Funktion unterbindet, ist für sinnvolle ÜberexpressionsExperimente zunächst eine genaue, am besten zelluläre Lokalisation der Genexpression notwendig. Solche Informationen sind aber selbst bei der Modellpflanze Arabidopsis bisher nur für wenige Transporter verfügbar. Als geeignetste Kandidaten erscheinen dabei Transporter, die an Transport-,Engpässen“ aktiv sind. Da die Gewebe des Embryos und der Mutterpflanze keine symplastische Verbindung haben, sind an der Samenbeladung beteiligte Transporter (Kwart et al. 1993, Hirner et al. 1998, Tegeder et al. 2000, Miranda et al. 2001, Okumoto et al. 2002) für gentechnische Veränderungen eventuell geeigneter als solche, die im Blatt exprimiert werden. Die Überexpression von VfAAP1 unter Kontrolle eines samenspezifischen Promotors in Vicia faba führte allerdings nur zu geringen Effekten auf den Proteingehalt der Samen (Rolletschek et al. 2003 und H. Weber, mündliche Mitteilung).

Eine Erhöhung der Sink-Stärke für Stickstoff in der Pflanze wird ebenfalls als Ansatz zur Verbesserung der N-Remobilisation diskutiert. Potentiell beeinflußbar wäre sowohl die Expression transienter vegetativer Speicherproteine (Volenec et al. 1996) als auch die NAkkumulation im Samen selber. Es hat sich allerdings herausgestellt, daß die Sinkstärke ein äußerst komplexes Phänomen ist, das sich den meisten Versuchen widersetzt, durch Veränderung der Expression einzelner „Schlüsselenzyme“ oder regulatorischer Gene generelle Veränderungen zu erreichen (Herbers \& Sonnewald 1998). Der direkteste denkbare Weg wäre die samenspezifische Überexpression der Samen-Speicherproteine Napin und Cruciferin (Crouch \& Sussex 1981). Es finden sich aber keine Publikationen über die Effekte solcher Experimente, vermutlich weil damit bisher keine Erfolge erzielt wurden. Dagegen berichteten Kohno-Murase et al. (1994), daß die Antisense-Inhibierung eines Napin-Gens nicht den Gesamtproteingehalt transgener Rapssamen beeinflußte.

Verschiedene Studien deuten darauf hin, daß Kohlenhydrate einen stärkeren Einfluß auf die Akkumulation von Speicherproteinen haben als stickstoffhaltige Verbindungen selber, wobei wahrscheinlich die regulatorische Wirkung von Zuckern (Wobus \& Weber 1999, Coruzzi \& Zhou 2001) eine große Rolle spielt. So wird z.B. der Patatin I-Promotor aus Kartoffelpflanzen von Zuckern induziert (Martin et al. 1997). Von Prolin abgesehen, das als Osmoregulator Stress signalisiert, wirkten dagegen Aminosäuren nur bei niedrigen Zuckerkonzentrationen induzierend (Hellman et al. 2000). Antisense-Repression der ADP-GlukosePyrophosphorylase in den Samen von Vicia narbonensis führte zu einer Erhöhung des 
Protein- und Gesamtstickstoffgehaltes ohne daß der Kohlenstoffgehalt der Samen sich veränderte. Der Effekt war wahrscheinlich auf eine verzögerte Zelldifferenzierung und eine dadurch verlängerte Samen-Beladungsperiode zurückzuführen (Weber et al. 2000). In vielen Pflanzen sind Kohlenhydrat- und Proteingehalt der Samen negativ miteinander korreliert (Perez et al. 1993, Boutin et al. 1998, Lohaus \& Möllers 2000). Dieser Zusammenhang ist auch aus der Rapszüchtung seit langem bekannt (Grami et al. 1977), wo ein Hauptziel der Züchtung darin liegt, sowohl den Öl- als auch den Proteingehalt der Samen zu maximieren. Letzten Endes ist durch eine Erhöhung des Speicherproteingehaltes von Rapssamen noch keine Verbesserung der N-Effizienz erreicht. Möglicherweise infolge des inversen Zusammenhangs zwischen Kohlenstoff- und Stickstoff-Akkumulation führt eine Erhöhung des Proteingehaltes der Samen meistens zu einer Verringerung der Samenmenge und damit des N-Ertrags (McNeal et al. 1972, Clements 1973, Sattelmacher et al. 1994, Kessel 2000).

Möglicherweise ist eine Verzögerung der Blattseneszenz der am ehesten erfolgversprechende Weg für eine gentechnische Verbesserung der N-Effizienz. Sogenannte „stay green“ Mutanten werden für unterschiedliche Nutzpflanzen als eine Möglichkeit diskutiert, Erträge signifikant zu steigern (z.B. Cha et al. 2002, Murchie et al. 2002, Spano et al. 2003) und sind teilweise bereits bis zur Patentanmeldung gelangt (Dunwell 2000). Gerade bei Winterraps mit seinem sehr frühen Blattabwurf könnte eine Verzögerung der Blattseneszenz bis zum Einsetzen der Samenreifung sehr deutliche Effekte erzielen. Auch die Blattseneszenz ist ein komplexes Phänomen, das bisher erst in Ansätzen verstanden wird (Lim et al. 2003). Dennoch gibt es erste Ansätze, Seneszenz gezielt zu verzögern. Gan \& Amasino (1995) nutzten beispielsweise die seneszenzverzögernde Wirkung von Cytokininen, indem sie in transgenen Tabakpflanzen ein Schlüsselenzym der Cytokinin-Biosynthese unter der Kontrolle des seneszenzspezifischen SAG12-Promotors exprimierten. Auch die Expression des Homeobox-Gens knottedl unter Kontrolle des SAG12-Promotors führt in Tabak zu einer Verzögerung der Blattseneszenz (Ori et al. 1999). Der Promotor des entsprechenden Gens ist auch aus Raps kloniert worden (Noh \& Amasino 1999a) und stünde für entsprechende Experimente zur Verfügung. 


\section{Zusammenfassung}

In der vorliegenden Arbeit wurden Untersuchungen zur Phloembeladung von Aminosäuren in Raps (Brassica napus L.) durchgeführt. Es sollte vor allem geklärt werden, ob der Phloemtransport für die Remobilisation von organischem Stickstoff aus seneszierenden Rapsblättern limitierend ist und eine Ursache für die schlechte Stickstoffeffizienz dieser Kulturpflanze darstellt. Dazu wurden zum einen die Aminosäurekonzentrationen in verschiedenen, an der Phloembeladung beteiligten subzellulären Kompartimenten des Blattes bestimmt. Zum anderen wurden möglicherweise an der Phloembeladung beteiligte Aminosäuretransporter identifiziert und mit molekularbiologischen Methoden charakterisiert. Beide Aspekte der Phloembeladung wurden besonders unter dem Gesichtspunkt möglicher Veränderungen im Verlauf der Blattentwicklung untersucht.

Daneben wurde in Zusammenarbeit mit dem Institut für Pflanzenbau und Pflanzenzüchtung der Universität Göttingen (Prof. Becker) eine Reihe doppelt haploider Rapslinien (DH-Linien) aus einer Kreuzung Bristol x Mansholts in mehrjährigen Feldversuchen physiologisch charakterisiert, um die Variabilität der Stickstoffnutzung in Raps zu untersuchen.

\section{Variabilität der Stickstoffnutzung von DH-Linien mit gemeinsamem genetischen Ursprung}

1. Die 45 untersuchten DH-Linien, die einen gemeinsamen genetischen Ursprung hatten, wiesen hinsichtlich ihrer Nitratreduktaseaktivität, ihres Aminosäuregehaltes in den Blättern sowie ihres Proteingehaltes im Samen eine große Variabilität auf. Die Variationsspanne war vergleichbar mit der, die in einem früheren Versuch mit nichtverwandten, genetisch stärker divergierender Linien beobachtet wurde (Zhou 2000). Die meisten DH-Linien waren bezüglich der Stickstoffakkumulation im Samen entweder sowohl N-effizient als auch N-responsiv oder keines von beidem. Sie zeigten mit und ohne N-Düngung eine konsistente Stickstoffnutzung. Es scheint, daß die Stickstoffeffizienz bei Raps ein stark genetisch determiniertes Merkmal ist, dessen hohe Variabilität noch ein großes Potential für züchterische Verbesserung aufweist. 


\section{Aminosäurekonzentrationen in subzellulären Kompartimenten von Rapsblättern}

1. Aminosäuren können in Mesophyllzellen von Rapsblättern Konzentrationen bis zu $200 \mathrm{mM}$ im Zytosol und in den Chloroplasten und bis $\mathrm{zu} 60 \mathrm{mM}$ in der Vakuole erreichen. Überschüssige Aminosäuren bei hoher Stickstoff-Versorgung werden vor allem in der Vakuole gespeichert. In allen Kompartimenten und bei hoher und niedriger Stickstoff-Versorgung sinken die Konzentrationen mit dem Blattalter. Alte Blätter bei $4 \mathrm{mM}$ und bei $0,5 \mathrm{mM}$ Nitrat angezogener Pflanzen unterscheiden sich nicht mehr hinsichtlich ihres Aminosäuregehaltes. Im Vergleich mit anderen Nutzpflanzen erhalten sie aber noch signifikante Mengen von Amino-Stickstoff.

2. Die apoplastischen Aminosäurekonzentrationen sinken ebenfalls mit dem Blattalter und sind bei hoher Stickstoff-Versorgung erhöht. Die meisten Aminosäuren liegen in Konzentrationen zwischen $<0,1 \mathrm{mM}$ und $2 \mathrm{mM}$ vor, einzelne erreichen bis über 10 mM. Aus bereits vorliegenden Daten zu den Konzentrationen im Phloemsaft ergibt sich, daß Aminosäuren bei der Phloembeladung in Raps etwa 1,5-2fach gegenüber dem Zytosol der Mesophyllzellen und etwa 20-60fach gegenüber dem Apoplasten angereichert werden.

\section{Charakterisierung von Aminosäuretransportern}

1. Aus Winterraps der Sorte Lirajet konnten zwei Aminosäuretransporter, BnAAP1 und BnAAP6, isoliert werden. Sie weisen eine hohe Homologie zu Aminosäuretransportern mit breiter Substratspezifität aus Arabidopsis auf. Von einem dritten Transporter, BnAAP2, wurde nur eine unvollständige cDNA erhalten.

2. BnAAP1 und BnAAP6 wurden heterolog in Xenopus-Oozyten exprimiert und elektrophysiologisch hinsichtlich ihrer Substratspezifität charakterisiert. Ähnlich den verwandten Poteinen aus Arabidopsis transportieren sie alle 18 getesteten proteinogenen Aminosäuren, wobei die Affinität für basische Aminosäuren am geringsten war. BnAAP6 besitzt eine höhere Affinität für Aspartat als BnAAP1. Im Gegensatz zu AtAAP1 aus Arabidopsis transportiert BnAAP1 auch Tryptophan effizient. 
3. Beide Transporter erzeugten auch bei $0,1 \mathrm{mM}$ Substratkonzentrationen deutliche Depolarisationen der Oozyten-Membran. Dies entspricht apoplastischen Konzentrationen seltenerer Aminosäuren und läßt den Schluß zu, daß die Transporter der AAP-Familie alleine für die Phloembeladung aller Aminosäuren mit Ausnahme der basischen Spezies verantwortlich sein könnten.

4. Eine in Arabidopsis transformierte GUS-Reportergenfusion des BnAAP6-Promotors zeigten, daß das Gen in den Blattadern von Source-Blättern exprimiert wird. Die GUS-Färbung trat sowohl in den blind endenden kleinsten Gefäßen auf als auch in den Hauptadern, nicht jedoch in der Mittelrippe.

5. Die mRNAs von BnAAP1 und BnAAP6 wurden auch noch in seneszierenden Blättern gefunden. Die homologen Arabidopsis-Proteine stellen in Blättern nicht die hauptsächlichen Aminosäuretransporter dar. Es ist deshalb anzunehmen, daß seneszierende Rapsblätter auch noch weitere Aminosäuretransporter besitzen.

Insgesamt weisen die biochemischen und molekularbiologischen Untersuchungen der Phloembeladung mit Aminosäuren in alten Rapsblättern darauf hin, daß nicht Transportvorgänge die Remobilisation von organischem Stickstoff aus den Blättern limitieren. Für eine gentechnische Verbesserung der Stickstoffeffizienz sollten deshalb andere Ansatzpunkte, wie z.B. eine Verzögerung der Blattseneszenz, gewählt werden. 


\section{Abkürzungsverzeichnis}

A

AAP

Amp

APS

ATP

BnAAP1

BnAAP2

BnAAP6

bp

BSA

$\mathrm{C}$

cDNA

cpm

cRNA

CTAB

DMF

DMSO

DNA

dNTPs

DTT

ECL

EDTA

EST

FAD

FG

g

G

GABA $\gamma$-Aminobuttersäure

GAP-DH Glycerinaldehydphosphat-Dehydrogenase

GFP Grün Fluoreszierendes Protein

GOGAT Glutamat-Synthase

GS

Adenin

Ampicillin

Ammoniumperoxodisulfat

Adenosintriphosphat

Brassica napus Aminosäuretransporter 1

Brassica napus Aminosäuretransporter 2

Brassica napus Aminosäuretransporter 3

Basenpaar

Rinderserumalbumin

Cytosin, Kohlenstoff

„copy-DNA“

„copy-RNA“

Hexadecyltrimethylammoniumbromid

Dimethylformamid

Dimethylsulfoxid

Desoxyribonukleinsäure

Dithiothreitol

„Enhanced Chemiluminescence”

Ethylendiamintetraacetat

„Expressed Sequence Tag”

Flavin-Adenin-Dinukleotid

Frischgewicht

Erdbeschleunigung

Guanin

Glutamin-Synthetase
Aminosäuretransporter („Amino Acid Permease“)

radioaktive Zerfälle pro Minute (counts per minute)

Desoxynukleotidtriphosphat-Gemisch (dATP, dCTP, dGTP, dTTP) 


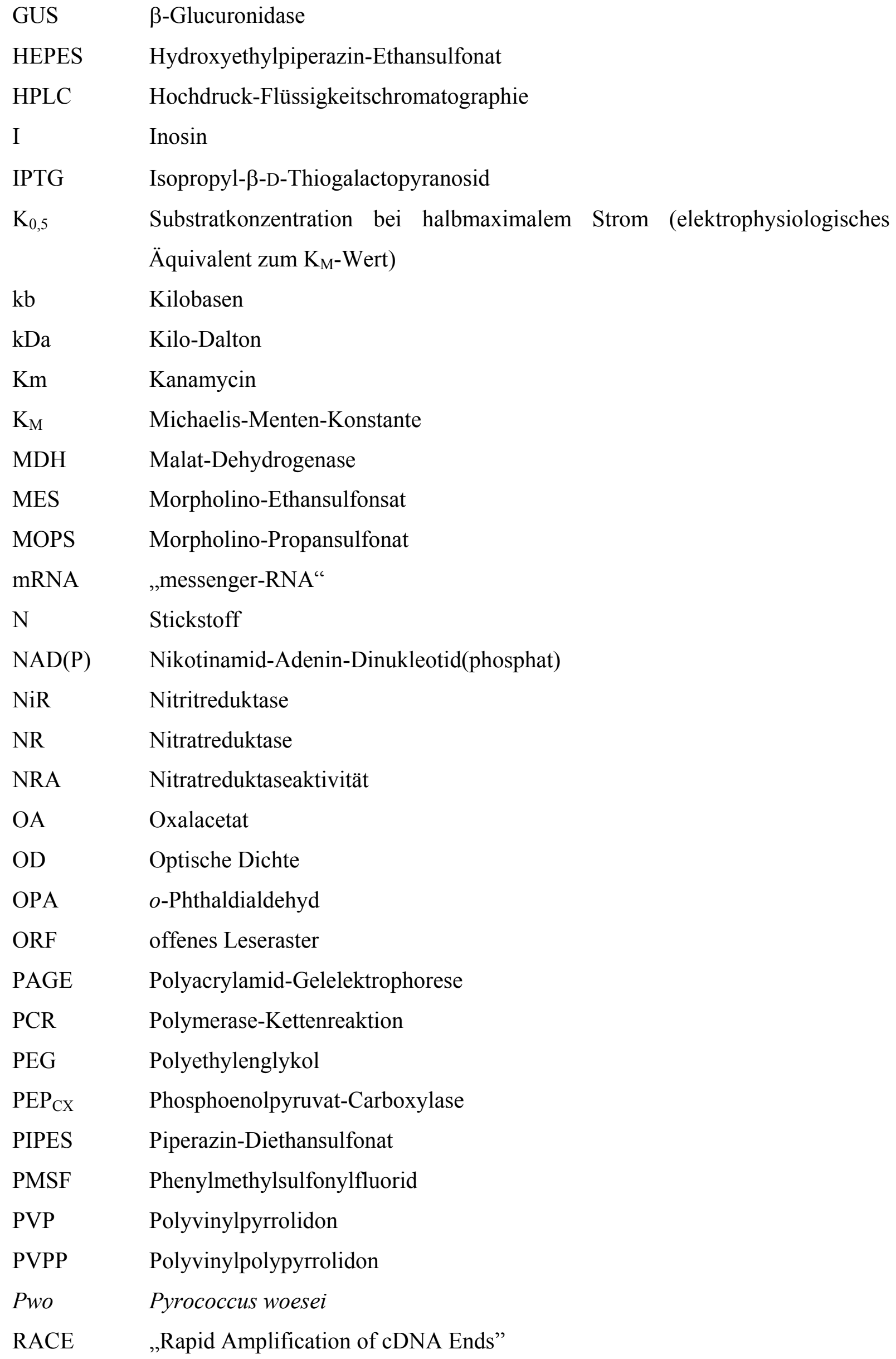


Rif Rifampicin

RNA Ribonukleinsäure

RT Reverse Transcriptase, Raumtemperatur

RubisCO Ribulosebisphosphat-Carboxylase-Oxygenase

SDS Natrium-Dodecylsulfat

T Thymin

Taq Thermus aquaticus

TdT Terminale Desoxynukleotidyl-Transferase

TEMED N,N,N',N'-Tetramethylendiamin

TG Trockengewicht

$\mathrm{T}_{\mathrm{m}} \quad$ Schmelztemperatur

Tris Trishydroxymethylaminomethan

Tth Thermus thermophilus

U Enzym-Einheit

Upm Umdrehungen pro Minute

Vol. Volumen

X-Gal 5-Brom-4-Chlor-3-Indolyl- $\beta$-D-Galactopyranosid

X-Gluc 5-Brom-4-Chlor-3-Indolyl- $\beta$-D-Glucuronat 


\section{Literaturverzeichnis}

Altschul SF, Gish W, Miller W, Myers EW \& Lipman DJ (1990) Basic local alignment search tool. J. Mol. Biol. 215: 403-410

Andrews M (1986) The partitioning of nitrate assimilation between root and shoot of higher plants. Plant Cell Environ. 9: 511-519

Aniol H (1994) Stickstoffverteilung in erntereifen Rapsbeständen. Raps 3: 144-146

Arnon DI (1949) Copper enzymes in isolated chloroplasts. Polyphenoloxidase in Beta vulgaris. Plant Physiol. 24: 1-15

Barker L, Kühn C, Weise A, Schulz A, Gebhardt C, Hirner B, Hellmann H, SChulze W, Ward JM \& Frommer WB (2000) SUT2, a putative sucrose sensor in sieve elements. Plant Cell 12: 1153-1164

Barszczak Z, Barszczak T \& Foy CD (1993) Effect of moisture, nitrogen rates, and soil acidity on seed yield and chemical composition of winter oilseed rape cultivars. J. Plant Nutr. 16: 85-96

Barth I, Meyer S \& Sauer N (2003) PmSUC3: characterization of a SUT2/SUC3-type sucrose transporter from Plantago major. Plant Cell 15: 1375-1385

Becker TB, Foyer C \& Caboche M (1992) Light-regulated expression of nitrate-reductase and nitrite-reductase genes in tomato and in the phytochrome-deficient aurea mutant of tomato. Planta 188: 39-47

Bennett MJ, Marchant A, Green HG, May ST, Ward SP, Millner PA, Walker AR, Schultz B \& Feldmann KA (1996) Arabidopsis AUX1 gene: a permease-like regulator of root gravitropism. Science 273: 948-950

Bhalerao R, Keskitalo J, Sterky F, Erlandsson R, Björbacka H, Birve SJ, Karlsson J, Gardeström P, Gustafsson P, Lunderberg J \& Jansson S (2003) Gene expression in autumn leaves. Plant Physiol. 131: 430-442

Bick JA, Neelam A, Hall JL \& Williams LE (1998) Amino acid carriers of Ricinus communis expressed during seedling development: Molecular cloning and expression analysis of two putative amino acid transporters, RcAAP1 and RcAAP2. Plant Mol. Biol. 36: 377-385

Birnboim HC \& Doly J (1979) A rapid alkaline lysis procedure for screening recombinant plasmid DNA. Nucl. Acids Res. 7: 1513-1522

Blum H, Beier H \& Gross HJ (1987) Improved silver staining of plant proteins, RNA and DNA in polyacrylamide gels. Electrophoresis 8: 93-99 
Boorer KJ \& Fischer W-N (1997) Specificity and stoichiometry of the Arabidopsis $\mathrm{H}^{+} /$amino acid transporter AAP5. J. Biol. Chem. 272: 13040-13046

Boorer KJ, Frommer WB, Bush DR, Kreman M, Loo DDF \& Wright EM (1996) Kinetics and specificity of a $\mathrm{H}^{+} /$amino acid transporter from Arabidopsis thaliana. J. Biol. Chem. 271: 2213-2220

Boutin JP, Colonna P, Duc G, Gueguen J, Moussy F, Rochat C, Roux Y \& Wuilleme S (1998) Isolation and characterization of new wrinkled-seeded mutants of pea. In: Proceedings of the $3^{\text {rd }}$ European Conference on Grain Legumes, 1998, Valladolid, Spain. European Association for Grain Legume Research, Paris: 196-197

Boyle MDP \& Reis KJ (1987) Bacterial Fc receptors. Biotechnology 5: 697-703

Bradford MM (1976) A rapid and sensitive method for the quantitation of microgram quantities of protein utilizing the priciple of protein-dye binding. Anal. Biochem. 72: $248-254$

Buchanan BB, Gruissem W \& Jones RL (Hrsg.) (2000) Biochemistry \& molecular biology of plants. American Society of Plant Physiologists, Rockville, Maryland

Buchanan-Wollaston V (1997) The molecular biology of leaf senescence. J. Exp. Bot. 48: 181-199

Bürkle L, Hibberd JM, Quick WPK, Kühn C, Hirner B \& Frommer WB (1998) The $\mathrm{H}^{+}$sucrose cotransporter NtSUT1 is essential for sugar export from tobacco leaves. Plant Physiol. 118: 59-68

Büttner M \& Sauer N (2000) Monosaccharide transporters in plants: Structure, function and physiology. Biochim. Biophys. Acta 1465: 263-274

Bullock WO, Fernandez JM \& Short JM (1987) XL1-Blue: A high efficiency plasmid transforming recA E. coli strain with $\beta$-galactosidase selection. Bio Techniques 5: 376378

Cha K-W, Lee Y-J, Koh H-J, Lee B-M, Nam Y-W \& Paek N-C (2002) Isolation, characterization, and mapping of the stay green mutant in rice. Theor. Appl. Genet. 104: 526-532

Chaillou H, Morot-Gaudry FJ, Salsac L, Lesaint C \& Jolivet E (1986) Compared effects of $\mathrm{NO}_{3}{ }^{-}$and $\mathrm{NH}_{4}{ }^{+}$on growth and metabolism of french bean. Physiol. Vég. 24: 679687

Champigny MH (1995) Integration of photosynthetic carbon and nitrogen metabolism in higher plants. Photosyn. Res. 46: 117-127 
Chang H-C \& Bush DR (1997) Topology of NAT2, a prototypical example of a new family of amino acid transporters. J. Biol. Chem. 272: 30552-30557

Chapin FS, Moilanen L \& Kielland K (1993) Preferential use of organic nitrogen for growth by a non-mycorrhizal arctic sedge. Nature 361: 150-152

Charest P, Iyer VN \& Miki BL (1989) Virulence of Agrobacterium tumefaciens strains with Brassica napus and Brassica juncea. Plant Cell Reports 8: 303-306

Chen L \& Bush DR (1997) LHT1, a lysine- and histidine-specific amino acid transporter in Arabidopsis. Plant Physiol. 115: 1127-1134

Chen L, Ortiz-Lopez A, Jung A \& Bush DR (2001) ANT1, an aromatic and neutral amino acid transporter in Arabidopsis. Plant Physiol. 125: 1813-1820

Clements RJ (1973) Selection for crude protein content in Phalaris tuberosa L. Aust. J. Agric. Res. 24: 21-58

Clough SJ \& Bent AF (1998) Floral dip: A simplified method for Agrobacterium-mediated transformation of Arabidopsis thaliana. Plant J. 16: 75-743

Cooper JDH, Ogden G, McIntosh J \& Turnell DC (1984) The stability of the $o$ phthalaldehyde/2-mercaptoethanol derivatives of amino acids: An investigation using high-pressure liquid chromatography with a precolumn derivatization technique. Anal. Biochem. 142: 98-102

Coruzzi GM \& Zhou L (2001) Carbon and nitrogen sensing and signaling in plants: emerging 'matrix effects'. Curr. Op. Plant Biol. 4: 247-253

Crawford TW, Rending VV \& Broadbent FE (1982) Sources, fluxes and sinks of nitrogen during early reproductive growth of maize (Zea mays L.). Plant Physiol. 70: 16541660

Crouch ML \& Sussex IM (1981) Development and storage protein synthesis in Brassica napus L. embryos in vivo and in vitro. Planta 153: 64-74

Dejoux J-F, Recous S \& Meynard J-M (1999) Decomposition of ${ }^{15} \mathrm{~N}$-labelled rapeseed leaves, frozen in winter: Evaluation of $\mathrm{N}$ mineralization and rape $\mathrm{N}$-uptake in spring under field and laboratory conditions. Proceedings, $10^{\text {th }}$ International Rapeseed Congress, Canberra. http://www.regional.org.au/au/gcirc/2/469.htm

Dejoux JF, Recous S, Meynard JM, Trinsoutrot I \& Leterme P (2000) The fate of nitrogen from winter-frozen rapeseed leaves: mineralization, fluxes to the environment and uptake by rapeseed crop in spring. Plant Soil 218: 257-272

Delauney AJ \& Verma DPS (1993) Proline biosynthesis and osmoregulation in plants. Plant J. 4: $215-223$ 
Delrot S (1989) Loading of photoassimilates. In: Baker DA \& Milburn JA (Hrsg.) Transport of photoassimilates. Longman Scientific and Technical, Harlow: 167-205

Delrot S, Atanassova R \& Maurousset L (2000) Regulation of sugar, amino acid and peptide plant membrane transporters. Biochim. Biophys. Acta 1465: 281-306

Desimone M, Catoni E, Ludewig U, Hilpert M, Scneider A, Kunze R, Tegeder M, Frommer WB \& Schumacher K (2002) A novel superfamily of transporters for allantoin and other oxo derivatives of nitrogen heterocyclic compounds in Arabidopsis. Plant Cell 14: 847-856

Duncan RR \& Baligar VC (1990) Genetics, breeding and physiological mechanism of nutrient uptake and use efficiency: An overview. In: Baligar VC, Duncan RR (Hrsg.) Crops as enhancers of nutrient use. Academic Press, San Diego

Dunwell JM (2000) Transgenic approaches to crop improvement. J. Exp. Bot. 51: 487-496

Durka W, Schulze E-D, Gebauer G \& Voerkelius S (1994) Effects of forest decline on uptake and leaching of deposited nitrate determined from ${ }^{15} \mathrm{~N}$ and ${ }^{18} \mathrm{O}$ measurements. Nature 372: 765-767

Ehlers K, Knoblauch M \& van Bel AJE (2000) Ultrastructural features of well-preserved and injured sieve elements: Minute clamps keep the phloem transport conduits free for mass flow. Protoplasma 214: 80-92

Ellenberg H (1977) Stickstoff als Standortfaktor, insbesondere für mitteleuropäische Pflanzengesellschaften. Oecol. Plant. 12: 1-22

Ellenberg H (1986) Veränderungen der Flora Mitteleuropas unter dem Einfluß von Düngung und Immissionen. Schweiz. Z. Forstw. 136: 19-36

Ellison AM \& Gotelli NJ (2002) Nitrogen availability alters the expression of carnivory in the northern pitcher plant, Sarracenia purpurea. Proc. Natl. Acad. Sci. USA 99: 44094412

Emanuelsson O, Nielsen H, Brunak S \& von Heijne G (2000) Predicting subcellular localization of proteins based on their N-terminal amino acid sequence. J. Mol. Biol. 300: $1005-1016$

Engels C \& Marschner H (1993) Influence of the form of nitrogen supply on root uptake and translocation of cations in the xylem exudate of maize (Zea mays L.). J. Exp. Bot. 44: 1695-1701 
Feller U \& Keist M (1986) Senescence and nitrogen metabolism in annual plants. In: Lambers H, Neeterson JJ \& Stulen I (Hrsg.) Fundamental, ecological and agricultural aspects of nitrogen metabolism in higher plants. Martinus Nijhoff Publishers, Dordrecht: $219-234$

Fernandez DE, Turner FR, Crouch M (1991) In situ localization of strorage protein mRNAs in developing meristems of Brassica napus embryos. Development 111: 299313

Finlayson AJ (1976) The seed protein contents of some Cruciferae. In: Vaughn JG, McLeod AJ \& Jones BMG (Hrsg.) The biology and chemistry of the Cruciferae. Academic Press, New York: 279-306

Fischer W-N, Kwart M, Hummel S \& Frommer WB (1995) Substrate specificity and expression profile of amino acid transporters (AAPs) in Arabidopsis. J. Biol. Chem. 270: $16315-16320$

Fischer W-N, André B, Rentsch D, Krolkiewicz S, Tegeder M, Breitkreuz K \& Frommer WB (1998) Amino acid transport in plants. Trends Plant Sci. 3: 188-195

Fischer W-N, Loo DDF, Koch W, Ludewig U, Boorer KJ, Tegeder M, Rentsch D, Wright EM \& Frommer WB (2002) Low and high affinity amino acid $\mathrm{H}^{+}$cotransporters for cellular import of neutral and charged amino acids. Plant J. 29: 717731

Fisher DB (1990) Measurement of phloem transport rates by an indicator-dilution technique. Plant Physiol. 94: 455-462

Fisher DB \& Frame JM (1984) A guide to the use of the exuding-stylet technique in phloem physiology. Planta 161: 385-393

Foyer CH \& Ferrario S (1994) Modulation of carbon and nitrogen metabolism in transgenic plants with a view to improved biomass production. Biochem. Biophys. Res. Com. 22: 908-915

Frohman MA, Dush MK \& Martin GR (1988) Rapid production of full-length cDNAs from rare transcripts: Amplification using a single gene-specific oligonucleotide primer. Proc. Natl. Acad. Sci. USA 85: 8998-9002

Frommer WB \& Ninnemann O (1995) Heterologous expression of genes in bacterial, fungal, animal and plant cells. Annu. Rev. Plant Physiol. Plant Mol. Biol. 46: 419-444

Frommer WB, Hummel S \& Riesmeier JW (1993) Expression cloning in yeast of a cDNA encoding a broad specificity amino acid permease from Arabidopsis thaliana. Proc. Natl. Acad. Sci. USA 90: 5944-5948 
Frommer WB, Hummel S \& Rentsch D (1994a) Cloning of an Arabidopsis histidine transporting protein related to nitrate and peptide transporters. FEBS Lett. 347: 185189

Frommer WB, Kwart M, Hirner B, Fischer WN, Hummel S \& Ninnemann O (1994b) Transporters for nitrogenous compounds in plants. Plant Mol. Biol. 26: 1651-1670

Frommer WB, Hummel S, Unseld M \& Ninnemann O (1995) Seed and vascular expression of a high-affinity transporter for cationic amino acids in Arabidopsis. Proc. Natl. Acad. Sci. USA 92: 12036-12040

Fulda M, Heinz E \& Wolter FP (1997) Brassica napus cDNAs encoding fatty acyl-CoA synthetase. Plant Mol. Biol. 33: 911-922

Gahrtz M, Stolz J \& Sauer N (1994) A phloem-specific sucrose- $\mathrm{H}^{+}$symporter from Plantago major L. supports the model of apoplastic phloem loading. Plant J. 6: 697706

Gan S \& Amasino RM (1995) Inhibition of leaf senescence by autoregulated production of cytokinin. Science 270: 1986-1988

Gan S \& Amasino RM (1997) Making sense of senescence. Plant Physiol. 113: 313-319

Gao Z, Maurousset L, Lemoine R, Yoo S-D, van Nocker S \& Loescher W (2003) Cloning, expression, and characterization of sorbitol transporters from developing sour cherry fruit and leaf sink tissues. Plant Physiol. 131: 1566-1575

Gerath H \& Balko C (1995) The influence of genotype and donor plant on the nitrogen efficiency of DH-lines of winter rape. Proc. Internl. Rapeseed Congress 9: 813-815

Gerath H \& Schweiger W (1991) Improvement of the use of nutrients in winter rape - a strategy of economically and ecologically responsible fertilizing. Proc. Internl. Rapeseed Congress 8: 1197-1201

Gerhardt R \& Heldt HW (1984) Measurement of subcellular metabolite levels in leaves by fractionation of freeze-stopped material in nonaqueous media. Plant Physiol. 75: 542547

Gilstring CF \& Ljungdahl PO (2000) A method for determining the in vivo topology of yeast polytopic membrane proteins demonstrates that Gaplp fully integrates into the membrane independently of Shr3p. J. Biol. Chem. 275: 31488-31495

Givan CV (1979) Metabolic detoxification of ammonia in tissues of higher plants. Phytochemistry 18: 375-382 
Glass AD, Britto DT, Kaiser BN, Kinghorn JR, Kronzucker HJ, Kumar A, Okamoto M, Rawat S, Siddiqi MY, Unkles SE \& Vidmar JJ (2002) The regulation of nitrate and ammonium transport systems in plants. J. Exp. Bot. 53: 855-864

Gottwald JR, Krysan PJ, Young JC, Evert RF \& Sussman MR (2000) Genetic evidence for the in planta role of phloem specific plasma membrane sucrose transporters. Proc. Natl. Acad. Sci. USA 97: 13979-13984

Grallath S, Weimar T, Meyer A \& Rentsch D (2003) Transporters for compatible solutes in plants. Abstract, Phloem 2003 - International Conference on Phloem Transport, Bayreuth

Grami B \& LaCroix LJ (1977) Cultivar variation in total nitrogen uptake in rape. Can. J. Plant Sci. 57: 619-624

Grami B, Baker RJ \& Stefansson BR (1977) Genetics of protein and oil content in summer rape: Heritability, number of effective factors, and correlations. Can. J. Plant Sci. 57: 937-943

Granli T \& Bøckman OC (1994) Nitrous oxide from agriculture. Norw. J. Agricul. Sci. Supplement No. 12

Gunning BES \& Pate JS (1969) “Transfer cells”. Plant cells with wall ingrowths, specialized in relation to short distance transport of solutes - their occurrence, structure, and development. Protoplasma 68: 107-133

Hanahan D (1983) Studies on transformation of Escherichia coli with plasmids. J. Mol. Biol. 166: $557-580$

Haritatos E, Medville R \& Turgeon R (2000) Minor vein structure and sugar transport in Arabidopsis thaliana. Planta 211: 105-111

Heinemeyer T, Wingender E, Reuter I, Hermjakob H, Kel AE, Kel OV, Ignatieva EV, Ananko EA, Podkolodnaya OA, Kolpakov FA, Podkolodny NL \& Kolchanov NA (1998) Databases on transcriptional regulation: TRANSFAC, TRRD, and COMPEL. Nucl. Acids Res. 26: 364-370

Hellman H, Funck D, Rentsch D \& Frommer WB (2000) Hypersensitivity of an Arabidopsis sugar signalling mutant toward exogenous proline application. Plant Physiol. 123: 779-789

Herbers K \& Sonnewald U (1998) Molecular determinants of sink strength. Curr. Op. Plant Biol. 1: 207-216 
Hirner B, Fischer WN, Rentsch D, Kwart M \& Frommer WB (1998) Developmental control of $\mathrm{H}^{+}$/amino acid permease gene expression during seed development in Arabidopsis. Plant J. 14: 535-544

Holthaus U \& Schmitz K (1991) Distribution and immunolocalization of stachyose synthase in Cucumis melo L. Planta 185: 479-486

Hood EE Gelvin SB, Melchers LS \& Hoekema A (1993) New Agrobacterium helper plasmids for gene transfer to plants. Transgenic Res. 2: 208-218

Housley TL, Peterson DM \& Schrader LE (1979) Long distance translocation of sucrose, serine, leucine, lysine, and $\mathrm{CO}_{2}$ assimilates. I. Soybean. Plant Physiol. 59: 217-220

Hsu L-C, Chiou T-J, Chen L \& Bush DR (1993) Cloning a plant amino acid transporter by functional complementation of a yeast amino acid transport mutant. Proc. Natl. Acad. Sci. USA 90: 7441-7445

Hu CY, Chee PP, Chesney RH, Zhou JH, Miller PD \& O'Brien WT (1990) Intrinsic GUS-like activities in seed plants. Plant Cell Rep. 9: 1-5

Hunt E, Newbury HJ, Bale J, Barrett D, Zhu X \& Pritchard J (2003) Investigating plantaphid interactions by manipulating aphid diet in planta. Abstract, Phloem 2003 International Conference on Phloem Transport, Bayreuth

Imlau A, Truernit E, Sauer N (1999) Cell-to-cell and long-distance trafficking of the green fluorescent protein in the phloem and symplasmic unloading of the protein into sink tissues. Plant Cell 11: 309-322

Inoue H, Nojima H \& Okayama H (1990) High efficiency transformation of Escherichia coli with plasmids. Gene 96: 23-28

Jefferson RA, Kavanagh TA \& Bevan MW (1987) GUS fusions: $\beta$-glucuronidase as a sensitive and versatile gene fusion marker in higher plants. EMBO J. 6: 3901-3908

Jensen LS, Mueller T, Magid J \& Nielsen NE (1997) Temporal variation of C and N mineralization, microbial biomass and extractable organic pools in soil after oilseed rape straw incorporation in the field. Soil Biol. Biochem. 29: 1043-1055

Kang J \& Turano FJ (2003) The putative glutamate receptor 1.1 (AtGLR1.1) functions as a regulator of carbon and nitrogen metabolism in Arabidopsis thaliana. Proc. Natl. Acad. Sci. USA 100: 6872-6877

Kassner N (2003) Vergleich des Aminosäuretransportes und der Stickstoff-Effizienz bei Arabidopsis und Raps. Diplomarbeit, Universität Göttingen 
Kavi Kishor PB, Hong Z, Miao GH, Hu CA \& Verma DPS (1995) Overexpression of $\Delta^{1}$ pyrroline-5-carboxylate synthetase increases proline production and confers osmotolerance in transgenic plants. Plant Physiol. 108: 1387-1394

Kessel B (2000) Genetische Variation und Vererbung der Stickstoff-Effizienz bei Winterraps (Brassica napus L.). Dissertation, Universität Göttingen

King GJ, Bennett MJ, May S, McEwan G, Ryder CD, Sarjeant A, Smith LB \& Teakle GR (1999) Comparing genetic and physical organisation of gene families affecting plant development within Brassica and Arabidopsis. Proceedings, $10^{\text {th }}$ International Rapeseed Congress, Canberra. http://www.regional.org.au/au/gcirc/4/ 468.htm

Kleiner D (1981) The transport of $\mathrm{NH}_{3}$ and $\mathrm{NH}_{4}{ }^{+}$across biological membranes. Biochim. Biophys. Acta 639: 41-52

Knop C (1998) Untersuchungen zum Zucker- und Aminosäuretransport bei der symplastischen Phloembeladung. Diplomarbeit, Universität Göttingen

Knop C (2001) Zur Bedeutung von Saccharose-Transportern in Pflanzen mit offener Phloemanatomie. Dissertation, Universität Göttingen

Knop C, Voitsekhovskaja O \& Lohaus G (2001) Sucrose transporters in two members of the Scrophulariaceae with different types of transport sugar. Planta 213: 80-91

Koch W, Kwart M, Laubner M, Heineke D, Stransky H, Frommer WB \& Tegeder M (2003) Reduced amino acid content in transgenic potato tubers due to antisense inhibition of the leaf $\mathrm{H}^{+}$/amino acid symporter StAAP1. Plant J. 33: 211-220

Kohno-Murase J, Murase M, Ichikawa H \& Imamura J (1994) Effects of an antisense napin gene on seed storage compounds in transgenic Brassica napus seeds. Plant Mol. Biol. 26: 1115-1124

Kowdley GC, Ackerman SJ, John E, Jones LR \& Moorman JR (1994) Hyperpolarizationactivated chloride currents in Xenopus oocytes. J. Gen. Physiol. 103: 217-230

Kühn C, Quick WP, Schulz A, Riesmeier JW, Sonnewald U \& Frommer WB (1996) Companion cell-specific inhibition of the potato sucrose transporter SUT1. Plant Cell Env. 19: 1115-1123

Kühn C, Franceschi VR, Schulz A, Lemoine R \& Frommer WB (1997) Macromolecular trafficking indicated by localization and turnover of sucrose transporters in enucleate sieve elements. Science 275: 1298-1300

Kullmann A (1987) Quantitative Untersuchungen zur Stickstofftranslokation in vegetativen und generativen Teilen der Rapspflanze (Brassica napus) als Grundlage der Ertragsbildung. Dissertation, Universität Kiel 
Kwart M, Hirner B, Hummel S \& Frommer WB (1993) Differential expression of two related amino acid transporters with differing substrate specificity in Arabidopsis thaliana. Plant J. 4: 993-1002

Kyte J \& Doolittle RF (1982) A simple method for displaying the hydropathic character of a protein. J. Mol. Biol. 157: 105-142

Laemmli UK (1970) Cleavage of structural proteins during the assembly of the head of bacteriophage T4. Nature 227: 680-685

Lagercrantz U (1998) Comparative mapping between Arabidopsis thaliana and Brassica nigra indicates that Brassica genomes have evolved through extensive genome replication accompanied by chromosome fusions and frequent rearrangements. Genetics 150: 1217-1228

Lainé P, Ourry A, Macduff JH, Boucaud J \& Salette J (1993) Kinetic parameters of nitrate uptake by different catch crop species: Effects of low temperatures or previous nitrate starvation. Physiol. Plant. 88: 85-92

Lainé P, Ourry A \& Boucaud J (1995) Shoot control of nitrate uptake rates by roots of Brassica napus L.: Effects of localized nitrate supply. Planta 196: 77-83

Lalanne E, Mathieu C, Roche O, Vedel F \& De Pape R (1997) Structure and specific expression of a Nicotiana sylvestris putative amino-acid transporter gene in mature and in vitro germinating pollen. Plant Mol. Biol. 35: 85-864

Laloi M, Delrot S \& M'Batchi B (1993) Characterization of sugar efflux from sugar beet leaf plasma membrane vesicles. Plant Physiol. Biochem. 31: 731-741

Lalonde S, Tegeder M, Throne-Holst M, Frommer WB \& Patrick JW (2003) Phloem loading and unloading of sugars and amino acids. Plant Cell Env. 26: 37-56

Lam H-M, Coschigano K, Schultz C, Melo-Oliveira R, Tjaden G, Oliveira I, Ngai N, Hsieh MH \& Coruzzi GM (1995) Use of Arabidopsis mutants and genes to study amide amino acid biosynthesis. Plant Cell 7: 887-898

Lam H-M, Coschigano KT, Oliveira IC, Melo-Oliveira R \& Coruzzi GM (1996) The molecular genetics of nitrogen assimilation into amino acids in higher plants. Annu. Rev. Plant Physiol. Plant Mol. Biol. 47: 569-593

Lam H-M, Chiu J, Hsieh M-H, Meisel L, Oliveira IC, Shin M, Coruzzi GM (1998) Glutamate-receptor genes in plants. Nature 396: 125-126

Lam H-M, Wong P, Chan H-K, Yam K-M, Chen L, Chow C-M \& Coruzzi GM (2003) Overexpression of the ASN1 gene enhances nitrogen status in seeds of Arabidopsis. Plant Physiol. 132: 926-935 
Lawton MA, Dean SM, Dron M, Kooter JM, Kragh KM, Harrison MJ, Yu L, Tanguay L, Dixon RA \& Lamb CJ (1991) Silencer region of a chacone synthase promoter contains multiple binding sites for a factor, SBF-1, closely related to GT-1. Plant Mol. Biol. 16: 235-249

Lee JA \& Steward GR (1978) Ecological aspects of nitrogen assimilation. Adv. Bot. Res. 6: $2-43$

Lee Y-H \& Tegeder M (2003) AtLHT2, a high affinity transporter for neutral and acidic amino acid transfer in anthers of Arabidopsis. Abstract, Phloem 2003 - International Conference on Phloem Transport, Bayreuth

Leegood RC, Lea PJ, Adcock MD \& Häusler RE (1995) The regulation and control of photorespiration. J. Exp. Bot. 46: 1397-1414

Le Gouill C, Parent JL, Rola-Pleszczynski M \& Stankova J (1994) Analysis of recombinant plasmids by a modified alkaline lysis method. Anal. Biochem. 219: 164

Leidreiter K, Kruse A, Heineke D, Robinson DG \& Heldt HW (1995) Subcellular volumes and metabolite concentrations in potato (Solanum tuberosum cv. Désirée) leaves. Bot. Acta 108: 439-444

Lemoine RK, Kühn C, Thiele N, Delrot S \& Frommer WB (1996) Antisense inhibition of the sucrose transporter in potato: Effects on amount and activity. Plant Cell Env. 19: 1124-1131

Li Z-C \& Bush DR (1990) $\Delta \mathrm{pH}$-dependent amino acid transport into plasma membrane vesicles isolated from sugar beet leaves. Plant Physiol. 94: 268-277

Li Z-C \& Bush DR (1991) $\Delta \mathrm{pH}$-dependent amino acid transport into plasma membrane vesicles isolated from sugar beet (Beta vulgaris L.) leaves. Plant Physiol. 96: 13381344

Li Z-C \& Bush DR (1992) Structural determinants in substrate recognition by proton-amino acid symports in plasma membrane vesicles isolated from sugar beet leaves. Arch. Biochem. Biophys. 294: 519-526

Lickfett T, Wildenhayn M \& Przemek E (1994) Zu viel Nitrat nach Raps - was tun? DLGMitteilungen 8: 32-33

Lillo C (1994) Light regulation of nitrate reductase in green leaves of higher plants. Physiol. Plant. 90: 616-620

Lim PO, Woo HR \& Nam GN (2003) Molecular genetics of leaf senescence in Arabidopsis. Trends Plant Sci. 8: 272-278 
Liu L-H, Ludewig U, Frommer WB \& von Wiren N (2003) AtDUR3 encodes a new type of high-affinity urea $/ \mathrm{H}^{+}$symporter in Arabidopsis. Plant Cell 15: 790-800

Lohaus G \& Möllers C (2000) Phloem transport of amino acids in two Brassica napus L. genotypes and one B. carinata genotype in relation to their seed protein content. Planta 211: 833-840

Lohaus G, Burba M \& Heldt HW (1994) Comparison of the contents of sucrose and amino acids in the leaves, phloem sap and taproots of high and low sugar-producing hybrids of sugar beet (Beta vulgaris L.). J. Exp. Bot. 45: 1097-1101

Lohaus G, Winter H, Riens B \& Heldt HW (1995) Further studies of the phloem loading process in leaves of barley and spinach. The comparison of metabolite concentrations in the apoplastic compartment with those in the cytosolic compartment and in the sieve tubes. Bot. Acta 108: 270-275

Lohaus G, Büker M, Hussmann M, Soave C \& Heldt HW (1998) Transport of amino acids with special emphasis on the synthesis and transport of asparagine in the Illinois Low Protein and Illinois High Protein strains in maize. Planta 205: 181-188

Lohaus G, Pennewiss K, Sattelmacher B, Hussmann M, Hermann Muehling K (2001) Is the infiltration-centrifugation technique appropriate for the isolation of apoplastic fluid? A critical evaluation with different plant species. Physiol. Plant. 111: 457-465

Lowry OH, Rosebrough NJ, Farr AL \& Randall RJ (1951) Protein measurement with the folin phenol reagent. J. Biol. Chem. 193: 265-275

Lukens L, Zou F, Lydiate D, Parkin I \& Osborn T (2003) Comparison of a Brassica oleracea genetic map with the genome of Arabidopsis thaliana. Genetics 164: 359372

Marschner H (1995) Mineral nutrition of higher plants. 2nd ed. Academic Press, London

Martin T, Hellman H, Schmidt R, Willmitzer \& Frommer WB (1997) Identification of mutants in metabolically regulated gene expresion. Plant J. 11: 53-62

McNeal FH, Berg MA, McGuire CF, Steward VR \& Balcridge DE (1972) Grain and plant nitrogen relationships in eight spring wheat crosses, Triticum aestivum L. Crop. Sci. 12: $599-602$

Meharg AA \& Blatt MR (1995) $\mathrm{NO}_{3}{ }^{-}$transport across the plasma membrane of Arabidopsis thaliana root hairs: Kinetic control by $\mathrm{pH}$ and membrane voltage. J. Membr. Biol. 145: 49-66

Mehrer I \& Mohr H (1989) Ammonium toxicity: Description of the syndrome in Sinapis alba and the search for its causation. Physiol. Plant. 77: 545-554 
Miller AJ \& Smith SJ (1992) The mechanism of nitrate transport across the tonoplast of barley root cells. Planta 187: 554-557

Miller AJ \& Zhou JJ (2000) Xenopus oocytes as an expression system for plant transporters. Biochim. Biophys. Acta 1465: 343-358

Miranda M, Borisjuk L, Tewes A, Heim U, Sauer N, Wobus U \& Weber H (2001) Amino acid permeases in developing seeds of Vicia faba L.: Expression precedes storage protein synthesis and is regulated by amino acid supply. Plant J. 28: 61-71

Miranda M, Borisjuk L, Tewes A, Dietrich D, Rentsch D, Weber H \& Wobus U (2003) Peptide and amino acid transporters are differentially regulated during seed development and germination in faba bean. Plant Physiol. 132: 1950-1960

Montamat F, Maurousset L, Tegeder M, Frommer WB \& Delrot S (1999) Cloning and expression of amino acid transporters from broad bean. Plant Mol. Biol. 41: 259-268

Münch E (1930) Die Stoffbewegungen in der Pflanze. Gustav Fischer, Jena

Mullis KB \& Faloona FA (1987) Specific synthesis of DNA in vitro via a polymerasecatalyzed chain reaction. Methods Enzymol. 155: 335-350

Murchie EH, Yang J, Hubbart S, Horton P \& Peng S (2002) Are there associations between grain-filling rate and photosynthesis in the flag leaves of field-grown rice? J. Exp. Bot. 53: 2217-2224

Mylona P, Pawlowski K, Bisseling T (1995) Symbiotic nitrogen fixation. Plant Cell 7: 869886

Näsholm T, Ekblad A, Nordin A, Giesler R, Högberg M \& Högberg P (1998) Boreal forest plants take up organic nitrogen. Nature 392: 914-916

Nelson RS \& van Bel AJE (1998) The mystery of virus trafficking into, through and out of the vascular bundles. Progr. Bot. 59: 476-533

Noh Y-S \& Amasino RM (1999a) Identification of a promoter region responsible for senescence-specific expression of SAG12. Plant Mol. Biol. 41: 181-194

Noh Y-S \& Amasino RM (1999b) Regulation of developmental senescence is conserved between Arabidopsis and Brassica napus. Plant Mol. Biol. 41: 195-206

Noiraud N, Maurousset L \& Lemoine R (2001) Identification of a mannitol transporter, AgMaT1, in celery phloem. Plant Cell 13: 695-705

Okumoto S, Schmidt R, Tegeder M, Fischer WN, Rentsch D, Frommer WB \& Koch W (2002) High affinity amino acid transporters specifically expressed in xylem parenchyma and developing seed of Arabidopsis. J. Biol. Chem. 277: 45338-45346 
Oparka KJ \& Santa Cruz S (2000) The great escape: Phloem transport and unloading of macromolecules. Annu. Rev. Plant Physiol. Plant Mol. Biol. 51: 323-347

Oparka KJ \& Turgeon R (1999) Sieve elements and companion cells - traffic control centers of the phloem. Plant Cell 11: 739-750

Ori N, Juarez NT, Jackson D, Yamaguchi J, Banowetz GM \& Hake S (1999) Leaf senescence is delayed in tobacco plants expressing the maize homeobox gene knotted 1 under the control of a senescence-activated promoter. Plant Cell 11: 1073-1080

Ortiz-Lopez A, Chang H-C \& Bush DR (2000) Amino acid transporters in plants. Biochim. Biophys. Acta 1465: 275-280

Osborn TC, Pires JC, Birchler JA, Auger DL, Chen ZJ, Lee H-S, Comai L, Madlung A, Doerge RW, Colot V \& Martienssen RA (2003) Understanding mechanisms of novel gene expression in polyploids. Trends Genet. 19: 141-147

Parker I \& Miledi R (1988) A calcium-independent chloride current activated by hyperpolarization in Xenopus oocytes. Proc. R. Soc. Lond. B 233: 191-199

Pate JS (1980) Transport and partitioning of nitrogenous solutes. Annu. Rev. Plant Physiol. 31: $313-340$

Pate JS, Sharkey PJ \& Atkins CA (1977) Nutrition of a developing legume fruit. Plant Physiol. 59: 506-510

Paterson AH, Lan T-H, Amasino R, Osborn TC \& Quiros C (2001) Brassica genomics: a complement to, and early beneficiary of, the Arabidopsis sequence. Genome Biol. 2: reviews1011.1-1011.4

Peoples MB \& Gifford RM (1990) Long distance transport of nitrogen and carbon from sources to sinks in higher plants. In: Dennis DT \& Turpin DH (Hrsg.) Plant Physiology, biochemistry, molecular biology. Longmann, Essex: 442-455

Perez MD, Chambers SJ, Bacon JR, Lambert N, Hedley CL \& Wang TL (1993) Seed protein content and composition of near-isogenic and induced mutant pea lines. Seed Sci. Res. 3: 187-194

Pfanz H \& Dietz KJ (1987) A fluorescence method for the determination of the apoplastic proton concentration in intact leaf tissues. J. Plant Physiol. 129: 41-48

Prussak CE, Almazan MT \& Tseng BY (1989) Peptide production from proteins separated by sodium dodecylsulfate polyacrylamide gel electrophoresis. Anal. Biochem. 178: 233-238 
Quirino BF, Normanly J \& Amasino RM (1999) Diverse range of gene activity during Arabidopsis thaliana leaf senescence includes pathogen-independent induction of defense-related genes. Plant Mol. Biol. 40: 267-278

Randall PJ \& Bouma D (1973) Zinc deficiency, carbonic anhydrase, and photosynthesis in leaves of spinach. Plant Physiol. 52: 229-232

Reese MG (2001) Application of a time-delay neural network to promoter annotation in the Drosophila melanogaster genome. Comput. Chem. 26: 51-56

Reinhold L \& Kaplan A (1984) Membrane transport of sugars and amino acids. Annu. Rev. Plant Physiol. 35: 45-83

Rentsch D, Laloi M, Rouhara I, Schmelzer E, Delrot S \& Frommer WB (1995) NRT1 encodes a high affinity oligopeptide transporter in Arabidopsis. FEBS Lett. 370: 264268

Rentsch D, Hirner B, Schmelzer E \& Frommer WB (1996) Salt stress-induced proline transporters and salt stress-repressed broad specificity amino acid permeases identified by suppression of a yeast amino acid permease-targeting mutant. Plant Cell 8: 14371446

Rentsch D, Boorer KJ \& Frommer WB (1998) Structure and function of plasma membrane amino acid, oligopeptide and sucrose transporters from higher plants. J. Membrane Biol. 162: 177-190

Rhodes J, Thain JF \& Wildon DC (1996) The pathway for systemic electrical signal transduction in the wounded tomato plant. Planta 200: 50-57

Riens B, Lohaus, G, Heineke D \& Heldt HW (1991) Amino acid and sucrose content determined in the cytosolic, chloroplastic, and vacuolar compartments and in the phloem sap of spinach leaves. Plant Physiol. 97: 227-233

Riesmeier JW, Willmitzer L \& Frommer WB (1992) Isolation and characterization of a sucrose carrier cDNA from spinach by functional expression in yeast. EMBO J. 11 : 4705-4713

Riesmeier JW, Willmitzer L \& Frommer WB (1994) Evidence for the essential role of the sucrose transporter in phloem loading and assimilate partitioning. EMBO J. $13: 1-7$

Roberts JKM \& Pang MKL (1992) Estimation of ammonium ion distribution between cytoplasm and vacuole using nuclear magnetic resonance spectroscopy. Plant Physiol. $100: 1571-1574$

Robinson DG \& Hinz G (2001) Organelle isolation. In: Satiat-Jeunemaitre B \& Hawes C (Hrsg.) Plant cell biology: A practical approach, 2nd ed. IRL Press, Oxford: 295-324 
Rogers MS \& Bendich AJ (1988) Extraction of DNA from plant tissues. Plant Mol. Biol. Manual A6: 1-10

Roitsch T, Ehneß R, Goetz M, Hause B, Hofmann M \& Sinha AK (2000) Regulation and function of extracellular invertase from higher plants in relation to assimilate partitioning, stress responses and sugar signalling. Austr. J. Plant Physiol. 27: 815-825

Rolletscheck H, Borisjuk L, Miranda M, Radchuk R, Golombek S, Wobus U \& Weber H (2003) Functional characterization of nitrogen transport and protein accumulation in crop seeds. Abstract, Phloem 2003 - International Conference on Phloem Transport, Bayreuth

Rossato L, Lainé P \& Ourry A (2001) Nitrogen storage and remobilization in Brassica napus L. during the growth cycle: nitrogen fluxes within the plant and changes in soluble protein patterns. J. Exp. Bot. 52: 1655-1663

Rost B (1996) PHD: predicting one-dimensional protein structure by profile-based neural networks. Methods Enzymol. 266: 525-539

Roychoudhury R, Jay E, Wu R (1976) Terminal labeling and addition of homopolymer tracts to duplex DNA fragments by terminal desoxynucleotidyl transferase. Nucl. Acids Res. 3: 863-877

Ruiz-Medrano R, Xoconostle-Cázares B \& Lucas WJ (2001) The phloem as a conduit for inter-organ communication. Curr. Op. Plant Biol. 4: 202-209

Ryals JA, Neuenschwander UH, Willits MG, Molina A, Steiner H-Y \& Hunt MD (1996) Systemic aquired resistance. Plant Cell 8: 1809-1819

Sakr S, Lemoine R, Gaillard C \& Delrot S (1993) Effect of cutting on solute uptake by plasma membrane vesicles from sugar beet (Beta vulgaris L.) leaves. Plant Physiol. 103: $49-58$

Sakr S, Noubahni M, Bourbouloux A, Riesmeier J, Frommer WB, Sauer N \& Delrot S (1997) Cutting, ageing and expression of plant membrane transporters. Biochim. Biophys. Acta 1330: 207-216

Sambrook J, Fritsch EF \& Maniatis T (1989) Molecular cloning: A laboratory manual. Cold Spring Harbor Laboratory Press, Cold Spring Harbor, New York

Sanger F, Nickler S \& Coulson AR (1977) DNA sequencing with chain-terminating inhibitors. Proc. Natl. Acad. Sci. USA 74: 5463-5467

Sattelmacher B, Horst WJ \& Becker HC (1994) Factors that contribute to genetic variation for nutrient efficiency of crop plants. Z. Pflanzenernähr. Bodenk. 157: 215-224 
Sauer N \& Stolz J (1994) SUC1 and SUC2: two sucrose transporters from Arabidopsis thaliana; expression and characterization in baker's yeast and identification of the histidine-tagged protein. Plant J. 6: 67-77

Sauer N \& Stolz $\mathbf{J}$ (2000) Expression of foreign transport proteins in yeast. In: Baldwin SA (Hrsg.) Membrane Transport. Oxford University Press, Oxford: 79-105

Sauer N \& Tanner W (1984) Partial purification and characterization of inducible proteins in Chlorella. Z. Pflanzenphysiol. 114: 367-375

Schjoerring JK (1995) Dynamics of nitrogen utilisation in Brassica napus. Workshop on Brassica napus L-4. Eucarpia, Helsingør

Schulze E-D (1989) Air pollution and forest decline in a spruce (Picea abies) forest. Science 244: $776-783$

Schulze E-D \& Gebauer G (1997) Nitrate nutrition of central European forest trees. In: Rennenberg H, Eschrich W \& Ziegler H (Hrsg.) Trees - contributions to modern tree physiology. SPB Academic Publishing, Amsterdam: 273-291

Schulze W, Frommer WB \& Ward JM (1999) Transporters for ammonium, amino acids and peptides are expressed in pitchers of the carnivorous plant Nepenthes. Plant J. 17: $637-646$

Seiffert B (2000) Molekularbiologische Untersuchungen zur Stickstoffeffizienz bei Brassica napus L. Dissertation, Universität Göttingen

Siegel LM \& Wilkerson JQ (1989) Structure and function of spinach ferredoxin-nitrite reductase. In: Wray JL \& Kinghorn JR (Hrsg.) Molecular and genetic aspects of nitrate assimilation. Oxford Science Publications, Oxford: 263-283

Sieling K \& Christen O (1999) Yield, N uptake and N-use efficiency of and N leaching after oilseed rape grown in different crop management systems in northern Germany. Proceedings, 10th International Rapeseed Congress, Canberra. http://www.regional.org.au/au/gcirc/2/95.htm

Sjöhdahl S, Gustavsson H, Rödin J, Lenman M, Höglund A \& Rask L (1993) Cruciferin gene families are expressed coordinately but with tissue-specific differences during Brassica napus seed development. Plant Mol. Biol. 23: 1165-1176

Sjölund RD (1997) The phloem sieve element: a river runs through it. Plant Cell 9: 11371146

Solomonson LP \& Barber MJ (1990) Assimilatory nitrate reductase: functional properties and regulation. Annu. Rev. Plant Physiol. Plant Mol. Biol. 41: 225-253 
Spano G, Di Fonzo N, Perrotta C, Platani C, Ronga G, Lawlor DW, Napier JA \& Shewry PR (2003) Physiological characterization of 'stay green' mutants in durum wheat. J. Exp. Bot. 54: 1415-1420

Stacey G, Koh S, Granger C \& Becker JM (2002) Peptide transport in plants. Trends Plant Sci. 7: $257-263$

Stadler R, Brandner J, Schulz A, Gahrtz M \& Sauer N (1995) Phloem loading by the PmSUC2 sucrose carrier from Plantago major occurs into companion cells. Plant Cell 7: $1545-1554$

Studier FW \& Moffat BA (1986) Use of bacteriophage T7 RNA polymerase to direct selective high-level expression of clones genes. J. Mol. Biol. 189: 113-130

Sturm A \& Tang GQ (1999) The sucrose-cleaving enzymes of plants are crucial for development, growth and carbon partitioning. Trends Plant Sci. 4: 401-407

Swarup R, Friml J, Marchant A, Ljung K, Sandberg G, Palme K \& Bennett M (2001) Localization of the auxin permease AUX1 suggests two functionally distinct hormone transport pathways operate in the Arabidopsis root apex. Genes Dev. 15: 2648-2653

Taylor DL \& Bruns TD (1997) Independent, specialized invasions of ectomycorhizal mutualism by two nonphotosynthetic orchids. Proc. Natl. Acad. Sci. USA 94: 45104515

Tegeder M, Offler CE, Frommer WB \& Patrick JW (2000) Amino acid transporters are localized to transfer cells of developing pea seeds. Plant Physiol. 122: 319-325

The Arabidopsis Genome Initiative (2000) Analysis of the genome sequence of the flowering plant Arabidopsis thaliana. Nature 408: 796-815

Theodoulou FL (2000) Plant ABC transporters. Biochim. Biophys. Acta 1465: 79-103

Thorne JH (1985) Phloem unloading of C and N assimilates in developing seeds. Ann. Rev. Plant Physiol. 36: 317-343

Towle DW, Baksinski A, Richard NE \& Kordyleski M (1991) Characterization of an endogenous $\mathrm{Na}+/ \mathrm{H}+$ antiporter in Xenopus laevis oocytes. J. Exp. Biol. 159: 359-369

Trinsoutrot I, Recous S, Mary B, Justes E \& Nicolardot B (1999) C and N mineralisation of oilseed rape crop residues in soil. Proceedings, 10th International Rapeseed Congress, Canberra. http://www.regional.org.au/au/gcirc/2/344.htm

Trinsoutrot I, Nicolardot B, Justes E \& Recous S (2000) Decomposition in the field of residues of oilseed rape grwon at two levels of nitrogen fertilisation. Effects of the dynamics of soil mineral nitrogen between successive crops. Nutr. Cycl. Agroecosyst. 56: $125-137$ 
Triplett EW, Barnett NM \& Blevins DG (1980) Organic acids and ionic balance in xylem exudate of wheat during nitrate or sulfate absorption. Plant Physiol. 65: 610-613

Turgeon R (1991) Symplastic phloem loading and the sink-source transition in leaves: A model. In: Bonnemain JL, Delrot S, Lucas WJ \& Dainty J (Hrsg.) Recent advances in phloem transport and assimilate compartmentation. Quest Editions, Nantes

Turgeon R (1996) Phloem loading and plasmodesmata. Trends Plant Sci. 1: 418-423

Uppström B (1995) Seed chemistry. In: Kimber D \& McGregor DI (Hrsg.) Brassica oilseeds, production and utilization. CAB International, Wallingford: 217-242

van Bel AJE (2003) The phloem, a miracle of ingenuity. Plant Cell Envir. 26: 125-149

van Beusichem ML, Kirkby EA \& Baas R (1988) Influence of nitrate and ammonium nutrition on the uptake, assimilation and distribution of nutrients in Ricinus communis. Plant Physiol. 86: 914-921

Viola R, Roberts AG, Haupt S, Gazzani S, Hancock RD, Marmiroli N, Machray GC \& Oparka KJ (2001) Tuberization in potato involves a switch from apoplastic to symplastic phloem unloading. Plant Cell 13: 385-398

Voegele RT, Struck C, Hahn M \& Mendgen K (2001) The role of haustoria in sugar supply during infection of broad bean by the rust fungus Uromyces fabae. Proc. Natl. Acad. Sci. USA 98: 8133-8138

Volenec JJ, Ourry A \& Joern BC (1996) A role for nitrogen reserves in forage regrowth and stress tolerance. Physiol. Plant. 97: 185-193

Wallbraun M (1997) Genetische Modifizierung der Glutamin-Synthetase-Aktivität in Brassica napus L. Dissertation, Universität Göttingen

Weber H, Rolletschek H, Heim U, Golombek S, Gubatz S \& Wobus U (2000) Antisenseinhibition of ADP-glucose pyrophosphorylase in developing seeds of Vicia narbonensis moderately decreases starch but increases protein content and affects seed maturation. Plant J. 24: 33-43

Weise A, Barker L, Kühn C, Lalonde S, Buschmann H, Frommer WB \& Ward JM (2000) A new subfamily of sucrose transporters, SUT4, with low affinity/high capacity localized in enucleate sieve elements of plants. Plant Cell 12: 1345-1355

Williams L \& Miller A (2001) Transporters responsible for the uptake and partitioning of nitrogenous solutes. Annu. Rev. Plant Physiol. Plant Mol. Biol. 52: 659-688

Winter H, Lohaus G \& Heldt HW (1992) Phloem transport of amino acids and sucrose in correlation to the corresponding metabolite levels in barley leaves. Plant Physiol. 99: 996-1004 
Winter H, Robinson DG \& Heldt HW (1993) Subcellular volumes and metabolite concentrations in barley leaves. Planta 191: 180-190

Winter H, Robinson DG \& Heldt HW (1994) Subcellular volumes and metabolite concentrations in spinach leaves. Planta 193: 530-535

Wipf D, Ludewig U, Tegeder M, Rentsch D, Koch W \& Frommer WB (2002) Conservation of amino acid transporters in fungi, plants and animals. Trends Biochem. Sci. 27: 139-147

Wobus U \& Weber H (1999) Sugars as signal molecules in plant seed development. Biol. Chem. 380: 937-944

Wright KM, Roberts AG, Martens HJ, Sauer N \& Oparka KJ (2003) Structural and functional vein maturation in developing tobacco leaves in relation to AtSUC2 promoter activity. Plant Physiol. 131: 1555-1565

Wurr DCE \& Fellows JR (1998) Leaf production and curd initiation of winter cauliflower in response to temperature. J. Horticult. Sci. Biotechn. 73: 691-697

Yau SK \& Thurling $\mathbf{N}$ (1987) Variation in nitrogen response among spring rape (Brassica napus) cultivars and its relationship to nitrogen uptake and utilization. Field Crops Res. 16: 139-155

Yoshida S, Ito M, Nishida I \& Watanabe A (2001) Islation and RNA gel blot analysis of genes that could serve as potential molecular markers for leaf senescence in Arabidopsis thaliana. Plant Cell Physiol. 42: 170-178

Zhou J-J, Theodoulou, Muldin I, Ingemarsson B \& Miller AJ (1998) Cloning and functional characterization of a Brassica napus transporter that is able to transport nitrate and histidine. J. Biol. Chem. 273: 12017-12023

Zhou Z (2000) Untersuchungen zum Blatt- und Wurzelmetabolismus sowie zum Phloemund Xylemtransport in Zusammenhang mit der Stickstoff-Effizienz bei Raps (Brassica napus L.). Dissertation, Universität Göttingen

Ziegler H (1975) Nature of transported substances. In: Zimmermann MH \& Milburn JA (Hrsg.) Encyclopedia of plant physiology. New series, vol. 1. Transport in plants I. Phloem transport. Springer Verlag, Berlin: 59-100

Zimmermann MH \& Ziegler H (1975) List of sugars and sugar alcohols in sieve-tube exudates. In: Zimmermann MH \& Milburn JA (Hrsg.) Encyclopedia of plant physiology. New series, vol. 1. Transport in plants I. Phloem transport. Springer Verlag, Berlin: 479-503 


\section{Anhang}

\subsection{Verteilung der Markerenyzme bei der nichtwässrigen Fraktionierung}
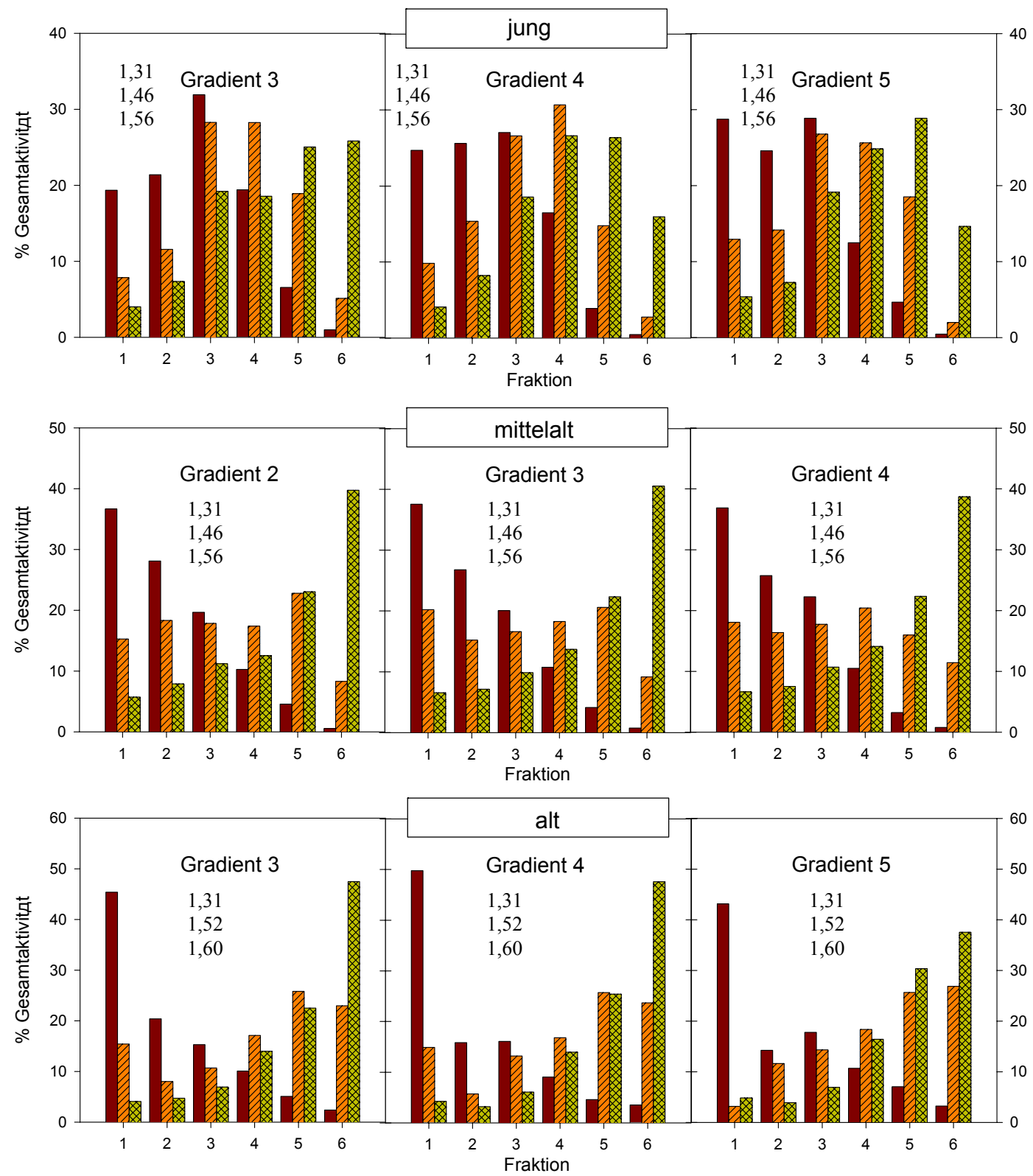

$$
\begin{aligned}
& \text { GAP-DH } \\
& \text { sEP-CX } \\
& \text { saure Phosphatase }
\end{aligned}
$$

Abb. 8.1: Nichtwässrige Fraktionierung von Blättern bei $0,5 \mathrm{mM} \mathrm{NO}_{3}^{-}$hydoponisch angezogener Rapspflanzen: Verteilungen der Markerenzyme in den verwendeten Gradienten. Enyzmaktivitäten sind in \% der Gesamtaktivität des betreffenden Enzyms in allen Fraktionen angegeben. Anstelle der sauren Phosphatase wurde z.T. $\alpha$-Mannosidase als vakuoläres Markerenzym gemessen. 1 = oberste (leichteste), $6=$ unterste (dichteste) Gradientenfraktion. Die Zahlenwerte bezeichnen die Dichten der drei zur Herstellung des Gradienten verwendeten Lösungen (s. 2.3.2) in $\mathrm{g} \mathrm{cm}^{-3}$. 

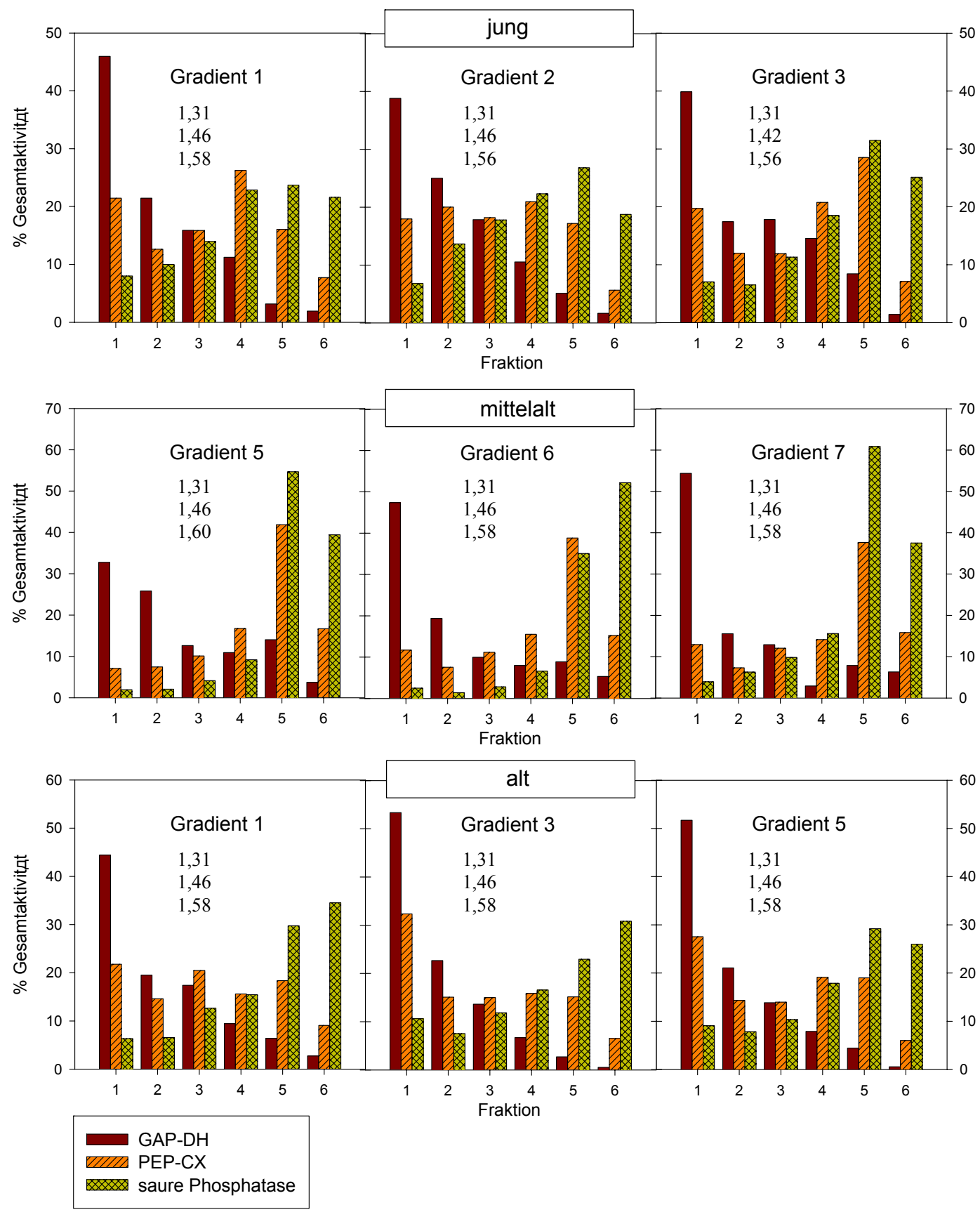

Abb. 8.2: Nichtwässrige Fraktionierung von Blättern bei $4 \mathrm{mM} \mathrm{NO}_{3}{ }^{-}$hydroponisch angezogener Rapspflanzen: Verteilungen der Markerenzyme in den verwendeten Gradienten. Enyzmaktivitäten sind in \% der Gesamtaktivität des betreffenden Enzyms in allen Fraktionen angegeben. Anstelle der sauren Phosphatase wurde z.T. $\alpha$-Mannosidase als vakuoläres Markerenzym gemessen. $1=$ oberste (leichteste), $6=$ unterste (dichteste) Gradientenfraktion. Die Zahlenwerte bezeichnen die Dichten der drei zur Herstellung des Gradienten verwendeten Lösungen (s. 2.3.2) in $\mathrm{g} \mathrm{cm}^{-3}$. 


\section{2 cDNA- und Aminosäuresequenz von BnAAP1 (GenBank Acc. No. AJ565847)}

Start- und Stopcodon der Translation sind durch Fettdruck hervorgehoben. Putative Transmembranhelices sind grau hinterlegt.

1 CTTCTTCGTTTACTCTCTCTCTCTCTCTCTGACTTACACATTTACTTATCTTCTTCTCTC 60

61 TGTCAACCTCCTTTGCTCTCTTCTCTCACTATGAAGAGTTTCAACACCGÁTCAACACGG' 120

$\begin{array}{llllllllllll}1 & \text { M } & K & S & F & N & T & D & Q & H & G & 10\end{array}$

121 CACTCCGCGGCGGAATCCGGCGACGTCTACGCCATGTCCGATCCAACAAÁGAACGTTGAT 180

$\begin{array}{llllllllllllllllllllll}11 & H & S & A & A & E & S & G & D & V & Y & A & M & S & D & P & T & K & N & V & D & 30\end{array}$

181 GACGATGGCCGAGAGAAGAGGACGGGGACGTGGCTTACGGCGAGTGCGCATATTATCACG 240

$\begin{array}{llllllllllllllllllllll}31 & D & D & G & R & E & K & R & T & G & T & W & L & T & A & S & A & H & I & I & T & 50\end{array}$

241 GCGGTAATAGGCTCAGGAGTGTTGTCGTTGGCATGGGCCATAGCTCAGCTTGGTTGGATA 300

$\begin{array}{llllllllllllllllllllll}51 & A & V & I & G & S & G & V & \text { L } & \text { S } & \text { L } & \text { A } & \text { W } & \text { A } & \text { I } & \text { A } & \text { Q } & \text { L } & \text { G } & \text { W } & \text { I } & 70\end{array}$

301 GCAGGGACTTTGATTCTGATCATTTTCTCGTTTATCACGTACTTCACTTCTACGATGCTC 360

$\begin{array}{lllllllllllllllllllllll}71 & A & G & T & L & I & L & I & I & F & S & F & I & T & Y & F & T & S & T & M & L & 90\end{array}$

361 GCTGATTGCTACCGTGCGCCGGATCCCCTCACCGGAAACGAAACTACACTTACATGGAC 420

$\begin{array}{llllllllllllllllllllll}91 & A & D & C & Y & R & A & P & D & P & L & T & G & K & R & N & Y & T & Y & M & D & 110\end{array}$

421 GTTGTTCGATCTTACCTCGg' $\begin{array}{llllllllllllllllllllll}101 & V & V & R & S & Y & \text { L } & G & G & R & \text { K } & \text { V } & \text { Q } & \text { L } & \text { C } & \text { G } & \text { V } & \text { A } & \text { Q } & \text { Y } & \text { G } & 130\end{array}$

481 AATCTGATAGGAATCACTGTTGGGTACACCATCACTGCTTCTATTAGTTTGGTAGCGATC 540 $\begin{array}{llllllllllllllllllllll}131 & N & L & I & G & I & T & V & G & \text { Y } & \text { T } & \text { I } & \text { T } & \text { A } & \text { S } & \text { I } & \text { S } & \text { L } & \text { V } & \text { A } & \text { I } & 150\end{array}$

541 GGGAAAGCGAACTGTTACCACAATAAAGGGCACCATGCAGATTGTACAATATCAAACTAT 600 $\begin{array}{llllllllllllllllllllll}151 & G & K & A & N & C & Y & H & N & K & G & H & H & A & D & C & T & I & S & N & Y & 170\end{array}$

601 CCATATATGG'GGCCTTCGGGATCATTCAAATCCTTCTTAGCCAGATCCCCAACTTTCAC 660 $\begin{array}{llllllllllllllllllllll}171 & P & Y & M & A & A & F & G & I & I & Q & I & L & L & S & Q & I & P & N & F & H & 190\end{array}$

661 AAGCTCTCTTTTCTCTCCCTTATGGCTGCGGTTATGTCTTTTCGCTTACGCAAGTATTGG 720 $\begin{array}{llllllllllllllllllllll}191 & \text { K } & \text { L } & \text { S } & \text { F } & \text { L } & \text { S } & \text { L } & \text { M } & \text { A } & \text { A } & \text { V } & \text { M } & \text { S } & \text { F } & \text { A } & \text { Y } & \text { A } & \text { S } & \text { I } & \text { G } & 210\end{array}$

721 ATTGGCCTAGCCATCGCGACGGTCGCAGGTGGGAAAGTGGGTAAGACGAATATGACGGGA 780 $\begin{array}{llllllllllllllllllllll}211 & \text { I } & G & \text { L } & \text { A } & \text { I } & \text { A } & \text { T } & \text { V } & \text { A } & \text { G } & \text { G } & \text { K } & \text { V } & \text { G } & \text { K } & \text { T } & \text { N } & \text { M } & \text { T } & \text { G } & 230\end{array}$

781 ACGgTGGTAGGAGTTGATGTAACTGCGGCTCAGAAGATATGGAGATCGTTTCAAGCGGTTं 840 $\begin{array}{llllllllllllllllllllll}231 & T & V & V & G & V & D & V & T & A & A & Q & K & I & W & R & S & F & Q & A & V & 250\end{array}$ 
841 GGAGACATAGCGTTTGCATÁTGCTTACGCCACGGTTCTCAंTTGAGATTCAGGACACATTG 900 $\begin{array}{llllllllllllllllllllll}251 & G & D & I & A & F & A & Y & A & Y & A & T & V & \text { L } & \text { I } & \text { E } & \text { I } & \text { Q } & \text { D } & \text { T } & \text { L } & 270\end{array}$

901 AgATCTAGCCCAGCAGAGAACAAAGCTATGAAAAGAGCAÄTTTTGTGGGAGTATCAACC 960 $\begin{array}{llllllllllllllllllllll}271 & R & S & S & P & A & E & N & K & A & M & K & R & A & S & F & V & G & V & S & T & 290\end{array}$

961 ACCACTTTCTTCTACATCTTATGTGGTTGTCTTGGATATGCTGCATTTGGAAACAAAGCC 1020 $\begin{array}{llllllllllllllllllllll}291 & T & T & F & F & Y & I & L & C & G & C & L & G & Y & A & A & F & G & N & K & A & 310\end{array}$

1021 CCTGGAGATTTCCTCACCAÄTTTCGGATTCTACGAGCCATTTTTGGTCATTGACTTTGCA 1080 $\begin{array}{llllllllllllllllllllll}311 & P & G & D & F & L & T & N & F & G & F & Y & E & P & F & W & L & I & D & F & A & 330\end{array}$

1081 AACGCTTGCATTGCTTTCCAंTCTCATTGGTGCCTATCAGGTGTTCGCGCÄGCCATATTC 1140 $\begin{array}{llllllllllllllllllllll}331 & N & A & C & I & A & F & H & \text { L } & \text { I } & G & A & \text { Y } & \text { Q } & \text { V } & \text { F } & \text { A } & \text { Q } & \text { P } & \text { I } & F & 350\end{array}$

1141 CAgTtTGtTGAgAagAAATGCAATAGAAACTgGCCTGACAACAAGTTCATCACATCTGAA 1200 $\begin{array}{llllllllllllllllllllll}351 & Q & F & V & E & K & K & C & N & R & N & \text { W } & \text { P } & \text { D } & \text { N } & \text { K } & \text { F } & \text { I } & \text { T } & \text { S } & \text { E } & 370\end{array}$

1201 TATTCAGTAAACATACCATTCCTTGGAAÄंTTTAGCATCAACCTCTTCAGACTAGTGTGG 1260 $\begin{array}{llllllllllllllllllllll}371 & \text { Y } & \text { S } & \text { V } & \text { N } & \text { I } & \text { P } & \text { F } & \text { L } & G & \text { K } & \text { F } & \text { S } & \text { I } & \text { N } & \text { L } & \text { F } & \text { R } & \text { L } & \text { V } & \text { W } & 390\end{array}$

1261 AGgACAGCTTATGTGGTTATAACAACTTTGGTAGCTATGATATTCCCTTTCTTCAACGCC 1320 $\begin{array}{llllllllllllllllllllll}391 & R & T & A & Y & V & V & I & T & T & L & V & A & M & I & F & P & F & F & N & A & 410\end{array}$

1321 ATCTTGGgTĆTTATCGgAGCAGCTTCCTTCTGGCCTTTAACGGTTTATTTCCCCGTGGA 1380 $\begin{array}{llllllllllllllllllllll}411 & I & L & G & L & I & G & A & A & S & F & W & P & L & T & V & Y & F & P & V & E & 430\end{array}$

1381 ATGCACATAGCACAAACTAÄGGTAAGAAÄTACTCTTCTAGATGGATTGGGCTGAAAATG 1440 $\begin{array}{llllllllllllllllllllll}431 & \text { M } & H & I & A & Q & T & K & V & K & K & Y & S & S & R & W & I & G & L & K & M & 450\end{array}$

1441 TTGTGCTGGGTTTGCTTGATCGTCTCCCTGTTAGCCGCTGCTGGATCCATCGCTGGACTG 1500 $\begin{array}{lllllllllllllllllllllll}451 & \text { L } & \text { C } & \text { W } & \text { V } & \text { C } & \text { L } & \text { I } & \text { V } & \text { S } & \text { L } & \text { L } & \text { A } & \text { A } & \text { A } & \text { G } & \text { S } & \text { I } & \text { A } & \text { G } & \text { L } & 470\end{array}$

1501 ATAAGTAGTGTCAAGACATÁCAAGCCCTTCCGGACTATCCATGAGTGAGTTTGAGATCCA 1560 $\begin{array}{llllllllllllllllll}471 & \text { I } & S & S & V & K & T & Y & K & P & F & R & T & I & H & E & * & 485\end{array}$

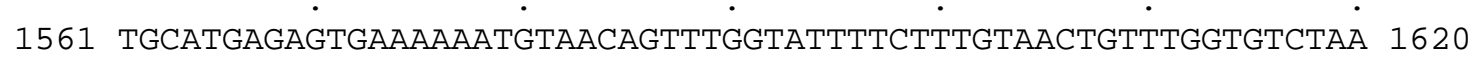
1621 AATCCAAATGAAAATATTGTATTGCTTAAÄAAGCTACATGAATGTCTATGTATCATCCAC 1680 1681 AACTTTCAGTGTAATACATÁTGACCCAATÁATAGCTTTTTCAAAAAAAAAAAAAAAAAA 1739 


\section{3 cDNA- und Aminosäuresequenz von BnAAP6 (GenBank Acc. No. AJ565848)}

Start- und Stopcodon der Translation sind durch Fettdruck hervorgehoben. Putative Transmembranhelices sind grau hinterlegt. Die für die Antikörperherstellung verwendeten Peptide Nterm und Seq5 sind unterstrichen.

1 ATATAAAAAACTACCTTTGCCTCTTCTTCCTATTTCAACATAATAGCAGAAAGGCAATCT 60

61 ATCTATGgAGAAAAAGAGCATGTTCATTGAACAAAGCTTCACCGATCACAAGAGTGGCGA 120 $\begin{array}{lllllllllllllllllllll}1 & M & E & K & K & S & M & F & I & E & Q & S & F & T & D & H & K & S & G & D & 19\end{array}$

121 TATGAACAAAAACTTTGACGATGATGGACGCCAGAAAAGAACAGGGACTTGGATGACGgG 180

$\begin{array}{llllllllllllllllllllll}20 & M & N & K & N & F & D & D & D & G & R & Q & K & R & T & G & T & W & M & T & G & 39\end{array}$

181 GAGCGCCCATATAATAACAGCGGTGATAGGATCAGGAGTGTTGTCACTGGCGTGGGCAAT 240 $\begin{array}{llllllllllllllllllllll}40 & \text { S } & A & H & \text { I } & \text { I } & \text { T } & A & \text { V } & \text { I } & G & \text { S } & G & V & \text { L } & \text { S } & \text { L } & \text { A } & \text { W } & \text { A } & \text { I } & 59\end{array}$

241 TGCACAGCTCGGATGGGTGGCAGGACCCGCCGTACTTATGGCTTTTTCCTTCATAACATA 300 $\begin{array}{llllllllllllllllllllll}60 & \text { A } & Q & L & G & W & V & A & G & P & A & V & L & M & A & F & S & F & I & T & Y & 79\end{array}$

301 CTTTACATCAACCATGCTTGCCGACTGTTATCGTTCCCCGGATCCTGTCACTGGAAAACG 360 $\begin{array}{lllllllllllllllllllllll}80 & \mathrm{~F} & \mathrm{~T} & \mathrm{~S} & \mathrm{~T} & \mathrm{M} & \mathrm{L} & \mathrm{A} & \mathrm{D} & \mathrm{C} & \mathrm{Y} & \mathrm{R} & \mathrm{S} & \mathrm{P} & \mathrm{D} & \mathrm{P} & \mathrm{V} & \mathrm{T} & \mathrm{G} & \mathrm{K} & \mathrm{R} & 99\end{array}$

361 AAACTATACCTACATGGAAGTTGTCCGCTCTTACTTAGGAgGAAGAAAAGTGATGTTATG 420 $\begin{array}{lllllllllllllllllllllll}100 & N & Y & T & Y & M & E & V & V & R & S & Y & L & G & G & R & K & V & M & L & C & 119\end{array}$

421 TGGATTGGCTCAATACGgGAATCTGATTGGAATAACAATCGGCTACACAATCACAGCGTC 480 $\begin{array}{lllllllllllllllllllllll}120 & G & L & A & Q & Y & G & N & \text { L } & \text { I } & G & \text { I } & \text { T } & \text { I } & G & \text { Y } & \text { T } & \text { I } & \text { T } & \text { A } & \text { S } & 139\end{array}$

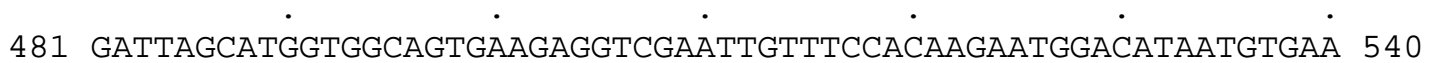
$\begin{array}{lllllllllllllllllllllll}140 & I & S & M & V & A & V & K & R & S & N & C & F & H & K & N & G & H & N & V & K & 159\end{array}$

541 ATGTTCCACTTCAAACACTCCCTTCATGATCATATTCGCÁTGCATCCAAÄTTGTACTTA 600 $\begin{array}{llllllllllllllllllllll}160 & C & S & T & S & N & T & P & F & M & I & I & F & A & C & I & Q & I & V & L & S & 179\end{array}$

601 CCAAATCCCAAATTTCCACAATCTCTCTTGGCTCTCCATTCTAGCGGCCGTAATGTCCTT 660 $\begin{array}{llllllllllllllllllllll}180 & \text { Q } & \text { I } & \text { P } & \text { N } & \text { F } & \text { H } & \text { N } & \text { L } & \text { S } & \text { W } & \text { L } & \text { S } & \text { I } & \text { L } & \text { A } & \text { A } & \text { V } & \text { M } & \text { S } & \text { F } & 199\end{array}$

661 TTCTTACGCCTCCATTGGTÄTCGGTCTCTCCATCGCCAAÄGTGGCCGGTGGGGGTGTGCA 720 $\begin{array}{lllllllllllllllllllllll}200 & S & Y & A & S & I & G & I & G & \text { L } & \text { S } & \text { I } & \text { A } & \text { K } & \text { V } & \text { A } & G & G & G & V & H & 219\end{array}$

721 CGCAAGGACGGCCCTGACAGGAGTTACGgTCGgAGTTGATGTTACTGGTTCTGAGAAAGT 780 $\begin{array}{llllllllllllllllllllll}220 & \text { A } & R & T & A & \text { L } & T & G & V & T & V & G & V & D & V & T & G & S & E & K & V & 239\end{array}$ 
841 TATTGAGATÁCAGGACACCTTAAAAGCAA'̈TCCACCATCÁGAAAACAAAGCCATGAAAA 900 $\begin{array}{llllllllllllllllllllll}260 & \text { I } & E & I & Q & D & T & L & K & A & S & P & P & S & E & N & K & A & M & K & R & 279\end{array}$

901 AGCAAGCCTTGTGGGTGTATCCACAACGACCTTCTTTTACATGTTATGCGGGTGTGTGGG 960 $\begin{array}{lllllllllllllllllllllll}280 & \text { A } & S & L & V & G & V & S & T & T & T & F & F & Y & M & L & C & G & C & V & G & 299\end{array}$

961 TTATGCTGCCTTTGGCAATAATGCGCCTGGAAATTTCCTAACCGGTTTTGGTTTTTATGA 1020 $\begin{array}{lllllllllllllllllllllll}300 & Y & A & A & F & G & N & N & A & P & G & N & F & L & T & G & F & G & F & Y & E & 319\end{array}$

1021 GCCCTTCTGGCTAATCGACTTTGCCAATGTCTGCATCGCTGTGCATCTTGTTGGGGCCTA 1080 $\begin{array}{llllllllllllllllllllll}320 & P & F & W & L & I & D & F & A & N & V & C & I & A & V & H & L & V & G & A & Y & 339\end{array}$

1081 TCAgGTCTTTTGCCAGCCAÁTCTTCCAATTTGTAGAGAGCCAGAGTGCAAAACGTTGGCC 1140 $\begin{array}{llllllllllllllllllllll}340 & Q & V & F & C & Q & P & I & F & Q & F & V & E & S & Q & S & A & K & R & W & P & 359\end{array}$

1141 AgATAACAAGTTTATTACAGGAGAGTACAAAATGAACGTCCCTTGCGGTGGTGATTTTGG 1200 $\begin{array}{lllllllllllllllllllllll}360 & D & N & K & F & I & T & G & E & Y & K & M & N & V & P & C & G & G & D & F & G & 379\end{array}$

1201 TATCAGCTTGTTTAGATTGGTTTGGAGGACTTCATATGTTGTAGTTACGGCTGTTGTAGC 1260 $\begin{array}{llllllllllllllllllllll}380 & \text { I } & S & L & F & R & L & V & W & R & T & S & Y & V & V & V & T & A & V & V & A & 399\end{array}$

1261 AATGATCTTCCCTTTCTTCAACGATTTCTTGGGTCTTATTGGAGCAGCTTCCTTTTGGCC 1320 $\begin{array}{llllllllllllllllllllll}400 & M & I & F & P & F & F & N & D & F & L & G & L & I & G & A & A & S & F & W & P & 419\end{array}$

1321 TTTGACTGTTTACTTTCCCÁTTGAGATGCATATTGCTCAGAAAAATATGÄAGAAATTTTC 1380 $\begin{array}{llllllllllllllllllllll}420 & \mathrm{~L} & \mathrm{~T} & \mathrm{~V} & \mathrm{Y} & \mathrm{F} & \mathrm{P} & \mathrm{I} & \mathrm{E} & \mathrm{M} & \mathrm{H} & \mathrm{I} & \mathrm{A} & \mathrm{Q} & \mathrm{K} & \mathrm{N} & \mathrm{M} & \mathrm{K} & \mathrm{K} & \mathrm{F} & \mathrm{S} & 439\end{array}$

1381 TTTCACTTGGACATGGCTGAAAATCTTGAGCTGGGCTTGTTTCCTCGTCTCCCTCGTTGC 1440 $\begin{array}{llllllllllllllllllllll}440 & \text { F } & \text { T } & \text { W } & \text { T } & \text { W } & \text { L } & \text { K } & \text { I } & \text { L } & \text { S } & \text { W } & \text { A } & \text { C } & \text { F } & \text { L } & \text { V } & \text { S } & \text { L } & \text { V } & \text { A } & 459\end{array}$

1441 TGCTGCTGGATCTGTGCAAGGACTCATACAAAGTCTTAAGGATTTCAAGCCTTTCCAGGC 1500 $\begin{array}{llllllllllllllllllllll}460 & \text { A } & \text { A } & G & S & V & Q & G & \text { L } & \text { I } & \text { Q } & \text { S } & \text { L } & \text { K } & \text { D } & \text { F } & \text { K } & \text { P } & \text { F } & \text { Q } & \text { A } & 479\end{array}$

1501 TCCCGAGTAGAACTGTGTTTTGTCTAATTTCTTCAAGAACACAACTCCCTTGCACTCTCT 1560 $480 \mathrm{P} \mathrm{E}$ * 481

1561 TTTCTCCAATAATAGTGTAт̈GTTCGTTTGTAATATATTTGTGTTCTTGTTCCATTACGAÁ 1620 1621 ATGTTGAACCTATATTTGCTTGTCTGAAACAAATCTATCÄCAATAAGTCCCTCTTTCTT 1680 


\subsection{Nukleotidsequenz des BnAAP6-Promotors (GenBank Acc. No. AJ580452)}

Der Transkriptionsstartpunkt ist durch Fettdruck hervorgehoben. Die putative Bindungsstelle für den Transkriptionsfaktor SBF-1 (Lawton et al. 1991) ist unterstrichen.

1 CTGTTGTTTÁAACGTTTATGAGAGAAAATCCTCATAAAAÁTAGTATATAÄTGCTGAGATG 60

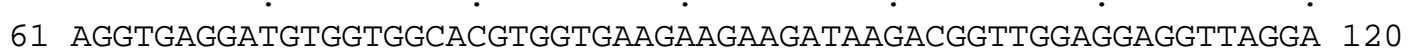

121 AACGACGAGTGGCGACAGTAGTGGAGgAGAATATGgTGACTATGATGAACAACCGGTAGC 180

181 GATAATGGTGATGAAGTTATGgGTAGAAGTGATTGATGTGGATCATAAGÁTCCACACTAG 240

241 AAATTTGGTAGTGATTATTTTGTAAAATATCAgGgAATAAATAACGTGAAAAATGATATT 300

301 TTTAGAACACAACGATACAATCAAATTCCAGCTGATAAAAAATAGACTTTTATTAACGAA 360

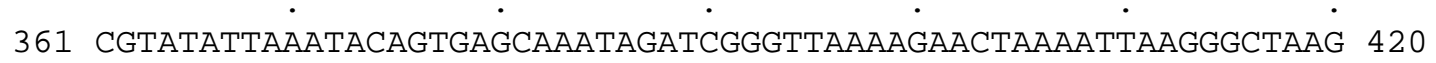

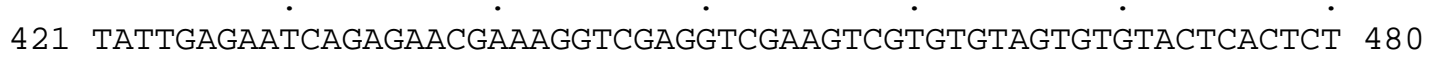

481 AGGATTCGAÄATGTCCTCAT̈CTCCCCTCTC̈сCTCTTTCCTTTTATGGCCTÄTTCCCGCCG 540

541 GCGAGATCGTCTCAACCTCCTCCGTCAATCTCGGCTTCATTCTCCTATAÄTTGCGGGÁ $60 \odot$ 601 GTCGTTCCTCCACTAATGTGGTCGGCCTGTTGGGATTTTCCACATATCGTGTTATTGGAT 660 661 CAAACAATTGAGGCGAAAGGAGGAGGCTGGTGGTGGTGGTGGTGATGTTGGTGTTATAA 720

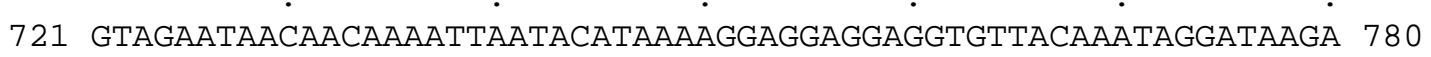

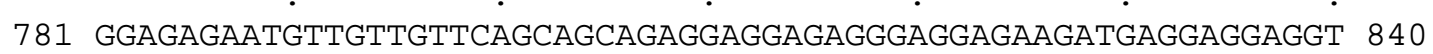
841 TTTAACATTCTATAATATCATCATATGGAATAGTATACTATAGTGTGTGCAAGAATTGGC 900 901 ACCAAAATGTTTATCTATTTTTTTACCGgAÄATGTATTATTंTTTAACGAATAAAAAAGTCT 960 961 CAAATTAGATGAAAAAGAATAAAgGAAGgAgAagAAgAAAAAGTAACACATATCGTATTA 1020 1021 GTGTGAAATCATATATTTATTCTATGTTTTCGTAATAAAATAGAATAACATATAACAATA 1080 


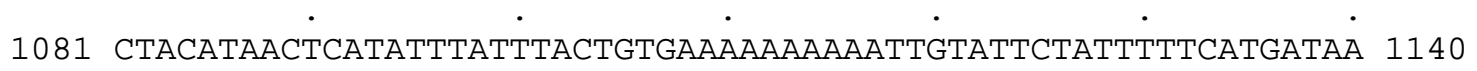

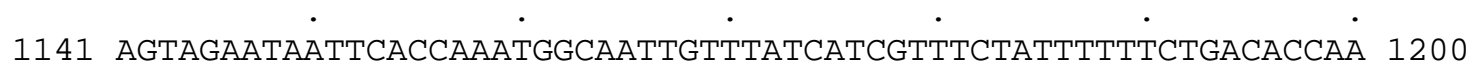
1201 CGATCAAATTTCTCAGTCCCTCAGAAAGCCATTGTAACTTTACCAAGATCACACAAACTC 1260 1261 AAGCTACTAAAAAAAAATTÁTAAGCCATTTCCTTGAACCCATCAATTTTT'TTTTTGTTTT 1320 1321 AAATCTTGTGCCTCTTCTTTATGTCTCTGCTTTATTTTTCATTCTGTTTGATAATTGTAT 1380

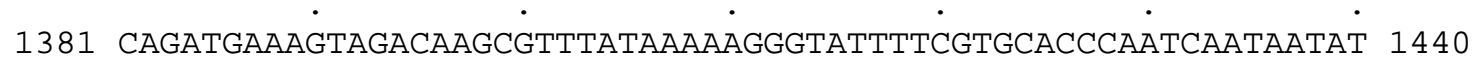
1441 GTATTATATCATAGTCATCÄGTTTGCTATGGTTACTCTGTGAATTATAATTTTTTTATGG 1500 1501 TCATAGCATCAAATTTCCCTATGCGTAATGTAATGGAAAGAAAAAAACTAGCAGACTTTT 1560 1561 GgAAAAGTCAACTATCATCÄGATTGGTTGÄAAAGGATATACAAAGGAAACCCGTGATTG 1620 1621 GTTCCAAGTTTCGTTGAAAAATCAAAAGCAAAATTCTATGAACGATATTGATTTTGCCCA 1680

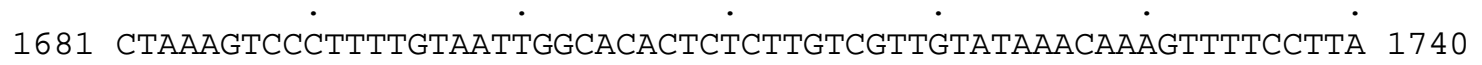
1741 TTCAAAAGATCCTAAAAGTTGGACCAATTGCGAATAGATTCATAAGACACंTAATGTTATT 1800 1801 GgTACTGAGÁgAgGATTAAÄGTAATTGTGÄAAATTTGAATGGATTCTTAÄGGAAATACA 1860 1861 TCATTATTATCAAATGAATG'ंTTGAAGAAÄATGTGGAAGTGGTGGACCTTंGAAACCAAA 1920

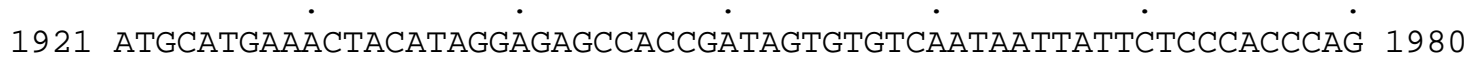
1981 CACACAGAAÄATGATAATTTAATTTGTGATTTGGTAAATTATAATCAACÄAAACCCCTAं 2040

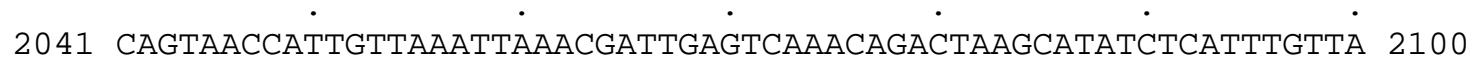
2101 ACAAAAGAAAAAATCGATTCCAAGCAATCCATTCTACATTAATGGATCTCATGGAATCGT 2160

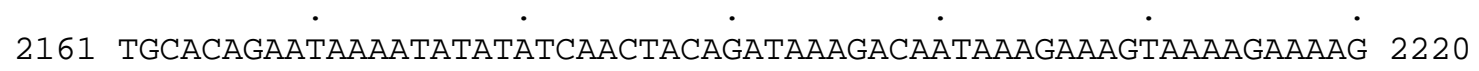
2221 AgGAATTTCTATATACATGAAACGgAAAgTGATTAGGCGTGAAATGTGCTTTGTCTATTT 2280 2281 AAGTGGGAAGAGTAGAGTCCंTCACACTTCAT 


\subsection{Partielle cDNA- und Aminosäuresequenz von BnAAP2}

1 GGGGTGCTGAGGTTGGCGTGGGCTATTGCTCAGCTTGGATGGATCGCTGGACCTGCGGTG $6 \odot$

$\begin{array}{llllllllllllllllllllll}1 & G & V & L & R & \text { L } & A & W & A & \text { I } & A & Q & \text { L } & G & \text { W } & \text { I } & \text { A } & \text { G } & \text { P } & \text { A } & \text { V } & 20\end{array}$

61 ATGCTATTGTTCTCTTTTGTTACTCTATACTCCTCAACACTTCTCAGTGACTGCTACAGA 120 $\begin{array}{llllllllllllllllllllll}21 & M & L & L & F & S & F & V & T & L & Y & S & S & T & L & L & S & D & C & Y & R & 40\end{array}$

121 ACCGGAGACGCGGTCTCCGGCAAGAGAAACTACACTTACATGGACGCAGTTCGGTCCATT 180 $\begin{array}{llllllllllllllllllllll}41 & T & G & D & A & V & S & G & K & R & N & Y & T & Y & M & D & A & V & R & S & I & 60\end{array}$

181 CTCGgTGGGTTCAAGTTCAÄGATATGTGGG'CTGATTCAATACTTGAATCTCTTTGGTATC 240 $\begin{array}{llllllllllllllllllllll}61 & L & G & G & F & K & F & K & I & C & G & L & I & Q & Y & L & N & L & F & G & I & 80\end{array}$

241 GCGGTTGGTTACACAATAGCAGCATCTATAAGCATGATGGCGATCAAGAGATCGCACTGT 300 $\begin{array}{llllllllllllllllllllll}81 & A & V & G & Y & T & I & A & A & S & I & S & M & M & A & I & K & R & S & H & C & 100\end{array}$

301 TTCCACAAGÄgGgagGAAÄgaCCCATGTCACATGTCAGCACCTTACATGATATATTGT 360 $\begin{array}{llllllllllllllllllllll}101 & F & H & K & S & G & G & K & D & P & C & H & M & S & A & P & Y & M & I & Y & C & 120\end{array}$

361 GTGACAGAGATCTGTCTCTCCCAGGTCCCTGATTTCGACCAGATTGTGATCTCAATGGTA 420 $\begin{array}{llllllllllllllllllllll}121 & V & T & E & I & C & L & S & Q & V & P & D & F & D & Q & I & V & I & S & M & V & 140\end{array}$

421 GCAGCTGTCÁTGTCTGTCACTTATTCAGCCATTTGTCTAGCTCTAGGGATCGTTCAAGTT 480 $\begin{array}{llllllllllllllllllllll}141 & \text { A } & \text { A } & V & \text { M } & \text { S } & \text { V } & \text { T } & \text { Y } & \text { S } & \text { A } & \text { I } & \text { C } & \text { L } & \text { A } & \text { L } & \text { G } & \text { I } & \text { V } & \text { Q } & \text { V } & 160\end{array}$ 481 GCTGCAAATGGAGTGTTCAAAGGAAGTCTCACGgGCATAÄGATTGGGACAGTGACTCAA 540 $\begin{array}{llllllllllllllllllllll}161 & A & A & N & G & V & F & K & G & S & \text { L } & T & G & I & S & I & G & T & V & T & Q & 180\end{array}$ 541 ACACAGAAGATATGGAGAACCTTTCAAGCACTTGGAGATÁTTGCGTTTGCTTATTCATAC 600 $\begin{array}{llllllllllllllllllllll}181 & \mathrm{~T} & \mathrm{Q} & \mathrm{K} & \mathrm{I} & \mathrm{W} & \mathrm{R} & \mathrm{T} & \mathrm{F} & \mathrm{Q} & \mathrm{A} & \mathrm{L} & \mathrm{G} & \mathrm{D} & \mathrm{I} & A & \mathrm{~F} & A & \mathrm{Y} & \mathrm{S} & \mathrm{Y} & 200\end{array}$

601 TCTGTTGTCCTAATAGAGATTCAGGATACTGTTAGATCCCCACCGTCAGAATCAACAACG 660 $\begin{array}{llllllllllllllllllllll}201 & S & V & V & L & I & E & I & Q & D & T & V & R & S & P & P & S & E & S & T & T & 220\end{array}$

661 ATGAAGAAAGCTACAAAGATCAGCATTGCAGTCACCACTÁTCTTCTACATGCTATGTGG' 720 $\begin{array}{llllllllllllllllllllll}221 & M & K & K & A & T & K & I & S & I & A & V & T & T & I & F & Y & M & L & C & G & 240\end{array}$ 


\subsection{Vektorkarten}

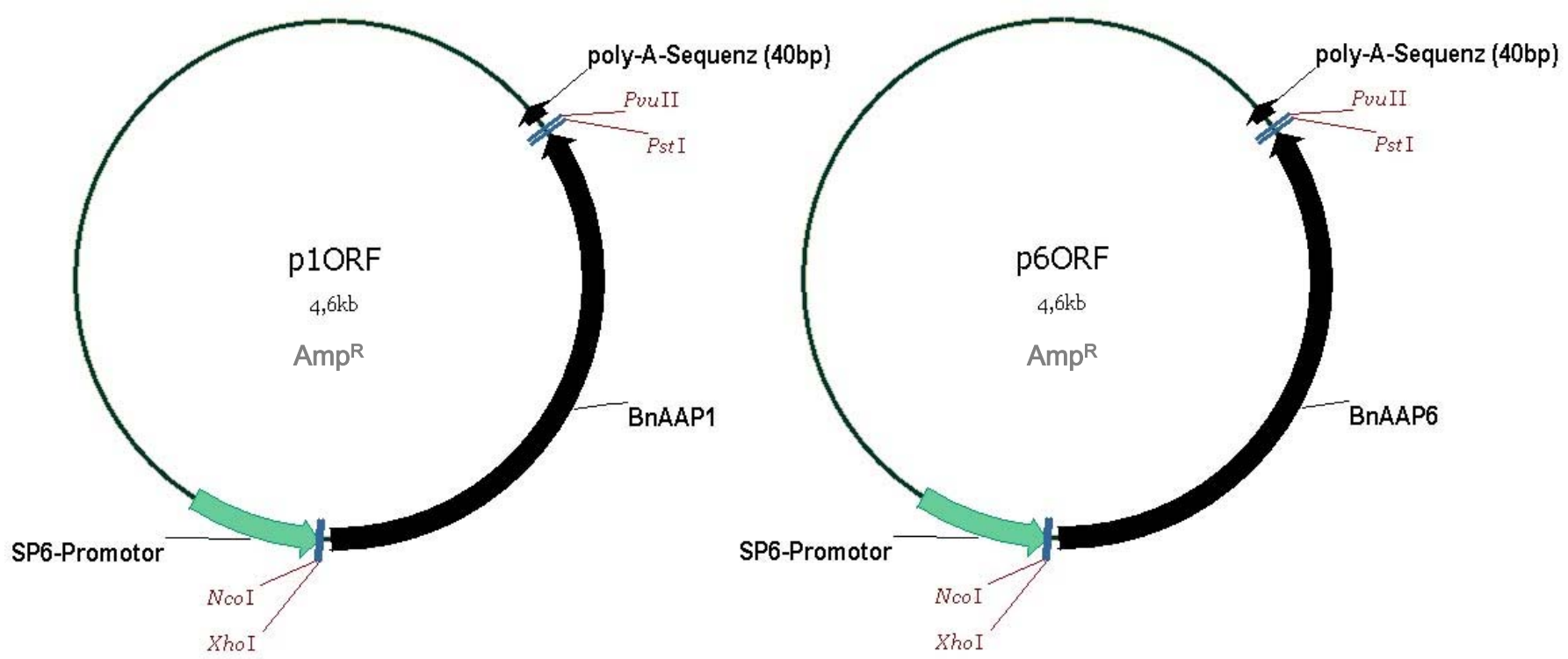

Abb. 8.3 Expressionsvektoren für die in vitro-Transkription von cRNA zur Injektion in Xenopus Oozyten. Siehe Abschnitt 3.5. Die Plasmide basieren auf pBF1 (W. Frommer, Tübingen)
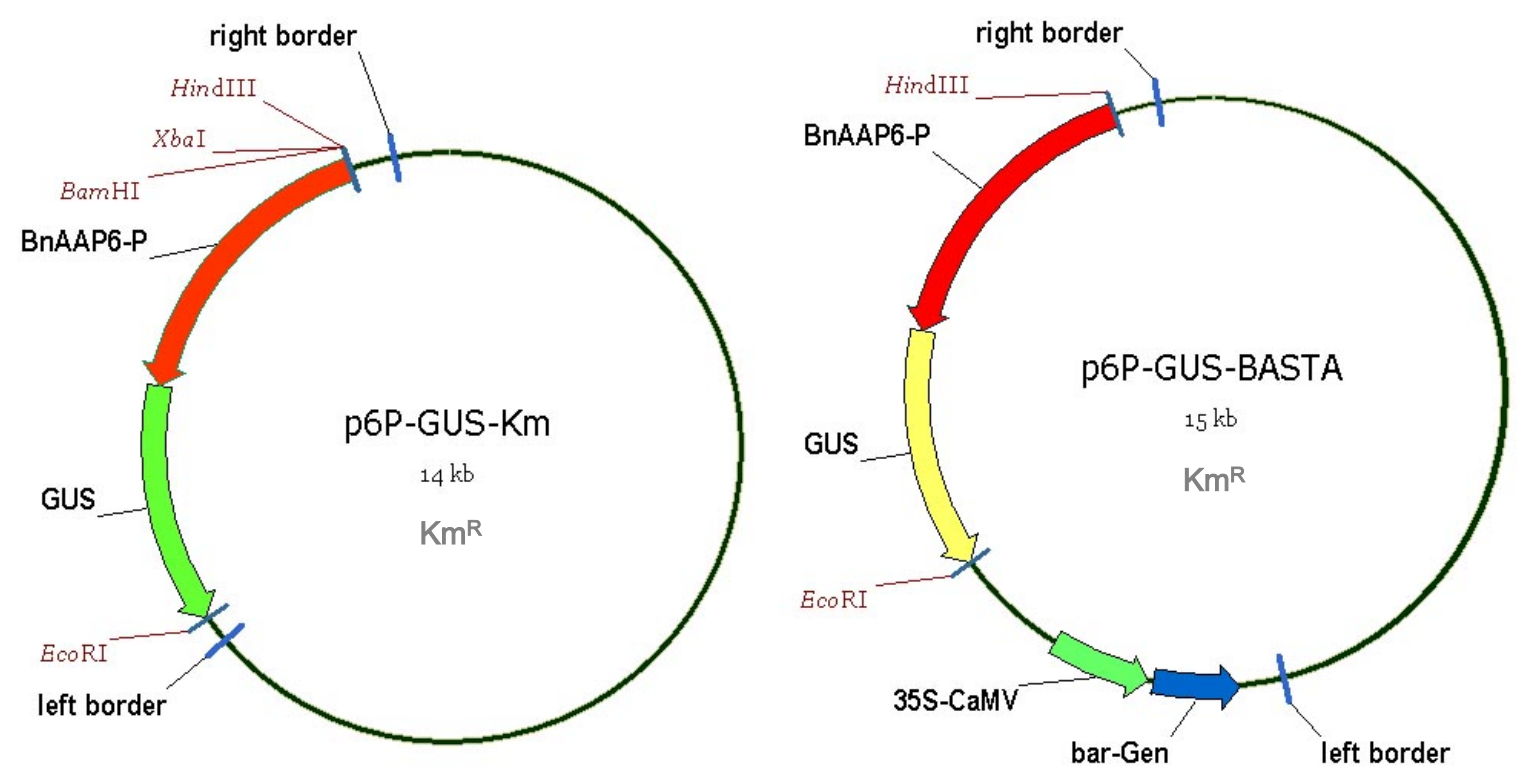

Abb. 8.4 Binäre Shuttle-Vektoren für die Transformation von Pflanzen mit einem BnAAP6-Promotor-GUS Reportergenkonstrukt. Siehe Abschnitt 3.6.1. p6P-GUS-Km basiert auf pBI101.3 (Jefferson et al. 1987) und p6P-GUS-BASTA auf pCAMBIA3300 (CAMBIA, Canberra, Australien). Das bar-Gen kodiert für die Resistenz gegen Glufosinat (,BASTA“). 



\section{Den folgenden Personen möchte ich ganz herzlich danken...}

Frau PD Dr. Gertrud Lohaus für die Ermöglichung dieser Arbeit und die unerschöpfliche Fähigkeit, einem Doktoranden immer wieder Ruhe und Zuversicht einzuflößen und ihn das Projekt in einem sinnvollen Licht sehen zu lassen.

Prof. Dr. Hans-Walter Heldt für die Möglichkeit, die Arbeit in seiner Abteilung durchzuführen, die freundliche Übernahme des Korreferats und dafür daß er sich die für einen Abteilungsleiter ungewöhnliche Mühe gemacht hat, meine Anfrage nach möglichen Doktorandenstellen auführlich zu beantworten.

Prof. Dr. Ivo Feußner für das problemlose Weiterarbeiten, daß er allen „alten“ Abteilungsmitgliedern ermöglicht hat und die Wiedereinführung des gewissen „Seminardrucks“, sowie für das Korrekturlesen der Diskussion.

Frau PD Dr. Katharina Pawlowski für die freiwillige Übernahme der zweiten $100 \%$ der Betreuung und dafür, daß auch nachts immer noch jemand da ist. Ich werde Dir weiterhin alle Daumen für noch kommende Bewerbungen gedrückt halten!

Frau PD Dr. Christine Struck für die Einarbeitung in die Oozyten-Elektrophysiologie, die hervorragende Vorbereitung der Experimente und die Möglichkeit, die Messungen in ihrem Labor in Konstanz durchführen zu können.

Frau Prof. Dr. Christiane Gatz und ihrer Arbeitsgruppe für das freundliche zur Verfügung Stellen von unentbehrlichen Geräten, Chemikalien und Know How in der guten alten Karspülen-Zeit.

Melanie Klenke und Marion Taube für die Einarbeitung am Anfang und all die Gradienten. Und das Rapsmörsern.

Herrn PD Dr. Christian Möllers, Alexandra Hüsken und Bettina Ritgen aus der Pflanzenzüchtung für die Hilfe bei der Rapstransformation und die Anzucht der Pflanzen.

Prof. Dr. Ernst Heinz (Hamburg), Dr. Günther Ochs (Mainz) und Prof. Dr. Dieter Strack (Halle) für die Überlassung von Raps cDNA-Banken.

Gerd Mader für's Unentbehrlichsein! 
Herrn Wedemeyer und Frau Mester für die ausgezeichnete Betreuung der Pflanzen (und Blattläuse).

Anne Brandeck, Dein ansteckendes Lachen wird mir aus der Promotionszeit am meisten fehlen.

Dr. Olga Voitsekhovskaja für die schöne gemeinsame Zeit und die geteilte Phloembegeisterung. Ich freue mich auf kommende deutsch-russische Zusammenarbeiten!

Dr. Christian Knop für den Ruhepol im Labor, degenerierte Primer und den inversen Touch-down und Gespräche von Mann zu Mann...

Michaela Strauß für das Korrekturlesen und Pferdegeschichten :)

Carolin Farke, Nina Kassner, Nikola Mesecke und Eric Schröter dafür, daß das letzte Laborjahr noch besonders nett wurde, Nina für die geteilten Northern-Leiden und nicht zu vergessen Caro und Yvonne Rathmann für's Rapsmörsern.

Wulf Winkelmüller für die wichtige Nicht-Wissenschaft im Labor und außerhalb, verschiedene Sorten intensiver Abende, aber auch dafür, daß NRA-Messungen Spaß machen können. Und für's Rapsmörsern.

Allen Kollegen in der Abteilung für Biochemie der Pflanze, Ehemaligen, ,,alten Karspülern“ und „,neuen Gaterslebenern“, für die wirklich angenehme und freundschaftliche Arbeitsatmosphäre und $\mathrm{zu}$ viele große und kleine Hilfen bei eigentlich allem, was man in einem Institut so tun kann, um sie hier aufzulisten. Knox und Thilo außerdem für die Sache mit dem Karate...

Meiner Mutter für die Unterstützung auf allen Ebenen und dafür, wie tapfer sie sich damit abfindet, daß meine Besuche in Hamburg meist nur noch dem Kampfsport dienen und ich oft nur für eine Fütterung und kostenlose Übernachtung aufkreuze.

Kathrin für all das Neue in meinem Leben und zerkratzte rote Schuhe. Wir müssen das mal warm machen... 


\section{Lebenslauf}

17.07.1972

1979-1983

1983-1992

Juni 1992

1992-1993

Oktober 1993

Oktober 1995

Dezember 1999

Januar-Oktober 1999

Mai 2000 geboren in Hamburg, Staatsangehörigkeit deutsch

Grundschule Hohnerkamp, Hamburg

Walddörfer-Gymnasium, Hamburg

Abitur

Zivildienst im Mobilen Sozialen Hilfsdienst der Dietrich BonnhöferKirche, Hamburg

Beginn des Studiums der Biologie (Diplom) an der Universität Bayreuth

Diplomvorprüfung in den Fächern Botanik, Organische Chemie und Physik

Mündliche Diplomhauptprüfung in den Fächern Botanik, Biochemie und Genetik

Anfertigung der Diplomarbeit mit dem Thema "Laborversuche und Freilandmessungen zu Bestimmung der natürlichen Isotopenhäufigkeit von $\mathrm{N}_{2} \mathrm{O}$ und der Emission von $\mathrm{N}_{2} \mathrm{O}$ und $\mathrm{NO}_{\mathrm{x}}$ aus einem extensiv bewirtschafteten Gründlandökosystem“ am Lehrstuhl für Pflanzenökologie der Universität Bayreuth, unter der Anleitung von PD Dr. G. Gebauer

Beginn der experimentellen Arbeiten zur vorliegenden Dissertation 